\title{
A line confusion-limited millimeter survey of Orion $\mathrm{KL}^{\star}$ III. Sulfur oxide species
}

\author{
G. B. Esplugues ${ }^{1}$, B. Tercero ${ }^{1}$, J. Cernicharo ${ }^{1}$, J. R. Goicoechea ${ }^{1}$, A. Palau ${ }^{2}$, N. Marcelino ${ }^{3}$, and T. A. Bell ${ }^{1}$ \\ ${ }^{1}$ Centro de Astrobiología (CSIC-INTA), Ctra. de Torrejón-Ajalvir, km. 4, 28850 Torrejón de Ardoz, Madrid, Spain \\ e-mail: espluguesbg@cab.inta-csic.es \\ 2 Institut de Ciències de l'Espai (CSIC-IEEC), Campus UAB-Facultat de Ciencies, Torre C5-parell 2, 08193 Bellaterra, Barcelona, \\ Spain \\ 3 National Radio Astronomy Observatory, 520 Edgemont Road, Charlottesville, VA 22903, USA
}

Received 13 February 2013 / Accepted 28 May 2013

\begin{abstract}
Context. We present a study of the sulfur-bearing species detected in a line confusion-limited survey towards Orion KL performed with the IRAM 30-m telescope in the frequency range $80-281 \mathrm{GHz}$.

Aims. This study is part of an analysis of the line survey divided into families of molecules. Our aim is to derive accurate physical conditions, as well as molecular abundances, in the different components of Orion KL from observed SO and $\mathrm{SO}_{2}$ lines.

Methods. As a starting point, we assumed local thermodynamic equilibrium (LTE) conditions obtain rotational temperatures. We then used a radiative transfer model, assuming either LVG or LTE excitation to derive column densities of these molecules in the different components of Orion KL.

Results. We have detected 68 lines of SO, ${ }^{34} \mathrm{SO},{ }^{33} \mathrm{SO}$, and $\mathrm{S}^{18} \mathrm{O}$ and 653 lines of $\mathrm{SO}_{2},{ }^{34} \mathrm{SO}_{2},{ }^{33} \mathrm{SO}_{2}, \mathrm{SO}^{18} \mathrm{O}$, and $\mathrm{SO}_{2} v_{2}=1$. We provide column densities for all of them and also upper limits for the column densities of $\mathrm{S}^{17} \mathrm{O},{ }^{36} \mathrm{SO},{ }^{34} \mathrm{~S}^{18} \mathrm{O}, \mathrm{SO}^{17} \mathrm{O}$, and ${ }^{34} \mathrm{SO}_{2}$ $v_{2}=1$ and for several undetected sulfur-bearing species. In addition, we present $2^{\prime} \times 2^{\prime}$ maps around Orion $\mathrm{IRc}^{\prime}$ of $\mathrm{SO}_{2}$ transitions with energies from 19 to $131 \mathrm{~K}$ and also maps with four transitions of $\mathrm{SO},{ }^{34} \mathrm{SO}$, and ${ }^{34} \mathrm{SO}_{2}$. We observe an elongation of the gas along the NE-SW direction. An unexpected emission peak appears at $20.5 \mathrm{~km} \mathrm{~s}^{-1}$ in most lines of $\mathrm{SO}$ and $\mathrm{SO}_{2}$. A study of the spatial distribution of this emission feature shows that it is a new component of a few arcseconds $\left(\sim 5^{\prime \prime}\right)$ in diameter, which lies $\sim 4^{\prime \prime}$ west of IRc2. We suggest the emission from this feature is related to shocks associated to the $B N$ object.

Conclusions. The highest column densities for $\mathrm{SO}$ and $\mathrm{SO}_{2}$ are found in the high-velocity plateau (a region dominated by shocks) and in the hot core. These values are up to three orders of magnitude higher than the results for the ridge components. We also find high column densities for their isotopologues in both components. Therefore, we conclude that $\mathrm{SO}$ and $\mathrm{SO}_{2}$ are good tracers, not only of regions affected by shocks, but also of regions with warm dense gas (hot cores).
\end{abstract}

Key words. astrochemistry - ISM: abundances - ISM: clouds - ISM: molecules - radio lines: ISM

\section{Introduction}

The hot core phase of massive star formation shows a particularly rich chemistry that results from gas-phase chemical reactions and dust grain mantle evaporation. During cloud collapse, depletion of molecules onto dust surfaces takes place. When a new protostar forms, the surrounding gas and dust are heated and molecules sublimate from the grain mantles, giving rise to new species in the warm gas and to enhanced abundances of pre-existing species. The existence of molecular outflows and associated shocked regions also plays an important role in the chemical evolution, because they heat up the gas significantly and modify its chemistry.

Orion $\mathrm{KL}$ is the closest high-mass star-forming region ( $\simeq 414$ pc, Menten et al. 2007). It is one of the most studied regions owing to its chemical complexity and high gas temperature, which lead to a dense and bright line spectrum. In the Orion KL cloud it is useful to differentiate five distinct components, characterized by different physical and chemical conditions (Blake et al. 1987; Persson et al. 2007; Tercero et al. 2010, and references therein): i) the hot core (HC) with

\footnotetext{
* Appendix $\mathrm{A}$ is available in electronic form at http://www. aanda.org
}

$10^{\prime \prime}$ diameter, which contains a high abundance of complex species (Wilson et al. 2000). It is characterized by line widths of $7 \leq \Delta v \leq 15 \mathrm{~km} \mathrm{~s}^{-1}$ at $v_{\mathrm{LSR}} \simeq 5 \mathrm{~km} \mathrm{~s}^{-1}$. It contains dense and warm gas with $T_{\mathrm{K}} \simeq 200 \mathrm{~K}$ and $n\left(\mathrm{H}_{2}\right) \simeq 10^{7} \mathrm{~cm}^{-3}$. ii) The plateau (PL), a component with $30^{\prime \prime}$ diameter, is affected by shocks with typical line widths of $\Delta v \simeq 20-25 \mathrm{~km} \mathrm{~s}^{-1}$ at $v_{\mathrm{LSR}} \simeq 6 \mathrm{~km} \mathrm{~s}^{-1}$. Typical temperatures and densities are $T_{\mathrm{K}} \simeq 150 \mathrm{~K}$ and $n\left(\mathrm{H}_{2}\right) \simeq 10^{6} \mathrm{~cm}^{-3}$, respectively. iii) The high velocity plateau, HVP, (component affected by shocks, with similar temperature and densitity to the PL) with line widths of $\Delta v \simeq 30-55 \mathrm{~km} \mathrm{~s}^{-1}$ at $v_{\mathrm{LSR}} \simeq 11 \mathrm{~km} \mathrm{~s}^{-1}$. iv) The compact ridge (CR), with $15^{\prime \prime}$ diameter, centered on $v_{\text {LSR }} \simeq 7.5 \mathrm{~km} \mathrm{~s}^{-1}$ with line widths of $\sim 4 \mathrm{~km} \mathrm{~s}^{-1}$. Temperatures are about $110 \mathrm{~K}$ and densities $\simeq 10^{6} \mathrm{~cm}^{-3}$. And v) an extended component, the extended ridge (ER) or ambient cloud, whose emission is characterized by low temperature and density ( $60 \mathrm{~K}$ and $10^{5} \mathrm{~cm}^{-3}$, respectively), and line widths similar to the compact ridge, but centered on a velocity of $v_{\mathrm{LSR}} \simeq 9 \mathrm{~km} \mathrm{~s}^{-1}$. The luminosity of the Orion BecklinNeugebauer/Kleinmann-Low complex is $\sim 10^{5} L_{\odot}$ (Gezari et al. 1998). From the model proposed by Wynn-Williams et al. (1984) and without observational evidence, IRc2 was thought to be the main source of luminosity, heating, and dynamics within the region. However, with the detection of two radio continuum point 
sources, $B$ (coincident with the BN Object) and $I$ (centroid of the Orion $\mathrm{SiO}$ maser), it was concluded that the intrinsic luminosity of IRc2 is only a fraction $\left(L \simeq 1000 L_{\odot}\right)$ of the total luminosity of the complex (Gezari et al. 1998), with source $I$ being the main contributor.

In this paper, we continue our analysis of the line survey towards Orion IRc2 in the frequency range $80-281 \mathrm{GHz}$, first presented by Tercero et al. (2010). Here we concentrate on SO, $\mathrm{SO}_{2}$, and their isotopologues; we model the different cloud components (hot core, plateau, ridge) and derive their physical and chemical conditions, such as column densities and temperatures. Since Gottlieb \& Ball (1973) discovered SO in Orion A, there have been many studies of this molecule, as well as $\mathrm{SO}_{2}$, in this region, including studies of the gas kinematics (Plambeck et al. 1982), molecular abundances (Blake et al. 1987), and spatial distribution (Sutton et al. 1995). Also we find several interferometric studies of these two molecules such as those from Wright et al. (1996) and Beuther et al. (2005). sulfur-bearing species are especially sensitive to physical and chemical variations during the lifetime of a hot core (Viti et al. 2001), and therefore are considered good probes of their time evolution (Hatchell et al. 1998). As such, they can be used as tools for investigating the chemistry and physical properties of complex starforming regions (SFRs) located in dense molecular clouds. On the other hand, it is known that some molecules $\left(\mathrm{SiO}, \mathrm{H}_{2} \mathrm{CS}, \mathrm{SO}\right.$, $\mathrm{SO}_{2}$ ) show increased abudances in regions affected by shocks (Bachiller et al. 1996) as a result of the action of outflows on the surrounding gas. The study of molecular lines from shocked areas provides valuable information about chemical processes and the physical conditions of the shocked components.

The observations are described in Sect. 2. We present more than 700 detected lines of $\mathrm{SO}, \mathrm{SO}_{2}$, their isotopologues, and their vibrationally excited states. In Sect. 3 we present the data and compute rotational temperatures as a first local thermodynamic equilibrium (LTE) approximation. In addition, we present maps of eight emission lines of $\mathrm{SO}_{2}, \mathrm{SO},{ }^{34} \mathrm{SO}_{2}$, and ${ }^{34} \mathrm{SO}$ in the $1.3 \mathrm{~mm}$ window, over a $2^{\prime} \times 2^{\prime}$ region around Orion IRc2 (Sect. 3.4). Unlike other studies of SO, we use a non-LTE radiative transfer code (LVG) to derive physical and chemical parameters (Sect. 4). We provide column density calculations for SO and $\mathrm{SO}_{2}$, and isotopic abundance ratios, which have been improved over previous works due to the much larger number of available lines and to the up-to-date information on the physical properties of the region and molecular constants. Discussions on our results are included in Sect. 5, while Sect. 6 summarizes the main conclusions.

\section{Observations}

We continue our analysis of the line survey towards Orion IRc 2 covering frequency ranges $80-115.5 \mathrm{GHz}, 130-178 \mathrm{GHz}$, and 197-281 GHz, first presented by Tercero et al. (2010). The observations were carried out using the IRAM 30-m radiotelescope during September 2004 (1.3 mm and $3 \mathrm{~mm}$ windows), March 2005 (full $2 \mathrm{~mm}$ window), and April 2005 (completion of the $1.3 \mathrm{~mm}$ and $3 \mathrm{~mm}$ windows). Four SiS receivers operating at $1.3,2$, and $3 \mathrm{~mm}$ were used simultaneously, with image sideband rejections within $\sim 13 \mathrm{~dB}$ (1.3 mm receivers), $12-16 \mathrm{~dB}$ ( $2 \mathrm{~mm}$ receivers), and $20-27 \mathrm{~dB}$ (3 mm receivers). System temperatures were in the range $200-800 \mathrm{~K}$ for the $1.3 \mathrm{~mm}$ receivers, 200-500 $\mathrm{K}$ for the $2 \mathrm{~mm}$ receivers, and 100-350 K for the $3 \mathrm{~mm}$ receivers, depending on the particular frequency, weather conditions, and source elevation. For the spectra between $172-178 \mathrm{GHz}$, the system temperature was significantly
Table 1. IRAM $30 \mathrm{~m}$ telescope efficiency data along the covered frequency range.

\begin{tabular}{lcc}
\hline \hline $\begin{array}{l}\text { Frequency } \\
(\mathrm{GHz})\end{array}$ & $\eta_{\mathrm{MB}}$ & $\begin{array}{c}\text { HVPBW } \\
\left({ }^{\prime \prime}\right)\end{array}$ \\
\hline 86 & 0.82 & 29.0 \\
100 & 0.79 & 22.0 \\
145 & 0.74 & 17.0 \\
170 & 0.70 & 14.5 \\
210 & 0.62 & 12.0 \\
235 & 0.57 & 10.5 \\
260 & 0.52 & 9.5 \\
279 & 0.48 & 9.0 \\
\hline
\end{tabular}

higher, 1000-4000 K, owing to proximity of the atmospheric water line at $183.31 \mathrm{GHz}$. The intensity scale was calibrated using two absorbers at different temperatures and using the atmospheric transmission model (ATM, Cernicharo 1985; Pardo et al. 2001).

Pointing and focus were regularly checked on the nearby quasars 0420-014 and 0528+134. Observations were made in the balanced wobbler-switching mode, with a wobbling frequency of $0.5 \mathrm{~Hz}$ and a beam throw in azimuth of $\pm 240^{\prime \prime}$. No contamination from the off position affected our observations, except for a marginal amount at the lowest elevations $\left(25^{\circ}\right)$ for molecules showing low- $J$ emission along the extended ridge. Two filter banks with $512 \times 1 \mathrm{MHz}$ channels and a correlator providing two $512 \mathrm{MHz}$ bandwidths and $1.25 \mathrm{MHz}$ resolution were used as backends. We pointed the observations towards IRc2 at $\alpha(\mathrm{J} 2000)=5^{\mathrm{h}} 35^{\mathrm{m}} 14.5^{\mathrm{s}}, \delta(\mathrm{J} 2000)=-5^{\circ} 22^{\prime} 30.0^{\prime \prime}$.

The data were processed using the IRAM GILDAS software $^{1}$ (developed by the Institut de Radioastronomie Millimétrique). In our analysis we only considered lines with intensities $\geq 0.02 \mathrm{~K}$, covering three or more channels. Spectra with Gaussian line fits are shown in units of antenna temperature $T_{\mathrm{A}}^{\star}$ corrected for atmospheric absorption and spillover losses. Figures with results from LVG/LTE analysis are shown in units of main beam temperature $T_{\mathrm{MB}}$, which is defined as

$T_{\mathrm{MB}}=\left(T_{\mathrm{A}}^{\star} / \eta_{\mathrm{MB}}\right)$,

where $\eta_{\mathrm{MB}}$ is the main beam efficiency. Table 1 shows the half power beam width (HVPBW) and the mean beam efficiencies over the covered frequency range. For further information about the data reduction and line identification, see Tercero et al. (2010).

We also used the 30-m telescope to map a $2^{\prime} \times 2^{\prime}$ region around IRc2 at $1.3 \mathrm{~mm}$. In this two-dimensional (2D) line survey (Marcelino et al., in prep.), we covered the $1.3 \mathrm{~mm}$ window using the nine pixel HERA receiver array $(216-250 \mathrm{GHz})$ and the EMIR single-pixel heterodyne receivers (200-216 and 250-282 GHz). We also mapped a small fraction of the $3 \mathrm{~mm}$ band taking advantage of simultaneous observations with the E230 and E090 receivers. Fully sampled maps over $140 \times 140 \operatorname{arcsec}^{2}$, centered on the position of IRc2, were performed in the on-the-fly (OTF) mapping mode, scanning both in $\alpha$ and $\delta$ with a $4^{\prime \prime}$ spacing, and using position-switching to an emission-free reference position at an offset $\left(-600^{\prime \prime}, 0^{\prime \prime}\right)$ with respect to IRc2. The observations presented here were obtained in February and December 2008 (HERA), February 2010, and January 2012 (EMIR). We used local oscillator settings at frequencies of 109.983, 221.600, 226.100, 235.100, 239.100,

http://www.iram.fr/IRAMFR/GILDAS 
and $258.000 \mathrm{GHz}$, depending on the observed transition. We used short Wobbler-switching observations on the central position with a slightly different frequency for each setting, in order to remove all features arising from the image side band. We used the WILMA spectrometer backend, with a total bandwidth of $4 \mathrm{GHz}$ (EMIR), $1 \mathrm{GHz}$ (HERA), and a spectral resolution of $2 \mathrm{MHz}$, corresponding to velocity resolutions of $5.4 \mathrm{~km} \mathrm{~s}^{-1}$ at $3 \mathrm{~mm}$ and $2.7-2.3$ at $1.3 \mathrm{~mm}$. Weather conditions were the typically good winter conditions (with opacities $\sim 0.1-0.2$ at $1.3 \mathrm{~mm}$ and $1.3-2 \mathrm{~mm}$ of precipitable water vapor) resulting in system temperatures of 230-250 K (EMIR) and 300-400 K (HERA), except for observations in February 2010, when conditions were $\tau \sim 0.3-0.4$ and $5 \mathrm{~mm}$ of pwv. In this case, system temperatures of $150 \mathrm{~K}$ and $300-400 \mathrm{~K}$ were obtained at 110 and $239 \mathrm{GHz}$, respectively. Pointing was checked every hour on strong and nearby quasars, and found to have errors of typically less than 3-4 arcsec.

The basic data reduction consisted of fitting and removing first-order polynomial baselines, checking for image sideband contamination and emission from the reference position. HERA data needed further reduction analysis due to the different performance of each pixel in the array. Spectra from all pixels were averaged to obtain a uniform map gridding of $4^{\prime \prime}$, taking their different flux calibration and internal pointing errors into account (see Marcelino et al., in prep. for details).

\section{Results}

In total, the survey covers a bandwidth of $168 \mathrm{GHz}$, and of the 15200 detected spectral features, about 10700 have been identified and attributed to 45 molecules, including 191 isotopologues and vibrationally excited states (Tercero et al. 2010). We identify 20 lines of SO, 21 lines of ${ }^{34} \mathrm{SO}, 13$ lines of ${ }^{33} \mathrm{SO}$, and 14 lines of $\mathrm{S}^{18} \mathrm{O}$. We also detect 166 lines of $\mathrm{SO}_{2}, 129$ lines of ${ }^{34} \mathrm{SO}_{2}, 85$ lines of ${ }^{33} \mathrm{SO}_{2}, 129$ lines of $\mathrm{SO}^{18} \mathrm{O}, 74$ lines of $\mathrm{SO}^{17} \mathrm{O}$, and 78 lines of $\mathrm{SO}_{2} v_{2}$. Observed transitions of $\mathrm{SO}$ have a range of energy $E_{\text {up }}$ between 16 and $100 \mathrm{~K}$ and a full width at half maximum (FWHM) of $40 \mathrm{~km} \mathrm{~s}^{-1}$. In the case of $\mathrm{SO}_{2}$ the energy range for the observed transitions is $12-1480 \mathrm{~K}$ and FWHM of $30-40 \mathrm{~km} \mathrm{~s}^{-1}$ for transitions $J<25$ and $F W H M \sim$ $10-20 \mathrm{~km} \mathrm{~s}^{-1}$ for transitions $J>25$. All these identifications are shown in Tables A.8 and A.9. Those tables list the spectroscopic parameters $^{2}$ of each transition, together with the observed line properties of the detected lines.

SO was the first molecule with a ${ }^{3} \Sigma$ electronic ground-state detected in space by radio techniques (Gottlieb \& Ball 1973). Its rotational levels are characterized by the rotational angular momentum quantum number, $N$, and the total angular momentum

\footnotetext{
2 Spectroscopic parameters for SO (dipole moment $\mu=1.535 \mathrm{D}$ ) have been obtained from Clark \& DeLucia (1976), Tiemann (1982), Lovas et al. (1992), Cazzoli et al. (1994), Klaus et al. (1996), Bogey et al. (1997), Powell \& Lide (1964), and Martin-Drumel (2012). For ${ }^{34} \mathrm{SO}$ and $\mathrm{S}^{18} \mathrm{O}(\mu=1.535 \mathrm{D})$ from Tiemann (1974), Tiemann (1982), Lovas et al. (1992), Klaus et al. (1996), Bogey et al. (1982), and Powell \& Lide (1964). And for ${ }^{33} \mathrm{SO}(\mu=1.535 \mathrm{D})$ from Klauss et al. (1996), Lovas et al. (1992), and Powell \& Lide (1964). In the case of $\mathrm{SO}_{2}$ and ${ }^{33} \mathrm{SO}_{2}$ $(\mu=1.633 \mathrm{D})$, the spectroscopic parameters were taken from Müller et al. (2000) and Patel et al. (1970). For ${ }^{34} \mathrm{SO}_{2}(\mu=1.633 \mathrm{D})$ from Belov et al. (1998) and Patel et al. (1979). For the isotopologue $\mathrm{SO}^{18} \mathrm{O}$ $\left(\mu_{a}=0.0328 \mathrm{D}, \mu_{b}=1.633 \mathrm{D}\right)$ obtained from Belov et al. (1998) and for $\mathrm{SO}^{17} \mathrm{O}\left(\mu_{a}=0.02 \mathrm{D}, \mu_{b}=1.633 \mathrm{D}\right)$ from Müller et al. (2000). For the vibrational state $\mathrm{SO}_{2} v_{2}=1,(\mu=1.626 \mathrm{D})$ from Müller \& Brünken (2005) and from Patel et al. (1979), and for ${ }^{34} \mathrm{SO}_{2} v_{2}=1,(\mu=1.626 \mathrm{D})$ from Maki \& Kuritsyn (1990).
}

quantum number, $J$, which includes the contribution of the angular momentum of two unpaired electrons. For ${ }^{33} \mathrm{~S}$ and ${ }^{17} \mathrm{O}$, the nuclear quadrupolar momentum couples with the rotation to produce a hyperfine splitting of the rotational levels. Selection rules for the electric dipole transitions are: $\Delta N= \pm 1, \Delta F=0$, \pm 1 , and $\Delta J=0, \pm 1$, in the absence of external fields. In the case of intermediate coupling, transitions are allowed for $\Delta N= \pm 3$. The magnetic dipole transitions occur with the selection rules: $\Delta N=0, \pm 2$ and $\Delta J=0, \pm 1$. However, these transitions are extremely weak compared to the electric dipole transitions. We have estimated that the magnetic dipole allowed transitions SO will have intensities $\sim 1-6 \mathrm{mK}$, i.e., lines within the confusion limit of Orion $\left(T_{\mathrm{A}}^{\star}=20 \mathrm{mK}\right)$.

$\mathrm{SO}_{2}$ is an asymmetric molecule. The rotational energy levels are characterized by the three quantum numbers $J, K_{-1}$, and $K_{+1}$. Since triatomic molecules are planar, the dipole moment components can only occur in the $a$ - and $b$-axis directions. The selection rules for a-type transitions are $\Delta J=0, \pm 1, \Delta K_{-1}=0, \pm 2$, and $\Delta K_{+1}= \pm 1, \pm 3$. For b-type transitions: $\Delta J=0, \pm 1, \Delta K_{-1}=$ $\pm 1, \pm 3$, and $\Delta K_{+1}=\mp 1, \mp 3 . \mathrm{SO}_{2}$ has its dipole moment along the $b$ axis of the molecule. The nuclear quadrupolar momentum of ${ }^{33} \mathrm{~S}$ and ${ }^{17} \mathrm{O}$ also couples with the rotation leading to hyperfine structure.

As a starting point, we fitted each observed line with Gaussian profiles using CLASS to derive the contribution of each cloud spectral component (see Sect. 3.1). We assumed that the emission is optically thin and the observed lines are thermalized at a given temperature that was derived from rotational diagrams (see Goldsmith \& Langer 1999), providing rotational temperatures for the different components of the cloud (Sect. 3.3). In Sect. 4 we use a radiative transfer code for a more advanced analysis of the LTE and non-LTE emission of $\mathrm{SO}$ and $\mathrm{SO}_{2}$ species.

\subsection{Line profiles}

Figures 1-4 show the line profiles of some observed transitions of $\mathrm{SO}$ and $\mathrm{SO}_{2}$, together with Gaussian fit results. To avoid degeneration, we fixed radial velocities $\left(v_{\mathrm{LSR}}\right)$ considering the characteristic values of each component of Orion KL. And we left the line width, the integrated intensity, and the antenna temperature as free parameters in the fits (in the results, we took the typical ranges of line widths into account for each component found in the bibliography, discarding those with large differences). In addition to the contribution from the usual components listed above, we also observe an unexpected emission peak centered on a velocity of $\simeq 20.5 \mathrm{~km} \mathrm{~s}^{-1}$. We discuss its origin in Sects. 3.2 and 5.2.

We have detected 20 rotational transitions of SO, eight of which are blended with lines of other species. Figure 1 shows the contribution of the different cloud components to the emerging profile. We tried to fit the lines by considering only one plateau instead of two (at high and low velocity). First we centered this single plateau component on a velocity around $6-7 \mathrm{~km} \mathrm{~s}^{-1}$, but with this we could not fit the part of the line profiles covering high $\left(>20 \mathrm{~km} \mathrm{~s}^{-1}\right)$ velocities. With an increase in the line width of the fit, we reproduced this part of the profiles, but we overestimated the part of the lines that covers negative velocities. We found the opposite behavior if we fixed the single plateau component at higher velocities. Therefore we deduced that the best fits were obtained by considering two plateau components: one at low velocity, PL, $\left(\sim 6.5 \mathrm{~km} \mathrm{~s}^{-1}\right)$ and the other at high velocity, HVP, $\left(\sim 12 \mathrm{~km} \mathrm{~s}^{-1}\right)$. We observe that the emission mainly arises from these both plateau components. For transitions with angular momentum quantum number $N \lesssim 5$, the strongest emission 

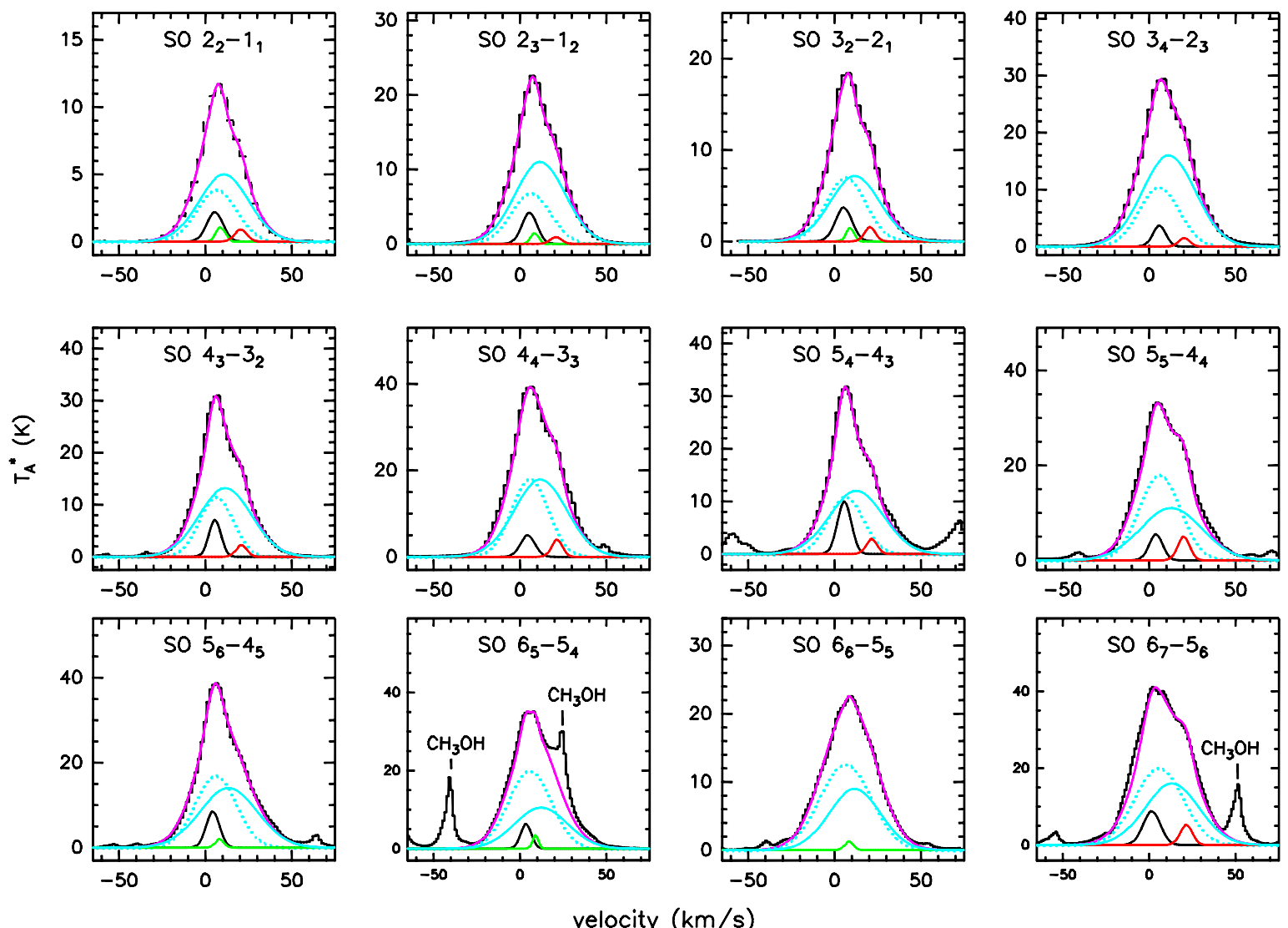

Fig. 1. Gaussian fits to the observed SO lines. Dashed line for the plateau, cyan (solid line) for the high-velocity plateau, black for hot core, green for extended ridge, and red for the contribution of the component at $20.5 \mathrm{~km} \mathrm{~s}^{-1}$. The total fit is shown in magenta. The data are the black histogram spectra.
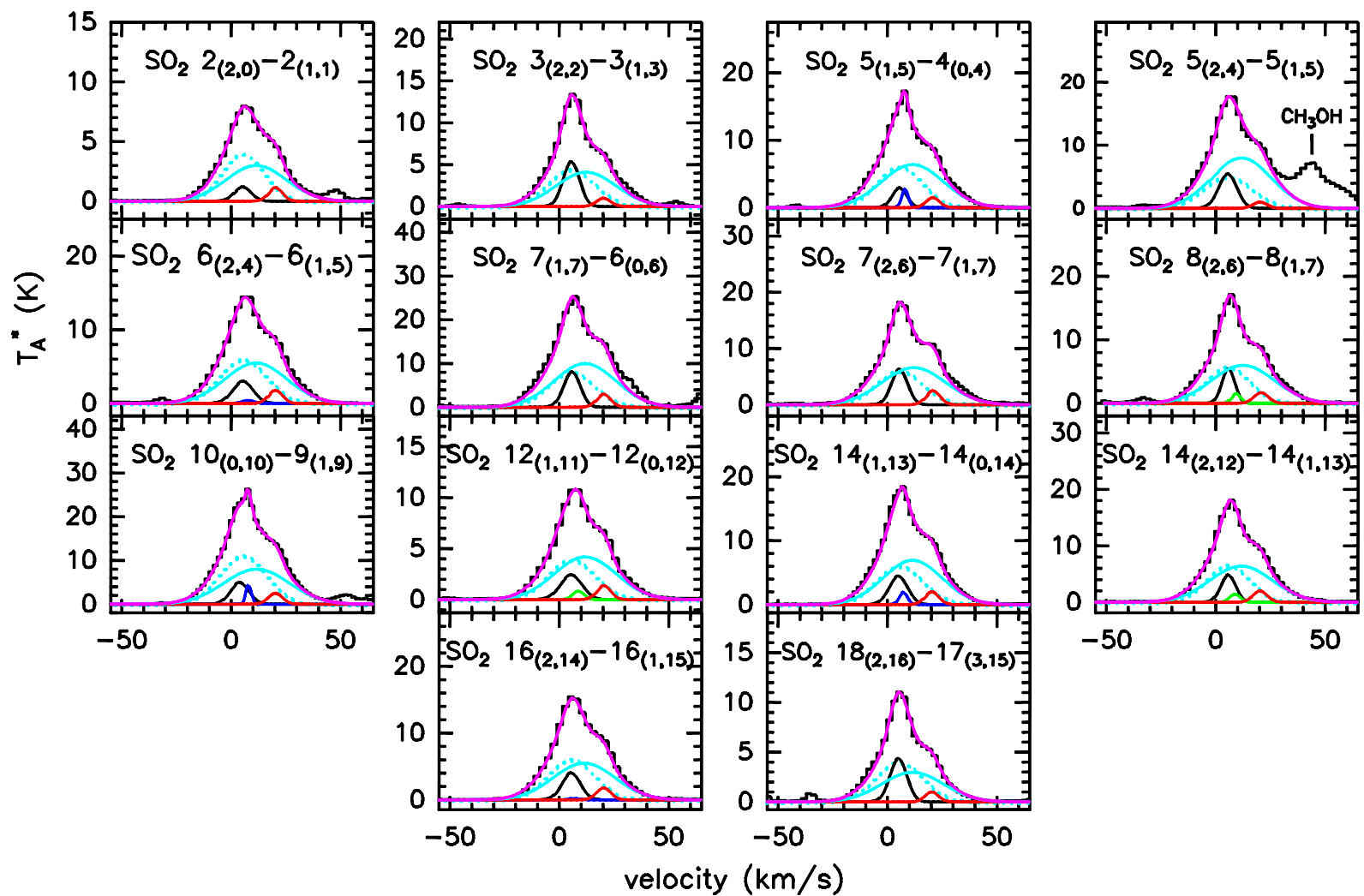

Fig. 2. Gaussian fits for the $\mathrm{SO}_{2}$ lines (2 mm data). The total fit is shown in magenta. Plateau is represented with the dashed line, high-velocity plateau in cyan (solid line), hot core in black, compact ridge in blue, extended ridge in green, and $20.5 \mathrm{~km} \mathrm{~s}^{-1}$ component in red. The data are the black histogram spectra. 
G. B. Esplugues et al.: Survey towards Orion KL. Sulfur oxide species
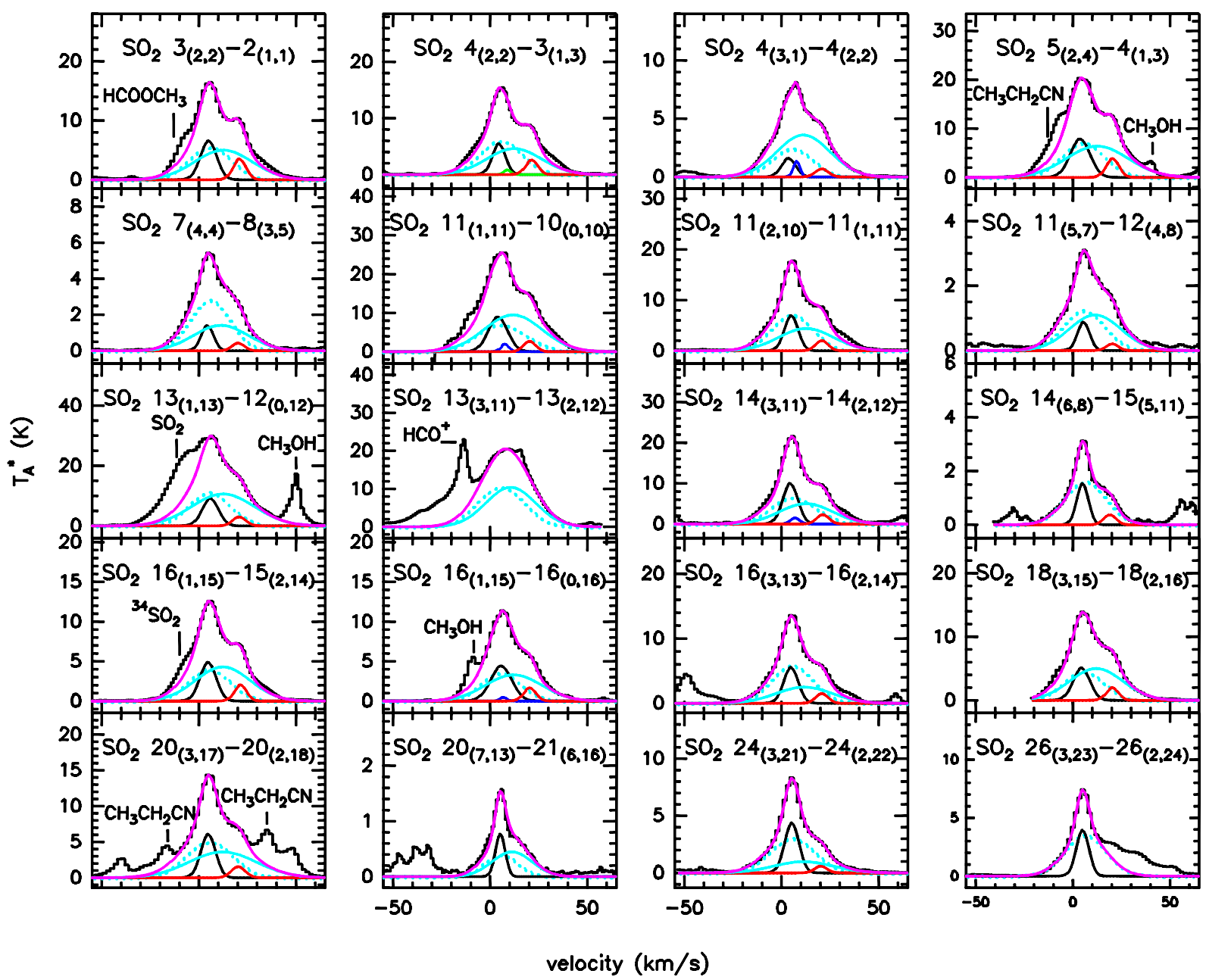

velocity $(\mathrm{km} / \mathrm{s})$

Fig. 3. Gaussian fits for the $\mathrm{SO}_{2}$ lines (1.3 mm data). The total fit is shown in magenta. Plateau is represented with the dashed line, high-velocity plateau in cyan (solid line), hot core in black, compact ridge in blue, extended ridge in green, and $20.5 \mathrm{~km} \mathrm{~s}^{-1}$ component in red. The data are the black histogram spectra.
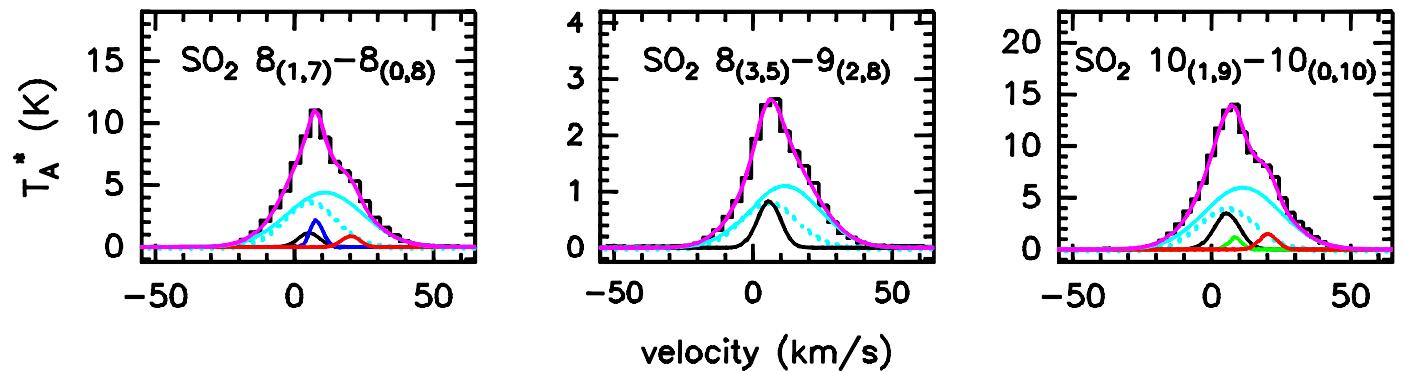

Fig. 4. Gaussian fits for the $\mathrm{SO}_{2}$ lines ( $3 \mathrm{~mm}$ data). The total fit is shown in magenta. Plateau is represented with the dashed line, high-velocity plateau in cyan (solid line), hot core in black, compact ridge in blue, extended ridge in green, and $20.5 \mathrm{~km} \mathrm{~s}^{-1}$ component in red. The data are the black histogram spectra.

is found from the HVP, while for $N \gtrsim 5$ PL presents the highest contribution to the emission. The contribution from the ER is very small. In this LTE analysis of SO, we have not considered the compact ridge component since its contribution is difficult to distinguish from the contribution from the HC. The parameters obtained from Gaussian fits for some of the SO lines are listed in Table A.1.

For $\mathrm{SO}_{2}$ we have clearly identified 166 rotational transitions (see Figs. 2-4). As indicated by their broad line profiles, we see that most of the emission comes from the plateau components, especially for transitions $J<20$ where the HVP plays an important role. However, for transitions $J>20$ the HC dominates. The parameters obtained for each component from Gaussian fits for $\mathrm{SO}_{2}$ lines are listed in Tables A.2 and A.3. Comparing this with SO lines, we see that the line profiles of both species are very similar.

\subsection{The $20.5 \mathrm{~km} \mathrm{~s}^{-1}$ feature and absorption at $15 \mathrm{~km} \mathrm{~s}^{-1}$}

Unlike the other species detected in the survey, we clearly observe an emission peak at $\simeq 20.5 \mathrm{~km} \mathrm{~s}^{-1}$ in most SO and $\mathrm{SO}_{2}$ lines. From Gaussian fits, we find that the line widths are $\sim 7.5 \mathrm{~km} \mathrm{~s}^{-1}$. This feature presents an increase in the line 


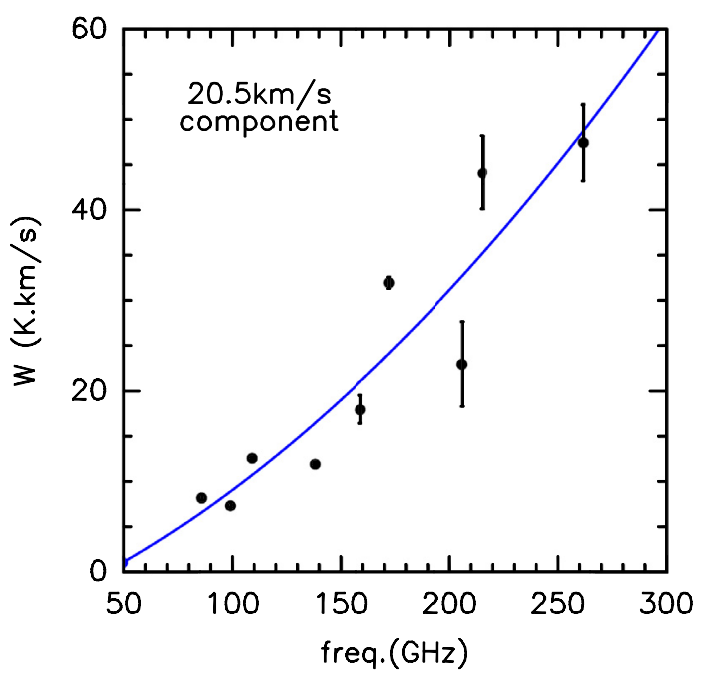

Fig. 5. Integrated line intensities of the $20.5 \mathrm{~km} \mathrm{~s}^{-1}$ component as a function of the line frequency for SO transitions.

intensity with frequency (i.e., with smaller beam). Figure 5 shows the integrated intensity, $W$, as a function of the frequency for the $20.5 \mathrm{~km} \mathrm{~s}^{-1}$ component for SO lines. We see that, for the same line width, $W$ increases with frequency with a dependence as $v^{2}$. This means that the size of the region responsible for this velocity componenent is only a few arcseconds in diameter $\left(<9^{\prime \prime}\right.$, smaller than the IRAM 30-m beam at the highest frequencies). The emission of this component could come from the interaction of the outflow with the ambient cloud; however, it should be noted that while in Orion-KL the $v_{\text {LSR }}$ of the different components varies approximately between 3 and $10 \mathrm{~km} \mathrm{~s}^{-1}$, Scoville et al. (1983) inferred that the $B N$ (Becklin-Neugebauer) object in Orion presents a significantly higher LSR velocity of around $21 \mathrm{~km} \mathrm{~s}^{-1}$, therefore another possibility is that this feature located at $20.5 \mathrm{~km} \mathrm{~s}^{-1}$ arises from the $B N$ source.

On the other hand, between the main emission peak of the line profiles of $\mathrm{SO}$ and $\mathrm{SO}_{2}$ and this emission peak at $20.5 \mathrm{~km} \mathrm{~s}^{-1}$, we observe a dip at $\simeq 15 \mathrm{~km} \mathrm{~s}^{-1}$. Tercero et al. (2011) also find a velocity component at $15.5 \mathrm{~km} \mathrm{~s}^{-1}$ in SiS emission lines $(v=0)$, and one component of the $\mathrm{SiO}$ maser emission $(v=1)$. Since the opacity is high for some lines of $\mathrm{SO}$ and $\mathrm{SO}_{2}$, as well as for $\mathrm{SiO}$, another possibility is that this dip may be the result of self-absorption. This could suggest that the SO and $\mathrm{SO}_{2}$ dips at $15.5 \mathrm{~km} \mathrm{~s}^{-1}$ are produced by the same gas observed in SiS. In Sect. 5 we draw firmer conclusions about the origin of the dip at $15.5 \mathrm{~km} \mathrm{~s}^{-1}$ and of the peak at $20.5 \mathrm{~km} \mathrm{~s}^{-1}$ from maps of $\mathrm{SO}$ and $\mathrm{SO}_{2}$.

\subsection{Rotational diagrams}

The results from the Gaussian fits have been used to build rotational diagrams for each species. This method involves the representation of the upper level column density normalized by the statistical weight of each rotational level versus the upper level energy, assuming optically thin emission filling the beam (see, e.g., Goldsmith \& Langer et al 1999). The expression used to obtain the rotational diagrams, taking an optical depth $\left(C_{\tau}\right)$ different to unity into account, is

$\ln \left(\gamma_{\mathrm{u}} W / g_{\mathrm{u}}\right)=\ln (N)-\ln \left(C_{\tau}\right)-\ln (Z)-\left(E_{\mathrm{u}} / k T\right)$,

where $W$ is the integrated line intensity, $g_{\mathrm{u}}$ is the statistical weight of each level, $N$ the column density, $Z$ the partition function, $E_{\mathrm{u}}$ the level energy, $k$ the Boltzman constant, $T$ the temperature considering LTE, and $\gamma_{\mathrm{u}}$ a constant that depends on the transition frequency and the Einstein coefficient $A_{\mathrm{ul}}$ (see Goldsmith \& Langer 1999 for more details). Each cloud component is considered separately in the analysis. The rotational diagrams, shown in Figs. A.1 and A.2, were obtained considering only lines without contamination from other species. The rotational temperatures obtained from $\mathrm{SO}_{2}$ lines are plateau $(\mathrm{PL})=120 \pm 20 \mathrm{~K}$, hot core $(\mathrm{HC})=190 \pm 60 \mathrm{~K}$, high-velocity plateau $(\mathrm{HVP})=110 \pm 20 \mathrm{~K}$, compact ridge $(\mathrm{CR})=80 \pm 30 \mathrm{~K}$, extended ridge $(\mathrm{ER})=83 \pm 40$ and $20.5 \mathrm{~km} \mathrm{~s}^{-1}$ component $=90 \pm$ $20 \mathrm{~K}$. The results from SO lines are $(\mathrm{PL})=130 \pm 20 \mathrm{~K}$, $(\mathrm{HC})=288 \pm 90 \mathrm{~K},(\mathrm{HVP})=111 \pm 15 \mathrm{~K},(\mathrm{ER})=107 \pm 40 \mathrm{~K}$, and $20.5 \mathrm{~km} \mathrm{~s}^{-1}$ component $=51 \pm 10 \mathrm{~K}$. These results are shown in Table A.4, together with the derived column densities and the optical depths. For each component, the obtained rotational temperatures for both molecules are consistent with each other, except for the $\mathrm{HC}$ where we obtain a large difference between both temperatures. This could indicate a temperature gradient in the hot core, or simply that the obtained rotational temperature could be overestimated due to the high scatter in the SO data. It would be necessary to have values of this species at higher energies in order to obtain firmer conlcusions. We observe that HVP presents a similar rotational temperature to the component of the plateau with lower velocity (PL). For the CR, we obtained a low temperature, probably due to the beam dilution, which is not corrected for in the rotational diagrams. From the diagrams, we also deduce that the new component at $20.5 \mathrm{~km} \mathrm{~s}^{-1}$ is not a very warm region.

\section{4. $2^{\prime} \times 2^{\prime}$ maps around IRc2}

From the 2D line survey data of Orion KL, (Marcelino et al., in prep.), we produced integrated intensity maps of several SO and $\mathrm{SO}_{2}$ transitions over different velocity ranges. Figure 7 shows the transitions $4_{(2,2)}-3_{(1,3)}, 11_{(1,11)}-10_{(0,10)}$, and $14_{(3,11)}-14_{(2,12)}$ of $\mathrm{SO}_{2}$; Fig. 6 shows the transitions $6_{6}-5_{5}$ and $3_{2}-2_{1}$ of SO; and Fig. 8 shows the transition $6_{7}-5_{6}$ of ${ }^{34} \mathrm{SO}$ and the transition $28_{(3,25)}-28_{(2,26)}$ of ${ }^{34} \mathrm{SO}_{2}$. Velocity intervals in the figures have been chosen to represent different source components. For all species and transitions, the strongest contribution arises from the velocity ranges $3-7 \mathrm{~km} \mathrm{~s}^{-1}$ and $10-14 \mathrm{~km} \mathrm{~s}^{-1}$, belonging to the $\mathrm{HC}$ and the HVP, respectively. The range $3-7 \mathrm{~km} \mathrm{~s}^{-1}$ also includes PL velocities. These maps show elongated emission along the direction NE-SW. This agrees with Plambeck et al. (2009), who find (from $\mathrm{SiO} J=2-1$ observations with an angular resolution of $\left.0.45^{\prime \prime}\right)$ that the strongest emission arises from a bipolar outflow covering velocities from -13 to $16 \mathrm{~km} \mathrm{~s}^{-1}$ along the NE-SW direction. This distribution is clearly seen in the maps of ${ }^{34} \mathrm{SO}$ and of SO (see lower panel in Fig. 6), especially in the ranges $7-10 \mathrm{~km} \mathrm{~s}^{-1}$ (ridge) and $10-14 \mathrm{~km} \mathrm{~s}^{-1}$ (HVP). Since the line widths corresponding to the HVP are the widest, with $F W H M \sim 30-40 \mathrm{~km} \mathrm{~s}^{-1}$, altogether this suggests that the gas of the HVP is expanding in the direction NE-SW. On the other hand, the spatial distribution of ${ }^{34} \mathrm{SO}_{2}$ is less extended and usually shows a peak to the NE of IRc2 (also seen in $\mathrm{SO}_{2}$ and $\mathrm{SO}$ at velocities 3-7 $\mathrm{km} \mathrm{s}^{-1}$ ). For this species, the NE-SW distribution is better traced by the 20.5 component. This different behavior should be due to the high energy level $\left(E_{\text {up }}=402.1 \mathrm{~K}\right)$ compared to the other mapped transitions, revealing the most compact and hottest regions in the KL cloud. Also evident on the maps is the new component at $20.5 \mathrm{~km} \mathrm{~s}^{-1}$. From Figs. 7 and 6 we observe that its emission peak is located between the $\mathrm{HC}$ and $\mathrm{BN}$ positions. 
G. B. Esplugues et al.: Survey towards Orion KL. Sulfur oxide species
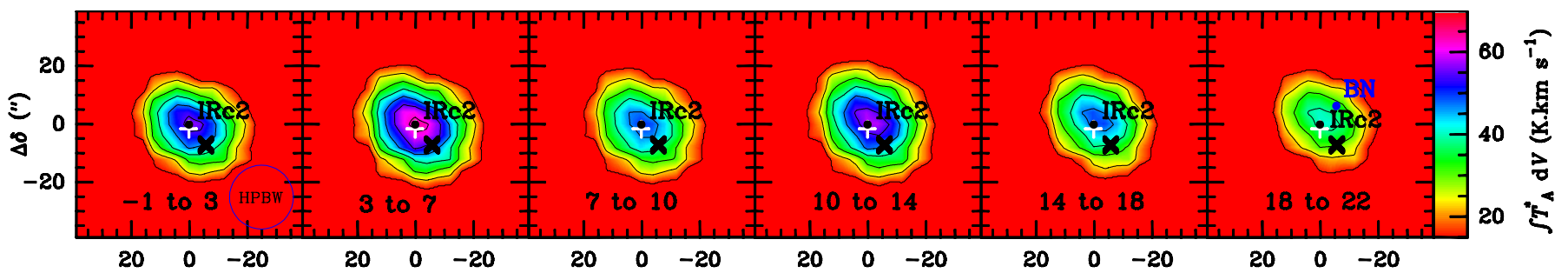

$20 \quad 0 \quad-20$

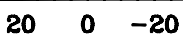

$20 \quad 0 \quad-20$

$20 \quad 0 \quad-20$

$20 \quad 0 \quad-20$

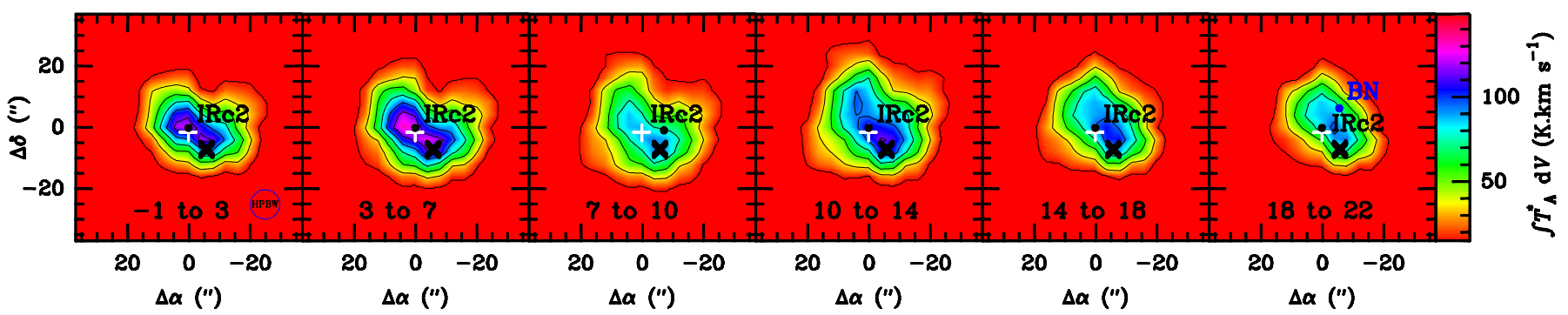

Fig. 6. SO-integrated intensity maps over different velocity ranges (indicated at the bottom of each panel in $\mathrm{km} \mathrm{s}^{-1}$ ). Row 1 shows the transition $3_{2}-2_{1}\left(E_{\mathrm{up}}=21.1 \mathrm{~K}, A_{\mathrm{ul}}=1.1 \times 10^{-5} \mathrm{~s}^{-1}, S=1.5\right)$. The interval between contours is $8 \mathrm{~K} \mathrm{~km} \mathrm{~s}^{-1}$ and the minimum contour is $15 \mathrm{~K} \mathrm{~km} \mathrm{~s}{ }^{-1}$. Row 2 shows the transition $6_{6}-5_{5}\left(E_{\mathrm{up}}=56.5 \mathrm{~K}, A_{\mathrm{ul}}=2.2 \times 10^{-4} \mathrm{~s}^{-1}, S=5.8\right)$. The interval between contours is $20 \mathrm{~K} \mathrm{~km} \mathrm{~s}{ }^{-1}$ and the minimum contour is $15 \mathrm{~K} \mathrm{~km} \mathrm{~s}^{-1}$. The white cross indicates the position of the hot core and the black cross the position of the compact ridge.
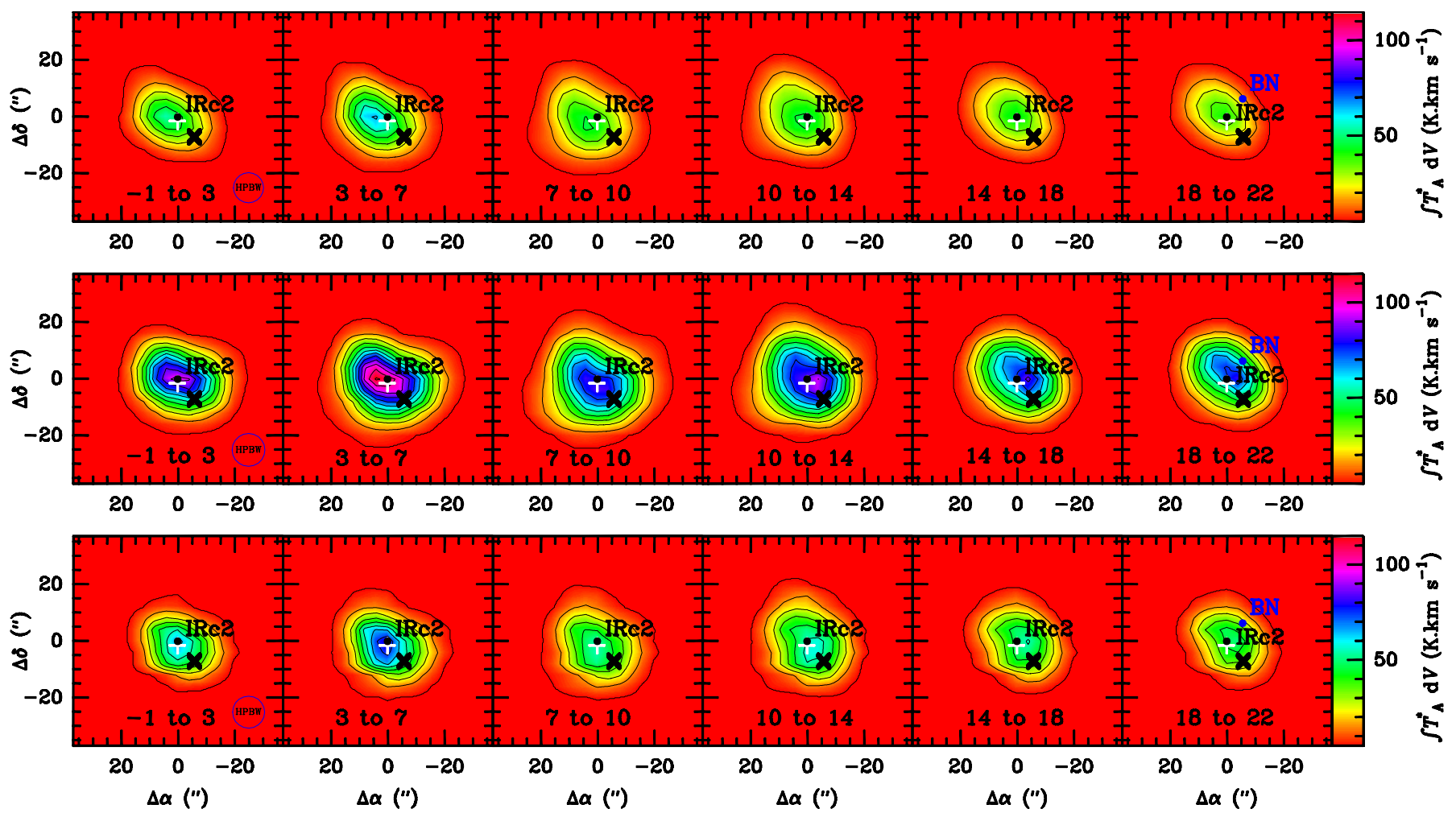

Fig. 7. $\mathrm{SO}_{2}$-integrated intensity maps over different velocity ranges (indicated at the bottom of each panel in $\mathrm{km} \mathrm{s}^{-1}$ ). Row 1 shows the transition $4_{(2,2)}-3_{(1,3)}$ (energy $E_{\text {up }}=19 \mathrm{~K}$, Einstein coefficient $A_{\text {ul }}=7.7 \times 10^{-5} \mathrm{~s}^{-1}$, and line strength $\left.S=1.7\right)$, row 2 the transition $11_{(1,11)}-10_{(0,10)}\left(E_{\text {up }}=60.4\right.$ $\left.\mathrm{K}, A_{\mathrm{ul}}=1.1 \times 10^{-4} \mathrm{~s}^{-1}, S=7.7\right)$, and the last row shows the transition $14_{(3,11)}-14_{(2,12)}\left(E_{\mathrm{up}}=119 \mathrm{~K}, A_{\mathrm{ul}}=1.1 \times 10^{-4} \mathrm{~s}^{-1}, S=8.1\right)$. The interval between contours is $10 \mathrm{~K} \mathrm{~km} \mathrm{~s}^{-1}$, the minimum contour is $5 \mathrm{~K} \mathrm{~km} \mathrm{~s}^{-1}$ and the maximum $155 \mathrm{~K} \mathrm{~km} \mathrm{~s}^{-1}$. The white cross indicates the position of the hot core and the black cross the position of the compact ridge.

\section{Analysis}

\subsection{LVG models of the SO lines}

In this section we analyze the non-LTE excitation and radiative transfer of SO lines. Following the study started by Tercero et al. (2010), we use an LVG (large velocity gradient) code, MADEX, developed by Cernicharo (2012) assuming that the width of the lines is due to the existence of large velocity gradients across the cloud, so that the radiative coupling between two relatively close points is negligible, and the excitation problem is local. The LVG models are based on the Goldreich \& Kwan (1974) formalism. The final considered fit is the one that reproduces more line profiles better from transitions covering a wide energy range, within a $\sim 30 \%$ of the uncertainty in line intensity. For each component of the cloud, we assume uniform physical conditions (kinetic temperature, density, line width, radial velocity, 

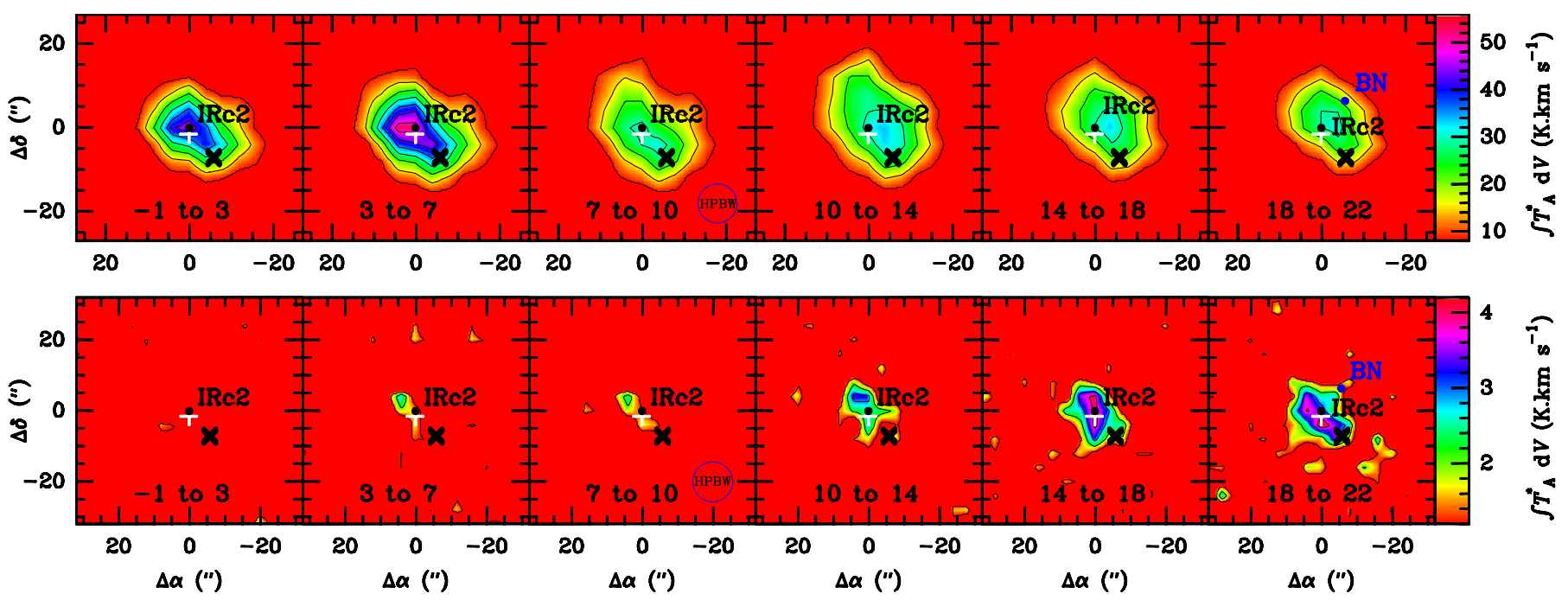

Fig. 8. ${ }^{34} \mathrm{SO}$ and ${ }^{34} \mathrm{SO}_{2}$-integrated intensity maps over different velocity ranges (indicated at the bottom of each panel in km ${ }^{-1}$ ). Row 1 shows the transition $6_{7}-5_{6}$ of ${ }^{34} \mathrm{SO}\left(E_{\mathrm{up}}=46.7 \mathrm{~K}, A_{\mathrm{ul}}=2.2 \times 10^{-4} \mathrm{~s}^{-1}\right)$. The contour interval is $7 \mathrm{~K} \mathrm{~km} \mathrm{~s}^{-1}$ and the minimum contour is $8 \mathrm{~K} \mathrm{~km} \mathrm{~s}{ }^{-1}$. Row 2 shows the transition $28_{(3,25)}-28_{(2,26)}$ of ${ }^{34} \mathrm{SO}_{2}\left(E_{\mathrm{up}}=402.1 \mathrm{~K}, A_{\mathrm{ul}}=1.5 \times 10^{-4} \mathrm{~s}^{-1}\right)$. The interval between contours is $0.9 \mathrm{~K} \mathrm{~km} \mathrm{~s}^{-1}$, and the minimum contour is $1.2 \mathrm{~K} \mathrm{~km} \mathrm{~s}^{-1}$. The white cross indicates the position of the hot core and the black cross the position of the compact ridge.

and source size) that we choose taking into account the parameters obtained from the Gaussians fits of the line profiles, the rotational diagrams (with the derived rotational temperatures), and the mapped transitions.

Only for the HC do we consider LTE, which means that most transitions will be thermalized to the same temperature ( $T_{\text {rot }} \simeq T_{\mathrm{K}}$ ). If this condition was not satisfied, but we kept considering LTE approxmation, the temperatures would be overestimated, and this would produce a variation in the column densities. We cannot estimate whether they would be overestimated or underestimated since we do not know the population of each level. However, the $\mathrm{HC}$ of Orion presents a condition of temperature $\left(T_{\mathrm{K}}>200 \mathrm{~K}\right)$ and density $\left(n\left(\mathrm{H}_{2}\right) \simeq 10^{7} \mathrm{~cm}^{-3}\right)$, which make the LTE assumption in this component feasible. Corrections for beam dilution are also applied for each line depending on the different beam sizes at different frequencies. Therefore, we fix all the above parameters (see Table 2) leaving only as a free parameter the column density fo each component. For the densitiy, $n\left(\mathrm{H}_{2}\right)$, we have adopted fixed values taken from typical values quoted in the literature. In order to determine the uncertainty of the values of hydrogen density and of temperature $\left(T_{\mathrm{K}}\right)$, we have run several models varying only the values for these parameters and fixing the rest.

Comparing the intensity differences between the spectra and the obtained line profiles for each case of $T$ and $n$, we deduce an uncertainty of 20 and $15 \%$ for the temperature and the hydrogen density, respectively. Although the parameter which could introduce higher uncertainty in the line profiles is the considered source size for each component, due to it varies depending on the molecular emission used for its determination. We fixed this parameter, as well as the hydrogen density, taking into account also the values used by Tercero et al. (2011) in her models of SiO and SiS. Other sources of uncertainty in the model predictions arise from the spatial overlap of the different cloud components. However, it has been possible to model their contribution thanks to the wide range of frequency and to the large number of lines from different isotopologues. We also find as a source of uncertainty the modest angular resolution of any single-dish line survey, pointing errors (errors as small as $2^{\prime \prime}$ could introduce important changes in the contribution from each cloud component to the observed line profiles, especially at $1.3 \mathrm{~mm}$ ), and line opacity effects. This last source of uncertainty becomes important when lines arising from the plateau are optically thick, causing an underestimation of the column densities of the components that are surrounded by the plateau (compact ridge, hot core, and the $20.5 \mathrm{~km} \mathrm{~s}^{-1}$ component) along the line of sight (Schultz et al. 1999). In Tercero et al. (2010), these sources of uncertainty are explained in more detail. We estimate an uncertainty in our model intensity predictions of $25 \%$ for $\mathrm{SO}$ and ${ }^{34} \mathrm{SO}$, and $35 \%$ for $\mathrm{SO}_{2},{ }^{34} \mathrm{SO}_{2},{ }^{33} \mathrm{SO}, \mathrm{S}^{18} \mathrm{O},{ }^{33} \mathrm{SO}_{2}$, and $\mathrm{SO}^{18} \mathrm{O}$ lines (higher uncertainty for $\mathrm{SO}_{2}$ with respect to $\mathrm{SO}$ because of considering LTE instead of LVG approximation).

\subsubsection{SO}

To model the rotational lines of SO (listed in Table A.8), we used the collisional rates from Lique et al. (2006) for collisions with $\mathrm{H}_{2}$. Figure 9 shows our best fit model. The component with the highest SO column density is the HVP, with $N(\mathrm{SO})=(5 \pm$ 1) $\times 10^{16} \mathrm{~cm}^{-2}$ (see Table 3 ), although in the $\mathrm{HC}$ we also find a high column density with $N(\mathrm{SO})=(9 \pm 3) \times 10^{15} \mathrm{~cm}^{-2}$. We find that the PL and the $20.5 \mathrm{~km} \mathrm{~s}^{-1}$ component also contribute to the emission, but with a column density that is one order of magnitude lower than the HVP. We did not need to consider any contribution from the $\mathrm{CR}$ for $\mathrm{SO}$. We could fit the narrow component by considering only the contribution from a single ridge (the extended ridge) at a temperature $T_{\mathrm{K}}=60 \mathrm{~K}$. This agrees with the previous SO analysis in Sect. 3.1.

The model indicates that some SO lines with emission coming mainly from the HVP are optically thick. The optical depths are $\tau=1.1-1.4$ for the transitions $6_{5}-5_{4}$ and $6_{6}-5_{5}$, and $\tau=$ 1.4-1.8 for the transitions $5_{6}-4_{5}$ and $6_{7}-5_{6}$. This means that the column densities obtained for the $\mathrm{HC}$ and $20.5 \mathrm{~km} \mathrm{~s}^{-1}$ components, which are surrounded by the plateau, must be considered as lower limits, because the gas in the plateau components can absorb the emission from them. The HVP column density also has to be considered as a lower limit due to this opacity effect. We have also calculated the SO column density from the column density of ${ }^{34} \mathrm{SO}$, whose lines are optically thin, and from the solar abundance ratio ${ }^{32} \mathrm{~S} /{ }^{34} S=23$ (Anders \& Grevesse 1989). 
Table 2. Physical parameters adopted for the Orion KL cloud components.

\begin{tabular}{lcccccc}
\hline \hline Component & $\begin{array}{c}\text { Source diameter } \\
\left({ }^{\prime \prime}\right)\end{array}$ & $\begin{array}{c}\text { Offset (IRc2) } \\
\left({ }^{\prime \prime}\right)\end{array}$ & $\begin{array}{c}n\left(\mathrm{H}_{2}\right) \\
\mathrm{cm}^{-3}\end{array}$ & $\begin{array}{c}T_{\mathrm{K}} \\
(\mathrm{K})\end{array}$ & $\begin{array}{c}\Delta v_{\mathrm{FWHM}} \\
\left(\mathrm{km} \mathrm{s}^{-1}\right)\end{array}$ & $\begin{array}{c}v_{\mathrm{LSR}} \\
\left(\mathrm{km} \mathrm{s}^{-1}\right)\end{array}$ \\
\hline Extended ridge (ER) & 120 & 0 & $10^{5}$ & 60 & 4 & 8.5 \\
Compact ridge (CR) & 15 & 7 & $10^{6}$ & 110 & 3 & 8 \\
High-velocity plateau (HVP) & 30 & 4 & $10^{6}$ & 100 & 30 & 11 \\
Plateau (PL) & 20 & 0 & $5 \times 10^{6}$ & 150 & 25 & 6 \\
Hot core (HC) & 10 & 2 & $1.5 \times 10^{7}$ & 220 & 10 & 5.5 \\
$20.5 \mathrm{~km} \mathrm{~s}^{-1}$ component & 5 & 2 & $5 \times 10^{6}$ & 90 & 7.5 & 20.5 \\
\hline
\end{tabular}
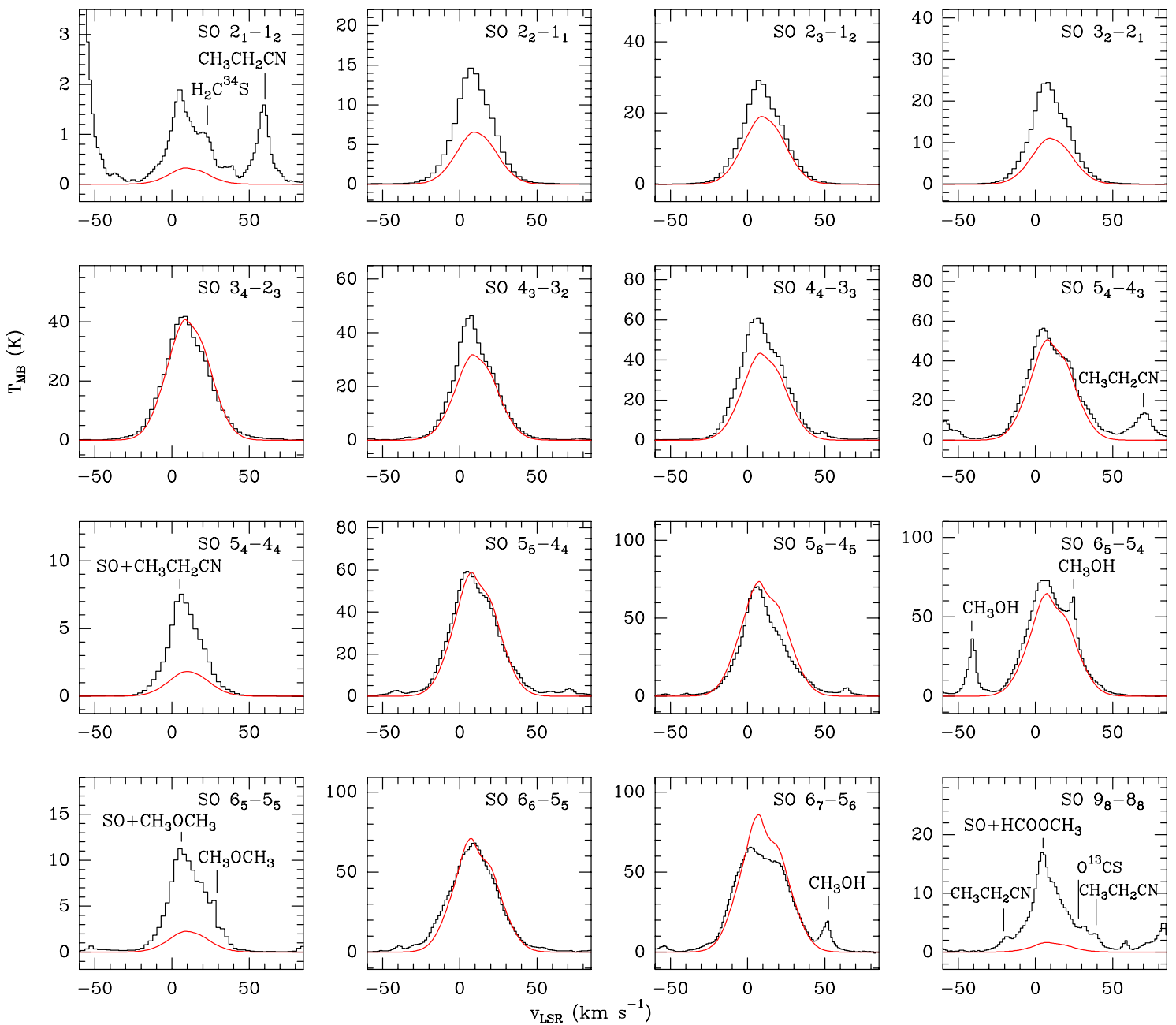

Fig. 9. Observed lines of SO (black histogram) and best fit LVG model results (red).

As we expected, Table 3 shows that the column densities of SO obtained from ${ }^{34} \mathrm{SO}$ are higher than those obtained from the fits. This confirms the presence of opacity effects on SO lines. We notice that the SO lines $2_{1}-1_{2}, 5_{4}-4_{4}, 6_{5}-$, and $98-8_{8}$ present a poor fit. This is because of the low Einstein coefficients $A_{\mathrm{ul}}$ and, mainly, to the low line strengths $\mathrm{S}\left(<4 \times 10^{-6} \mathrm{~s}^{-1}\right.$ and $<0.35$, respectively) of these lines, which provides small fits. The profile lines that we observe for these transitions are probably caused by stronger emission from other species.

Compared with values obtained in previous studies, such as those of Turner et al. (1991) or Blake et al. (1987), who derived (from source-averaged) $N(\mathrm{SO}) \sim 3 \times 10^{16} \mathrm{~cm}^{-2}$ in the plateau and $N \sim 3 \times 10^{15} \mathrm{~cm}^{-2}$ in the $\mathrm{HC}$, we see our results agree. If we compare these results with our obtained column densities from
${ }^{34} \mathrm{SO}$, we see that the plateau remains in agreement with these previous studies, but our column density in the $\mathrm{HC}$ is one order of magitude higher.

From the spatial distribution of the SO emission (Fig. 6), we find the integrated intensity peak to be in the velocity ranges $3-7 \mathrm{~km} \mathrm{~s}^{-1}$ and $10-14 \mathrm{~km} \mathrm{~s}^{1}$ for both transitions. These ranges correspond to emission arising mainly from the $\mathrm{HC}$ and the HVP, respectively, which agrees with the results obtained for the column densities in these regions. The transition with lowest energy (upper panel) shows a concentric emission distribution around IRc2, while for the transition with higher energy, the emission distribution is elongated toward NE-SW direction. We also observe that, for high energies, the emission peak in the velocity range $3-7 \mathrm{~km} \mathrm{~s}^{1}$ is shifted toward the NE of the $\mathrm{HC}$. 

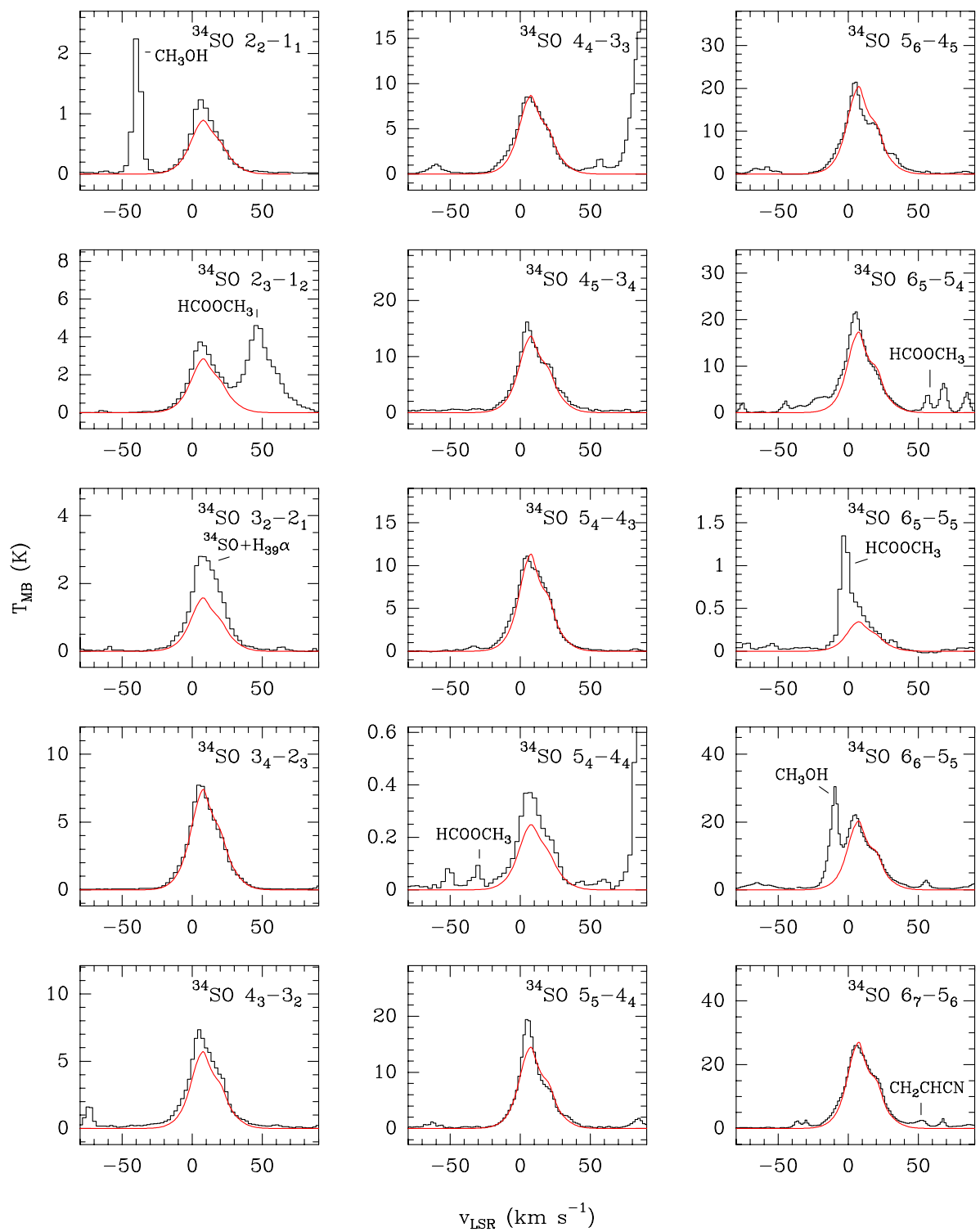

Fig. 10. Observed lines of ${ }^{34} \mathrm{SO}$ (black histogram) and best fit LVG model results (red).

\subsection{2. ${ }^{34} \mathrm{SO},{ }^{33} \mathrm{SO}$, and $\mathrm{S}^{18} \mathrm{O}$}

Figure 10 shows our best fit model for several rotational lines of ${ }^{34} \mathrm{SO}$, which are listed in Table A.8. We find that the HVP is also responsible for most of the emission, together with the PL and the $20.5 \mathrm{~km} \mathrm{~s}^{-1}$ component. According to our models, all transitions are optically thin with $\tau<0.4$, therefore this result is not considered to be a lower limit. The $20.5 \mathrm{~km} \mathrm{~s}^{-1}$ component presents a similar column density to the HVP, and as for SO, its contributon is greater for higher $J$. In the $\mathrm{HC}$ we also find a strong contribution to the emission, however in the ER we find the lowest column density with $N\left({ }^{34} \mathrm{SO}\right)=(7 \pm 2) \times 10^{12} \mathrm{~cm}^{-2}$.

For the case of ${ }^{33} \mathrm{SO}$ we observe in Fig. A.3 that lines are partially blended with other species, which produces a large uncertainty in the derived fit. In addition, the hyperfine structure is noticeable in these transitions, adding more complexity to the line profiles. The fits for this isotopologue were done by adopting the calculated frequencies, intensities, and energies for hyperfine levels up to $N=30$ provided by the CDMS catalogs. We obtain similar column densities for all components, with $N\left({ }^{33} \mathrm{SO}\right)=(3-6) \times 10^{14} \mathrm{~cm}^{-2}($ see Table 3$)$.
As was the case for ${ }^{33} \mathrm{SO}$, some lines of $\mathrm{S}^{18} \mathrm{O}$ are blended with other species (Fig. A.4 and Table A.8). In this case we also find similar column densities for all the components, $N\left(\mathrm{~S}^{18} \mathrm{O}\right)=(1-5) \times 10^{14} \mathrm{~cm}^{-2}$, except for the CR, the ER, and the $20.5 \mathrm{~km} \mathrm{~s}^{-1}$ component, where we do not find contribution to the emission.

\subsection{3. $\mathrm{S}^{17} \mathrm{O},{ }^{36} \mathrm{SO}$, and ${ }^{34} \mathrm{~S}^{18} \mathrm{O}$}

Owing to the presence of other more intense species, we have detected neither $\mathrm{S}^{17} \mathrm{O}$ nor ${ }^{36} \mathrm{SO}$ in this survey, but from our data we derive upper limits for their column densities of $N\left(\mathrm{~S}^{17} \mathrm{O}\right)<1.3 \times$ $10^{14} \mathrm{~cm}^{-2}$ and $N\left({ }^{36} \mathrm{SO}\right)<1.6 \times 10^{14} \mathrm{~cm}^{-2}$, respectively. We note that $\mathrm{C}^{36} \mathrm{~S}$ was detected by Mauersberger et al. (1996) in Orion. They found ${ }^{32} \mathrm{~S} /{ }^{36} S \simeq 3500$ which is consistent with our upper limit. We have not detected ${ }^{34} \mathrm{~S}^{18} \mathrm{O}$ either; however, assuming the same physical conditions as those for the main isotopologue, we obtain an upper limit for its column density of $N\left({ }^{34} \mathrm{~S}^{18} \mathrm{O}\right)<1.4 \times 10^{14} \mathrm{~cm}^{-2}$. 
Table 3. Column densities, $N$, for $\mathrm{SO}$ and its isotopologues obtained from LVG model fits.

\begin{tabular}{|c|c|c|c|c|c|}
\hline Component & $\begin{array}{c}\mathrm{SO} \\
N \times 10^{15}\left(\mathrm{~cm}^{-2}\right) \\
\end{array}$ & $\begin{array}{c}{ }^{34} \mathrm{SO} \\
N \times 10^{15}\left(\mathrm{~cm}^{-2}\right) \\
\end{array}$ & $\begin{array}{c}\mathrm{SO}^{a} \\
N \times 10^{15}\left(\mathrm{~cm}^{-2}\right) \\
\end{array}$ & $\begin{array}{c}{ }^{33} \mathrm{SO} \\
N \times 10^{15}\left(\mathrm{~cm}^{-2}\right) \\
\end{array}$ & $\begin{array}{c}\mathrm{S}^{18} \mathrm{O} \\
N \times 10^{15}\left(\mathrm{~cm}^{-2}\right) \\
\end{array}$ \\
\hline Extended ridge (ER) & $0.018 \pm 0.005$ & $0.007 \pm 0.002$ & $0.16 \pm 0.05$ & & \\
\hline High-velocity plateau (HVP) & $45 \pm 10$ & $4 \pm 1$ & $92 \pm 23$ & $0.25 \pm 0.06$ & $0.24 \pm 0.08$ \\
\hline Plateau (PL) & $5 \pm 1$ & $3.0 \pm 0.8$ & $69 \pm 19$ & $0.5 \pm 0.2$ & $0.10 \pm 0.04$ \\
\hline Hot core $(\mathrm{HC})$ & $9 \pm 3$ & $2.2 \pm 0.5$ & $20 \pm 11$ & $0.4 \pm 0.1$ & $0.5 \pm 0.2$ \\
\hline $20.5 \mathrm{~km} \mathrm{~s}^{-1}$ component & $5 \pm 1$ & $3.5 \pm 0.8$ & $81 \pm 19$ & $0.6 \pm 0.2$ & $\ldots$ \\
\hline
\end{tabular}

Notes. ${ }^{(a)}$ Values calculated from the solar abundance ratio ${ }^{32} \mathrm{~S} /{ }^{34} \mathrm{~S}=23$ and from the column densities obtained for ${ }^{34} \mathrm{SO}$ (optically thin lines).

Table 4. Column densities, $N$, for $\mathrm{SO}_{2}$ and its isotopologues, obtained from LTE model analysis.

\begin{tabular}{|c|c|c|c|c|c|c|c|c|}
\hline Component & $\begin{array}{c}\mathrm{SO}_{2} \\
N \times 10^{15} \\
\left(\mathrm{~cm}^{-2}\right)\end{array}$ & $\begin{array}{c}{ }^{34} \mathrm{SO}_{2} \\
N \times 10^{15} \\
\left(\mathrm{~cm}^{-2}\right)\end{array}$ & $\begin{array}{c}\mathrm{SO}_{2}{ }^{(a)} \\
N \times 10^{15} \\
\left(\mathrm{~cm}^{-2}\right)\end{array}$ & $\begin{array}{c}{ }^{33} \mathrm{SO}_{2} \\
N \times 10^{15} \\
\left(\mathrm{~cm}^{-2}\right)\end{array}$ & $\begin{array}{c}\mathrm{SO}^{18} \mathrm{O} \\
N \times 10^{15} \\
\left(\mathrm{~cm}^{-2}\right)\end{array}$ & $\begin{array}{c}\mathrm{SO}^{17} \mathrm{O} \\
N \times 10^{15} \\
\left(\mathrm{~cm}^{-2}\right)\end{array}$ & $\begin{array}{c}\mathrm{SO}_{2} v_{2}=1 \\
N \times 10^{15} \\
\left(\mathrm{~cm}^{-2}\right)\end{array}$ & $\begin{array}{c}{ }^{34} \mathrm{SO}_{2} v_{2}=1 \\
N \times 10^{15} \\
\left(\mathrm{~cm}^{-2}\right)\end{array}$ \\
\hline Extended ridge & $.23 \pm 0.06$ & $0.10 \pm 0.04$ & $2.3 \pm 0.7$ & $0.04 \pm 0.001$ & $0.020 \pm 0.007$ & $0.007 \pm 0.003$ & $0.013 \pm 0.003$ & \\
\hline Comp & $1.2=$ & 0.5 & $12 \pm$ & $0.07 \pm$ & 0.03 & $0.007=$ & 0.20 & $0.05 \pm$ \\
\hline High-velocity plateau & $130=$ & & $161 \pm$ & $1.0=$ & 0.9 & 0.10 & $0.4 \pm 0.1$ & $0.06 \pm 0.02$ \\
\hline Plateau & $10 \pm$ & $0.6 \pm$ & $14 \pm 3$ & $0.5 \pm$ & $0.06 \pm 0.02$ & $0.03 \pm$ & & \\
\hline Hot core & $100 \pm 40$ & $10 \pm 4$ & $230 \pm 60$ & $4 \pm 1$ & $1.5 \pm 0.5$ & $0.9 \pm 0.3$ & $4 \pm 1$ & $0.7 \pm 0.2$ \\
\hline $20.5 \mathrm{~km} \mathrm{~s}^{-1}$ comp. & $0.17 \pm 0.06$ & $0.04 \pm 0.01$ & $0.8 \pm 0.2$ & $0.009 \pm 0.003$ & $\ldots$ & $\ldots$ & $\ldots$ & $\ldots$ \\
\hline
\end{tabular}

Notes. ${ }^{(a)}$ Values calculated from the solar abundance ratio ${ }^{32} \mathrm{~S} /{ }^{34} \mathrm{~S}=23$ and from the column densities obtained for ${ }^{34} \mathrm{SO}_{2}$ (optically thin lines).

\subsection{LTE models of the $\mathrm{SO}_{2}$ lines}

Due to the lack of collisional rates for levels with energies higher than $90 \mathrm{~K}$, we have assumed LTE excitation to derive the $\mathrm{SO}_{2}$ column densities. As stated before, this can overestimate or underestimate the calculated column densities. Given that we have collisional rates for SO, we ran our SO models again but considering LTE approximation, in order to compare the results. We observed that the new fits underestimated the line profiles, especially for low transitions. Probably this also happens with the $\mathrm{SO}_{2}$ case, so we should consider our $\mathrm{SO}_{2}$ column densities as lower limits. Table A.9 lists the 166 observed rotational lines. Figures 11-14 show a sample of 90 observed lines (ordered by increasing energy) with our best fits overlaid.

The main contribution to the emission of $\mathrm{SO}_{2}$ comes from the HVP (affecting mainly the lines with energies $E<400 \mathrm{~K}$ ), with a column density of $N\left(\mathrm{SO}_{2}\right)=(1.3 \pm 0.5) \times 10^{17} \mathrm{~cm}^{-2}$. The hottest region (the $\mathrm{HC}$ ) also presents a similar high value, $N\left(\mathrm{SO}_{2}\right)=(1.0 \pm 0.4) \times 10^{17} \mathrm{~cm}^{-2}$. We find that the CR presents a column density of $N\left(\mathrm{SO}_{2}\right) \sim 10^{15} \mathrm{~cm}^{-2}$, whereas the $20.5 \mathrm{~km} \mathrm{~s}^{-1}$ component presents the lowest contribution to the emission (Table 4).

If we compare our results for $\mathrm{SO}_{2}$ with those of $\mathrm{SO}$, we find that $\mathrm{SO}_{2}$ column densities are about one order of magintude larger in all components, except in the $20.5 \mathrm{~km} \mathrm{~s}^{-1}$ component, where SO presents a higher contribution to the emission. As for $\mathrm{SO}$, we also calculated the $\mathrm{SO}_{2}$ column densities from ${ }^{34} \mathrm{SO}_{2}$ (optically thin lines) and the ${ }^{32} \mathrm{~S} /{ }^{34} \mathrm{~S}$ solar abundance ratio (Table 4). Except for the plateau components, we obtain that the column densities of $\mathrm{SO}_{2}$ obtained from ${ }^{34} \mathrm{SO}_{2}$ are larger than those obtained from fits, suggesting they are opacity effects on the $\mathrm{SO}_{2}$ lines. Comparing with previous results, Blake et al. (1987) obtained (source-averaged) that $\mathrm{SO}_{2}$ presents a column density in the plateau, $N \sim 10^{16} \mathrm{~cm}^{-2}$. Schilke et al. (2001) derived (beam-averaged) for the same region $N\left(\mathrm{SO}_{2}\right)=9.7 \times 10^{16} \mathrm{~cm}^{-2}$, which is very similar to our result in the HVP. For the HC, Sutton et al. (1995) found (also source-averaged) a column density, $N\left(\mathrm{SO}_{2}\right) \sim 9 \times 10^{16} \mathrm{~cm}^{-2}$. Our results agree with these values; however, the large number of transitions that we observed let us determine more accurately that it is the lower temperature plateau component, i.e. the HVP, which contributes more to the emission of $\mathrm{SO}_{2}$.

From the spatial distribution of the $\mathrm{SO}_{2}$ emission (Fig. 7), we find the maximum integrated line intensity between the velocity ranges $3-7 \mathrm{~km} \mathrm{~s}^{-1}$ and $10-14 \mathrm{~km} \mathrm{~s}^{-1}$, as well as for SO. These velocity ranges correspond to emission of the $\mathrm{HC}$ and the HVP, respectively, which agrees with the column density results obtained above. The emission peak is located towards the NE of IRc2 for the range $3-7 \mathrm{~km} \mathrm{~s}^{-1}$, while the emission peak for the HVP range is located $\sim 4^{\prime \prime}$ to the SW of IRc2. Emission from the $20.5 \mathrm{~km} \mathrm{~s}^{-1}$ component presents similar integrated intensity to the ridge (range of $7-10 \mathrm{~km} \mathrm{~s}^{-1}$ ). On the other hand, the map of ${ }^{34} \mathrm{SO}_{2}$ (Fig. 8) shows the strongest peak emission located northeast of IRc2 for all velocity ranges, although extended emission is seen to the southwest of IRc2, between $10 \mathrm{~km} \mathrm{~s}^{-1}$ and $22 \mathrm{~km} \mathrm{~s}^{-1}$. The ${ }^{34} \mathrm{SO}_{2}$ transition shown in Fig. 8 has an upper energy level of $\sim 400 \mathrm{~K}$ and therefore may trace only the hottest component of the gas.

\subsection{1. ${ }^{34} \mathrm{SO}_{2}$}

We have detected 130 rotational lines of ${ }^{34} \mathrm{SO}_{2}$ (Table A.9). A sample of more than 30 lines is shown in Fig. 15.

This isotopologue, whose lines are optically thin, has the highest contribution to its emission from the $\mathrm{HC}$, with $N\left({ }^{34} \mathrm{SO}_{2}\right)=(1.0 \pm 0.4) \times 10^{16} \mathrm{~cm}^{-2}$. The other components with high column densities are the HVP and the PL with $N\left({ }^{34} \mathrm{SO}_{2}\right)=(7 \pm 2) \times 10^{15} \mathrm{~cm}^{-2}$ and $N\left({ }^{34} \mathrm{SO}_{2}\right)=(6 \pm 2) \times$ $10^{14} \mathrm{~cm}^{-2}$, respectively. Particulary interesting is the column density found in the ER, which presents the same order of magnitude as the PL. The same behavior is also observed in the isotopologues ${ }^{33} \mathrm{SO}_{2}$ and $\mathrm{SO}^{18} \mathrm{O}$, where the column densities in the ER are only 3 to 12 times lower than in PL. This could 

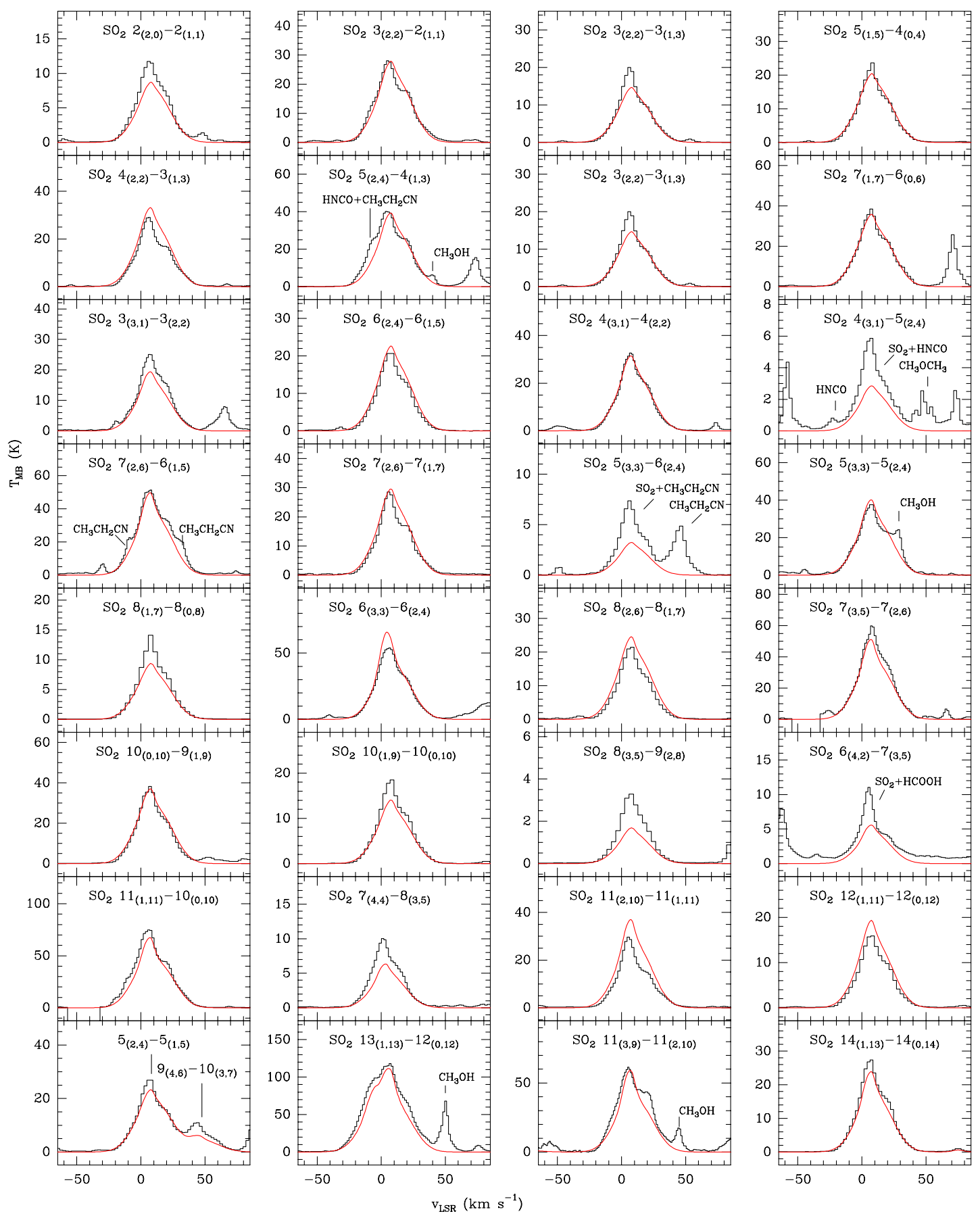

Fig. 11. Observed lines (black histogram) of $\mathrm{SO}_{2}$ with upper state energies lower than $400 \mathrm{~K}$, ordered by increasing energy from top left to bottom right. Best fit LTE model results are overlaid in red.

be due to the strong emission emerging from the HVP and HC affecting the excitation of the energy levels of this isotopologue in the ER, which means that line photons emitted from the inner components will be scattered by the lower density gas in the ER component (radiative scattering). For the compact ridge, we find the emission contributes mainly to the lines at low frequencies. The column density for ${ }^{34} \mathrm{SO}_{2}$ obtained in the $20.5 \mathrm{~km} \mathrm{~s}^{-1}$ component is about 100 times lower than for ${ }^{34} \mathrm{SO}$ (see Table 4).

\subsection{2. ${ }^{33} \mathrm{SO}_{2}, \mathrm{SO}^{18} \mathrm{O}$, and $\mathrm{SO}^{17} \mathrm{O}$}

Figure A.5 shows transitions of ${ }^{33} \mathrm{SO}_{2}$ in the frequency range covered at 1.3, 2, and $3 \mathrm{~mm}$. Several of these are blended with other species, which makes the derived fits a bit biased. As for ${ }^{33} \mathrm{SO}$, hyperfine structure affects the line profiles; however, we did not consider it in the ${ }^{33} \mathrm{SO}_{2}$ model, so the derived column densities could be underestimated.

The most important contribution to the emission of ${ }^{33} \mathrm{SO}_{2}$ comes from the hot core, with $N\left({ }^{33} \mathrm{SO}_{2}\right)=(4 \pm 1) \times 10^{15} \mathrm{~cm}^{-2}$, and from the HVP. The lowest contribution to the emission arises from the $20.5 \mathrm{~km} \mathrm{~s}^{-1}$ component, with $N\left({ }^{33} \mathrm{SO}_{2}\right)=(9 \pm 3) \times$ $10^{12} \mathrm{~cm}^{-2}$.

For $\mathrm{SO}^{18} \mathrm{O}$ (Fig. A.6), the highest column density is also found in the $\mathrm{HC}$, with $N\left(\mathrm{SO}^{18} \mathrm{O}\right)=(1.5 \pm 0.5) \times 10^{15} \mathrm{~cm}^{-2}$. The HVP also presents an important contribution to the emission across the frequency range, whereas the PL mainly affects 
G. B. Esplugues et al.: Survey towards Orion KL. Sulfur oxide species
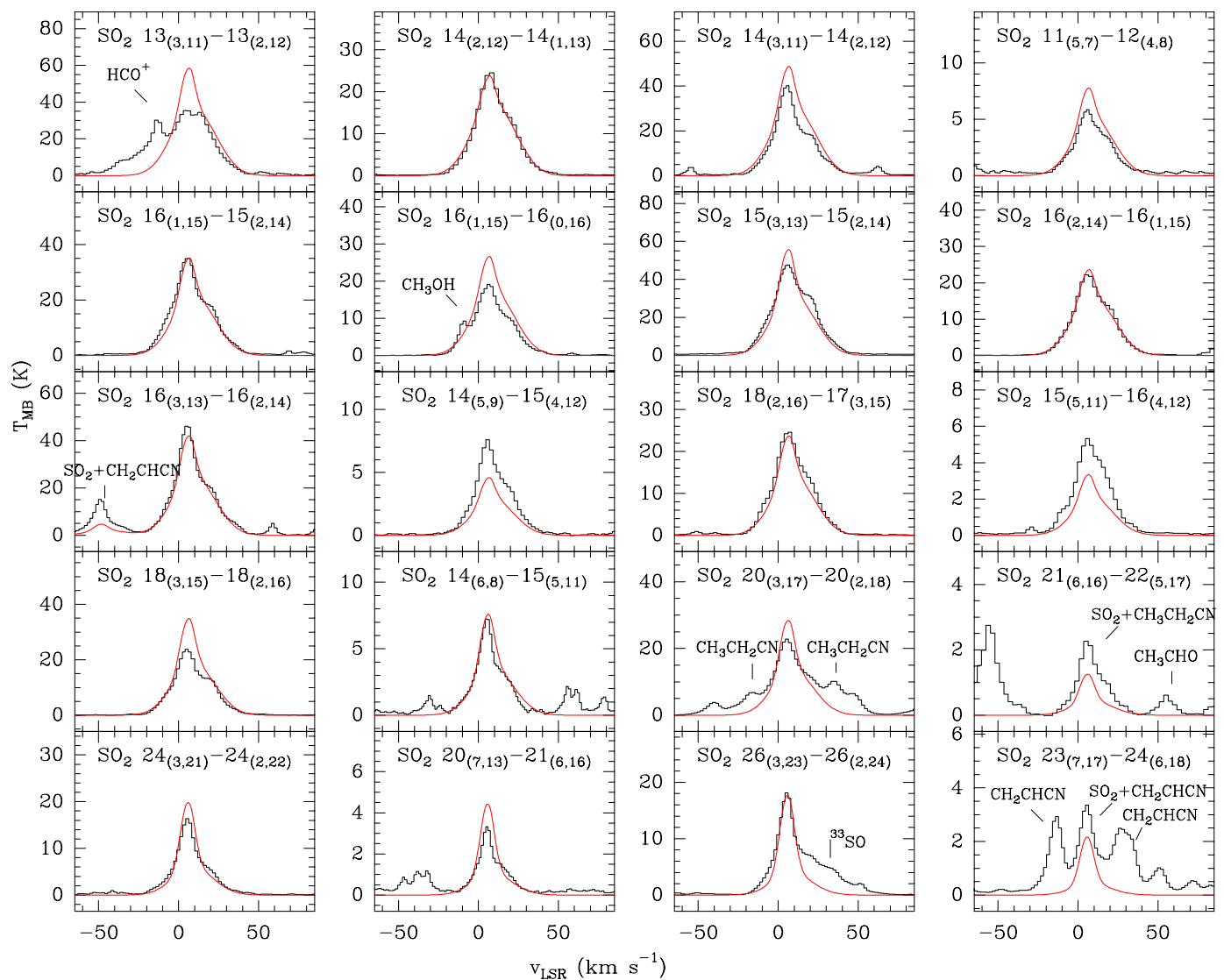

Fig. 12. Observed lines of $\mathrm{SO}_{2}$ (black histogram) with upper state energies lower than $400 \mathrm{~K}$ (continued), ordered by increasing energy from top left to bottom right. Best fit LTE model results are overlaid in red.

lines at $2 \mathrm{~mm}$. The weakest contribution is from the ER, with $N\left(\mathrm{SO}^{18} \mathrm{O}\right) \sim 10^{13} \mathrm{~cm}^{-2}$.

Figure A.7 shows the spectra that contain some frequencies of $\mathrm{SO}^{17} \mathrm{O}$, together with our best model. The maximum contribution to the emission of this isotopologue arises from the hot core with $N\left(\mathrm{SO}^{17} \mathrm{O}\right)=(8 \pm 3) \times 10^{14} \mathrm{~cm}^{-2}$. We find that the PL and HVP also contribute to the emission, but about four to eight times less than the HC. However, because all lines are weak $\left(T_{\mathrm{MB}}<0.3 \mathrm{~K}\right)$ and blended with other species, we should consider these results as upper limits.

\subsection{3. $\mathrm{SO}_{2} v_{2}=1$}

Figure 16 shows some of the detected lines of vibrationally excited $\mathrm{SO}_{2} v_{2}$, which are also listed in Table A.9. The hot core is responsible for most of the emission of this vibrational mode, with a column densitiy one order of magnitude higher than in the other components. From the column densities in the $\mathrm{HC}$ for $\mathrm{SO}_{2}$ in its ground and vibrationally excited states, we can estimate a vibrational temperature, considering that

$\frac{\exp \left(-E_{v_{\mathrm{x}}} / T_{\mathrm{vib}}\right)}{f_{v}}=\frac{N\left(S O_{2} v_{x}\right)}{N\left(S O_{2}\right)}$,

where $E_{v_{\mathrm{x}}}$ is the energy of the vibrational state $\left(E_{v_{2}}=745.1 \mathrm{~K}\right)$, $T_{\text {vib }}$ is the vibrational temperature, $N\left(\mathrm{SO}_{2} v_{\mathrm{x}}\right)$ is the column density of $\mathrm{SO}_{2}$ in the excited vibrational state, $N\left(\mathrm{SO}_{2}\right)$ the total column density, and $f_{v}$ is the vibrational partition function, given by

$f_{v}=1+\exp \left(-E_{v_{3}} / T_{\mathrm{vib}}\right)+2 \exp \left(-E_{v_{2}} / T_{\mathrm{vib}}\right)+\exp \left(-E_{v_{1}} / T_{\mathrm{vib}}\right)$.
Taking into account that $N\left(\mathrm{SO}_{2}\right)=N_{\text {(ground) }} \times f_{v}$, we only need the energy of the vibrational state and the calculated column densities to derive the vibrational temperature.

We obtain $T_{\text {vib }}=(230 \pm 40) \mathrm{K}$ for $\mathrm{SO}_{2} v_{2}=1$. This value is similar to the kinetic temperature we assumed for the $\mathrm{HC}$ component $(220 \mathrm{~K})$. It is unlikely that the $v_{2}=1$ level at $745 \mathrm{~K}$ above the ground is excited by collisions. The main pumping mechanism could be IR radiation from the HC. A similar situation was found by Tercero et al. (2010) for OCS and other species.

\subsection{4. ${ }^{34} \mathrm{SO}_{2} v_{2}=1$}

Figure A.8 shows some observed lines of ${ }^{34} \mathrm{SO}_{2} v_{2}=1$. The strongest emission comes from the hot core with $N\left({ }^{34} \mathrm{SO}_{2} v_{2}=\right.$ $1)=(7 \pm 2) \times 10^{14} \mathrm{~cm}^{-2}$, although we also find a small contribution from the HVP and the CR, with $N\left({ }^{34} \mathrm{SO}_{2} v_{2}=1\right) \sim$ $5 \times 10^{13} \mathrm{~cm}^{-2}$ for both. These contributions mainly affect the lines at $2 \mathrm{~mm}$. Since all the lines we detect are very weak and mixed with other species, we should consider these results as upper limits.

\subsection{Isotopic and molecular abundances}

From the derived column densities of $\mathrm{SO}, \mathrm{SO}_{2}$, and their isotopologues, we can estimate abundance ratios. These are shown in Table A.5. We compare these ratios with solar isotopic abundance values from Anders \& Grevesse (1989).

${ }^{32} \mathrm{~S} /{ }^{34} \mathrm{~S}$ : from the $\mathrm{SO}_{2}$ lines we obtain a column density ratio for the PL of ${ }^{32} \mathrm{~S} /{ }^{34} S=16 \pm 10$, in agreement with previous studies $\left({ }^{32} \mathrm{~S} /{ }^{34} \mathrm{~S} \simeq 16\right.$ by Johansson et al. $1984,{ }^{32} \mathrm{~S} /{ }^{34} \mathrm{~S} \simeq 13-16$ by 
A\&A 556, A143 (2013)
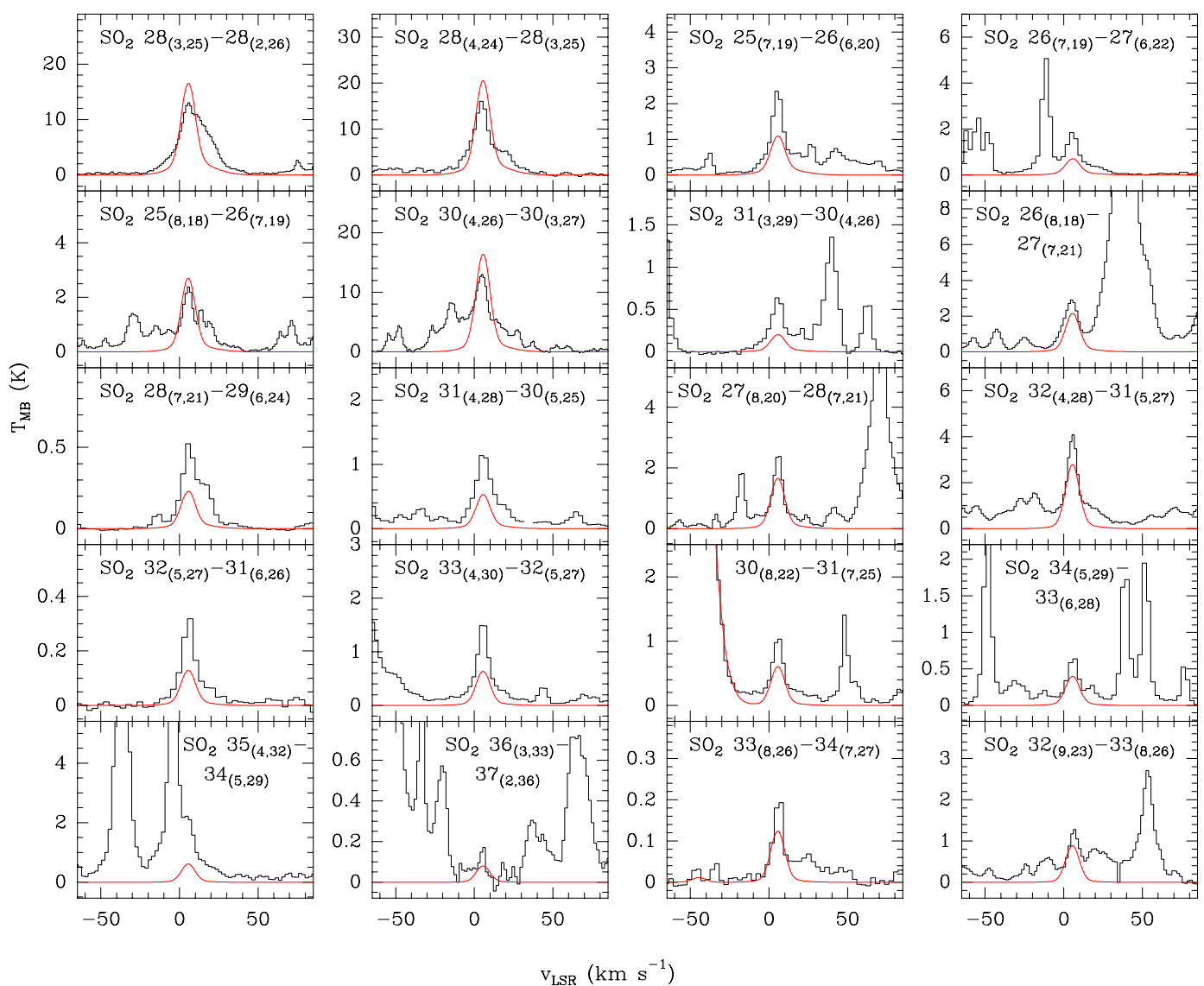

Fig. 13. Observed lines of $\mathrm{SO}_{2}$ (black histogram) with upper state energies between $400 \mathrm{~K}$ and $700 \mathrm{~K}$, ordered by increasing energy from top left to bottom right. Best fit LTE model results are overlaid in red.
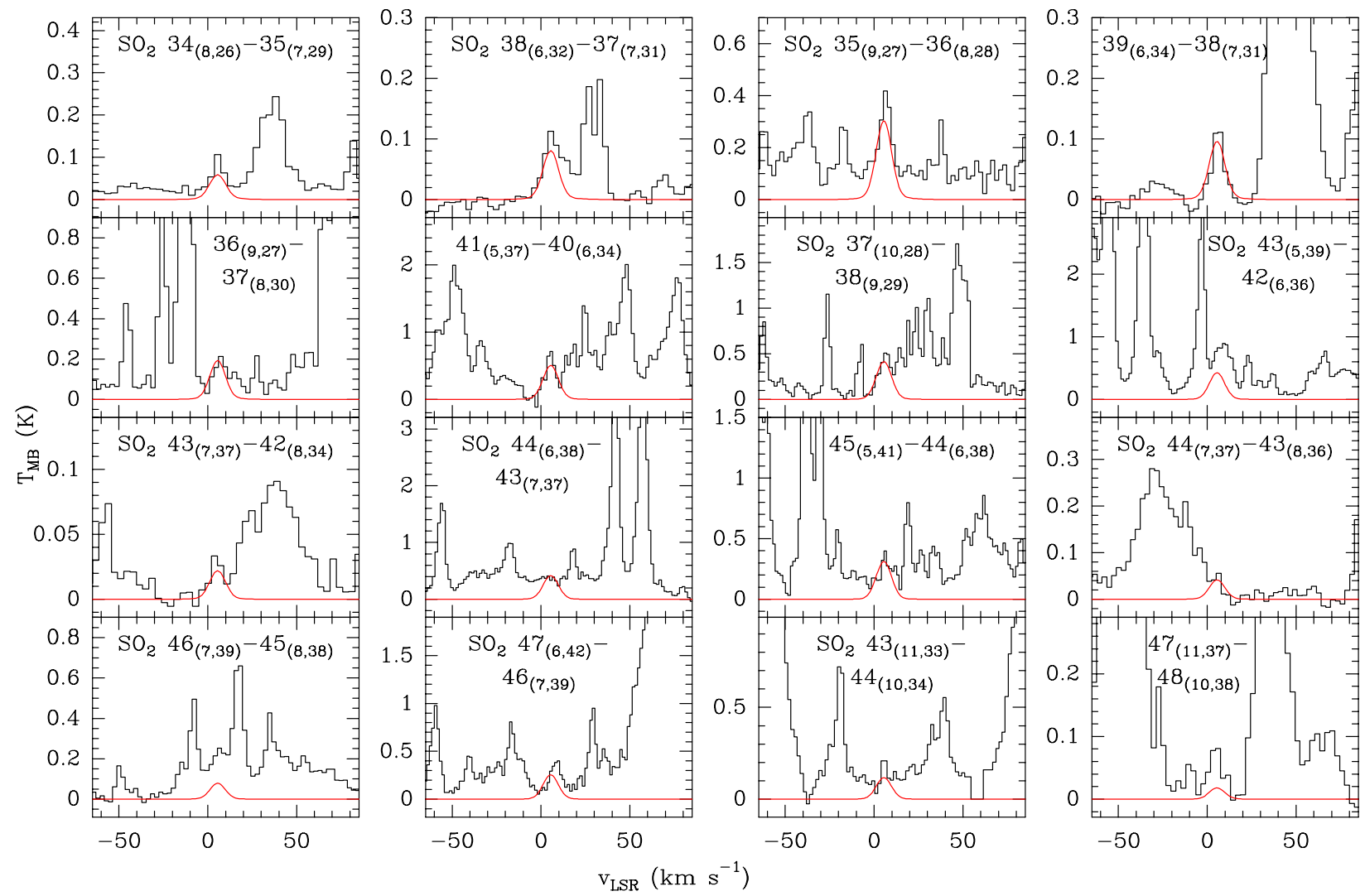

Fig. 14. Observed lines of $\mathrm{SO}_{2}$ (black histogram) with energies higher than $700 \mathrm{~K}$, ordered by increasing energy from top left to bottom right. Best fit LTE model results are overlaid in red. 
G. B. Esplugues et al.: Survey towards Orion KL. Sulfur oxide species
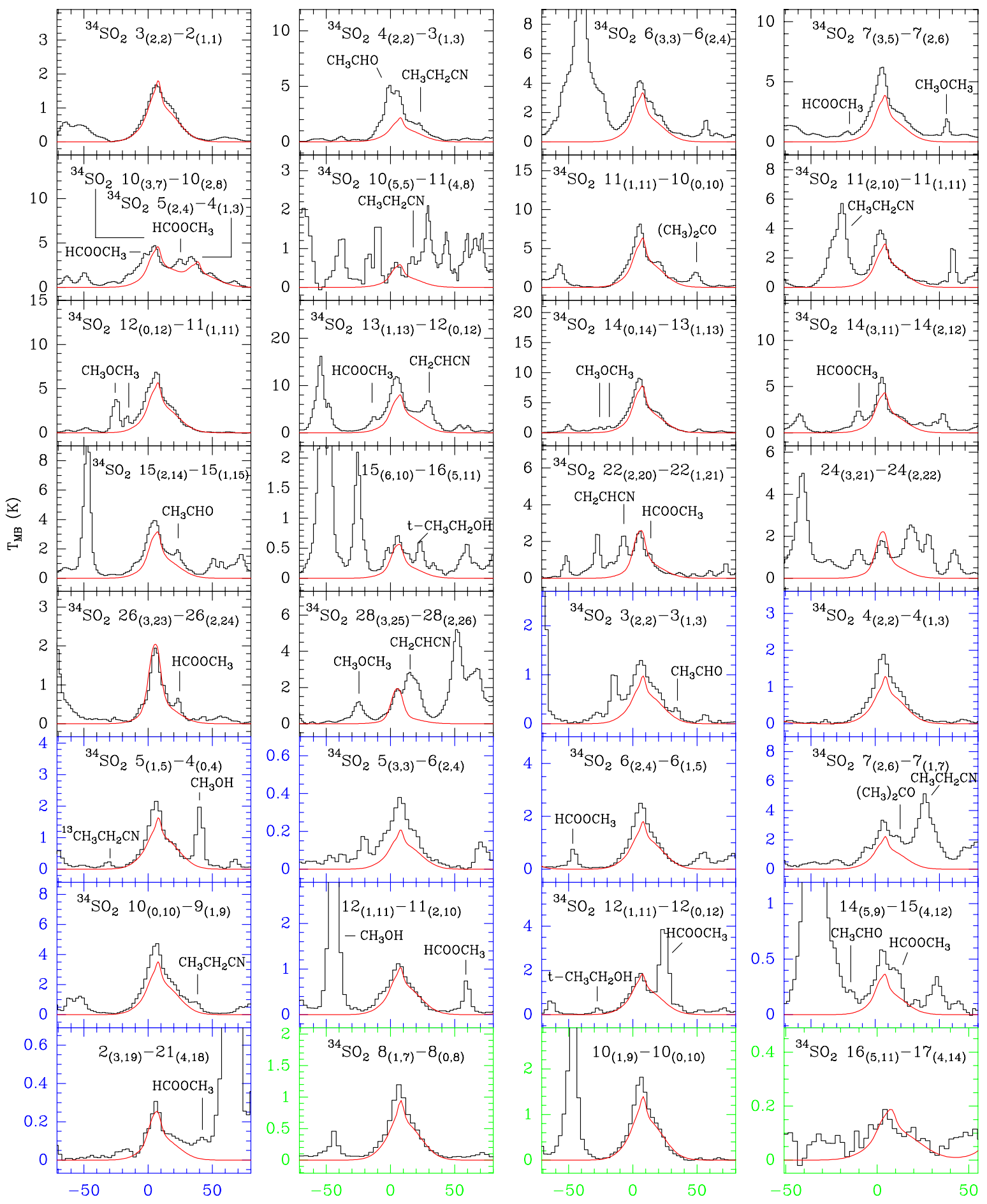

$\mathrm{v}_{\mathrm{LSR}}\left(\mathrm{km} \mathrm{s}^{-1}\right)$

Fig. 15. Observed lines of ${ }^{34} \mathrm{SO}_{2}$ (black histogram). Best fit LTE model results are shown in red. Boxes with black, blue and green borders correspond to lines observed at $1.3,2$, and $3 \mathrm{~mm}$, respectively.

Blake et al. 1987, and ${ }^{32} \mathrm{~S} /{ }^{34} \mathrm{~S}=15 \pm 5$ by Tercero et al. 2010). For the HVP, ${ }^{32} \mathrm{~S} /{ }^{34} \mathrm{~S}=20 \pm 13$, which is similar to the value for the solar isotopic abundance ratio and to the result deduced by Persson et al. (2007) where ${ }^{32} \mathrm{~S} /{ }^{34} \mathrm{~S} \simeq 23 \pm 7$. From the SO lines, with the exception of the HVP, we obtain low ratios for ${ }^{32} \mathrm{~S} /{ }^{34} \mathrm{~S}$ in comparison with the solar abundance, which could be due to opacity effects on the SO lines.
${ }^{32} \mathrm{~S} /{ }^{33} \mathrm{~S}$ : from $N(\mathrm{SO}) / N\left({ }^{33} \mathrm{SO}\right)$ we obtain ${ }^{32} \mathrm{~S} /{ }^{33} \mathrm{~S}=180 \pm 80$ for the HVP. This value agrees with the solar isotopic abundance ratio, 127, from Anders \& Grevesse (1989). For the other three components, the obtained ratios are very low compared to the solar abundance, probably also due to the opacity effects for SO lines. These values should be considered as lower limits. We find similar behavior for the ratio $N\left(\mathrm{SO}_{2}\right) / N\left({ }^{33} \mathrm{SO}_{2}\right)$. 

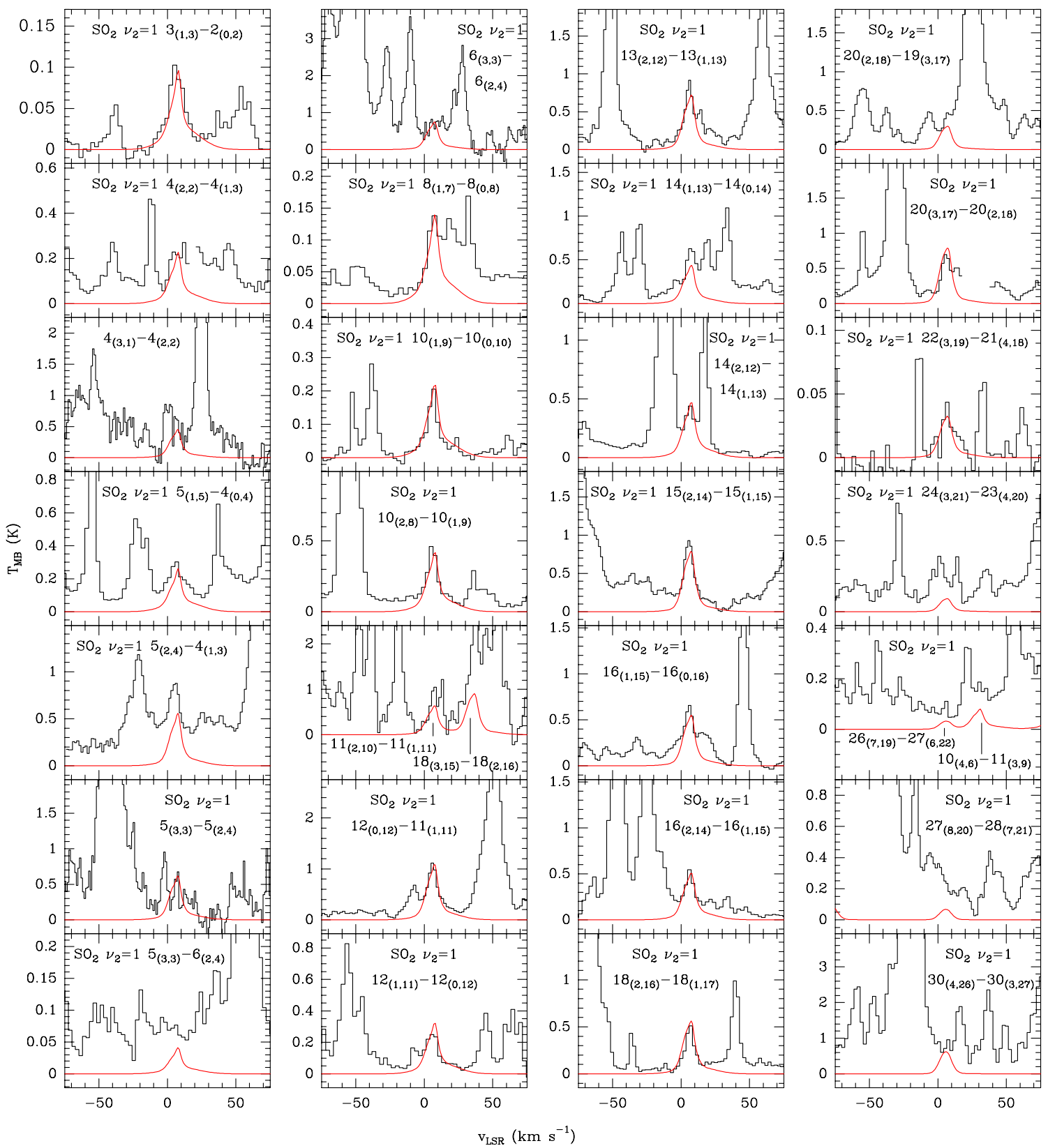

Fig. 16. Observed lines of $\mathrm{SO}_{2} v_{2}=1$ (black histogram). Best fit LTE model results are shown in red.

${ }^{34} \mathrm{~S} /{ }^{33} \mathrm{~S}$ : from $N\left({ }^{34} \mathrm{SO}_{2}\right) / N\left({ }^{33} \mathrm{SO}_{2}\right)$ we obtain ${ }^{34} \mathrm{~S} /{ }^{\beta 3} \mathrm{~S}=4 \pm 3$ for the $20.5 \mathrm{~km} \mathrm{~s}^{-1}$ component and ${ }^{34} \mathrm{~S} /{ }^{\beta 3} \mathrm{~S}=3-7$ for the ridge (ER and CR), the HVP, and the HC. These values are similar to the solar abundance ratio (5.5). From $N\left({ }^{34} \mathrm{SO}\right) / N\left({ }^{33} \mathrm{SO}\right)$ the obtained ratio is ${ }^{34} \mathrm{~S} /{ }^{33} \mathrm{~S}=6 \pm 3$ for the $\mathrm{HC}$ and both plateau components.

${ }^{16} \mathrm{O} /{ }^{18} \mathrm{O}$ : our results for this ratio in the plateau agree with those obtained by Tercero et al. (2010), who derived ${ }^{16} \mathrm{O} /{ }^{18} \mathrm{O}=250 \pm 135$ in the plateau from a study of OCS in this region. The compact ridge also presents similar ratio to that obtained by them. However, all these values are lower than the solar isotopic abundance $(\simeq 500)$.

$\mathrm{SO} / \mathrm{SO}_{2}$ : in Fig. 18 we present the ratio $N(\mathrm{SO}) / N\left(\mathrm{SO}_{2}\right)$ for the different components, as well as for the different isotopologues of $\mathrm{SO}$ and $\mathrm{SO}_{2}$. We find that $\mathrm{SO}_{2}$ is more abundant than $\mathrm{SO}$ in all components, except in the $20.5 \mathrm{~km} \mathrm{~s}^{-1}$ component. In the $\mathrm{HVP}, \mathrm{SO}_{2}$ is three times more abundant than $\mathrm{SO}$, while in the
$\mathrm{HC}$ is up to 11 times more. However, in the $20.5 \mathrm{~km} \mathrm{~s}^{-1}$ component, $\mathrm{SO}$ is $\sim 30$ times more abundant than $\mathrm{SO}_{2}$.

${ }^{34} \mathrm{SO} /{ }^{34} \mathrm{SO}_{2}$ : in the region affected by shocks, this ratio implies that ${ }^{34} \mathrm{SO}_{2}$ is more abundant $(\sim 1.7$ times $)$ than ${ }^{34} \mathrm{SO}$. In the hot core, we also find that ${ }^{34} \mathrm{SO}_{2}$ is more abundant (5 times) than ${ }^{34} \mathrm{SO}$, whereas in the ER the ratio is much larger $\left({ }^{34} \mathrm{SO}_{2}\right.$ is 14 times more abundant). As was found for $\mathrm{SO} / \mathrm{SO}_{2}$, the main difference is in the $20.5 \mathrm{~km} \mathrm{~s}^{-1}$ component, where ${ }^{34} \mathrm{SO}$ is $\sim 100$ times more abundant than ${ }^{34} \mathrm{SO}_{2}$.

Table A.6 shows the molecular abundances, $X$, of SO and $\mathrm{SO}_{2}$ with respect to hydrogen in each component. They were derived using $\mathrm{H}_{2}$ column density by means of the $\mathrm{C}^{18} \mathrm{O}$ column density, from the isotopic abundance ${ }^{16} \mathrm{O} /{ }^{18} \mathrm{O}$, and assuming that $\mathrm{CO}$ is a good tracer of $\mathrm{H}_{2}$ and therefore their abundance ratio is roughly constant. The column densities for $\mathrm{H}_{2}$ are $7.5 \times 10^{22}$, $7.5 \times 10^{22}, 2.1 \times 10^{23}, 6.2 \times 10^{22}, 4.2 \times 10^{23} \mathrm{~cm}^{-2}$, and $1.0 \times 10^{23}$ for the ER, CR, PL, HVP, HC, and the $20.5 \mathrm{~km} \mathrm{~s}^{-1}$ component, 
respectively (see Tercero et al. 2011). We observe that the highest abundance of SO is obtained in the HVP, whereas in the $\mathrm{HC}$ and in the PL this abundance is $~ 30$ times lower. The extended ridge presents the lowest abundance of sulfur monoxide. The abundance of this molecule in the $20.5 \mathrm{~km} \mathrm{~s}^{-1}$ component is about twice larger than in the $\mathrm{HC}$. $\mathrm{SO}_{2}$ is also more abundant in the HVP (between 8 and 600 times more abundant than in the rest of components). With respect to hydrogen, $\mathrm{SO}_{2}$ is about one order of magnitude more abundant than $\mathrm{SO}$ in the $\mathrm{HC}$ and in the $\mathrm{ER}$, while in both plateaus sulfur dioxide is only two-three times more abundant than SO.

\subsection{Other sulfur-bearing molecules}

We provide here upper limits for the column densities of several sulfur-bearing molecules not detected in our survey. We have assumed the same spectral components as for $\mathrm{SO}$ and $\mathrm{SO}_{2}(\mathrm{HC}$, PL, HVP, CR, and ER) and an LTE approximation, due to the lack of available collision rates. Table 2 shows the adopted temperature values, among other parameters, for each component, and Table A.7 shows the results obtained, the dipole moment of each species, and references for the spectroscopic constants. The upper limit of column density for each species were obtained summing the contribution of all the components.

$\mathrm{SO}^{+}$: first detected in the interstellar medium towards the supernova remnant IC443 (Turner et al. 1992), it was proposed as a tracer of dissociative shocks, although later surveys carried out in dark clouds, SFRs, and high velocity molecular outflows suggest that this reactive ion is not associated with shock chemistry (Turner et al. 1994). $\mathrm{SO}^{+}$presents a high abundance in PDRs like NGC 7023 and in the Orion Bar (Fuente et al. 2003). In Orion KL, we obtain an upper limit to its column density of $N\left(\mathrm{SO}^{+}\right) \leq 2.5 \times 10^{14} \mathrm{~cm}^{-2}$, providing an abundance ratio of $N(\mathrm{SO}) / N\left(\mathrm{SO}^{+}\right) \geq 2080$. This result implies that $\mathrm{UV}$ radiation does not play an important role in this region.

(cis)-HOSO${ }^{+}$: it is the most stable isomeric form of this ion. This species has not yet been detected in the interstellar medium, but its large dipole moment $(1.74 \mathrm{D})$, its easy formation through $\mathrm{H}_{3}^{+}$reacting with $\mathrm{SO}_{2}$ and the fact that it does not react with $\mathrm{H}_{2}$ make this ion an excellent candidate for being detected, mainly in hot regions where the parent $\mathrm{SO}_{2}$ is very abundant. The upper limit calculated for this ion is $N\left(\right.$ cis-HOSO $\left.{ }^{+}\right) \leq 3.6 \times 10^{13} \mathrm{~cm}^{-2}$.

SSO: this molecule has not been detected yet in the interstellar medium, but it is a plausible candidate, since the oxides $\mathrm{SO}$ and $\mathrm{SO}_{2}$ are particulary abundant, especially in SFRs. Disulfur monoxide (SSO) was spectroscopically studied first by Meschi \& Myers (1959) who detected rotational transitions in the ground vibrational state and in the $v_{2}=1$ state. Later, Thorwirth et al. (2006) carried out a millimeter and submillimeter wave investigation of SSO in the ground vibrational state to frequencies as high as $470 \mathrm{GHz}$. We have not detected SSO in our line survey, but we obtain an upper limit for its column density of $N(\mathrm{SSO}) \leq 7.6 \times 10^{14} \mathrm{~cm}^{-2}$, providing an abundance ratio of $N(\mathrm{SO}) / N(\mathrm{SSO}) \geq 1155$.

OSiS: silicon oxysulfide was first characterized in the gas phase at high spectral resolution by Thorwirth et al. (2011). It prosseses a large dipole moment $\left(\mu_{a}=1.47 \mathrm{D}\right)$ and its bond distances are very short in comparison with those of $\mathrm{SiO}$ and $\mathrm{SiS}$. It has not been detected yet in the interstellar medium, and we obtained an upper limit for the column density of this molecule in Orion KL of $N(\mathrm{OSiS}) \leq 6.3 \times 10^{13} \mathrm{~cm}^{-2}$. Tercero et al. (2010) found that in Orion KL the total column density for $\mathrm{SiS}$ in the ground state is $N(\mathrm{SiS})=(1.4 \pm 0.4) \times 10^{15} \mathrm{~cm}^{-2}$. This result provides an abundance ratio of $N(\mathrm{SiS}) / N(\mathrm{OSiS}) \geq 22$.
$\mathrm{S}_{3}$ : thiozone is a bent chain with a bond to the apex $S$ whose rotational spectrum was first measured by McCarthy et al. (2004a). $S_{3}$ has not yet been observed in the interstellar medium; however, it is an excellent candidate for astronomical detection in rich interstellar sources. In addition, $\mathrm{S}_{3}$ may also exist in the atmosphere of Io, where $S_{2}$ has already been detected in the ultraviolet. Owing to the presence of more intense lines from other species we have not detected $\mathrm{S}_{3}$ in our line survey. We provide an upper limit for its column density of $N\left(\mathrm{~S}_{3}\right) \leq 1 \times 10^{15} \mathrm{~cm}^{-2}$.

$\mathrm{S}_{4}$ : tetrasulfur is a singlet planar trapezoid whose rotational spectrum was observed for the first time by McCarthy et al. (2004a). $\mathrm{S}_{4}$ has a substantial dipole moment, $0.87 \mathrm{D}$, hence an intense rotational spectrum across the entire radio band. The upper limit column density we calculated for this molecule is $N\left(\mathrm{~S}_{4}\right) \leq 7 \times 10^{14} \mathrm{~cm}^{-2}$.

$\mathrm{CH}_{3} \mathrm{SOCH}_{3}$ : Barnes et al. (1994) obtained this molecule in the laboratory while investigating the gas-phase reaction of $\mathrm{OH}$ with the oxidation of dimethyl sulfide at room temperature. Dimethyl sulfoxide has not been observed yet in the interstellar medium, but we provide an upper limit for its column density of $N\left(\mathrm{CH}_{3} \mathrm{SOCH}_{3}\right) \leq 1 \times 10^{14} \mathrm{~cm}^{-2}$.

$\mathrm{H}_{2}$ CSO: sulfine was first identified in 1976 as a product of the pyrolysis of a variety of sulfur-bearing precursors. $\mathrm{H}_{2} \mathrm{CSO}$ is a planar molecule of $\mathrm{C}_{s}$ symmetry. Joo et al. (1995) analyzed its infrared spectrum at high resolution. We provide an upper limit for the column density for this undetected molecule in the interstellar medium of $N\left(\mathrm{H}_{2} \mathrm{CSO}\right) \leq 3 \times 10^{13} \mathrm{~cm}^{-2}$.

HNSO: thionylimide is a semi-stable molecule that adopts a cis-planar structure of $\mathrm{C}_{s}$ symmetry in the ground state. HNSO is the simplest molecule in the group of organic nitrogen-sulfur compounds. We calculated an upper limit for its column density of $N(\mathrm{HNSO}) \leq 4.1 \times 10^{14} \mathrm{~cm}^{-2}$, which provides an abundance ratio $N(\mathrm{SO}) / N(\mathrm{HNSO}) \geq 2600$.

$\mathrm{o}-\mathrm{H}_{2} \mathrm{~S}_{2}$ : the rotational spectrum of disulfane $\left(\mathrm{H}_{2} \mathrm{~S}_{2}\right)$ has been measured in the far-infrared, millimeter, and submillimeter (Winnewisser et al. 1966). The density of its spectrum is enhanced by the presence of low-lying torsional and S-S stretching modes. We did not observe this molecule in our line survey but we provide an upper limit for its column density of $N(\mathrm{o}-$ $\left.\mathrm{H}_{2} \mathrm{~S}_{2}\right) \leq 1.6 \times 10^{14} \mathrm{~cm}^{-2}$.

SSH and $\mathrm{H}_{2} \mathrm{SO}_{4}$ : these molecules have not yet been detected in the interstellar medium. The calculated upper limits for their column densities are $N(\mathrm{SSH}) \leq 7.1 \times 10^{13} \mathrm{~cm}^{-2}$ and $N\left(\mathrm{H}_{2} \mathrm{SO}_{4}\right) \leq 1.3 \times 10^{14} \mathrm{~cm}^{-2}$, respectively.

$\mathrm{CH}_{3} \mathrm{SSH}$ : methyl hydrodisulfide has not been observed in the interstellar medium. Tyblewski et al. (1986) studied its rotational spectrum, together with that of $\mathrm{CH}_{3} \mathrm{SSD}$, between 18 and $40 \mathrm{GHz}$ providing rotational constants. We derive an upper limit for its column density of $N\left(\mathrm{CH}_{3} \mathrm{SSH}\right) \leq 2.6 \times 10^{14} \mathrm{~cm}^{-2}$.

(tr)-HCSSH: the spectrum of dithioformic acid has been studied by Bak et al. (1978), who assigned the rotational transitions of this species in its ground state to a trans and cis rotamer. We provide an upper limit for the column densitiy of $(t r)$ HCSSH (more stable) $N \leq 3.6 \times 10^{13} \mathrm{~cm}^{-2}$.

\section{Discussion}

There have been many spectral line surveys of Orion KL aimed at determining the physical and chemical structure of this region (e.g., Blake et al. 1987, Sutton et al. 1995; Schilke et al. 2001). The survey analyzed here was first presented by Tercero et al. (2010), covers the widest frequency range of all of them (80-281 GHz). Due to this wide range and to the large number of observed transitions of $\mathrm{SO}$, and particularly of $\mathrm{SO}_{2}$, it has 

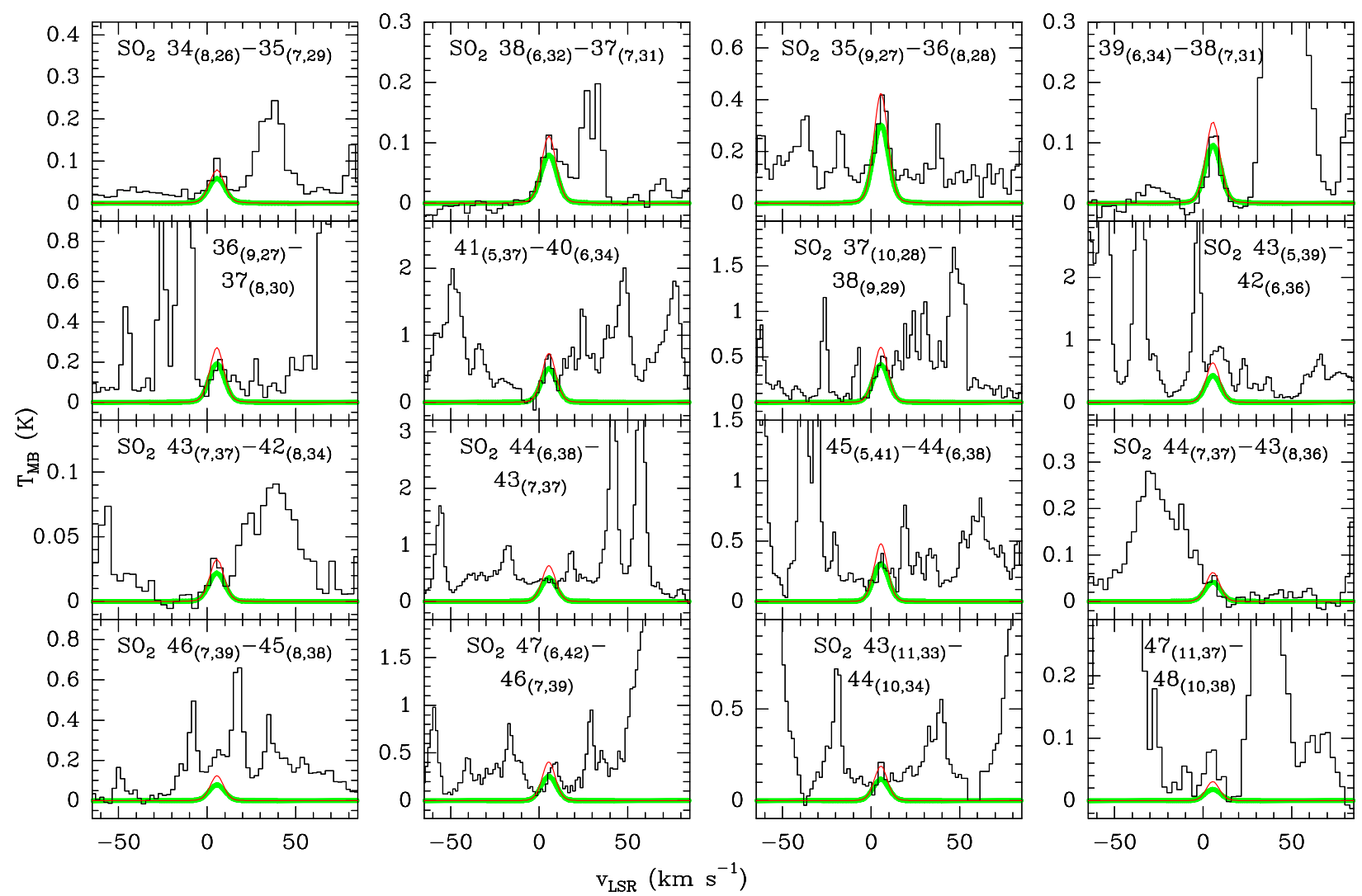

Fig. 17. Observed lines of $\mathrm{SO}_{2}$ (black histogram) with energies higher than $700 \mathrm{~K}$, ordered by increasing energy from top left to bottom right. Best fit LTE model results considering a hot core at $T_{\mathrm{K}}=220 \mathrm{~K}$ (green curve) and with a hot core at $T_{\mathrm{K}}=280 \mathrm{~K}$ (red curve).

been possible not only to determine the structure of the cloud (gas temperature, gas density, size of components, etc.) with better accuracy (the $3 \mathrm{~mm}$ window shows best the coldest regions, such as the ER, whereas the $1.3 \mathrm{~mm}$ window probes the warmest regions), but also to demonstrate the need for considering a density and temperature gradient in the HC of Orion KL. From rotational diagrams, we found a large difference $(\sim 100 \mathrm{~K})$ between the rotational temperatures of $\mathrm{SO}$ and $\mathrm{SO}_{2}$, indicating the possibility of a hotter inner region to the $\mathrm{HC}$. We draw the same conclusion from the fits for $\mathrm{SO}_{2}$ lines with energies $E>400 \mathrm{~K}$. To obtain better fits for lines with energies $E>700 \mathrm{~K}$, we considered a high column density for the $\mathrm{HC}$, which overestimates in the fit for the lines with energy around $400 \mathrm{~K}$ (see Figs. 12 and 13). But by considering an additional inner component to the $\mathrm{HC}$ with higher temperature, it would probably be possible to obtain a better fit to the lines with high energies, while avoiding overestimation of lines with intermediate energies. To test this possibility, we fit the $\mathrm{SO}_{2}$ line profiles with energies $E>700 \mathrm{~K}$ considering a hotter $\left(T_{\mathrm{K}}=280 \mathrm{~K}\right) \mathrm{HC}$ (affecting only the highest energy transitions), with $n\left(\mathrm{H}_{2}\right)=5 \times 10^{6} \mathrm{~cm}^{-3}$, located at $5.5 \mathrm{~km} \mathrm{~s}^{-1}$, and with $\triangle v_{\mathrm{FWHM}}=7 \mathrm{~km} \mathrm{~s}^{-1}$. For a $\mathrm{SO}_{2}$ column density of $(4 \pm 1) \times 10 \mathrm{~m}^{16} \mathrm{~cm}^{-2}$, we improve the line profile fits of these high energies transitions (see Fig. 17). This shows the existence of a temperature and density gradient in the $\mathrm{HC}$ of Orion KL. However, its structure should be determined accurately with observations of $\mathrm{SO}$ and $\mathrm{SO}_{2}$ (and mainly of its isotopologues ${ }^{3}$, which are optically thin) at higher frequencies with telescopes such as APEX.

On the other hand, the large number of observed lines of the ${ }^{34} \mathrm{~S}$ and ${ }^{33} \mathrm{~S}$ isotopologues has allowed us to calculate column

\footnotetext{
3 The energies of the observed isotoplogues in this survey are $<680 \mathrm{~K}$.
}

densities and isotopic and molecular abundances that are key to understanding the chemical evolution of this region.

\section{1. $\mathrm{SO}$ and $\mathrm{SO}_{2}$ as tracers of shocks and hot gas}

In Sect. 4 we showed that an important contribution to the emission of $\mathrm{SO}$ and $\mathrm{SO}_{2}$ comes from the HC component of Orion KL. In Fig. 18 we plotted the ratio of $N(\mathrm{SO}) / N\left(\mathrm{SO}_{2}\right)$ for the different components, as well as for the different isotopologues of $\mathrm{SO}$ and $\mathrm{SO}_{2}$. The figure shows that the column density of $\mathrm{SO}_{2}$ in the $\mathrm{HC}$ is higher than that for SO. We should take into account that our column densities for $\mathrm{SO}_{2}$ may have been slightly underestimated because of using an LTE model to infer the column density (instead of LVG, as was used for SO). For that reason, we considered a higher uncertainty $(35 \%)$ in the model intensity predictions for $\mathrm{SO}_{2}$, than for $\mathrm{SO}(20 \%)$, as said previously. Moreover, the opacity may affect $\mathrm{SO}$ and $\mathrm{SO}_{2}$ differently, which would in turn affect their column density ratio. But if we consider the result of the ratio ${ }^{34} \mathrm{SO} /{ }^{34} \mathrm{SO}_{2}$ in the hot core, we observe that $\mathrm{SO}_{2}$ continues to be more abundant than SO. This could indicate that $\mathrm{SO}_{2}$ is a better tracer of warm gas than $\mathrm{SO}$.

Our results are consistent with predictions from chemical models of hot cores (e.g., Hatchell et al. 1998). Viti et al. (2004a) modeled the evaporation of ices near massive stars and found that $\mathrm{SO}_{2}$ becomes more abundant than $\mathrm{SO}$ in the hot core from 31.500 years after the formation of a high-mass star. For shorter timescales, $\mathrm{SO}$ is much more abundant than $\mathrm{SO}_{2}$. Thus, the $\mathrm{SO} / \mathrm{SO}_{2}$ ratio could be regarded as a chemical clock (which should decrease with time), and our results showing a lower $\mathrm{SO} / \mathrm{SO}_{2}$ ratio for the $\mathrm{HC}$ component seem to suggest a late stage for the hot core evolution in Orion KL. 
G. B. Esplugues et al.: Survey towards Orion KL. Sulfur oxide species

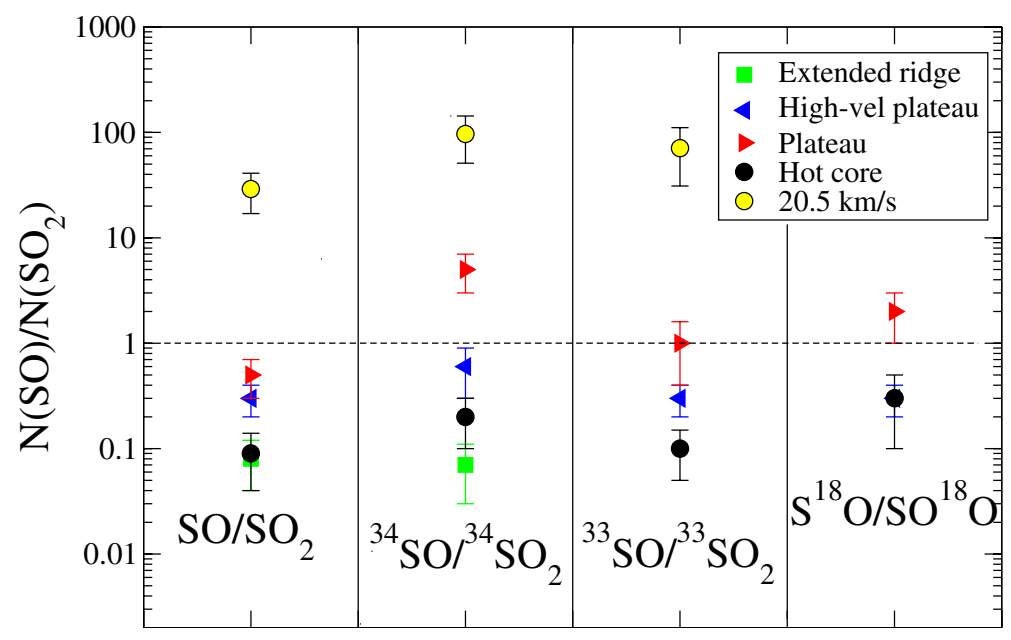

Fig. 18. Ratio $N(\mathrm{SO}) / N\left(\mathrm{SO}_{2}\right)$ for each component and for the different isotopologues of $\mathrm{SO}$ and $\mathrm{SO}_{2}$.

On the other hand, the ratio of $\mathrm{SO} / \mathrm{SO} 2$ is higher in the $\mathrm{PL}$ and the HVP than in the HC and the ER (see Fig. 18), and in particular for the PL, this ratio reaches values close to or even higher than 1. Since SO is a well-known outflow tracer (e.g., Chernin et al. 1994; Codella \& Scappini 2003; Lee et al. 2010; Tafalla et al. 2010), and SO seems to be more enhanced than SO2 in shocks (from an observational point of view, e.g., Codella \& Bachiller 1999, Jiménez-Serra et al. 2005, and from a theoretical point of view, e.g., Viti et al. 2004b; Benedettini et al. 2006, for timescales $\sim 10000 \mathrm{yr}$ ), it seems very feasible that the high $\mathrm{SO} / \mathrm{SO}_{2}$ ratios measured in the (high velocity) plateau are the consequence of a definite enhancement of the SO abundance with respect to $\mathrm{SO}_{2}$, due to shocks propagating into the surrounding medium of Orion KL.

\subsection{Nature of the $15 \mathrm{~km} \mathrm{~s}^{-1}$ dip and $20.5 \mathrm{~km} \mathrm{~s}^{-1}$ velocity component}

To properly fit the $\mathrm{SO}$ and $\mathrm{SO}_{2}$ spectra in Orion $\mathrm{KL}$, a new velocity component at $20.5 \mathrm{~km} \mathrm{~s}^{-1}$ had to be included in the model (see Sect. 3.2). In addition, a possible dip at $15.5 \mathrm{~km} \mathrm{~s}^{-1}$ in the $\mathrm{SO}$ and $\mathrm{SO}_{2}$ spectra has been identified. The dip at $15.5 \mathrm{~km} \mathrm{~s}^{-1}$ could be self-absorption due to the high opacity of the observed transitions. However, in all cases, the line strength $S$ is uncorrelated with the amount of absorption. For example, the transition $11_{(1,11)}-10_{(0,10)}$ of $\mathrm{SO}_{2}$, with a line strength of $S=7.7$ and Einstein coefficient $A_{\mathrm{ul}}=1.1 \times 10^{-4} \mathrm{~s}^{-1}$, would be expected to display more self-absorption and therefore a lower integrated intensity than the transition $4_{(2,2)}-3_{(1,3)}$ with $S=1.7$ and $A_{\mathrm{ul}}=7.7 \times 10^{-5} \mathrm{~s}^{-1}$, but we see the opposite (especially in the range at $14.5-16.5 \mathrm{~km} \mathrm{~s}^{-1}$ ). In addition, we obtain in Fig. 7 a high integrated intensity in the velocity range $14-18 \mathrm{~km} \mathrm{~s}^{-1}$, when the integrated intensity in the ranges $10-14 \mathrm{~km} \mathrm{~s}^{-1}$ and $18-22 \mathrm{~km} \mathrm{~s}^{-1}$ is also large. Altogether, this suggests that the emission at $15 \mathrm{~km} \mathrm{~s}^{-1}$ is only the sum of contributions of emission coming from the HVP and the $20.5 \mathrm{~km} \mathrm{~s}^{-1}$ component.

With respect to the nature of the emission at $20.5 \mathrm{~km} \mathrm{~s}^{-1}$, Fig. 18 shows that the column density ratio of $\mathrm{SO} / \mathrm{SO}_{2}$ of this component is about two to three orders of magnitude higher than the other velocity components in Orion KL. This is also true for the ${ }^{34} \mathrm{SO} /{ }^{34} \mathrm{SO}_{2}$ and ${ }^{33} \mathrm{SO} /{ }^{33} \mathrm{SO}_{2}$ ratios, suggesting that it is not an opacity effect. Such a high ratio could be due in part to filling factor problems, if the $20.5 \mathrm{~km} \mathrm{~s}^{-1}$ component is much more compact in $\mathrm{SO}_{2}$ than in $\mathrm{SO}^{4}$, and/or could be the result of applying a different method ( $\mathrm{LVG}$ for $\mathrm{SO}$ vs LTE for $\mathrm{SO}_{2}$ ) to infer the column densities. However, the large difference compared to the other components suggests that it is a definite chemical effect, and since the $\mathrm{SO} / \mathrm{SO}_{2}$ ratio is higher in regions associated with shocks such as the HVP and the PL (Sect. 5.1), the $20.5 \mathrm{~km} \mathrm{~s}^{-1}$ component could be related to shocks as well, maybe associated with the explosive dynamical interaction that took place in Orion KL (Gómez et al. 2005; Zapata et al. 2011a) and more especifically to shocks associated with the BN object. This is consistent with the fact that the BN object in Orion presents significantly high $\mathrm{CO}$ and ${ }^{13} \mathrm{CO}$ emission at $\sim 20 \mathrm{~km} \mathrm{~s}^{-1}$ (Scoville et al. 1983). Observations combining both single-dish and interferometric data are required to definitely identify the spatial region in Orion KL emitting the bulk of emission at $20 \mathrm{~km} \mathrm{~s}^{-1}$.

\section{Summary and conclusions}

This study is part of a series of papers with the goal of analyzing the physical and chemical conditions of Orion KL. The study is divided into different molecular families, and here we have focused on the emission lines of $\mathrm{SO}$ and $\mathrm{SO}_{2}$ and their isotopologues. We have analyzed the IRAM 30-m line survey of Orion KL observed by Tercero et al. (2010), which covers the frequency range $80-281 \mathrm{GHz}$. We identified more than 700 rotational transitions of these molecules, including lines from the vibrational state $v_{2}=1$ of $\mathrm{SO}_{2}$ and the isotopologue $\mathrm{SO}^{17} \mathrm{O}$, detected for the first time in the interstellar medium. This large sample has let us improve our knowledge about the physical and chemical conditions in Orion KL, especially due to the observation of a large number of $\mathrm{SO}_{2}$ transitions at high energies. The analysis of $\mathrm{SO}$ and $\mathrm{SO}_{2}$ was carried out using an LTE and LVG radiative transfer model, taking the physical structure of the source into account (hot core, compact ridge, extended ridge, and plateau components).

First, we fit $\mathrm{SO}$ and $\mathrm{SO}_{2}$ lines with Gaussian profiles to obtain an approximate $T_{\text {rot }}$ value in each component. We detected a

\footnotetext{
4 In fact, interferometric maps of ${ }^{34} \mathrm{SO}$ in Orion KL reveal emission only from 1 to $15 \mathrm{~km} \mathrm{~s}^{-1}$ (Beuther et al. 2005), indicating that the emission from the $20 \mathrm{~km} \mathrm{~s}^{-1}$ component has probably been filtered out by the interferometer. Given the minimum baseline of the interferometric observations (Beuther et al. 2005), the largest angular scale detectable is $\sim 6^{\prime \prime}$ (following the Appendix in Palau et al. 2010), similar to the size adopted in this work for the $20.5 \mathrm{~km} \mathrm{~s}^{-1}$ component.
} 
dip at $\sim 15 \mathrm{~km} \mathrm{~s}^{-1}$ in most of the lines and an emission peak centered on $20.5 \mathrm{~km} \mathrm{~s}^{-1}$. For the dip at $15 \mathrm{~km} \mathrm{~s}^{-1}$, we discarded selfabsorption as a possible cause, concluding instead that the weak emission is due to the sum of small contributions coming from the HVP and from the $20.5 \mathrm{~km} \mathrm{~s}^{-1}$ feature, which corresponds to an unresolved component ( $\sim 5^{\prime \prime}$ diameter), with line width of $\sim 7.5 \mathrm{~km} \mathrm{~s}^{-1}$ and with an especially high column density of SO in comparison to $\mathrm{SO}_{2}$. Its rotational temperature is $50 \pm 10 \mathrm{~K}$ from $\mathrm{SO}$ lines and $90 \pm 20 \mathrm{~K}$ from $\mathrm{SO}_{2}$ lines. For the rest of the components, the rotational temperatures obtained from $\mathrm{SO}_{2}$ lines are: plateau $(\mathrm{PL})=120 \pm 20 \mathrm{~K}$, hot core $(\mathrm{HC})=190 \pm 60 \mathrm{~K}$, $(\mathrm{HVP})=110 \pm 20 \mathrm{~K}$, compact ridge $(\mathrm{CR})=80 \pm 30 \mathrm{~K}$, and extended ridge $(\mathrm{ER})=83 \pm 40$. The results from $\mathrm{SO}$ lines are: $(\mathrm{PL})=130 \pm 20 \tilde{\mathrm{A}} \mathrm{K},(\mathrm{HC})=288 \pm 90 \mathrm{~K},(\mathrm{HVP})=111 \pm 15 \mathrm{~K}$, and $(\mathrm{ER})=107 \pm 40 \mathrm{~K}$.

The second part of the analysis was carried out using a radiative transfer code. For the case of SO, we analyzed its nonLTE excitation, however, for $\mathrm{SO}_{2}$ we assumed LTE excitation due to the lack of collisional rates for energies higher than $90 \mathrm{~K}$ (we observe $\mathrm{SO}_{2}$ lines with energies up to $1500 \mathrm{~K}$ ). We found that most of the emission of $\mathrm{SO}_{2}$ and $\mathrm{SO}$ arises from the HVP, with column densities of $N\left(\mathrm{SO}_{2}\right)=(1.3 \pm 0.3) \times 10^{17} \mathrm{~cm}^{-2}$ and $N(\mathrm{SO})=(5 \pm 1) \times 10^{16} \mathrm{~cm}^{-2}$, respectively, and from the hot core, in particular in the case of $\mathrm{SO}_{2}$, whose column density is similar to that obtained in the HVP. These values are up to three orders of magnitude higher than the column densities obtained for the ridge components. These results let us conclude that $\mathrm{SO}$ and $\mathrm{SO}_{2}$ are good tracers not only of shock-affected areas, but also of hot dense gas. In addition, from the ratios ${ }^{34} \mathrm{SO} /{ }^{34} \mathrm{SO}_{2},{ }^{33} \mathrm{SO} /{ }^{33} \mathrm{SO}_{2}$, and $\mathrm{S}^{18} \mathrm{O} / \mathrm{SO}^{18} \mathrm{O}_{2}$ in the different components of the cloud, we observe that in the HVP (region affected by shocks) sulfur dioxide is up to five times more abundant than SO. The same trend is found in the hot core.

We have also carried out $2^{\prime} \times 2^{\prime}$ mapping around Orion IRc2 in a number of lines of $\mathrm{SO}, \mathrm{SO}_{2}$, and their ${ }^{34} \mathrm{~S}$ isotopologues. In Sect. 3.4 we presented maps of three transitions of $\mathrm{SO}_{2}$ (Fig. 7), two transitions of SO (Fig. 6), one transition of ${ }^{34} \mathrm{SO}$ and one of ${ }^{34} \mathrm{SO}_{2}$ (Fig. 8). We plotted different velocity ranges for each transition to explore the spatial distribution of the emission. In agreement with our column density results, we found the maximum integrated intensities in the range containing the hot core (3-7 $\mathrm{km} \mathrm{s}^{-1}$ ) and in the range $10-14 \mathrm{~km} \mathrm{~s}^{-1}$ (corresponding to the HVP), whose emission peak is centered approximately $4^{\prime \prime}$ to the southwest of IRc2. In all mapped transitions, but especially in those of SO and ${ }^{34} \mathrm{SO}$, we observe an elongation of the gas along the NE-SW direction. In these maps, we also detected a strong emission in the velocity range located at $20.5 \mathrm{~km} \mathrm{~s}^{-1}$. From the spatial distribution of this feature and from the analysis of the line profiles, we suggest that this emission is probably related to shocks associated to the $B N$ source or to a gas cloudlet ejected in the explosive event that could have taken place in Orion KL.

In this paper, we have also demonstrated the need to consider a temperature and density gradient in the hot core of Orion $\mathrm{KL}$, with a comparison between fits of $\mathrm{SO}_{2}$ line profiles at high energies, assuming two different temperatures $\left(T_{\mathrm{K}}=220 \mathrm{~K}\right.$ and $T_{\mathrm{K}}=280 \mathrm{~K}$ ) in the hot core. Only with the low temperature it was not possible to obtain good line fits for $E>700 \mathrm{~K}$, without avoiding overestimation for lines with intermediate energies. In addition, the large difference between the rotational temperatures in the hot core and the need to consider a large contribution to the $\mathrm{SO}_{2}$ isotopologue emission in the extended ridge support the conclusion of the presence of temperature and density gradients in Orion KL. However, it would be necessary to also consider emission lines (mainly from isotopologues) spanning a wider frequency range with observations from other telescopes, such as APEX, in order to determine these gradients accurately. Moreover, to describe this molecular cloud in greater detail while avoiding spectral confusion would require interferometric observations with higher spectral resolution and higher sensitivity (such as those provided by ALMA).

Acknowledgements. We thank the Spanish MICINN for funding support through grants AYA2006-14876, AYA2009-07304, and CSD2009-00038. J.R.G. is supported by a Ramón y Cajal research contract. A.P. is supported by a JAEDoc CSIC fellowship co-funded with the European Social Fund under the program "Junta para la Ampliación de Estudios", by the Spanish MICINN grant AYA2011-30228-C03-02 (co-funded with FEDER funds), and by the AGAUR grant 2009SGR1172 (Catalonia). T.A.B. is supported by a JAE-Doc research contract.

\section{References}

Anders, E., \& Gevesse, N. 1989, GeCoA, 53, 197

Bachiller, R. 1996, A\&A, 34, 111

Bak, B., Nielsen, J., \& Svanholt, H. 1978, J. Mol. Spectrosc., 69, 401

Barnes, I., Becker, K. H., \& Patroescu, I. 1994, GeoRL, 21, 2389

Behrend, J., Mittler, P., Winnewisser, G., \& Yamada, K. M. T. 1990, J. Mol. Espectrosc., 141, 265

Belov, S. P., Tretyakov, M. Y., Kozin, I. N., et al. 1998, J. Mol. Espectrosc., 191, 17

Benedettini, M., Yates, J. A., Viti, S., \& Codella, C., et al. 2006, MNRAS, 370, 229

Beuther, H., Zhang, Q., \& Greenhill, L. J., et al. 2005, ApJ, 632, 355

Blake, G., Sutton, E. C., Masson, C. R., \& Phillips, T. G. 1987, ApJ, 315, 621

Bogey, M. 1982, Chem. Phys., 66, 99

Bogey, M., Civis, S., Delcroix, B., et al. 1997, J. Mol. Spectrosc., 182, 85

Cazzoli, G., Cludi, L., Cotti, G., et al. 1994, J. Mol. Spectrosc., 167, 468

Cernicharo, J. 1985, ATM, A Program to compute atmospheric absorption for frequencies below $1000 \mathrm{GHz}$, IRAM Internal Report No. 52

Cernicharo, J. 2012, in ECLA-2011: Proc. Eur. Conf. Lab. Astrophys. EAS PS, 2012

Chernin, L. M., Masson, C. R., \& Fuller, G. A. 1994, ApJ, 436, 741

Clark, F. O., \& Johnson, D. R. 1974, ApJ, 191, L87

Clark, W. W., \& DeLucia, F. C. 1976, J. Mol. Spectrosc., 60, 332

Codella, C., \& Bachiller, R. 1999, A\&A, 350, 659

Codella, C., \& Scappini, F. 2003, MNRAS, 344, 1257

Dreizler, H., \& Dendl, G. 1964, Naturforsch. 19a, 512

Fuente, A., Rodríguez-Franco, A., García-Burillo, S., et al. 2003, A\&A, 406, 899

Gezari, D. Y., Backman, D. E., \& Werner, M. W. 1998 ApJ, 509, 283

Goicoechea, J. R., Cernicharo, J., Lerate, M. R., et al. 2006, ApJ, 641, L49

Goldreich, P., \& Kwan, J. 1974, ApJ, 189, 441

Goldsmith, P. F., \& Langer, W. D. 1999, ApJ, 517, 209

Gómez, L., Rodríguez, L. F., Loinard, L., \& Lizano, S. 2005, ApJ, 635, 1166

Gottlieb, C. A., \& Ball, J. A. 1973, ApJ, 184, L59

Guélin, M., Brouillet, N., Cernicharo, J., et al. 2008, Ap\&SS, 313, 45

Hatchell, J., Thompson, M. A., Millar, T. J., \& MacDonald, G. H. 1998, A\&A, 338,713

Jiménez-Serra, I., Martín-Pintado, J., Rodríguez-Franco, A., \& Martín, S. 2005, ApJ, 627, L121

Joo, D. L., Clouthier, D. J., Chan, C. P., et al. 1995, J. Mol. Spectrosc., 171, 113 Joo, D. L., Harjanto, H., \& Clouthier, D. J. 1996, J. Mol. Spectrosc., 178, 78 Kirchhoff, W. H. 1969, J. Am. Chem. Soc., 91, 2437

Klaus, Th., Saleck, A. H., Belov S. P., et al. 1996, J. Mol. Spectrosc., 180, 197

Lattanzi, V., Gottlieb, C. A., Thaddeus, P., et al. 2011, A\&A, 533, L11

Lee, C. F., Hasegawa, T. I., Hirano, N., Palau, A., et al. 2010, ApJ, 713

Lique, F., \& Spielfiedel, A. 2007, AA, 462, 1179

Lique, F., Spielfiedel, A., Dhont, G., \& Feautrier, N. 2006, A\&A, 458, 331

Lovas, F. J., Suenram, R. D., Ogata, T., \& Yamamoto, S. 1992, ApJ, 399, 325

Maki, \& Kuritsyn, 1990, J. Mol. Spectrosc., 144, 242

Marconi, M. L., Mendis, D. A., Mitchell, D. L., et al. 1991, ApJ, 378, 756

Margules, L., et al. 2010, J. Mol. Spectrosc., 260, 23

Martin-Drumel, M. A. 2012, Ph.D. Thesis, Paris University

Mauersberger, R., Henkel, C., Langer, N., \& Chin, Y. N. 1996, A\&A, 313, L1

McCarthy, M. C., Thorwirth, S., Gottlieb, C. A., \& Thaddeus, P. 2004a, J. Chem. Phys. 126, 4096

McCarthy, M. C., Thorwirth, S., Gottlieb, C. A., \& Thaddeus, P. 2004b, J. Chem. Phys. 121, 632 
G. B. Esplugues et al.: Survey towards Orion KL. Sulfur oxide species

Menten, K. M., Reid, M. J., Forbrich, J., \& Brunthaler, A. 2007, A\&A, 474, 515 Meschi, D. J., \& Myers, R. J. 1959, J. Mol. Spectrosc., 3, 405

Müller H. S. P., \& Brünken, S. 2005, J. Mol. Spectrosc., 232, 213

Müller, H. S. P., Farhoomand, J., Cohen E. A., et al. 2000, J. Mol. Spectrosc., 232, 213

Müller, H. S. P., Thorwirth, S., Roth, D. A., \& Winnewisser, G. 2001, A\&A, 370, L49

Palau, A., Sánchez-Monge, Á., Busquet, G., et al. 2010, A\&A, 510, A5

Pardo, J. R., \& Encrenaz, P. J., Berton, D. 2001, IAU Symp., 196, 255

Patel, D., Margolese, D., \& Dykea, T. R. 1979, J. Chem. Phys., 70, 2740

Penn, R. E., \& Olsen, R. J. 1976, J. Mol. Spectrosc., 61, 21

Persson, C. M., Olofsson, A. O. H., Koning, N., et al. 2007, A\&A, 476, 807

Pickett, H. M., Poynter, R. L., Cohen, E. A., et al. 1998, JQSRT, 60, 5

Plambeck, R. L., Wright, M. C. H., Welch, W. J., et al. 1982, ApJ, 259, 617

Plambeck, R. L., Wright, M. C. H., Friedel, D. N., et al. 2009, ApJ, 704, L25

Powell, F. X., \& Lide, D. R., et al. 1964, J. Chem. Phys., 41, 1413

Rawling, J. M. C., \& Yates, J. A. 2001, MNRAS, 326, 1423

Schilke, P., Benford, D. J., Hunter, T. R., et al. 2001, ApJ, 132, 281

Schultz, A. S. B., Colgan, S. W. J., Erickson, E. F., et al. 1999, ApJ, 511, 282

Scoville, N., Kleinmann, S. G., Hall, D. N. B., \& Ridgway, S. T. 1983, ApJ, 275, 201

Sedo, G., Schultz, J., \& Leopold, K. R. 2008, J. Mol. Spectrosc., 251, 4

Sutton, E. C., Peng, R., Danchi, W. C., et al. 1995, AJSS, 97, 455

Tafalla, M., Santiago-García, J., Hacar, A., \& Bachiller, R. 2010, A\&A, 522, A9
Tercero, B., Cernicharo, J., Pardo, J. R., \& Goicoechea, J. R. 2010, A\&A, 517, A96

Tercero, B., Vincent, L., Cernicharo, J., et al. 2011, A\&A, 528, A26

Thorwirth, S., McCarthy, M. C., Gottlieb, C. A., et al. 2005, J. Chem. Phys., 123, 54326

Thorwirth, S., Theulé, P., Gottlieb, C. A., et al. 2006, J. Mol. Struc., 795, 219

Thorwirth, S., Mück, L. A., Gauss, F., et al. 2011, J. Chem. Phys. Lett., 2, 1228

Tiemann, E. 1974, J. Phys. Chem., 3, 259

Tiemann, E. 1982, J. Mol. Spectrosc., 91, 60

Turner, B. E. 1991, ApJ, 76, 617

Turner, B. E. 1994, ApJ, 430, 727

Turner, B. E., Chan, Kin-Wing, Green, S., \& Lubowich, D. A. 1992, ApJ, 399, 114

Tyblewski, M., Ha, T. K., Bauder, A., et al. 1986, J. Mol. Spectrosc., 115, 353

Viti, S., \& Williams, D. A. 1999, MNRAS, 305, 755

Viti, S., Caselli, P., Hartquist, T. W., \& Williams, D. A. 2001, A\&A, 370, 1017

Viti, S., Collings, M. P., Dever, J. W., et al. 2004a, MNRAS, 354, 1141

Viti, S., Codella, C., Benedettini, M., \& Bachiller, R. 2004b, MNRAS, 350, 1029

White, G. J., \& Phillips, J. P. 1983, MNRS, 203

Wilson, T. L., Gaume, R. A., Gensheimer, P., \& Johnston, K. J. 2000, ApJ, 538, 665

Winnewisser, G., Winnewisser, M., \& Gordy, W. 1966, Bull. Am. Phys. Soc., 11, 312

Wright M. C. H., Plambeck R. L., \& Wilner D. J. 1996, ApJ, 469, 216

Zapata, L. A., Schmid-Burgk, J., \& Menten, K. M. 2011a, A\&A, 529, A24 


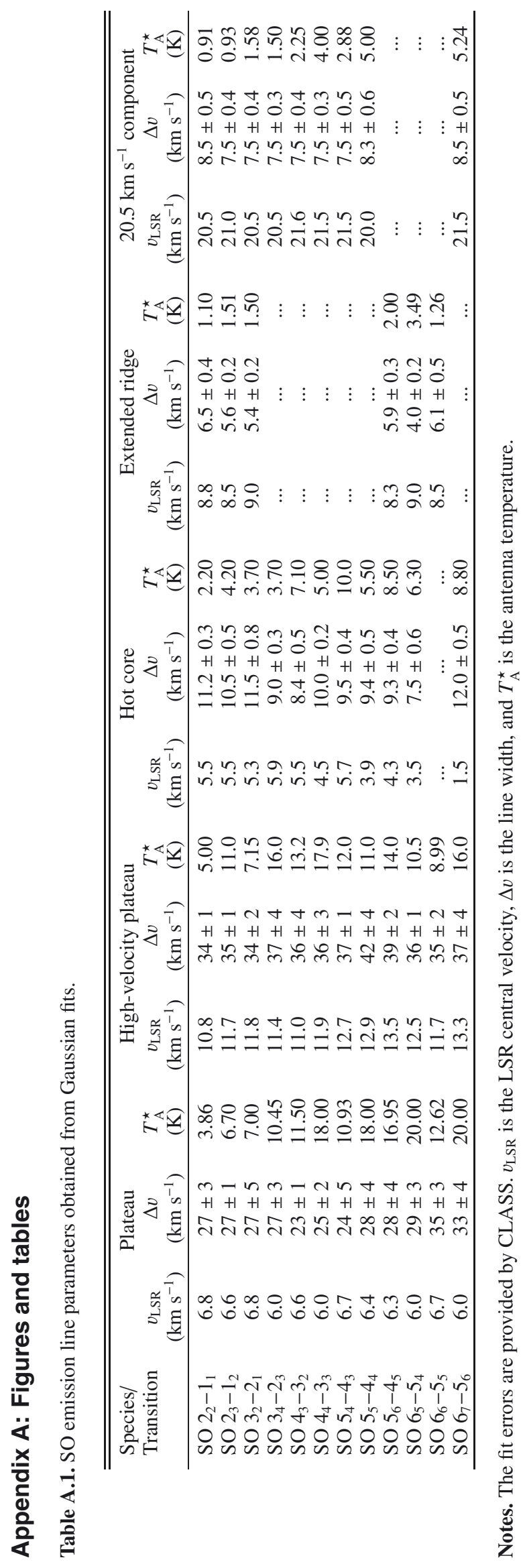


G. B. Esplugues et al.: Survey towards Orion KL. Sulfur oxide species

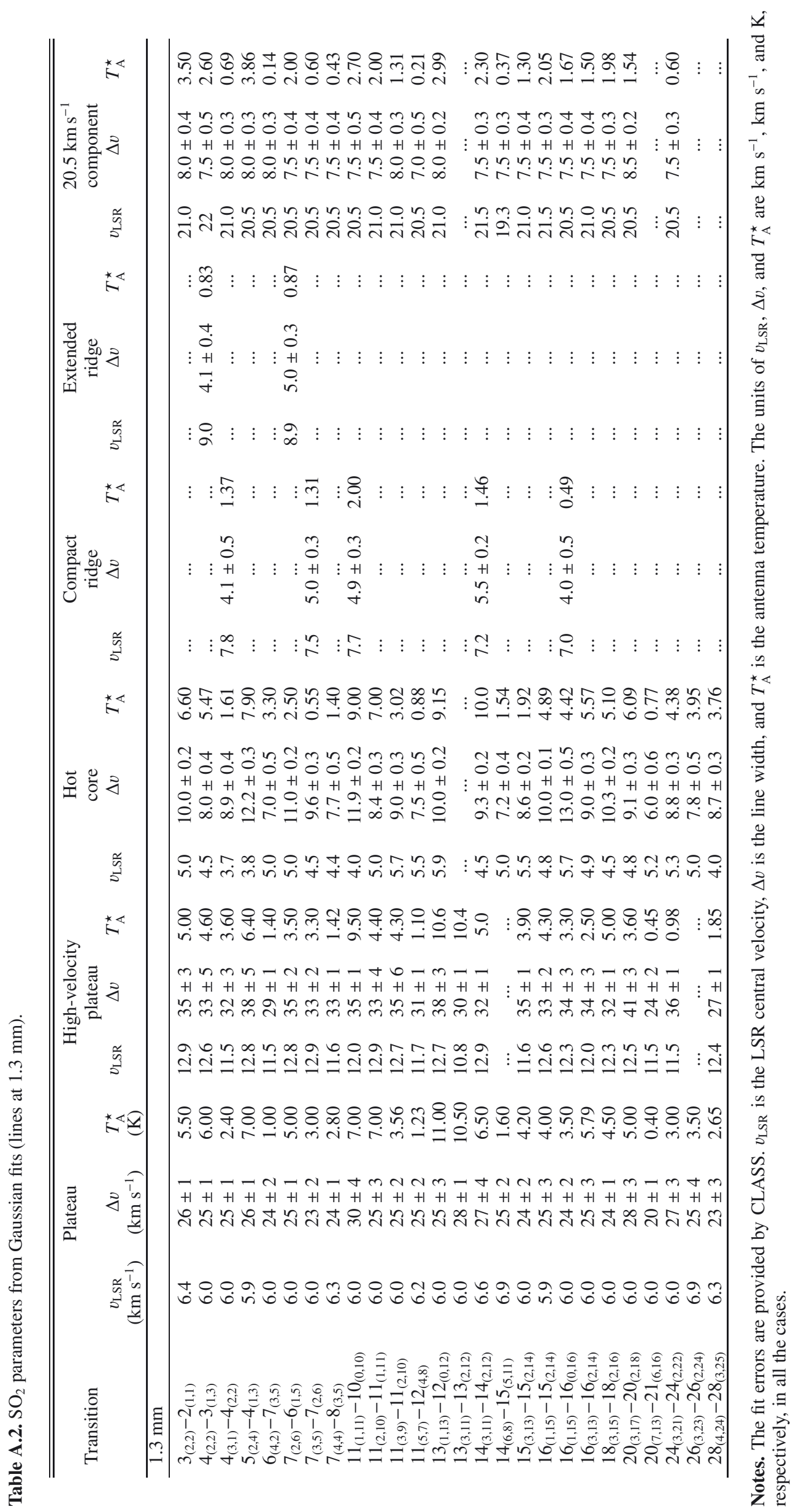


A\&A 556, A143 (2013)

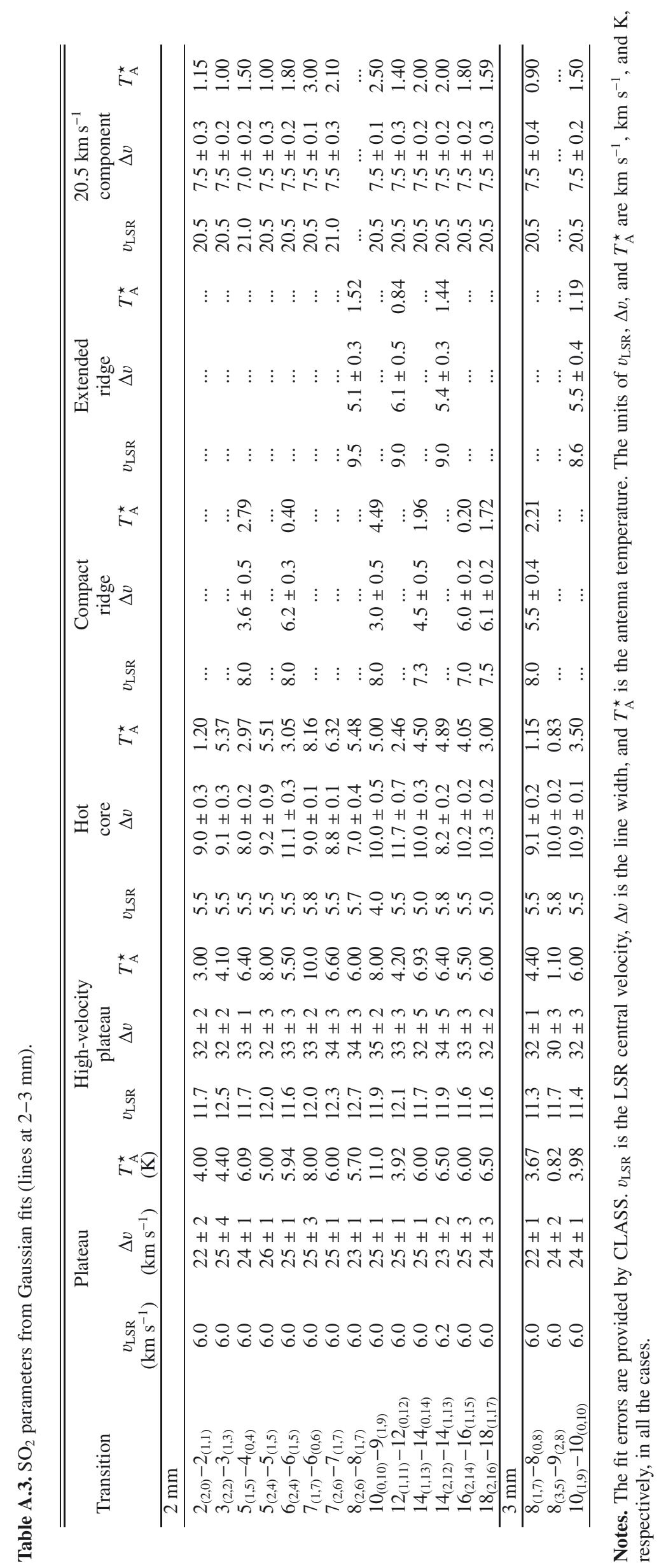


G. B. Esplugues et al.: Survey towards Orion KL. Sulfur oxide species

Table A.4. Rotational temperatures, $T_{\text {rot }}$, and column densities, $N$, obtained from rotational diagrams.

\begin{tabular}{lcccccc}
\hline \hline Component & $\begin{array}{c}T_{\text {rot }}(\mathrm{SO}) \\
(\mathrm{K})\end{array}$ & $\begin{array}{c}N(\mathrm{SO}) \times 10^{15} \\
\left(\mathrm{~cm}^{-2}\right)\end{array}$ & $\begin{array}{c}\mathrm{C}_{\tau}(\mathrm{SO}) \\
T_{\text {rot }}\left(\mathrm{SO}_{2}\right) \\
(\mathrm{K})\end{array}$ & $\begin{array}{c}N\left(\mathrm{SO}_{2}\right) \times 10^{15} \\
\left(\mathrm{~cm}^{-2}\right)\end{array}$ & $\mathrm{C}_{\tau}\left(\mathrm{SO}_{2}\right)$ \\
\hline Extended ridge (ER) & $107 \pm 40$ & $0.017 \pm 0.001$ & $1.00-1.02$ & $83 \pm 40$ & $0.023 \pm 0.009$ & $1.04-1.15$ \\
Compact ridge (CR) & $\ldots$ & $\ldots$ & $\ldots$ & $80 \pm 30$ & $1.2 \pm 0.2$ & $1.00-1.63$ \\
High-velocity plateau (HVP) & $111 \pm 15$ & $3.9 \pm 0.5$ & $1.01-2.12$ & $110 \pm 20$ & $9.5 \pm 0.6$ & $1.0-1.60$ \\
Plateau (PL) & $130 \pm 20$ & $4.6 \pm 0.2$ & $1.01-1.11$ & $120 \pm 20$ & $13 \pm 1$ & $1.01-1.69$ \\
Hot core (HC) & $288 \pm 90$ & $18 \pm 1$ & $1.02-1.64$ & $190 \pm 60$ & $33 \pm 3$ & $1.00-1.71$ \\
$20.5 \mathrm{~km} \mathrm{~s}^{-1}$ comp. & $51 \pm 10$ & $0.014 \pm 0.02$ & $1.06-1.36$ & $90 \pm 20$ & $4.6 \pm 0.1$ & $1.00-1.58$ \\
\hline
\end{tabular}

Notes. $\mathrm{C}_{\tau}$ is the range of optical depths in each component.

Table A.5. Isotopologue ratios and molecular ratios.

\begin{tabular}{|c|c|c|c|c|c|c|c|}
\hline Ratio & $\begin{array}{l}\text { Extended } \\
\text { ridge } \\
\text { (ER) }\end{array}$ & $\begin{array}{l}\text { Compact } \\
\text { ridge } \\
\text { (CR) }\end{array}$ & $\begin{array}{l}\text { High-velocity } \\
\text { plateau } \\
\text { (HVP) }\end{array}$ & $\begin{array}{l}\text { Plateau } \\
\text { (PL) }\end{array}$ & $\begin{array}{l}\text { Hot } \\
\text { core } \\
\text { (HC1) }\end{array}$ & $\begin{array}{c}20.5 \\
\mathrm{~km} \mathrm{~s}^{-1} \\
\text { component }\end{array}$ & $\begin{array}{c}\text { Solar } \\
\text { isotopic } \\
\text { abundance }\end{array}$ \\
\hline \multicolumn{8}{|c|}{ Isotopologues ratios } \\
\hline $\mathrm{SO}_{2} /{ }^{34} \mathrm{SO}_{2}$ & $2 \pm 1$ & $2 \pm 1$ & $20 \pm 13$ & $16 \pm 10$ & $10 \pm 8$ & $5 \pm 3$ & 23 \\
\hline $\mathrm{SO}_{2} /{ }^{33} \mathrm{SO}_{2}$ & $7 \pm 4$ & $17 \pm 10$ & $137 \pm 90$ & $19 \pm 13$ & $29 \pm 19$ & $20 \pm 14$ & 127 \\
\hline $\mathrm{SO}_{2} / \mathrm{SO}^{18} \mathrm{O}$ & $12 \pm 8$ & $40 \pm 26$ & $151 \pm 100$ & $164 \pm 100$ & $67 \pm 48$ & $\ldots$ & 500 \\
\hline $\mathrm{SO}_{2} / \mathrm{SO}^{17} \mathrm{O}$ & $34 \pm 27$ & $180 \pm 110$ & $1300 \pm 900$ & $334 \pm 200$ & $111 \pm 80$ & $\ldots$ & 2625 \\
\hline${ }^{34} \mathrm{SO}_{2} /{ }^{33} \mathrm{SO}_{2}$ & $3 \pm 2$ & $7 \pm 4$ & $7 \pm 4$ & $1.2 \pm 0.8$ & $3 \pm 2$ & $4 \pm 3$ & 5.5 \\
\hline${ }^{34} \mathrm{SO}_{2} / \mathrm{SO}^{18} \mathrm{O}$ & $5 \pm 3$ & $17 \pm 11$ & $8 \pm 5$ & $10 \pm 6$ & $7 \pm 5$ & $\ldots$ & $\ldots$ \\
\hline${ }^{33} \mathrm{SO}_{2} / \mathrm{SO}^{18} \mathrm{O}$ & $2 \pm 1$ & $2 \pm 1$ & $1.1 \pm 0.7$ & $8 \pm 6$ & $2 \pm 1$ & $\ldots$ & $\ldots$ \\
\hline $\mathrm{SO} /{ }^{34} \mathrm{SO}$ & $3 \pm 1$ & $\ldots$ & $11 \pm 5$ & $1.7 \pm 0.8$ & $4 \pm 2$ & $1.4 \pm 0.6$ & 23 \\
\hline $\mathrm{SO} /{ }^{33} \mathrm{SO}$ & $\ldots$ & $\ldots$ & $180 \pm 80$ & $10 \pm 5$ & $26 \pm 14$ & $8 \pm 4$ & 127 \\
\hline $\mathrm{SO} / \mathrm{S}^{18} \mathrm{O}$ & $\ldots$ & $\ldots$ & $188 \pm 90$ & $50 \pm 30$ & $18 \pm 9$ & $\ldots$ & 500 \\
\hline${ }^{34} \mathrm{SO} /{ }^{33} \mathrm{SO}$ & $\ldots$ & $\ldots$ & $16 \pm 7$ & $6 \pm 3$ & $6 \pm 3$ & $6 \pm 3$ & 5.5 \\
\hline${ }^{34} \mathrm{SO} / \mathrm{S}^{18} \mathrm{O}$ & $\ldots$ & $\ldots$ & $17 \pm 8$ & $30 \pm 15$ & $4 \pm 2$ & $\ldots$ & $\ldots$ \\
\hline${ }^{33} \mathrm{SO} / \mathrm{S}^{18} \mathrm{O}$ & $\ldots$ & $\ldots$ & $1.1 \pm 0.6$ & $5 \pm 3$ & $0.7 \pm 0.5$ & $\ldots$ & $\ldots$ \\
\hline \multicolumn{8}{|l|}{ Molecular ratios } \\
\hline $\mathrm{SO} / \mathrm{SO}_{2}$ & $0.08 \pm 0.05$ & $\ldots$ & $0.3 \pm 0.2$ & $0.5 \pm 0.3$ & $0.09 \pm 0.06$ & $29 \pm 16$ & $\ldots$ \\
\hline${ }^{34} \mathrm{SO} /{ }^{\beta 4} \mathrm{SO}_{2}$ & $0.07 \pm 0.04$ & $\ldots$ & $0.6 \pm 0.3$ & $5 \pm 3$ & $0.2 \pm 0.1$ & $97 \pm 49$ & $\ldots$ \\
\hline${ }^{33} \mathrm{SO} /{ }^{\beta 3} \mathrm{SO}_{2}$ & $\ldots$ & $\ldots$ & $0.3 \pm 0.1$ & $1.0 \pm 0.6$ & $0.10 \pm 0.05$ & $71 \pm 40$ & $\ldots$ \\
\hline $\mathrm{S}^{18} \mathrm{O} / \mathrm{SO}^{18} \mathrm{O}$ & $\ldots$ & $\ldots$ & $0.3 \pm 0.1$ & $2 \pm 1$ & $0.3 \pm 0.2$ & $\ldots$ & $\ldots$ \\
\hline
\end{tabular}

Table A.6. Molecular abundances, $X$.

\begin{tabular}{|c|c|c|}
\hline Region & Species & $\begin{array}{c}X \\
\left(\times 10^{-8}\right)\end{array}$ \\
\hline $\begin{array}{l}\text { Extended } \\
\text { Ridge }^{a} \\
\end{array}$ & $\begin{array}{c}\mathrm{SO} \\
\mathrm{SO}_{2} \\
\end{array}$ & $\begin{array}{l}0.02 \\
0.31 \\
\end{array}$ \\
\hline $\begin{array}{l}\text { Compact } \\
\text { Ridge }^{b}\end{array}$ & $\begin{array}{l}\mathrm{SO} \\
\mathrm{SO}_{2} \\
\end{array}$ & $\begin{array}{c}\ldots \\
1.60 \\
\end{array}$ \\
\hline Plateau $^{c}$ & $\begin{array}{l}\mathrm{SO} \\
\mathrm{SO}_{2} \\
\end{array}$ & $\begin{array}{l}2.38 \\
4.76 \\
\end{array}$ \\
\hline $\begin{array}{l}\text { High } \\
\text { velocity } \\
\text { Plateau }^{d}\end{array}$ & $\begin{array}{c}\mathrm{SO} \\
\mathrm{SO}_{2}\end{array}$ & $\begin{array}{l}72.5 \\
210\end{array}$ \\
\hline $\begin{array}{l}\text { Hot } \\
\text { core }^{e}\end{array}$ & $\begin{array}{l}\mathrm{SO} \\
\mathrm{SO}_{2} \\
\end{array}$ & $\begin{array}{l}2.14 \\
23.8 \\
\end{array}$ \\
\hline $\begin{array}{l}20.5 \mathrm{~km} \mathrm{~s}^{-1} \\
\text { component }^{f}\end{array}$ & $\begin{array}{c}\mathrm{SO} \\
\mathrm{SO}_{2} \\
\end{array}$ & $\begin{array}{l}5.00 \\
0.17 \\
\end{array}$ \\
\hline
\end{tabular}

Notes. Derived molecular abundances, $X$, assuming: ${ }^{(a)} N_{\mathrm{H}_{2}}=7.5 \times 10^{22} \mathrm{~cm}^{-2},{ }^{(b)} N_{\mathrm{H}_{2}}=7.5 \times 10^{22} \mathrm{~cm}^{-2},{ }^{(c)} N_{\mathrm{H}_{2}}=2.1 \times 10^{23} \mathrm{~cm}^{-2},{ }^{(d)} N_{\mathrm{H}_{2}}=$ $6.2 \times 10^{22} \mathrm{~cm}^{-2},{ }^{(e)} N_{\mathrm{H}_{2}}=4.2 \times 10^{23} \mathrm{~cm}^{-2},{ }^{(f)} N_{\mathrm{H}_{2}}=1.0 \times 10^{23} \mathrm{~cm}^{-2}$. 
A\&A 556, A143 (2013)

Table A.7. Column density upper limits for undetected sulfur-bearing molecules in Orion KL.

\begin{tabular}{|c|c|c|c|}
\hline Molecule & $\begin{array}{l}\text { Column density } \\
\leq N \times 10^{14} \\
\left(\mathrm{~cm}^{-2}\right)\end{array}$ & $\begin{array}{l}\text { Dipole } \\
\text { moment } \\
\text { (D) }\end{array}$ & $\begin{array}{l}\text { References for spectroscopic } \\
\text { constants }\end{array}$ \\
\hline $\mathrm{SO}^{+}$ & 2.5 & 2.30 & 1 \\
\hline$(c i s)-\mathrm{HOSO}^{+}$ & 0.36 & $\mu_{a}=1.74 \mu_{b}=0.49$ & 2 \\
\hline SSO & 7.6 & $\mu_{a}=0.87 \mu_{b}=1.18$ & 3,4 \\
\hline OSiS & 0.63 & 1.47 & 5 \\
\hline $\mathrm{S}_{3}$ & 10 & 0.51 & 6 \\
\hline $\mathrm{S}_{4}$ & 7.0 & 0.87 & 6 \\
\hline $\mathrm{H}_{2} \mathrm{SO}_{4}$ & 1.3 & $\mu_{c}=2.96$ & 7 \\
\hline $\mathrm{CH}_{3} \mathrm{SOCH}_{3}$ & 1.0 & $\mu_{b}=3.94 \mu_{c}=0.4$ & 8,9 \\
\hline $\mathrm{H}_{2} \mathrm{CSO}$ & 0.3 & $\mu_{a}=2.95 \mu_{b}=0.50$ & 10,11 \\
\hline HNSO & 4.1 & $\mu_{a}=0.89 \mu_{b}=0.18$ & 12,13 \\
\hline $\mathrm{o}-\mathrm{H}_{2} \mathrm{~S}_{2}$ & 1.6 & 0.69 & 14 \\
\hline $\mathrm{SSH}$ & 0.71 & $\mu_{a}=1.16 \mu_{b}=0.83$ & 1 \\
\hline $\mathrm{CH}_{3} \mathrm{SSH}$ & 2.6 & $\mu_{a}=1.08 \mu_{b}=1.22 \mu_{c}=0.76$ & 15 \\
\hline$(t r)-\mathrm{HCSSH}$ & 0.36 & 1.53 & 16 \\
\hline
\end{tabular}

References. (1) CDMS catalog; (2) Lattanzi et al. (2011); (3) Thorwirth et al. (2006); (4) Meschi et al. (1959); (5) Thorwirth et al. (2011); (6) Thorwirth et al. (2005); (7) Sedo et al. (2008); (8) Dreizler \& Dendl (1964); (9) Margules et al. (2010); (10) Joo et al. (1995); (11) Penn \& Olsen (1976); (12) Joo et al. (1996); (13) Kirchhoff (1969); (14) Behrend et al. (1990); (15) Tyblewski et al. (1997); (16) Bak et al. (1978). 
G. B. Esplugues et al.: Survey towards Orion KL. Sulfur oxide species

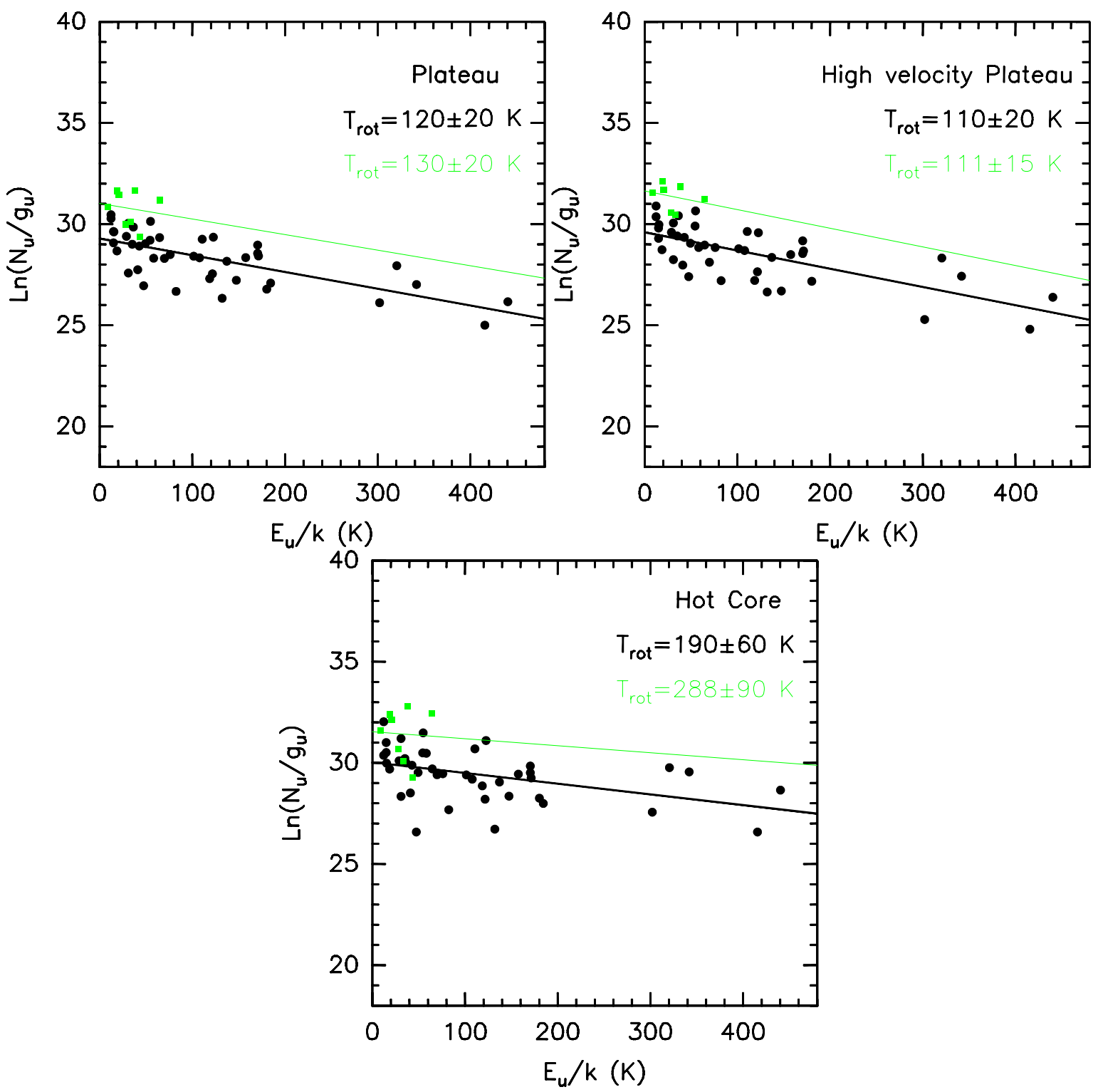

Fig. A.1. Rotational diagrams for the plateau, high-velocity plateau, and hot core components. Black dots for $\mathrm{SO}_{2}$ and green dots for $\mathrm{SO}$ The black and green lines are the best linear fits to the $\mathrm{SO}_{2}$ and $\mathrm{SO}$ points, respectively. 

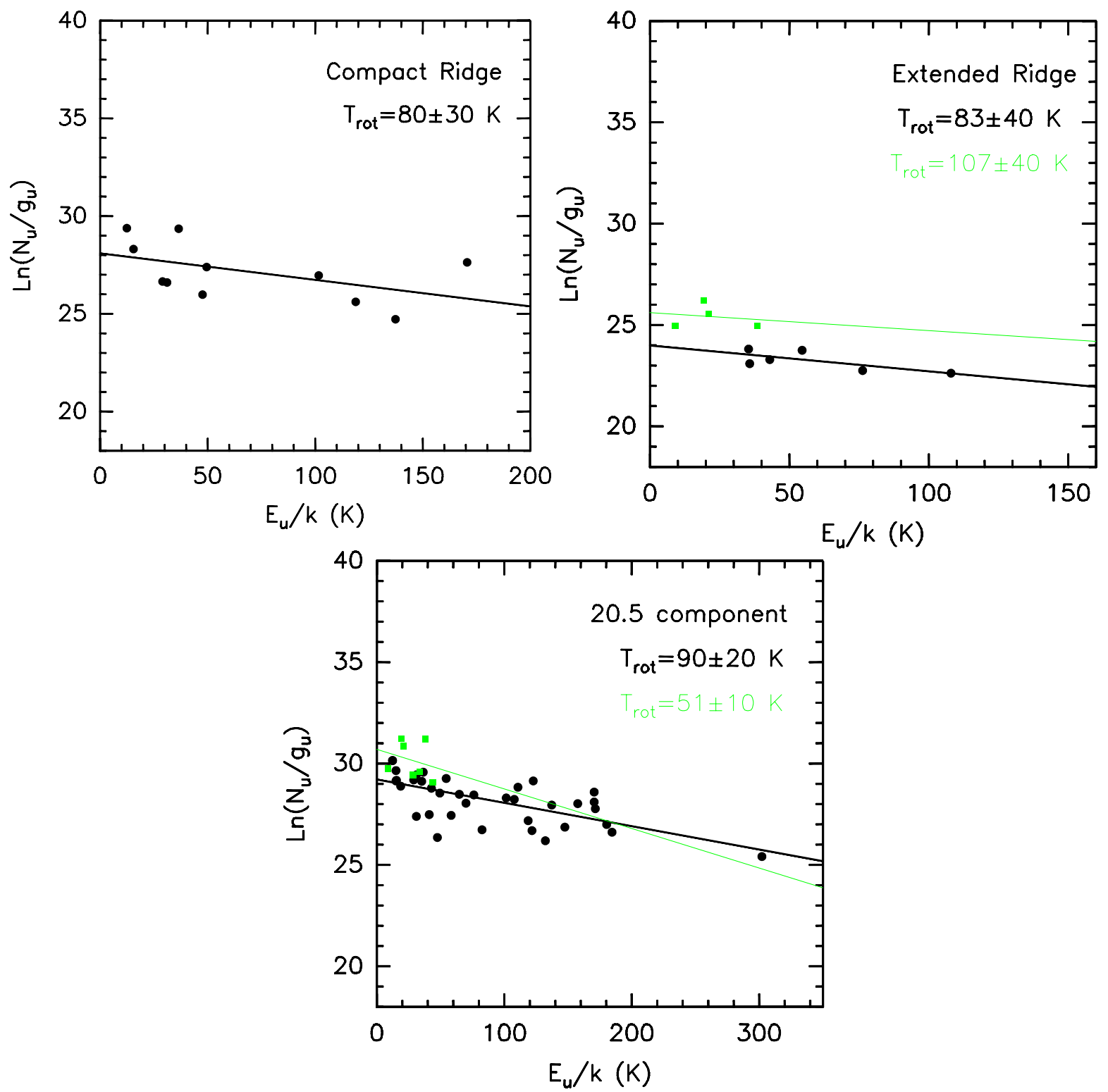

Fig. A.2. Rotational diagrams for the compact ridge, extended ridge, and $20.5 \mathrm{~km} \mathrm{~s}^{-1}$ component. Black dots for $\mathrm{SO}_{2}$ and green dots for $\mathrm{SO}$. The black and green lines are the best linear fits to the $\mathrm{SO}_{2}$ and $\mathrm{SO}$ points, respectively. 
G. B. Esplugues et al.: Survey towards Orion KL. Sulfur oxide species
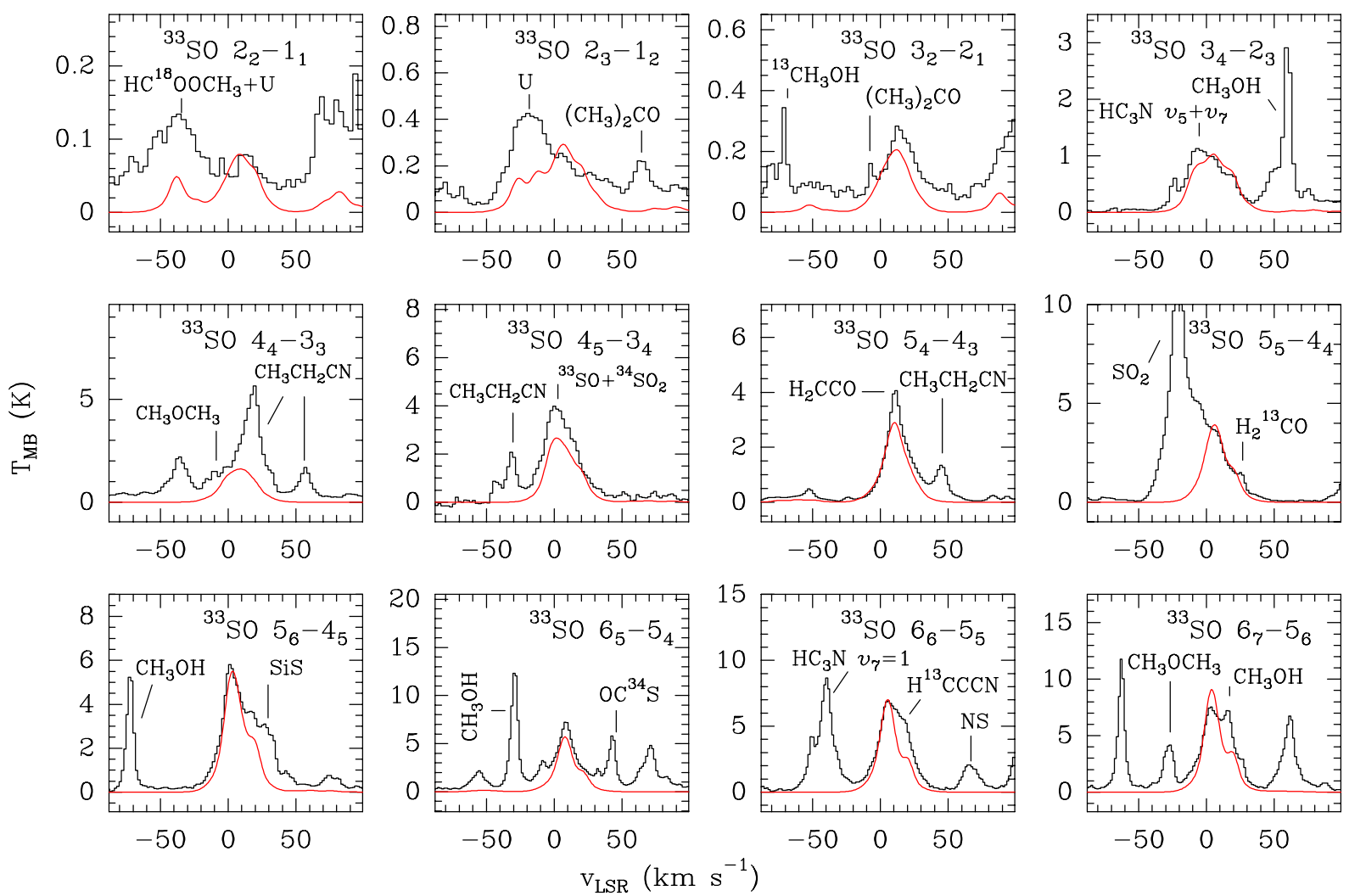

Fig. A.3. Observed lines of ${ }^{33} \mathrm{SO}$ (black histogram) and best fit LVG model results (red).
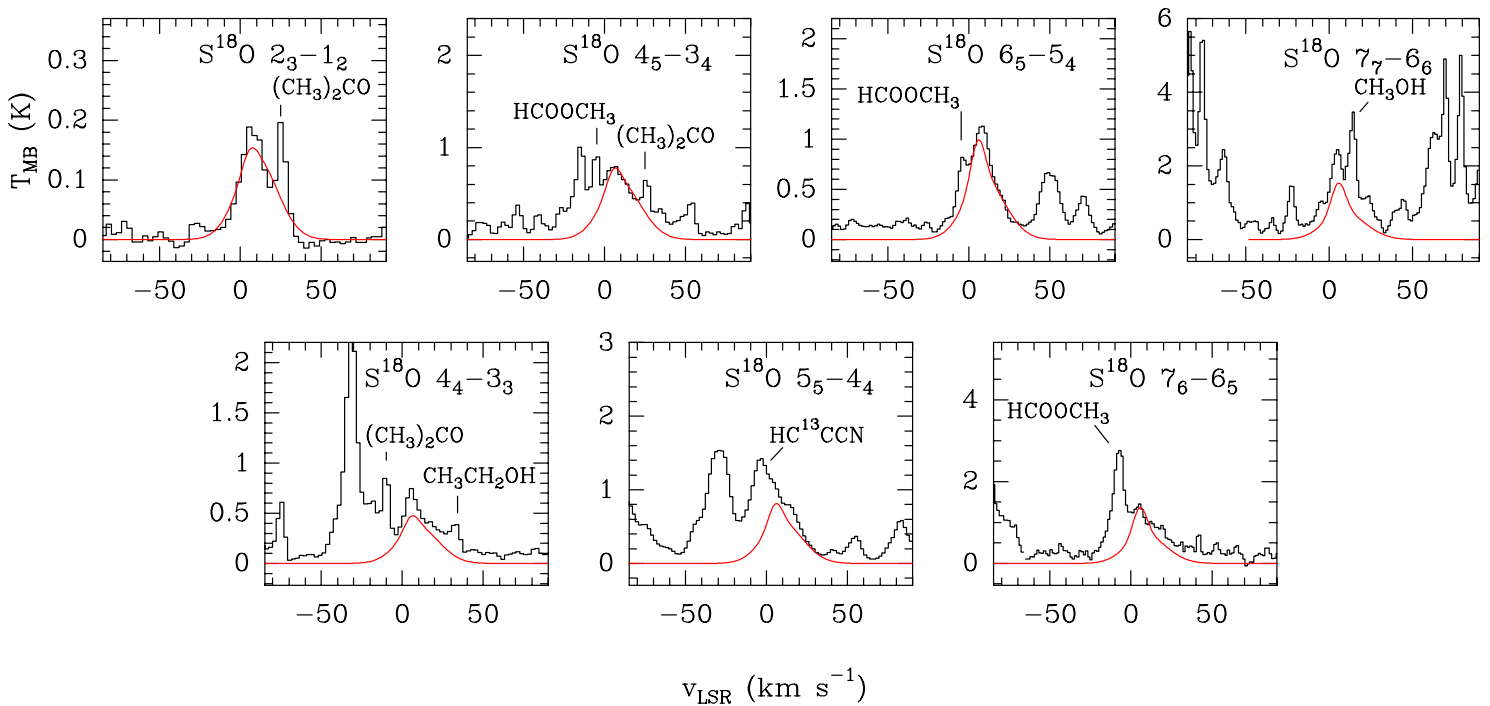

Fig. A.4. Observed lines of $S^{18} \mathrm{O}$ (black histogram) and best fit LVG model results (red). 

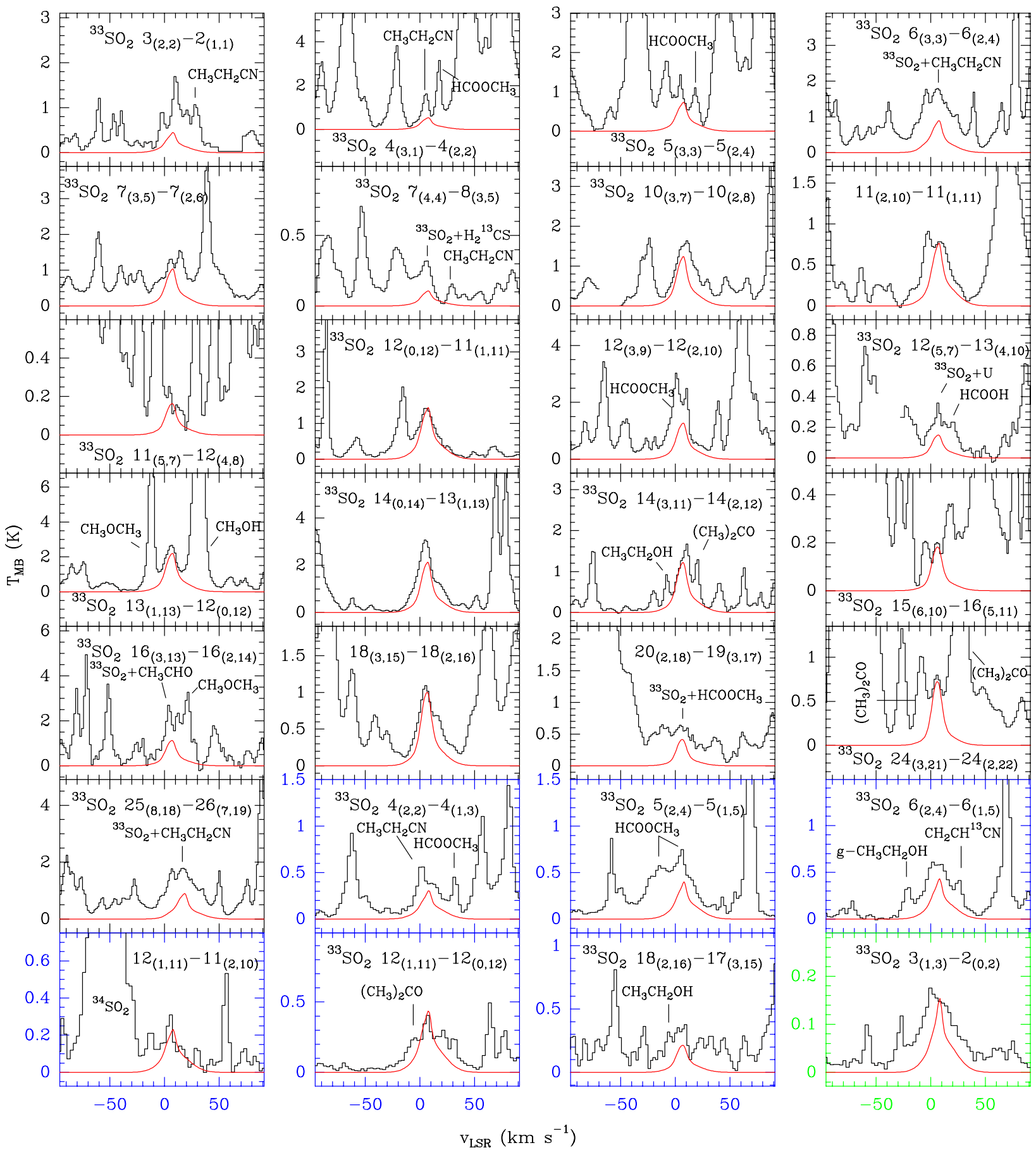

Fig. A.5. Observed lines of ${ }^{33} \mathrm{SO}_{2}$ (black histogram) and best fit LTE model (red). Boxes in black, blue, and green correspond to frequencies at 1.3, 2 , and $3 \mathrm{~mm}$, respectively. 
G. B. Esplugues et al.: Survey towards Orion KL. Sulfur oxide species
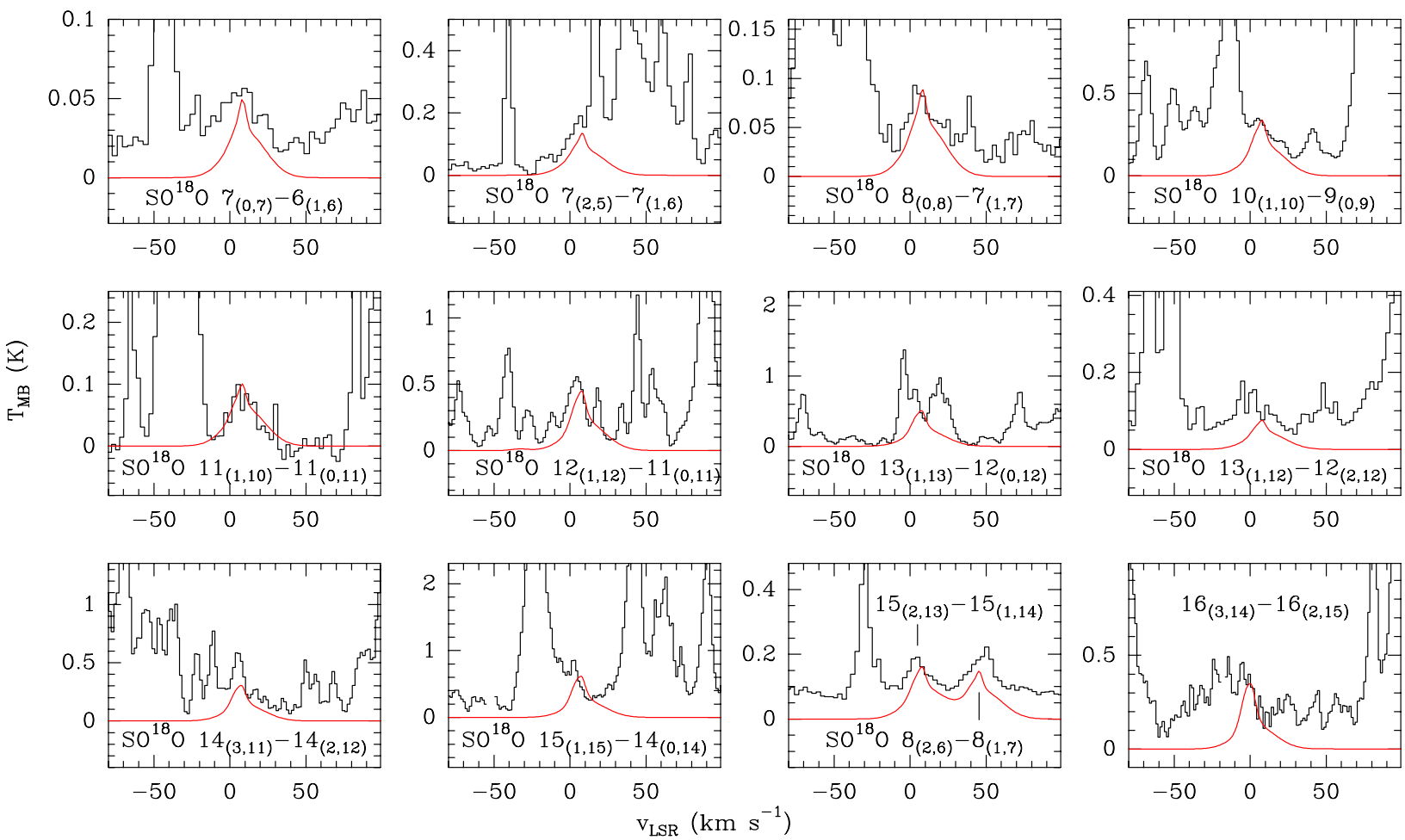

Fig. A.6. Observed lines of $\mathrm{SO}^{18} \mathrm{O}$ (black histogram) and best fit LTE model (red).
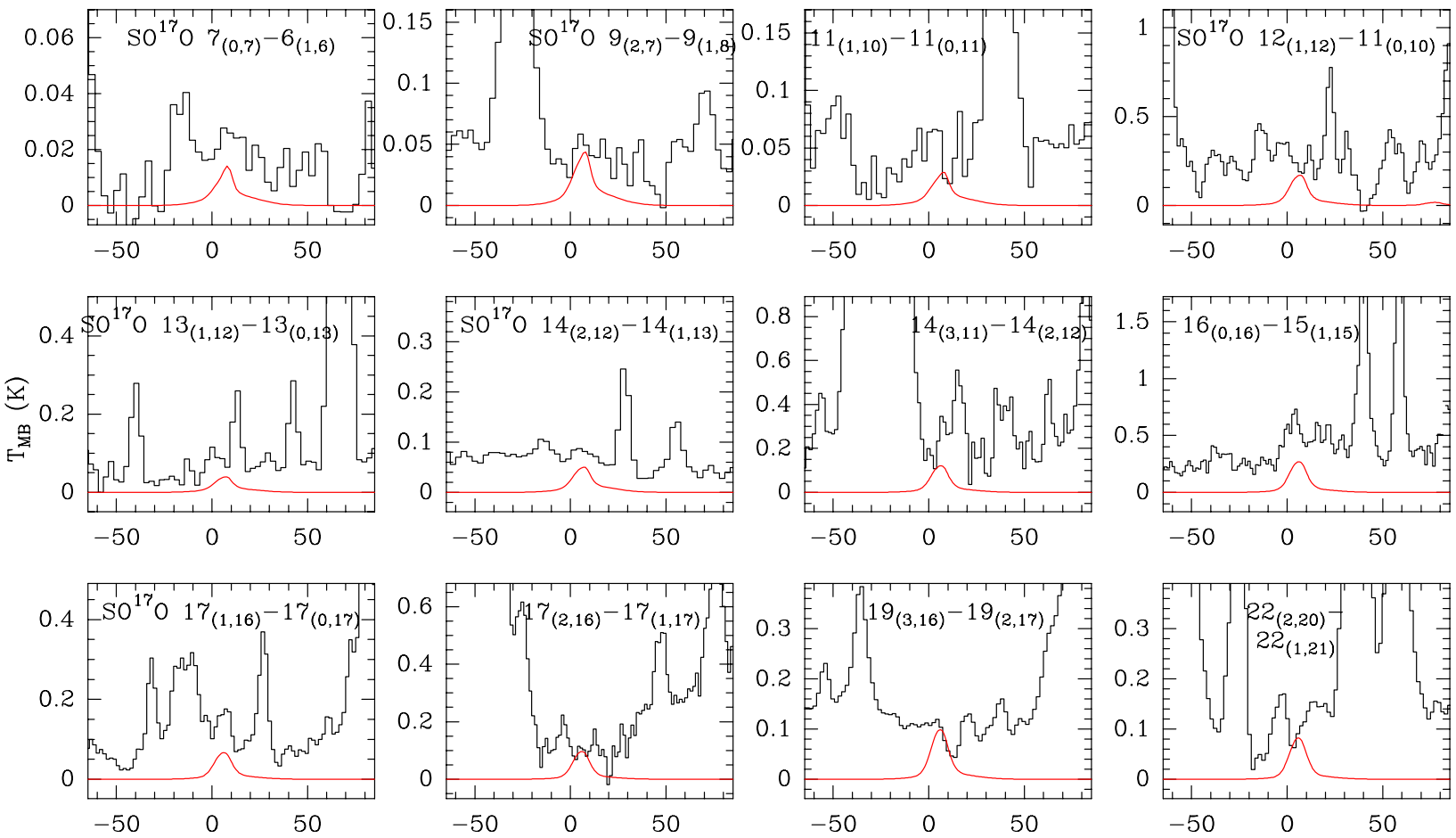

$\mathrm{v}_{\mathrm{LSR}}\left(\mathrm{km} \mathrm{s}^{-1}\right)$

Fig. A.7. Observed lines of $\mathrm{SO}^{17} \mathrm{O}$ (black histogram) and best fit LTE model (red). 
A\&A 556, A143 (2013)

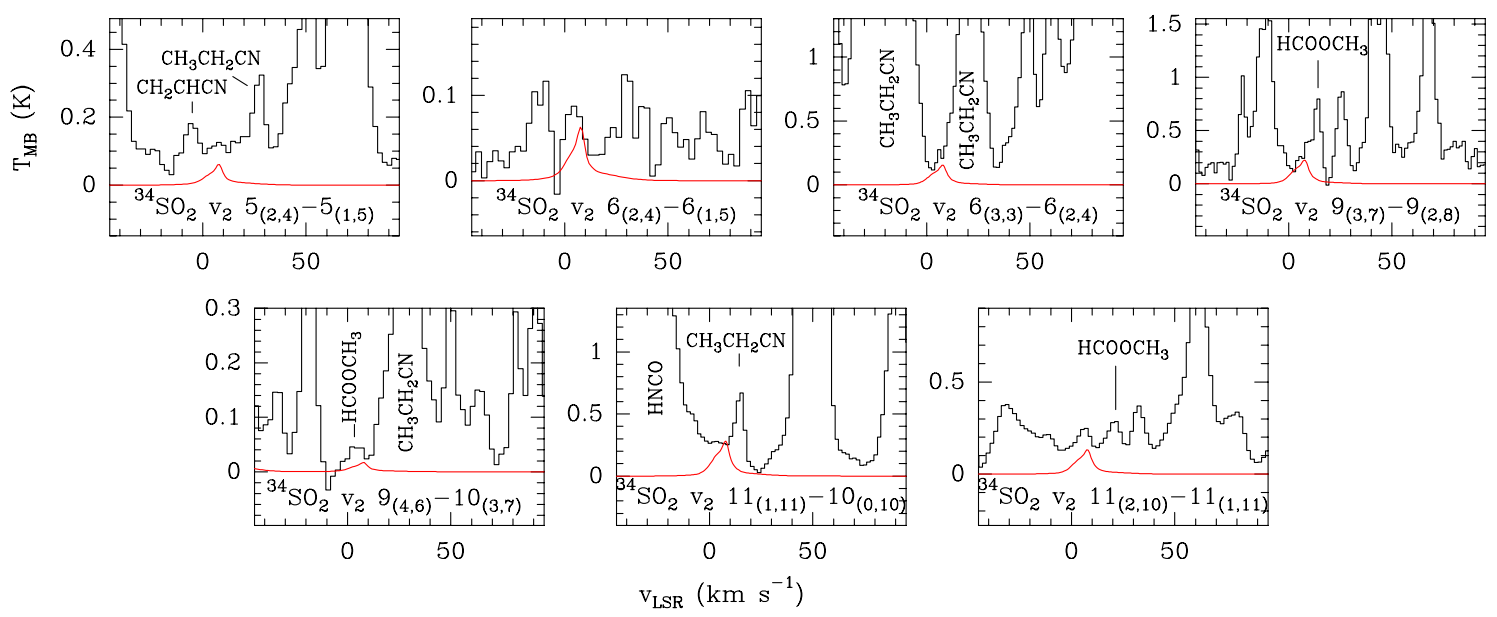

Fig. A.8. Observed lines of ${ }^{34} \mathrm{SO}_{2} v_{2}=1$ (black histogram) and best fit LTE model (red). 
G. B. Esplugues et al.: Survey towards Orion KL. Sulfur oxide species

Table A.8. Observed lines of SO and its isotopologues.

\begin{tabular}{|c|c|c|c|c|c|c|c|c|}
\hline Species & $\begin{array}{l}\text { Transition } \\
N_{J}-N^{\prime}{ }_{J^{\prime}}\end{array}$ & $\begin{array}{l}\text { Predicted } \\
\text { freq. } \\
(\mathrm{MHz}) \\
\end{array}$ & $S_{\mathrm{ij}}$ & $\begin{array}{c}E_{\mathrm{u}} \\
(\mathrm{K})\end{array}$ & $\begin{array}{c}\text { Observed } \\
\text { freq. } \\
(\mathrm{MHz})\end{array}$ & $\begin{array}{c}\text { Observed } \\
v_{\mathrm{LSR}} \\
\left(\mathrm{km} \mathrm{s}^{-1}\right) \\
\end{array}$ & $\begin{array}{c}\text { Observed } \\
T_{\mathrm{A}}^{*} \\
(\mathrm{~K}) \\
\end{array}$ & $\begin{array}{l}\text { Blended } \\
\text { with }\end{array}$ \\
\hline SO & $2_{2}-1_{1}$ & 86093.958 & 1.50 & 19.3 & 86094.4 & 7.4 & 11.73 & \\
\hline SO & $2{ }_{3}-1_{2}$ & 99299.887 & 2.93 & 38.6 & 99300.4 & 7.4 & 22.52 & \\
\hline SO & $5_{4}-4_{4}$ & 100029.550 & 0.36 & 38.6 & 100030.5 & 6.2 & 5.90 & $\mathrm{CH}_{3} \mathrm{CH}_{2} \mathrm{CN}$ \\
\hline SO & $3_{2}-2_{1}$ & 109252.181 & 1.51 & 21.1 & 109252.5 & 8.1 & 18.38 & \\
\hline SO & $6_{5}-5_{5}$ & 136634.660 & 0.28 & 50.7 & 136636.4 & 5.2 & 7.98 & $\mathrm{CH}_{3} \mathrm{OCH}_{3}$ \\
\hline $\mathrm{SO}$ & $3_{4}-2_{3}$ & 138178.654 & 3.94 & 15.9 & 138178.9 & 8.5 & 29.4 & \\
\hline SO & $4_{3}-3_{2}$ & 158971.811 & 2.69 & 28.7 & 158972.6 & 7.5 & 30.99 & \\
\hline SO & $4_{4}-3_{3}$ & 172181.403 & 3.75 & 33.8 & 172182.7 & 6.7 & 39.33 & \\
\hline SO & $7_{6}-6_{6}$ & 174928.886 & 0.22 & 64.9 & 174931.4 & 4.7 & 9.43 & $\mathrm{HCOOCH}_{3}$ \\
\hline SO & $5_{4}-4_{3}$ & 206176.013 & 3.78 & 38.6 & 206177.5 & 6.8 & 31.82 & \\
\hline SO & $8_{7}-7_{7}$ & 214357.054 & 0.19 & 81.2 & 214359.9 & 5.0 & 6.95 & $\begin{array}{c}\mathrm{CH}_{3} \mathrm{OCH}_{3},{ }^{13} \mathrm{CH}_{3} \mathrm{CN} \\
\mathrm{CH}_{3} \mathrm{CH}_{2} \mathrm{CN} v_{13} / v_{21}\end{array}$ \\
\hline SO & $5_{5}-4_{4}$ & 215220.650 & 4.80 & 44.1 & 215223.6 & 4.9 & 33.22 & \\
\hline SO & $5_{6}-4_{5}$ & 219949.389 & 5.95 & 35.0 & 219951.1 & 6.7 & 38.65 & \\
\hline $\mathrm{SO}$ & $2{ }_{1}-1_{2}$ & 236452.293 & 0.012 & 15.8 & 236455.1 & 5.4 & 1.02 & $\mathrm{H}_{2} \mathrm{C}^{34} \mathrm{~S}$ \\
\hline SO & $3_{2}-2_{3}$ & 246404.588 & 0.012 & 21.1 & 246406.9 & 6.2 & 1.62 & ${ }^{33} \mathrm{SO}$ \\
\hline \multirow[t]{3}{*}{ SO } & \multirow[t]{3}{*}{$6_{5}-5_{4}$} & \multirow{3}{*}{251825.759} & \multirow{3}{*}{4.84} & \multirow{3}{*}{50.7} & two peaks & & & $\mathrm{CH}_{3} \mathrm{OH}$ \\
\hline & & & & & 251826.5 & 8.1 & 35.11 & \\
\hline & & & & & 251829.5 & 4.6 & 35.11 & \multirow{8}{*}{$\mathrm{HCOOCH}_{3}$} \\
\hline \multirow{3}{*}{ SO } & \multirow{3}{*}{$9_{8}-8_{8}$} & \multirow[t]{3}{*}{254573.628} & \multirow[t]{3}{*}{0.16} & \multirow[t]{3}{*}{99.7} & two peaks & & & \\
\hline & & & & & 254571.5 & 11.5 & 6.30 & \\
\hline & & & & & 254577.4 & 4.6 & 8.92 & \\
\hline SO & $6_{6}-5_{5}$ & 258255.826 & 5.83 & 56.5 & 258255.2 & 9.7 & 25.94 & \\
\hline \multirow[t]{3}{*}{ SO } & $6_{7}-5_{6}$ & 261843.705 & 6.95 & 47.6 & two peaks & & & \\
\hline & & & & & 261844.5 & 9.0 & 40.10 & \\
\hline & & & & & 261849.5 & 2.4 & 41.06 & \\
\hline $\mathrm{SO}$ & $4_{3}-3_{4}$ & 267197.745 & 0.0095 & 28.7 & 267202.5 & 3.7 & 4.47 & $\mathrm{HCN} v_{2}=1$ \\
\hline${ }^{34} \mathrm{SO}$ & $2_{2}-1_{1}$ & 84410.684 & 1.50 & 19.2 & 84411.4 & 6.5 & 0.96 & \\
\hline${ }^{34} \mathrm{SO}$ & $5_{4}-4_{4}$ & 96781.825 & 0.36 & 38.1 & 96783.4 & 4.1 & 0.27 & \\
\hline${ }^{34} \mathrm{SO}$ & $2_{3}-1_{2}$ & 97715.405 & 2.93 & 9.1 & 97716.3 & 6.3 & 2.93 & $\mathrm{HCOOCH}_{3}$ \\
\hline${ }^{34} \mathrm{SO}$ & $3_{2}-2_{1}$ & 106743.363 & 1.51 & 20.9 & 106744.4 & 6.1 & 2.17 & $\mathrm{H}_{39} \alpha$ \\
\hline${ }^{34} \mathrm{SO}$ & $6_{5}-5_{5}$ & 132432.200 & 0.28 & 49.9 & 132437.5 & -3.0 & 0.96 & $\mathrm{HCOOCH}_{3}$ \\
\hline${ }^{34} \mathrm{SO}$ & $3_{4}-2_{3}$ & 135775.651 & 3.94 & 15.6 & 135777.4 & 5.1 & 6.29 & \\
\hline${ }^{34} \mathrm{SO}$ & $4_{3}-3_{2}$ & 155506.801 & 2.69 & 28.4 & 155508.7 & 5.3 & 5.11 & \\
\hline${ }^{34} \mathrm{SO}$ & $4_{4}-3_{3}$ & 168815.109 & 3.75 & 33.4 & 168817.5 & 4.8 & 6.01 & \\
\hline${ }^{34} \mathrm{SO}$ & $7_{6}-6_{6}$ & 169787.430 & 0.22 & 63.8 & 169791.6 & 1.6 & 0.77 & $\mathrm{NH}_{2} \mathrm{CHO}$ \\
\hline${ }^{34} \mathrm{SO}$ & $4_{5}-3_{4}$ & 175352.753 & 4.94 & 24.0 & 175354.9 & 5.3 & 10.3 & \\
\hline${ }^{34} \mathrm{SO}$ & $5_{4}-4_{3}$ & 201846.655 & 3.78 & 38.1 & 201849.3 & 5.1 & 6.35 & \\
\hline${ }^{34} \mathrm{SO}$ & $8_{7}-7_{7}$ & 208292.093 & 0.19 & 79.9 & 208297.1 & 1.8 & 0.46 & \\
\hline${ }^{34} \mathrm{SO}$ & $5_{5}-4_{4}$ & 211013.019 & 4.80 & 43.5 & 211015.7 & 5.2 & 12.1 & \\
\hline${ }^{34} \mathrm{SO}$ & $5_{6}-4_{5}$ & 215839.916 & 5.95 & 34.4 & 215842.2 & 5.8 & 13.4 & $\begin{array}{c}\mathrm{CH}_{3} \mathrm{CH}_{2} \mathrm{CN} v_{13} / v_{21} \\
\mathrm{HCOOCH}_{3} v_{t}=1\end{array}$ \\
\hline${ }^{34} \mathrm{SO}$ & $2{ }_{1}-1_{2}$ & 237107.766 & 0.01 & 15.8 & 237112.6 & 2.9 & 0.25 & U line \\
\hline${ }^{34} \mathrm{SO}$ & $3_{2}-2_{3}$ & 246135.724 & 0.01 & 20.9 & 246137.8 & 6.5 & 0.07 & $\mathrm{CH}_{3} \mathrm{CH}_{2}^{13} \mathrm{CN}$ \\
\hline${ }^{34} \mathrm{SO}$ & $6_{5}-5_{4}$ & 246663.394 & 4.83 & 49.9 & 246666.3 & 5.5 & 10.9 & \\
\hline${ }^{34} \mathrm{SO}$ & $9_{8}-8_{8}$ & 247598.441 & 0.16 & 98.0 & 247598.5 & 8.9 & 0.62 & $\left(\mathrm{CH}_{3}\right)_{2} \mathrm{CO}$ \\
\hline${ }^{34} \mathrm{SO}$ & $6_{6}-5_{5}$ & 253207.017 & 5.83 & 55.7 & 253210.3 & 5.1 & 11.8 & $\mathrm{CH}_{3} \mathrm{OH}$ \\
\hline${ }^{34} \mathrm{SO}$ & $6_{7}-5_{6}$ & 256877.810 & 6.95 & 46.7 & 256880.2 & 6.2 & 15.5 & \\
\hline${ }^{34} \mathrm{SO}$ & $4_{3}-3_{4}$ & 265866.874 & 0.01 & 28.4 & 265884.5 & -10.9 & 34.8 & $\mathrm{HCN}$ \\
\hline${ }^{33} \mathrm{SO}$ & $22_{2}-1_{1}$ & 85225.608 & 1.50 & 19.3 & 85224.3 & 13.6 & 0.06 & \\
\hline${ }^{33} \mathrm{SO}$ & $5_{4}-4_{4}$ & 98350.735 & 0.36 & 38.3 & 98353.5 & 0.6 & $<0.02$ & \\
\hline${ }^{33} \mathrm{SO}$ & $2_{3}-1_{2}$ & 98483.142 & 2.93 & 9.2 & 98484.3 & 5.5 & 0.18 & U \\
\hline${ }^{33} \mathrm{SO}$ & $3_{2}-2_{1}$ & 107956.681 & 1.51 & 21.0 & 107955.2 & 13.1 & 0.20 & $\left(\mathrm{CH}_{3}\right)_{2} \mathrm{CO}$ \\
\hline${ }^{33} \mathrm{SO}$ & $6_{5}-5_{5}$ & 134463.407 & 0.28 & 50.3 & $\ldots$ & $\ldots$ & $\ldots$ & $\mathrm{CH}_{3} \mathrm{CH}_{2} \mathrm{CN}\left(v=0\right.$ and $\left.v_{13} / v_{21}\right)$ \\
\hline${ }^{33} \mathrm{SO}$ & $3_{4}-2_{3}$ & 136939.179 & 3.94 & 15.7 & 136941.4 & 4.1 & 0.70 & $\mathrm{HC}_{3} \mathrm{~N} v_{5}+v_{7}$ \\
\hline${ }^{33} \mathrm{SO}$ & $4_{3}-3_{2}$ & 157183.674 & 2.69 & 28.5 & $\ldots$ & $\ldots$ & $\ldots$ & $\mathrm{CH}_{3} \mathrm{OH}$ \\
\hline${ }^{33} \mathrm{SO}$ & $4_{4}-3_{3}$ & 170444.835 & 3.75 & 33.6 & $\ldots$ & $\ldots$ & $\ldots$ & $\mathrm{CH}_{3} \mathrm{CH}_{2} \mathrm{CN}$ \\
\hline${ }^{33} \mathrm{SO}$ & $7_{6}-6_{6}$ & 172273.415 & 0.22 & 64.4 & 172267.6 & 19.1 & 0.64 & U line \\
\hline
\end{tabular}

Notes. Emission lines of SO and its isotopologues in the frequency range of the 30-m Orion KL survey. Column 1 indicates the species; Col. 2 the quantum numbers of the line transition; Col. 3 gives the assumed rest frequencies; Col. 4 the line strength; Col. 5 the energy of the upper level; Col. 6 observed frequency assuming a $v_{\mathrm{LSR}}$ of $9.0 \mathrm{~km} \mathrm{~s}^{-1}$; Col. 7 the observed radial velocities; Col. 8 the peak line antenna temperature; and Col. 9 the blended species. 
Table A.8. continued.

\begin{tabular}{|c|c|c|c|c|c|c|c|c|}
\hline Species & $\begin{array}{l}\text { Transition } \\
N_{J}-N^{\prime}{ }_{J^{\prime}}\end{array}$ & $\begin{array}{l}\text { Predicted } \\
\text { freq. } \\
(\mathrm{MHz}) \\
\end{array}$ & $S_{\mathrm{ij}}$ & $\begin{array}{c}E_{\mathrm{u}} \\
(\mathrm{K})\end{array}$ & $\begin{array}{l}\text { Observed } \\
\text { freq. } \\
(\mathrm{MHz})\end{array}$ & $\begin{array}{c}\text { Observed } \\
v_{\mathrm{LSR}} \\
\left(\mathrm{km} \mathrm{s}^{-1}\right) \\
\end{array}$ & $\begin{array}{c}\text { Observed } \\
T_{\mathrm{A}}^{*} \\
(\mathrm{~K}) \\
\end{array}$ & $\begin{array}{l}\text { Blended } \\
\text { with }\end{array}$ \\
\hline${ }^{33} \mathrm{SO}$ & $4_{5}-3_{4}$ & 176927.358 & 4.94 & 24.2 & $\begin{array}{l}176926.4 \\
176932.5\end{array}$ & $\begin{array}{c}10.6 \\
0.5\end{array}$ & $\begin{array}{l}2.15 \\
2.66\end{array}$ & \\
\hline${ }^{33} \mathrm{SO}$ & $5_{4}-4_{3}$ & 203942.465 & 3.78 & 38.3 & 203940.6 & 11.7 & 2.74 & $\mathrm{H}_{2} \mathrm{CCO}$ \\
\hline${ }^{33} \mathrm{SO}$ & $87-7_{7}$ & 211225.385 & 1.87 & 80.5 & & $\ldots$ & $\ldots$ & $\mathrm{H}_{2} \mathrm{CO}$ \\
\hline${ }^{33} \mathrm{SO}$ & $5_{5}-4_{4}$ & 213050.062 & 4.80 & 43.8 & 213052.3 & 5.9 & 2.09 & $\mathrm{SO}_{2}, \mathrm{H}_{2}^{13} \mathrm{CO}$ \\
\hline${ }^{33} \mathrm{SO}$ & $5_{6}-4_{5}$ & 217829.254 & 5.95 & 34.7 & 217834.6 & 1.6 & 3.23 & $\mathrm{SiS}$ \\
\hline${ }^{33} \mathrm{SO}$ & $2_{1}-1_{2}$ & 236786.517 & 0.01 & 15.8 & $\ldots$ & $\ldots$ & $\ldots$ & \\
\hline${ }^{33} \mathrm{SO}$ & $3_{2}-2_{3}$ & 246260.056 & 0.01 & 21.0 & $\ldots$ & $\ldots$ & $\ldots$ & $\mathrm{CH}_{3} \mathrm{CH}_{2} \mathrm{CN}$ \\
\hline${ }^{33} \mathrm{SO}$ & $65-5_{4}$ & 249162.733 & 4.83 & 50.3 & 249162.5 & 9.3 & 4.05 & $\mathrm{CH}_{3} \mathrm{CH}_{2} \mathrm{CN} v_{20}=1$ \\
\hline${ }^{33} \mathrm{SO}$ & $9_{8}-8_{8}$ & 250972.610 & 0.16 & 98.8 & $\ldots$ & $\ldots$ & $\ldots$ & $\mathrm{CH}_{3} \mathrm{OH}$ \\
\hline${ }^{33} \mathrm{SO}$ & $6_{6}-5_{5}$ & 255651.300 & 5.83 & 56.1 & 255654.1 & 5.7 & 3.71 & $\mathrm{H}^{13} \mathrm{CCCN}$ \\
\hline${ }^{33} \mathrm{SO}$ & $6_{7}-5_{6}$ & 259281.738 & 6.95 & 47.1 & 259286.5 & 3.5 & 4.16 & $\mathrm{CH}_{3} \mathrm{OH}$ \\
\hline${ }^{33} \mathrm{SO}$ & $4_{3}-3_{4}$ & 266504.551 & 0.01 & 28.5 & 266510.4 & 2.4 & 0.18 & \\
\hline $\mathrm{S}^{18} \mathrm{O}$ & $5_{4}-4_{4}$ & 87876.593 & 0.36 & 36.6 & 87877.5 & 5.9 & 0.03 & $\left(\mathrm{CH}_{3}\right)_{2} \mathrm{CO}$ \\
\hline $\mathrm{S}^{18} \mathrm{O}$ & $2{ }_{3}-1_{2}$ & 93267.376 & 2.94 & 8.7 & 93268.5 & 5.4 & 0.17 & $\left(\mathrm{CH}_{3}\right)_{2} \mathrm{CO}$ \\
\hline $\mathrm{S}^{18} \mathrm{O}$ & $3_{2}-2_{1}$ & 99803.663 & 1.51 & 20.5 & 99804.5 & 6.5 & 0.07 & $\operatorname{HCCCN} v_{6}=1$ \\
\hline $\mathrm{S}^{18} \mathrm{O}$ & $4_{3}-3_{2}$ & 145874.497 & 2.69 & 27.5 & $\ldots$ & $\ldots$ & $\ldots$ & $\mathrm{CH}_{3} \mathrm{CH}_{2} \mathrm{CN} v_{13} / v_{21}$ \\
\hline $\mathrm{S}^{18} \mathrm{O}$ & $7_{6}-6_{6}$ & 155591.913 & 0.23 & 60.9 & $\ldots$ & $\ldots$ & $\ldots$ & $\mathrm{CH}_{3} \mathrm{CH}_{2} \mathrm{CN} v_{13} / v_{21}$ \\
\hline $\mathrm{S}^{18} \mathrm{O}$ & $4_{4}-3_{3}$ & 159428.315 & 3.75 & 32.4 & 159429.9 & 6.0 & 0.54 & \\
\hline $\mathrm{S}^{18} \mathrm{O}$ & $4_{5}-3_{4}$ & 166285.312 & 4.95 & 22.9 & 166286.7 & 6.5 & 0.52 & \\
\hline $\mathrm{S}^{18} \mathrm{O}$ & $5_{5}-4_{4}$ & 199280.161 & 4.80 & 42.0 & 199283.5 & 4.0 & 0.68 & $\mathrm{HC}^{13} \mathrm{CCN}$ \\
\hline $\mathrm{S}^{18} \mathrm{O}$ & $5_{6}-4_{5}$ & 204387.945 & 5.95 & 32.7 & $\ldots$ & $\ldots$ & $\ldots$ & $\mathrm{SO}_{2}$ \\
\hline $\mathrm{S}^{18} \mathrm{O}$ & $9_{8}-8_{8}$ & 228271.646 & 0.16 & 93.1 & 228271.3 & 9.5 & 0.21 & $\mathrm{HCOOCH}_{3}$ \\
\hline $\mathrm{S}^{18} \mathrm{O}$ & $6_{5}-5_{4}$ & 232265.872 & 4.83 & 47.8 & 232267.3 & 7.2 & 0.64 & $\mathrm{HCOOCH}_{3}$ \\
\hline $\mathrm{S}^{18} \mathrm{O}$ & $2_{1}-1_{2}$ & 239102.492 & 0.11 & 15.7 & $\ldots$ & $\ldots$ & $\ldots$ & $\mathrm{CH}_{3} \mathrm{CN}$ \\
\hline $\mathrm{S}^{18} \mathrm{O}$ & $6_{6}-5_{5}$ & 239128.519 & 5.83 & 53.4 & $\ldots$ & $\ldots$ & $\ldots$ & $\mathrm{CH}_{3} \mathrm{CN}$ \\
\hline $\mathrm{S}^{18} \mathrm{O}$ & $6_{7}-5_{6}$ & 243039.305 & 6.95 & 44.4 & 243042.5 & 5.1 & 1.34 & $\mathrm{CH}_{2} \mathrm{DCN}$ \\
\hline $\mathrm{S}^{18} \mathrm{O}$ & $3_{2}-2_{3}$ & 245638.780 & 0.01 & 20.5 & 245641.5 & 5.7 & 0.24 & \\
\hline $\mathrm{S}^{18} \mathrm{O}$ & $4_{3}-3$ & 262447.093 & 0.01 & 27.5 & 262448.5 & 7.4 & 0.12 & $\mathrm{HCOO}^{13} \mathrm{CH}_{3}$ \\
\hline $\mathrm{S}^{18} \mathrm{O}$ & $10_{9}-9_{9}$ & 265637.956 & 0.01 & 112.1 & 265642.6 & 3.8 & 0.08 & \\
\hline $\mathrm{S}^{18} \mathrm{O}$ & $7_{6}-6_{5}$ & 273858.128 & 5.87 & 60.9 & 273861.3 & 5.5 & 0.85 & $\mathrm{HCOOCH}_{3}$ \\
\hline $\mathrm{S}^{18} \mathrm{O}$ & $7_{7}-6_{6}$ & 278972.690 & 6.86 & 66.8 & 278976.6 & 4.8 & 1.02 & $\mathrm{CH}_{3} \mathrm{OH}$ \\
\hline
\end{tabular}


Table A.9. Observed lines of $\mathrm{SO}_{2}$, its isotopologues, and vibrationally excited states.

\begin{tabular}{|c|c|c|c|c|c|c|}
\hline $\begin{array}{l}\text { Species/Transition } \\
J_{K_{a}, K_{c}}-J_{K_{a}^{\prime}, K_{c}^{\prime}}^{\prime}\end{array}$ & $\begin{array}{l}\text { Predicted } \\
\text { freq. } \\
(\mathrm{MHz})\end{array}$ & $S_{\mathrm{ij}}$ & $\begin{array}{c}E_{\mathrm{u}} \\
(\mathrm{K})\end{array}$ & $\begin{array}{l}\text { Observed } \\
\text { freq. } \\
(\mathrm{MHz})\end{array}$ & $\begin{array}{c}\text { Observed } \\
v_{\mathrm{LSR}} \\
\left(\mathrm{km} \mathrm{s}^{-1}\right)\end{array}$ & $\begin{array}{c}\text { Observed } \\
T_{\mathrm{A}}^{*} \\
(\mathrm{~K})\end{array}$ \\
\hline $\mathrm{SO}_{2} 34_{8,26}-35_{7,29}$ & 82409.542 & 5.20 & 704.4 & 82410.5 & 5.5 & 0.08 \\
\hline $\mathrm{SO}_{2} 13_{4,10}-14_{3,11}$ & 82951.936 & 1.93 & 123.0 & 82952.5 & 7.0 & 2.18 \\
\hline $\mathrm{SO}_{2} 8_{1,7}-8_{0,8}$ & 83688.092 & 6.38 & 36.7 & 83688.5 & 7.5 & 11.0 \\
\hline $\mathrm{SO}_{2} 32_{5,27}-31_{6,26}$ & 84320.877 & 5.05 & 549.4 & 84321.5 & 6.8 & 0.25 \\
\hline $\mathrm{SO}_{2} 43_{7,37}-42_{8,34}$ & 85247.002 & 6.77 & 992.8 & 85248.5 & 3.7 & 0.03 \\
\hline $\mathrm{SO}_{2} 39_{9,31}-40_{8,32}$ & 86153.761 & 5.97 & 916.2 & 1 & $\ldots$ & \\
\hline $\mathrm{SO}_{2} 8_{3,5}-9_{2,8}$ & 86639.090 & 1.13 & 55.2 & 86639.4 & 7.9 & 2.65 \\
\hline $\mathrm{SO}_{2} 20_{2,18}-21_{1,21}$ & 86828.940 & 0.27 & 207.8 & $86830.4^{2}$ & 4.0 & 0.25 \\
\hline $\mathrm{SO}_{2} 32_{5,29}-32_{6,26}$ & 87926.274 & 5.16 & 579.2 & 3 & & \\
\hline $\mathrm{SO}_{2} 44_{10,34}-45_{9,37}$ & 90005.126 & 6.73 & 1155.7 & 90005.5 & 7.8 & 0.02 \\
\hline $\mathrm{SO}_{2} 25_{3,23}-24_{4,20}$ & 90548.146 & 3.26 & 320.9 & 90549.5 & 4.5 & 1.16 \\
\hline $\mathrm{SO}_{2} 18_{5,13}-19_{4,16}$ & 91550.440 & 2.69 & 218.7 & $91551.5^{4}$ & 5.5 & 2.55 \\
\hline $\mathrm{SO}_{2} 23_{6,18}-24_{5,19}$ & 94064.694 & 3.46 & 342.2 & 94065.5 & 6.4 & 0.81 \\
\hline $\mathrm{SO}_{2} 38_{6,32}-37_{7,31}$ & 97466.369 & 6.00 & 772.6 & 97467.6 & 5.2 & 0.09 \\
\hline $\mathrm{SO}_{2} 7_{3,5}-8_{2,6}$ & 97702.334 & 0.94 & 47.8 & $97703.5^{5,6}$ & 5.4 & 3.61 \\
\hline $\mathrm{SO}_{2} 33_{3,31}-32_{4,28}$ & 97994.088 & 2.01 & 535.8 & $97996.5^{7}$ & 1.6 & 0.24 \\
\hline $\mathrm{SO}_{2} 28_{7,21}-29_{6,24}$ & 98976.292 & 4.23 & 493.7 & 98977.5 & 5.3 & 0.43 \\
\hline $\mathrm{SO}_{2} 29_{4,26}-28_{5,23}$ & 99392.512 & 4.37 & 440.7 & 99393.5 & 6.0 & 0.76 \\
\hline $\mathrm{SO}_{2} 2_{2,0}-3_{1,3}$ & 100878.107 & 0.16 & 12.6 & 100878.5 & 7.8 & 1.21 \\
\hline $\mathrm{SO}_{2} 33_{8,26}-34_{7,27}$ & 102690.061 & 4.99 & 673.0 & 102690.4 & 8.0 & 0.15 \\
\hline $\mathrm{SO}_{2} 49_{8,42}-48_{9,39}$ & 102707.256 & 7.73 & 1286.5 & 102708.6 & 5.1 & 0.02 \\
\hline $\mathrm{SO}_{2} 3_{1,3}-2_{0,2}$ & 104029.419 & 2.01 & 7.7 & 104030.0 & 7.3 & 12.5 \\
\hline $\mathrm{SO}_{2} 16_{2,14}-15_{3,13}$ & 104033.582 & 2.99 & 137.5 & 8 & $\ldots$ & $\ldots$ \\
\hline $\mathrm{SO}_{2} 10_{1,9}-10_{0,10}$ & 104239.299 & 6.70 & 54.7 & $104239.5^{5,6}$ & 8.4 & 14.0 \\
\hline $\mathrm{SO}_{2} 38_{9,29}-39_{8,32}$ & 106674.825 & 5.76 & 880.2 & $106676.5^{9}$ & 4.3 & 0.13 \\
\hline $\mathrm{SO}_{2} 27_{3,25}-26_{4,22}$ & 107060.210 & 3.10 & 369.4 & $107061.5^{10}$ & 5.4 & 1.38 \\
\hline $\mathrm{SO}_{2} 12_{2,8}-13_{3,11}$ & 107843.470 & 1.70 & 111.0 & 107844.5 & 6.1 & 3.98 \\
\hline $\mathrm{SO}_{2} 42_{4,38}-43_{3,41}$ & 108915.425 & 0.76 & 887.0 & 11 & 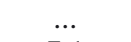 & $\ldots$ \\
\hline $\mathrm{SO}_{2} 39_{6,34}-38_{7,31}$ & 108955.919 & 6.14 & 808.3 & 108956.6 & 7.1 & 0.08 \\
\hline $\mathrm{SO}_{2} 17_{5,13}-18_{4,14}$ & 109757.585 & 2.48 & 202.1 & $109758.5^{1,12}$ & 6.5 & 2.78 \\
\hline $\mathrm{SO}_{2} 43_{10,34}-44_{9,35}$ & 110363.835 & 6.52 & 1115.1 & 13 & & $\ldots$ \\
\hline $\mathrm{SO}_{2} 31_{3,29}-30_{4,26}$ & 111755.021 & 2.42 & 476.9 & 111756.4 & 5.3 & 0.49 \\
\hline $\mathrm{SO}_{2} 44_{7,37}-43_{8,36}$ & 111875.546 & 6.95 & 1033.8 & 111876.6 & 6.2 & 0.04 \\
\hline $\mathrm{SO}_{2} 29_{3,27}-28_{4,24}$ & 114565.369 & 2.81 & 421.4 & 114566.5 & 6.0 & 0.75 \\
\hline $\mathrm{SO}_{2} 22_{6,16}-23_{5,19}$ & 115317.555 & 3.24 & 321.1 & 115318.5 & 6.5 & 1.25 \\
\hline $\mathrm{SO}_{2} 42_{10,32}-43_{9,35}$ & 130679.975 & 6.31 & 1075.5 & 130680.5 & 7.8 & 0.04 \\
\hline $\mathrm{SO}_{2} 31_{4,28}-30_{5,25}$ & 130859.427 & 4.49 & 497.0 & 130860.5 & 6.5 & 0.84 \\
\hline $\mathrm{SO}_{2} 12_{1,11}-12_{0,12}$ & 131014.841 & 6.64 & 76.4 & 131015.5 & 7.5 & 12.7 \\
\hline $\mathrm{SO}_{2} 16_{5,11}-17_{4,14}$ & 131274.861 & 2.26 & 186.4 & 131276.4 & 5.5 & 2.89 \\
\hline $\mathrm{SO}_{2} 14_{2,12}-14_{1,13}$ & 132744.832 & 11.7 & 108.1 & 132745.5 & 7.5 & 18.1 \\
\hline $\mathrm{SO}_{2} 8_{2,6}-8_{1,7}$ & 134004.812 & 5.69 & 43.1 & 134005.5 & 7.5 & 17.1 \\
\hline
\end{tabular}

Notes. Emission lines of $\mathrm{SO}_{2}$, its isotopologues, and its vibrationally excited states present in the frequency range of the 30-m Orion KL survey. Column 1 indicates the species and the quantum numbers of the line transition, Col. 2 gives the assumed rest frequencies, Col. 3 the line strength, Col. 4 the energy of the upper level, Col. 5 observed frequency assuming a $v_{\text {LSR }}$ of $9.0 \mathrm{~km} \mathrm{~s}^{-1}$, Col. 6 the observed radial velocities, and Col. 7 the peak line antenna temperature. (1) Blended with $\mathrm{HCOOCH}_{3} v_{t}=1 .{ }^{(2)}$ Blended with $\mathrm{CH}_{2} \mathrm{DCN}$. ${ }^{(3)}$ Blended with $\mathrm{HNCO}$. ${ }^{(4)}$ Blended with $\mathrm{CH}_{3} \mathrm{CH}_{2} \mathrm{CN}$. (5) Blended with $\mathrm{HCOOCH}_{3}$. ${ }^{(6)}$ Blended with $\mathrm{CH}_{3} \mathrm{CH}_{2} \mathrm{CN} v_{13} / v_{21}$. ${ }^{\text {(7) }}$ Blended with $\mathrm{CH}_{3} \mathrm{OCH}_{3}$. ${ }^{(8)}$ Blended with the previous transition. ${ }^{(9)}$ Blended with $\mathrm{g}^{+}-\mathrm{CH}_{3} \mathrm{CH}_{2} \mathrm{OH}$. ${ }^{(10)}$ Blended with $\mathrm{CH}_{3} \mathrm{C}^{15} \mathrm{~N}$. ${ }^{(11)}$ Blended with SiS. ${ }^{(12)}$ Blended with $\mathrm{NH}_{2} \mathrm{CHO}$. ${ }^{(13)} \mathrm{Blended}^{3}$ with $\mathrm{CH}_{3} \mathrm{CN}$. ${ }^{(14)}$ Blended with OCS. ${ }^{(15)}$ Blended with $\mathrm{H}_{2} \mathrm{CO} .{ }^{(16)}$ Blended with $\mathrm{CH}_{3} \mathrm{OH} .{ }^{(17)}$ Blended with U line. ${ }^{(18)}$ Blended with ${ }^{33} \mathrm{SO}_{2} .{ }^{(19)} \mathrm{Blended}$ with $\mathrm{CH}_{3}{ }^{13} \mathrm{CH}_{2} \mathrm{CN}$. ${ }^{(20)}$ Blended with $\mathrm{SO}^{18} \mathrm{O}$. ${ }^{(21)}$ Blended with $\mathrm{S}^{18} \mathrm{O}$. ${ }^{(22)}$ Blended with ${ }^{33} \mathrm{SO} .{ }^{(23)}$ Blended with ${ }^{34} \mathrm{SO}_{2}$. ${ }^{(24)} \mathrm{Blended}^{2}$ with $\mathrm{CH}_{3} \mathrm{CN} v_{8}=1$. ${ }^{(25)}$ Blended with $\mathrm{HC}_{3} \mathrm{~N} v_{7}=2 .{ }^{\left({ }^{26)}\right.}$ Blended with $\mathrm{CH}_{3} \mathrm{CHO}$. ${ }^{(27)}$ Blended with NO. ${ }^{(28)}$ Blended with ${ }^{30} \mathrm{SiO} .{ }^{(29)}$ Blended with NS. ${ }^{(30)} \mathrm{Blended}$ with ${ }^{13} \mathrm{CH}_{3} \mathrm{CH}_{2} \mathrm{CN}$. ${ }^{(31)}$ Blended with ${ }^{13} \mathrm{CH}_{3} \mathrm{OH}$. ${ }^{(32)}$ Blended with $\mathrm{CH}_{2} \mathrm{CHCN}$. ${ }^{(33)}$ Blended with $\mathrm{HC}^{13} \mathrm{CCN}$. ${ }^{(34)}$ Blended with $\left(\mathrm{CH}_{3}\right)_{2} \mathrm{CO} .{ }^{(35)} \mathrm{Blended}$ with $\mathrm{H}_{2} \mathrm{CS}$. ${ }^{(36)}$ Blended with t- $\mathrm{CH}_{3} \mathrm{CH}_{2} \mathrm{OH}$. ${ }^{(37)}$ Blended with $\mathrm{H}^{15} \mathrm{NCO}$. ${ }^{(38)}$ Blended with $\mathrm{HCC}^{13} \mathrm{CN}$. ${ }^{(39)}$ Blended with ${ }^{13} \mathrm{CH}_{3} \mathrm{CN}$. ${ }^{(40)} \mathrm{Blended}^{3}$ with $\mathrm{CH}_{2}{ }^{13} \mathrm{CHCN}$. (41) Blended with $\mathrm{CH}_{3} \mathrm{CH}_{2} \mathrm{C}^{15} \mathrm{~N}$. ${ }^{(42)}$ Blended with $\mathrm{OC}^{33} \mathrm{~S}$. ${ }^{(43)}$ Blended with $\mathrm{CH}_{3} \mathrm{CH}_{2} \mathrm{CN} v_{20}=1$. (44) Blended with SO. ${ }^{(45)}$ Blended with $\mathrm{H}_{2} \mathrm{CCO} .{ }^{(46)}$ Blended with $\mathrm{CCH}$. ${ }^{(47)}$ Blended with $\mathrm{CH}_{2} \mathrm{CHCN} v_{11}=1 .{ }^{(48)}$ Blended with $\mathrm{NH}_{2} \mathrm{CHO}_{12}=1 .{ }^{(49)} \mathrm{Blended}$ with $\mathrm{SO}_{2}$. ${ }^{(50)}$ Blended with $\mathrm{H}_{2} \mathrm{C}^{34} \mathrm{~S}$. ${ }^{(51)}$ Blended with ${ }^{34} \mathrm{SO}$. ${ }^{(52)}$ Blended with $\mathrm{H}^{13} \mathrm{CN} .{ }^{(53)}$ Blended with $\mathrm{H}^{13} \mathrm{COOCH}_{3}$. ${ }^{(54)} \mathrm{Blended}$ with $\mathrm{CH}_{2} \mathrm{CHCN}$ $v_{11}=2$. ${ }^{(55)}$ Blended with $\mathrm{H}_{2}{ }^{13} \mathrm{CS}$. ${ }^{(56)}$ Blended with $\mathrm{HC}_{3} \mathrm{~N}$. ${ }^{(57)}$ Blended with $\mathrm{CH}_{3}{ }^{13} \mathrm{CN}$. ${ }^{(58)}$ Blended with g- $-\mathrm{CH}_{3} \mathrm{CH}_{2} \mathrm{OH}$. ${ }^{(59)} \mathrm{Blended} \mathrm{with} \mathrm{SO}_{2}$ $v_{2}=1 .{ }^{(60)}$ Blended with $\mathrm{CH}_{2} \mathrm{CHCN} v_{15}=1 .{ }^{\left({ }^{(61)}\right.}$ Blended with $\mathrm{H}_{30} \alpha .{ }^{(62)}$ Blended with $\mathrm{HC}_{3} \mathrm{~N} v_{7}=1 .{ }^{(63)}$ Blended with $\mathrm{HN}{ }^{13} \mathrm{CO} .{ }^{(64)} \mathrm{Blended}$ with $\mathrm{H}^{13} \mathrm{CO}^{+}$. ${ }^{(65)}$ Blended with $\mathrm{CS} v=1$. ${ }^{(66)}$ Blended with $\mathrm{HC}_{3} \mathrm{~N} v_{6}=1$. ${ }^{(67)}$ Blended with $\mathrm{H}_{65} \epsilon .^{(68)}$ Blended with $\mathrm{HCOO}^{13} \mathrm{CH}_{3} .{ }^{(69)} \mathrm{Blended}^{(73)}$ with the next transition. ${ }^{(70)}$ Blended with $\mathrm{CH}_{3} \mathrm{CH}_{2}{ }^{13} \mathrm{CN}$. ${ }^{(71)}$ Blended with $\mathrm{HNC}^{18} \mathrm{O}$. ${ }^{(72)}$ Blended with $\mathrm{DCOOCH}_{3}$. ${ }^{(73)} \mathrm{Blended}$ with $\mathrm{CH}_{3} \mathrm{OD}$. ${ }^{(74)}$ Blended with SiO. ${ }^{(75)}$ Blended with $\mathrm{H}^{13} \mathrm{CCCN}$. (76) Blended with SHD. ${ }^{(77)}$ Blended with $\mathrm{c}-\mathrm{C}_{2} \mathrm{H}_{4} \mathrm{O}$. ${ }^{\text {(78) }} \mathrm{Blended}$ with $\mathrm{CH}_{3} \mathrm{OH} v_{t}=1$. ${ }^{(79)}$ Blended with $\mathrm{HCC}^{13} \mathrm{CN} v_{7}=1 .{ }^{(80)}$ Blended with $\mathrm{HC}_{3} \mathrm{CN} v_{7}+v_{6} .{ }^{(81)}$ Blended with $\mathrm{HC}^{18} \mathrm{OOCH}_{3} .{ }^{(82)}$ Blended with $\mathrm{HC}_{3}{ }^{15} \mathrm{~N}$. ${ }^{\left({ }^{83}\right)} \mathrm{Blended}$ with $\mathrm{O}^{13} \mathrm{CS}$. ${ }^{(84)}$ Blended with CO. ${ }^{(85)}$ Blended with $\mathrm{OC}^{34} \mathrm{~S}$. ${ }^{(86)}$ Blended with $\mathrm{c}-\mathrm{C}_{3} \mathrm{H}_{2}$. ${ }^{(87)}$ Blended with $\mathrm{HCOOH} .{ }^{(88)}$ Blended with $\mathrm{C}_{3} \mathrm{~S}$. ${ }^{\left({ }^{(8)}\right)} \mathrm{Blended}$ with $\mathrm{g}^{+}-\mathrm{g}^{-}-\mathrm{CH}_{3} \mathrm{CH}_{2} \mathrm{OH} .{ }^{(90)}$ Blended with ${ }^{13} \mathrm{CH}_{3} \mathrm{CCH}$. ${ }^{(91)}$ Blended with HDCS. 
Table A.9. continued.

\begin{tabular}{|c|c|c|c|c|c|c|}
\hline $\begin{array}{l}\text { Species/Transition } \\
J_{K_{a}, K_{c}}-J_{K_{a}^{\prime}, K_{c}^{\prime}}^{\prime}\end{array}$ & $\begin{array}{r}\text { Predicted } \\
\text { freq. } \\
(\mathrm{MHz})\end{array}$ & $S_{\mathrm{ij}}$ & $\begin{array}{r}E_{\mathrm{u}} \\
(\mathrm{K})\end{array}$ & $\begin{array}{l}\text { Observed } \\
\text { freq. } \\
(\mathrm{MHz})\end{array}$ & $\begin{array}{r}\text { Observed } \\
v_{\text {LSR }} \\
\left(\mathrm{km} \mathrm{s}^{-1}\right)\end{array}$ & $\begin{array}{l}\text { Observed } \\
T_{\mathrm{A}}^{*} \\
(\mathrm{~K})\end{array}$ \\
\hline $\mathrm{SO}_{2} 47_{11,37}-48_{10,38}$ & 134203.832 & 7.08 & 1333.6 & 134205.2 & 5.9 & 0.06 \\
\hline $\mathrm{SO}_{2} 21_{6,16}-22_{5,17}$ & 134943.290 & 3.03 & 300.8 & 134944.5 & 6.3 & 1.69 \\
\hline $\mathrm{SO}_{2} 5_{1,5}-4_{0,4}$ & 135696.017 & 3.13 & 15.7 & 135696.5 & 7.9 & 17.3 \\
\hline $\mathrm{SO}_{2} 34_{5,29}-33_{6,28}$ & 135963.028 & 5.41 & 612.0 & 135964.5 & 5.8 & 0.50 \\
\hline $\mathrm{SO}_{2} 5_{3,3}-6_{2,4}$ & 139355.030 & 0.50 & 35.9 & 139356.4 & 6.1 & 5.14 \\
\hline $\mathrm{SO}_{2} 26_{7,19}-27_{6,22}$ & 139474.500 & 3.80 & 443.0 & 139476.3 & 5.1 & 1.29 \\
\hline $\mathrm{SO}_{2} 6_{2,4}-6_{1,5}$ & 140306.166 & 3.83 & 29.2 & 140307.0 & 7.2 & 14.4 \\
\hline $\mathrm{SO}_{2} 16_{2,14}-16_{1,15}$ & 143057.080 & 13.0 & 137.5 & 143058.8 & 5.4 & 15.4 \\
\hline $\mathrm{SO}_{2} 31_{8,24}-32_{7,25}$ & 143357.818 & 4.57 & 613.1 & $143358.9^{4}$ & 6.7 & 4.27 \\
\hline $\mathrm{SO}_{2} 51_{8,44}-50_{9,41}$ & 145970.266 & 8.08 & 1380.0 & 14 & & 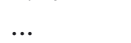 \\
\hline $\mathrm{SO}_{2} 40_{6,34}-39_{7,33}$ & 146393.711 & 6.35 & 846.1 & $146396.4^{7}$ & 3.5 & 0.18 \\
\hline $\mathrm{SO}_{2} 10_{4,6}-11_{3,9}$ & 146550.044 & 1.27 & 89.8 & 146551.3 & 6.4 & 4.02 \\
\hline $\mathrm{SO}_{2} 4_{2,2}-4_{13}$ & 146605.519 & 2.27 & 19.0 & 146606.5 & 7.0 & 10.9 \\
\hline $\mathrm{SO}_{2} 36_{9,27}-37_{8,30}$ & 147239.288 & 5.34 & 811.1 & 147240.2 & 7.1 & 0.14 \\
\hline $\mathrm{SO}_{2} 15_{5,11}-16_{4,12}$ & 150381.071 & 2.04 & 171.7 & 150382.6 & 6.0 & 3.61 \\
\hline $\mathrm{SO}_{2} 41_{6,36}-40_{7,33}$ & 150486.942 & 6.45 & 883.4 & 15 & $\cdots$ & \\
\hline $\mathrm{SO}_{2} 41_{10,32}-42_{9,33}$ & 150878.808 & 6.10 & 1036.8 & 16 & $\ldots$ & $\ldots$ \\
\hline $\mathrm{SO}_{2} 2_{2,0}-2_{11}$ & 151378.663 & 0.87 & 12.6 & 151380.1 & 6.2 & 7.98 \\
\hline $\mathrm{SO}_{2} 43_{4,40}-42_{5,37}$ & 153677.158 & 2.50 & 909.7 & 5 & & \\
\hline $\mathrm{SO}_{2} 46_{11.35}-47_{10,38}$ & 154373.328 & 6.87 & 1290.3 & $154367.6^{17}$ & 20.1 & 0.09 \\
\hline $\mathrm{SO}_{2} 20_{6,14}-21_{5,17}$ & 155389.625 & 2.81 & 281.4 & 155391.4 & 5.6 & 3.29 \\
\hline $\mathrm{SO}_{2} 33_{4,30}-32,5,27$ & 157135.255 & 4.47 & 556.9 & 157137.7 & 4.3 & 1.00 \\
\hline $\mathrm{SO}_{2} 3_{2,2}-3_{1,3}$ & 158199.781 & 1.44 & 15.3 & 158201.4 & 5.9 & 13.4 \\
\hline $\mathrm{SO}_{2} 46_{7,39}-45_{8,38}$ & 158845.079 & 7.30 & 1118.3 & $158846.5^{18}$ & 6.3 & 0.17 \\
\hline $\mathrm{SO}_{2} 25_{7,19}-26_{6,20}$ & 159447.934 & 3.58 & 419.1 & 159450.1 & 4.9 & 1.56 \\
\hline $\mathrm{SO}_{2} 18_{2,16}-18_{1,17}$ & 160342.971 & 13.6 & 170.8 & 160343.9 & 7.3 & 16.4 \\
\hline $\mathrm{SO}_{2} 4_{3,1}-5_{2,4}$ & 160543.024 & 0.30 & 31.3 & 160543.6 & 7.9 & 3.96 \\
\hline $\mathrm{SO}_{2} 10_{0,10}-9_{1,9}$ & 160827.841 & 6.43 & 49.7 & 160828.5 & 7.8 & 26.3 \\
\hline $\mathrm{SO}_{2} 18_{2,16}-17_{3,15}$ & 163119.379 & 3.72 & 170.8 & 163121.4 & 5.3 & 11.1 \\
\hline $\mathrm{SO}_{2} 30_{8,22}-31_{7,25}$ & 163567.675 & 4.35 & 584.6 & 163569.5 & 5.7 & 0.73 \\
\hline $\mathrm{SO}_{2} 14_{1,13}-14_{0,14}$ & 163605.533 & 6.41 & 101.8 & 163606.5 & 7.2 & 18.5 \\
\hline $\mathrm{SO}_{2} 37_{5,33}-36_{6,30}$ & 163924.734 & 5.63 & 710.8 & 5 & 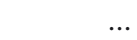 & $\ldots$ \\
\hline $\mathrm{SO}_{2} 9_{4,6}-10_{3,7}$ & 165123.634 & 1.05 & 80.6 & 165125.2 & 6.2 & 7.24 \\
\hline $\mathrm{SO}_{2} 5_{2,4}-5_{1,5}$ & 165144.652 & 2.46 & 23.6 & 165145.7 & 7.1 & 17.7 \\
\hline $\mathrm{SO}_{2} 7_{1,7}-6_{0,6}$ & 165225.452 & 4.43 & 27.1 & 165226.4 & 7.3 & 25.3 \\
\hline $\mathrm{SO}_{2} 44_{4,40}-45_{3,43}$ & 166387.129 & 0.66 & 969.1 & 1 & $\ldots$ & $\ldots$ \\
\hline $\mathrm{SO}_{2} 35_{9,27}-36_{8,28}$ & 167367.348 & 5.12 & 777.9 & 167368.9 & 6.2 & 0.27 \\
\hline $\mathrm{SO}_{2} 24_{2,22}-25_{1,25}$ & 168790.063 & 0.18 & 292.8 & 1,5 & $\ldots$ & $\ldots$ \\
\hline $\mathrm{SO}_{2} 34_{3,31}-35_{2,34}$ & 170293.819 & 0.41 & 581.9 & 4 & $\ldots$ & $\ldots$ \\
\hline $\mathrm{SO}_{2} 14_{5,9}-15_{4,12}$ & 170754.546 & 1.82 & 157.9 & 170756.5 & 5.6 & 4.99 \\
\hline $\mathrm{SO}_{2} 40_{10,30}-41_{9,33}$ & 171018.058 & 5.89 & 999.0 & 4 & 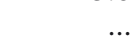 & $\ldots$ \\
\hline $\mathrm{SO}_{2} 47_{7,41}-46_{8,38}$ & 171036.705 & 7.43 & 1161.5 & $171038.9^{5,19}$ & 5.2 & 0.29 \\
\hline $\mathrm{SO}_{2} 19_{6,14}-20_{5,15}$ & 175101.318 & 2.59 & 263.0 & 175103.9 & 4.6 & 4.34 \\
\hline $\mathrm{SO}_{2} 7_{2,6}-7_{1,7}$ & 175275.722 & 3.30 & 35.5 & 175277.6 & 5.8 & 18.2 \\
\hline $\mathrm{SO}_{2} 41_{4,38}-40_{5,35}$ & 176295.902 & 3.01 & 832.2 & $176297.6^{5}$ & 6.1 & 0.43 \\
\hline $\mathrm{SO}_{2} 35_{4,32}-34_{5,29}$ & 176466.255 & 4.30 & 620.4 & 176468.9 & 4.5 & 1.42 \\
\hline $\mathrm{SO}_{2} 20_{3,17}-20_{2,18}$ & 197142.060 & 15.4 & 217.2 & $197144.9^{4}$ & 4.7 & 14.4 \\
\hline $\mathrm{SO}_{2} 39_{5,35}-38_{6,32}$ & 197585.319 & 5.74 & 782.1 & 4 & & ... \\
\hline $\mathrm{SO}_{2} 49_{12,38}-50_{11,39}$ & 197709.365 & 7.21 & 1478.6 & $197711.0^{6}$ & 6.5 & 0.10 \\
\hline $\mathrm{SO}_{2} 42_{6,36}-41_{7,35}$ & 198847.847 & 6.67 & 923.6 & 6 & & \\
\hline $\mathrm{SO}_{2} 23_{7,17}-24_{6,18}$ & 199415.871 & 3.15 & 373.9 & 199418.6 & 4.9 & 2.25 \\
\hline $\mathrm{SO}_{2} 24_{3,21}-24_{2,22}$ & 200287.422 & 19.4 & 302.4 & 200289.9 & 5.3 & 8.35 \\
\hline $\mathrm{SO}_{2} 16_{1,15}-16_{0,16}$ & 200809.321 & 6.17 & 130.7 & 200811.2 & 6.2 & 11.4 \\
\hline $\mathrm{SO}_{2} 12_{0,12}-11_{1,11}$ & 203391.484 & 8.43 & 70.1 & 203391.9 & 8.4 & 17.5 \\
\hline $\mathrm{SO}_{2} 28_{8,20}-29_{7,23}$ & 203570.093 & 3.92 & 530.2 & $203570.6^{7}$ & 8.3 & 2.02 \\
\hline $\mathrm{SO}_{2} 18_{3,15}-18_{2,16}$ & 204246.762 & 13.0 & 180.6 & 204249.4 & 5.1 & 13.9 \\
\hline $\mathrm{SO}_{2} 7_{4,4}-8_{3,5}$ & 204384.191 & 0.63 & 65.0 & $204387.0^{21}$ & 4.9 & 5.43 \\
\hline $\mathrm{SO}_{2} 11_{2,10}-11_{1,11}$ & 205300.539 & 4.55 & 70.2 & 205302.3 & 6.4 & 17.7 \\
\hline $\mathrm{SO}_{2} 33_{9,25}-34_{8,26}$ & 207421.450 & 4.69 & 714.3 & 5,6 & $\ldots$ & $\ldots$ \\
\hline $\mathrm{SO}_{2} 48_{7,41}-47_{8,40}$ & 208302.827 & 7.63 & 1206.7 & 2 & $\ldots$ & $\ldots$ \\
\hline \multirow[t]{3}{*}{$\mathrm{SO}_{2} 3_{2,2}-2_{1,1}$} & 208700.337 & 1.67 & 15.3 & two peaks: & $\ldots$ & \\
\hline & & & & 208692.4 & 20.4 & 10.3 \\
\hline & & & & 208702.4 & 6.0 & 16.5 \\
\hline $\mathrm{SO}_{2} 53_{5,49}-52_{6,46}$ & 209874.382 & 2.96 & 1381.3 & 5 & $\ldots$ & $\ldots$ \\
\hline
\end{tabular}


Table A.9. continued.

\begin{tabular}{|c|c|c|c|c|c|c|}
\hline $\begin{array}{l}\text { Species/Transition } \\
J_{K_{a}, K_{c}}-J_{K_{a}^{\prime}, K_{c}^{\prime}}^{\prime}\end{array}$ & $\begin{array}{r}\text { Predicted } \\
\text { freq. } \\
(\mathrm{MHz})\end{array}$ & $S_{\mathrm{ij}}$ & $\begin{array}{r}E_{\mathrm{u}} \\
(\mathrm{K})\end{array}$ & $\begin{array}{l}\text { Observed } \\
\text { freq. } \\
(\mathrm{MHz})\end{array}$ & $\begin{array}{r}\text { Observed } \\
v_{\mathrm{LSR}} \\
\left(\mathrm{km} \mathrm{s}^{-1}\right) \\
\end{array}$ & $\begin{array}{l}\text { Observed } \\
T_{\mathrm{A}}^{*} \\
(\mathrm{~K}) \\
\end{array}$ \\
\hline $\mathrm{SO}_{2} 12_{5,7}-13_{4,10}$ & 209936.041 & 1.39 & 133.0 & 209938.7 & 5.2 & 5.51 \\
\hline $\mathrm{SO}_{2} 38_{10,28}-39_{9,31}$ & 211053.096 & 5.46 & 926.3 & 211054.6 & 6.9 & 0.08 \\
\hline $\mathrm{SO}_{2} 26_{3,23}-26_{2,24}$ & 213068.427 & 20.4 & 350.8 & $213071.1^{22}$ & 5.2 & 11.0 \\
\hline $\mathrm{SO}_{2} 49_{7,43}-48_{8,40}$ & 213703.045 & 7.72 & 1251.5 & & & $\ldots$ \\
\hline $\mathrm{SO}_{2} 43_{11,33}-44_{10,34}$ & 214451.816 & 6.23 & 1166.0 & $214454.9^{17}$ & 4.7 & 0.11 \\
\hline $\mathrm{SO}_{2} 16_{3,13}-16_{2,14}$ & 214689.395 & 10.6 & 147.8 & 214692.3 & 4.9 & 13.6 \\
\hline $\mathrm{SO}_{2} 17_{6,12}-18_{5,13}$ & 214728.280 & 2.16 & 229.0 & 214731.2 & 4.9 & 4.52 \\
\hline $\mathrm{SO}_{2} 26_{2,24}-27_{1,27}$ & 215094.516 & 0.15 & 340.6 & 4 & $\ldots$ & $\ldots$ \\
\hline \multirow{3}{*}{$\mathrm{SO}_{2} 22_{2,20}-22_{1,21}$} & 216643.304 & 13.2 & 248.5 & two peaks: & $\ldots$ & \\
\hline & & & & 216636.1 & 19.0 & 4.49 \\
\hline & & & & 216646.1 & 5.1 & 10.3 \\
\hline $\mathrm{SO}_{2} 22_{7,15}-23_{6,18}$ & 219275.970 & 2.93 & 352.8 & 219278.6 & 5.4 & 3.05 \\
\hline $\mathrm{SO}_{2} 11_{1,11}-10_{0,10}$ & 221965.221 & 7.71 & 60.4 & 221967.4 & 6.1 & 44.2 \\
\hline $\mathrm{SO}_{2} 36_{3,33}-37_{2,36}$ & 222869.135 & 0.36 & 648.6 & 222871.2 & 6.2 & 0.09 \\
\hline $\mathrm{SO}_{2} 27_{8,20}-28_{7,21}$ & 223434.487 & 3.70 & 504.4 & 223436.4 & 6.4 & 1.29 \\
\hline $\mathrm{SO}_{2} 6_{4,2}-7_{3,5}$ & 223883.568 & 0.43 & 58.6 & 223886.2 & 5.5 & 5.57 \\
\hline $\mathrm{SO}_{2} 20_{2,18}-19_{3,17}$ & 224264.815 & 4.62 & 207.8 & 224267.3 & 5.7 & 12.7 \\
\hline $\mathrm{SO}_{2} 46_{4,42}-47_{3,45}$ & 224473.442 & 0.59 & 1054.6 & 4 & $\ldots$ & $\ldots$ \\
\hline \multirow[t]{3}{*}{$\mathrm{SO}_{2} 13_{2,12}-13_{1,13}$} & 225153.705 & 4.97 & 93.0 & two peaks: & $\ldots$ & \\
\hline & & & & 225146.2 & 19.0 & 8.47 \\
\hline & & & & 225156.1 & 5.8 & 16.2 \\
\hline $\mathrm{SO}_{2} 14_{3,11}-14_{2,12}$ & 226300.028 & 8.61 & 119.0 & 226302.2 & 6.1 & 21.6 \\
\hline $\mathrm{SO}_{2} 41_{5,37}-40_{6,34}$ & 226508.309 & 5.72 & 857.0 & 226509.9 & 6.9 & 0.36 \\
\hline $\mathrm{SO}_{2} 32_{9,23}-33_{8,26}$ & 227335.786 & 4.47 & 684.0 & 227337.4 & 6.9 & 0.74 \\
\hline $\mathrm{SO}_{2} 11_{5,7}-12_{4,8}$ & 229347.627 & 1.17 & 122.0 & 229349.9 & 6.0 & 3.10 \\
\hline $\mathrm{SO}_{2} 45_{6,40}-44_{7,37}$ & 229749.763 & 6.89 & 1044.8 & 16 & & 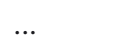 \\
\hline $\mathrm{SO}_{2} 37_{10,28}-38_{9,29}$ & 230965.232 & 5.24 & 891.3 & 230968.5 & 4.8 & 0.15 \\
\hline \multirow[t]{3}{*}{$\mathrm{SO}_{2} 28_{3,25}-28_{2,26}$} & 234187.057 & 20.7 & 403.1 & two peaks: & & \\
\hline & & & & 234185.5 & 11.0 & 1.95 \\
\hline & & & & 234189.5 & 5.9 & 2.33 \\
\hline $\mathrm{SO}_{2} 42_{11,31}-43_{10,34}$ & 234352.997 & 6.01 & 1126.4 & $234357.6^{17}$ & 3.1 & 0.31 \\
\hline $\mathrm{SO}_{2} 16_{6,10}-17_{5,13}$ & 234421.582 & 1.94 & 213.3 & $234426.3^{4}$ & 3.0 & 6.75 \\
\hline \multirow[t]{3}{*}{$\mathrm{SO}_{2} 4_{2,2}-3_{1,3}$} & 235151.721 & 1.71 & 19.0 & two peaks: & & \\
\hline & & & & 235144.5 & 18.2 & 8.85 \\
\hline & & & & 235153.5 & 6.7 & 15.4 \\
\hline $\mathrm{SO}_{2} 16_{1,15}-15_{2,14}$ & 236216.688 & 6.05 & 130.7 & $236219.0^{23}$ & 6.1 & 12.6 \\
\hline \multirow[t]{3}{*}{$\mathrm{SO}_{2} 12_{3,9}-12_{2,10}$} & 237068.834 & 6.90 & 94.0 & two peaks: & $\ldots$ & \\
\hline & & & & 237061.0 & 18.9 & 8.51 \\
\hline & & & & 237071.5 & 5.6 & 14.1 \\
\hline $\mathrm{SO}_{2} 47_{12,36}-48_{11,37}$ & 237501.891 & 6.78 & 1389.2 & & & \\
\hline $\mathrm{SO}_{2} 17_{3,15}-18_{0,18}$ & 238166.384 & 0.12 & 162.9 & 238169.5 & 5.1 & 0.55 \\
\hline \multirow[t]{3}{*}{$\mathrm{SO}_{2} 21_{7,15}-22_{6,16}$} & 238992.525 & 2.71 & 332.5 & two peaks: & & \\
\hline & & & & 238989.5 & 12.8 & 1.79 \\
\hline & & & & 238995.5 & 5.3 & 3.53 \\
\hline $\mathrm{SO}_{2} 15_{3,13}-16_{0,16}$ & 239832.819 & 0.10 & 132.5 & 24 & $\cdots$ & $\ldots$ \\
\hline \multirow[t]{3}{*}{$\mathrm{SO}_{2} 18_{1,17}-18_{0,18}$} & 240942.792 & 5.99 & 163.1 & two peaks: & $\ldots$ & \\
\hline & & & & 240940.0 & 12.5 & 10.3 \\
\hline & & & & 240946.1 & 4.9 & 11.5 \\
\hline $\mathrm{SO}_{2} 51_{5,47}-50_{6,44}$ & 241044.688 & 3.54 & 1285.2 & & $\cdots$ & $\ldots$ \\
\hline \multirow{3}{*}{$\mathrm{SO}_{2} 5_{2,4}-4_{1,3}$} & 241615.798 & 2.12 & 23.6 & two peaks: & & \\
\hline & & & & 241608.0 & 18.7 & 12.9 \\
\hline & & & & $241620.5^{3,4}$ & 3.2 & 20.3 \\
\hline $\mathrm{SO}_{2} 19_{3,17}-20_{0,20}$ & 242997.814 & 0.13 & 197.0 & 243000.5 & 5.7 & 1.06 \\
\hline $\mathrm{SO}_{2} 5_{4,2}-6_{3,3}$ & 243087.646 & 0.25 & 53.1 & 243090.2 & 5.9 & 2.91 \\
\hline $\mathrm{SO}_{2} 26_{8,18}-27_{7,21}$ & 243245.422 & 3.48 & 479.6 & 243248.9 & 4.7 & 1.01 \\
\hline \multirow[t]{3}{*}{$\mathrm{SO}_{2} 14_{0,14}-13_{1,13}$} & 244254.220 & 10.5 & 93.9 & two peaks: & $\ldots$ & \\
\hline & & & & 244245.2 & 20.1 & 15.3 \\
\hline & & & & 244256.4 & 6.3 & 24.6 \\
\hline $\mathrm{SO}_{2} 26_{3,23}-25_{4,22}$ & 245339.234 & 4.86 & 350.8 & 245342.6 & 4.9 & 6.56 \\
\hline $\mathrm{SO}_{2} 10_{3,7}-10_{2,8}$ & 245563.423 & 5.44 & 72.7 & 245565.5 & 6.5 & 18.6 \\
\hline $\mathrm{SO}_{2} 31_{9,23}-32_{8,24}$ & 247169.754 & 4.25 & 654.5 & 16,25 & & $\ldots$ \\
\hline $\mathrm{SO}_{2} 15_{2,14}-15_{1,15}$ & 248057.403 & 5.27 & 119.3 & 248060.1 & 5.7 & 18.2 \\
\hline $\mathrm{SO}_{2} 13_{3,11}-14_{0,14}$ & 248436.938 & 0.74 & 105.8 & $248440.2^{4,21}$ & 5.1 & 2.44 \\
\hline $\mathrm{SO}_{2} 10_{5,5}-11_{4,8}$ & 248830.822 & 0.96 & 111.9 & 248833.5 & 5.8 & 8.35 \\
\hline
\end{tabular}


Table A.9. continued.

\begin{tabular}{|c|c|c|c|c|c|c|}
\hline $\begin{array}{l}\text { Species/Transition } \\
J_{K_{a}, K_{c}}-J_{K_{a}^{\prime}, K_{c}^{\prime}}^{\prime}\end{array}$ & $\begin{array}{r}\text { Predicted } \\
\text { freq. } \\
(\mathrm{MHz}) \\
\end{array}$ & $S_{\mathrm{ij}}$ & $\begin{array}{c}E_{\mathrm{u}} \\
(\mathrm{K})\end{array}$ & $\begin{array}{l}\text { Observed } \\
\text { freq. } \\
(\mathrm{MHz})\end{array}$ & $\begin{array}{r}\text { Observed } \\
v_{\mathrm{LSR}} \\
\left(\mathrm{km} \mathrm{s}^{-1}\right) \\
\end{array}$ & $\begin{array}{l}\text { Observed } \\
T_{\mathrm{A}}^{*} \\
(\mathrm{~K}) \\
\end{array}$ \\
\hline $\mathrm{SO}_{2} 43_{5,39}-42_{6,36}$ & 248995.137 & 5.54 & 935.6 & 248997.5 & 6.2 & 0.45 \\
\hline $\mathrm{SO}_{2} 36_{10,26}-37_{9,29}$ & 250816.770 & 5.03 & 857.2 & & & \\
\hline $\mathrm{SO}_{2} 13_{1,13}-12_{0,12}$ & 251199.676 & 9.63 & 82.2 & 251201.3 & 7.1 & 29.9 \\
\hline $\mathrm{SO}_{2} 8_{3,5}-8_{2,6}$ & 251210.586 & 4.14 & 55.2 & & & \\
\hline $\mathrm{SO}_{2} 32_{4,28}-31_{5,27}$ & 252563.897 & 5.37 & 531.1 & 252566.4 & 6.0 & 2.03 \\
\hline $\mathrm{SO}_{2} 21_{3,19}-22_{0,22}$ & 253753.446 & 0.14 & 234.7 & $253757.4^{16}$ & 4.3 & 12.8 \\
\hline $\mathrm{SO}_{2} 38_{5,33}-37_{6,32}$ & 253935.893 & 6.11 & 749.1 & $253940.0^{23}$ & 4.2 & 3.63 \\
\hline $\mathrm{SO}_{2} 15_{6,10}-16_{5,11}$ & 253956.563 & 1.72 & 198.6 & 253959.6 & 5.4 & 6.22 \\
\hline $\mathrm{SO}_{2} 41_{11,31}-42_{10,32}$ & 254194.858 & 5.80 & 1087.7 & 28 & & \\
\hline $\mathrm{SO}_{2} 6_{3,3}-6_{2,4}$ & 254280.537 & 2.89 & 41.4 & $254282.7^{23}$ & 6.5 & 28.1 \\
\hline $\mathrm{SO}_{2} 24_{2,22}-24_{1,23}$ & 254283.322 & 12.7 & 292.8 & & & \\
\hline $\mathrm{SO}_{2} 4_{3,1}-4_{2,2}$ & 255553.303 & 1.61 & 31.3 & 255554.5 & 7.6 & 17.5 \\
\hline $\mathrm{SO}_{2} 51_{7,45}-50_{8,42}$ & 255595.369 & 7.97 & 1345.2 & & $\cdots$ & $\ldots$ \\
\hline $\mathrm{SO}_{2} 44_{6,38}-43_{7,37}$ & 255818.422 & 6.99 & 1005.1 & 255819.5 & 7.7 & 0.21 \\
\hline $\mathrm{SO}_{2} 3_{3,1}-3_{2,2}$ & 255958.045 & 0.89 & 27.6 & 255959.6 & 7.2 & 13.8 \\
\hline $\mathrm{SO}_{2} 5_{3,3}-5_{2,4}$ & 256246.946 & 2.26 & 35.9 & 256248.3 & 7.4 & 19.6 \\
\hline $\mathrm{SO}_{2} 7_{3,5}-7_{2,6}$ & 257099.967 & 3.48 & 47.8 & 257101.3 & 7.4 & 31.2 \\
\hline $\mathrm{SO}_{2} 46_{12,34}-47_{11,37}$ & 257318.855 & 6.57 & 1346.0 & 4 & & \\
\hline $\mathrm{SO}_{2} 32_{4,28}-32_{3,29}$ & 258388.714 & 25.5 & 531.1 & 258391.4 & 5.9 & 2.08 \\
\hline $\mathrm{SO}_{2} 20_{7,13}-21_{6,16}$ & 258666.959 & 2.49 & 313.2 & 258669.5 & 6.1 & 1.57 \\
\hline $\mathrm{SO}_{2} 9_{3,7}-9_{2,8}$ & 258942.200 & 4.65 & 63.5 & 258943.4 & 7.6 & 9.56 \\
\hline $\mathrm{SO}_{2} 30_{4,26}-30_{3,27}$ & 259599.446 & 23.3 & 471.5 & 259602.5 & 5.5 & 3.25 \\
\hline $\mathrm{SO}_{2} 49_{5,45}-48_{6,42}$ & 260269.339 & 4.15 & 1192.5 & 6 & $\ldots$ & $\ldots$ \\
\hline $\mathrm{SO}_{2} 50_{7,43}-49_{8,42}$ & 261062.785 & 7.93 & 1299.0 & 16 & $\ldots$ & $\ldots$ \\
\hline $\mathrm{SO}_{2} 27_{4,24}-28_{1,27}$ & 261091.176 & 0.31 & 388.0 & $261096.4^{5}$ & 3.0 & 0.89 \\
\hline $\mathrm{SO}_{2} 11_{3,9}-11_{2,10}$ & 262256.907 & 5.78 & 82.8 & 262258.9 & 6.7 & 26.1 \\
\hline $\mathrm{SO}_{2} 4_{4,0}-5_{3,3}$ & 262333.965 & 0.10 & 48.5 & 262341.4 & 0.5 & 2.17 \\
\hline $\mathrm{SO}_{2} 28_{2,26}-29_{1,29}$ & 262524.931 & 0.13 & 391.8 & $262528.8^{30}$ & 4.6 & 0.27 \\
\hline $\mathrm{SO}_{2} 25_{8,18}-26_{7,19}$ & 262969.717 & 3.26 & 455.6 & 262972.5 & 5.8 & 1.09 \\
\hline $\mathrm{SO}_{2} 45_{5,41}-44_{6,38}$ & 263216.484 & 5.21 & 1017.7 & 263218.9 & 6.3 & 0.20 \\
\hline $\mathrm{SO}_{2} 30_{3,27}-30_{2,28}$ & 263543.954 & 20.3 & 459.1 & $263546.4^{12}$ & 6.2 & 3.99 \\
\hline $\mathrm{SO}_{2} 25_{4,22}-26_{1,25}$ & 263897.868 & 0.28 & 339.0 & 263900.5 & 6.0 & 0.35 \\
\hline $\mathrm{SO}_{2} 11_{3,9}-12_{0,12}$ & 264165.962 & 0.04 & 82.8 & 264171.5 & 2.7 & 1.18 \\
\hline $\mathrm{SO}_{2} 29_{4,26}-30_{1,29}$ & 265461.469 & 0.33 & 440.7 & $265465.1^{25}$ & 4.9 & 0.54 \\
\hline $\mathrm{SO}_{2} 34_{4,30}-34_{3,31}$ & 265481.970 & 27.1 & 594.7 & $265485.1^{4,23}$ & 5.5 & 1.93 \\
\hline $\mathrm{SO}_{2} 47_{6,42}-46_{7,39}$ & 265608.359 & 6.99 & 1131.1 & 265610.6 & 6.5 & 0.20 \\
\hline $\mathrm{SO}_{2} 30_{9,21}-31_{8,24}$ & 266943.308 & 4.04 & 625.9 & $266944.5^{32}$ & 7.7 & 1.05 \\
\hline $\mathrm{SO}_{2} 47_{5,43}-46_{6,40}$ & 267428.351 & 4.73 & 1103.4 & $267433.8^{10}$ & 2.9 & 0.11 \\
\hline $\mathrm{SO}_{2} 13_{3,11}-13_{2,12}$ & 267537.453 & 6.87 & 105.8 & 267538.5 & 7.8 & 13.1 \\
\hline $\mathrm{SO}_{2} 28_{4,24}-28_{3,25}$ & 267719.839 & 20.6 & 415.9 & 267723.5 & 4.9 & 4.24 \\
\hline \multirow[t]{3}{*}{$\mathrm{SO}_{2} 9_{5,5}-10_{4,6}$} & 268168.331 & 0.76 & 102.7 & two peaks: & $\ldots$ & \\
\hline & & & & 268165.1 & 12.6 & 2.75 \\
\hline & & & & 268171.4 & 5.6 & 4.36 \\
\hline $\mathrm{SO}_{2} 23_{3,21}-24_{0,24}$ & 269786.414 & 0.14 & 276.0 & 269789.5 & 5.6 & 0.78 \\
\hline $\mathrm{SO}_{2} 35_{10,26}-36_{9,27}$ & 270605.490 & 4.81 & 824.1 & 270608.5 & 5.7 & 0.24 \\
\hline $\mathrm{SO}_{2} 7_{2,6}-6_{1,5}$ & 271529.016 & 2.67 & 35.5 & 271530.1 & 7.8 & 24.5 \\
\hline $\mathrm{SO}_{2} 37_{5,33}-38_{2,36}$ & 271726.167 & 0.53 & 710.8 & 33 & & \\
\hline $\mathrm{SO}_{2} 14_{6,8}-15_{5,11}$ & 273462.663 & 1.51 & 184.8 & 273466.4 & 4.9 & 3.12 \\
\hline \multirow[t]{3}{*}{$\mathrm{SO}_{2} 17_{2,16}-17_{1,17}$} & 273752.962 & 5.48 & 149.2 & two peaks: & & \\
\hline & & & & 273744.5 & 18.3 & 5.64 \\
\hline & & & & 273754.5 & 7.3 & 8.77 \\
\hline $\mathrm{SO}_{2} 40_{11,29}-41_{10,32}$ & 273982.611 & 5.58 & 1050.0 & $273981.5^{4}$ & 10.2 & 0.51 \\
\hline $\mathrm{SO}_{2} 47_{6,42}-48_{3,45}$ & 274075.204 & 0.79 & 1131.1 & 34 & $\ldots$ & $\cdots$ \\
\hline $\mathrm{SO}_{2} 35_{5,31}-36_{2,34}$ & 274521.579 & 0.49 & 643.1 & $274522.6^{6,35}$ & 7.9 & 3.12 \\
\hline $\mathrm{SO}_{2} 23_{4,20}-24_{1,23}$ & 274525.462 & 0.23 & 293.7 & & $\ldots$ & $\ldots$ \\
\hline $\mathrm{SO}_{2} 15_{3,13}-15_{2,14}$ & 275240.185 & 7.88 & 132.5 & 275242.6 & 6.4 & 21.6 \\
\hline $\mathrm{SO}_{2} 38_{3,35}-39_{2,38}$ & 275375.696 & 0.32 & 718.7 & 7,13 & & \\
\hline $\mathrm{SO}_{2} 31_{4,28}-32_{1,31}$ & 276254.571 & 0.33 & 497.0 & 276257.6 & 5.7 & 0.70 \\
\hline $\mathrm{SO}_{2} 45_{6,40}-46_{3,43}$ & 276301.223 & 0.74 & 1044.8 & 1 & $\ldots$ & $\ldots$ \\
\hline $\mathrm{SO}_{2} 39_{5,35}-40_{2,38}$ & 276558.354 & 0.56 & 782.1 & 12,36 & $\ldots$ & $\ldots$ \\
\hline $\mathrm{SO}_{2} 39_{5,35}-40_{2,38}$ & 276558.354 & 0.56 & 782.1 & 12,36 & $\ldots$ & $\ldots$ \\
\hline $\mathrm{SO}_{2} 45_{12,34}-46_{11,35}$ & 277085.908 & 6.35 & 1303.6 & 9,37 & $\ldots$ & $\ldots$ \\
\hline $\mathrm{SO}_{2} 19_{7,13}-20_{6,14}$ & 278250.961 & 2.27 & 294.8 & $278255.1^{4}$ & 4.5 & 7.82 \\
\hline
\end{tabular}


Table A.9. continued.

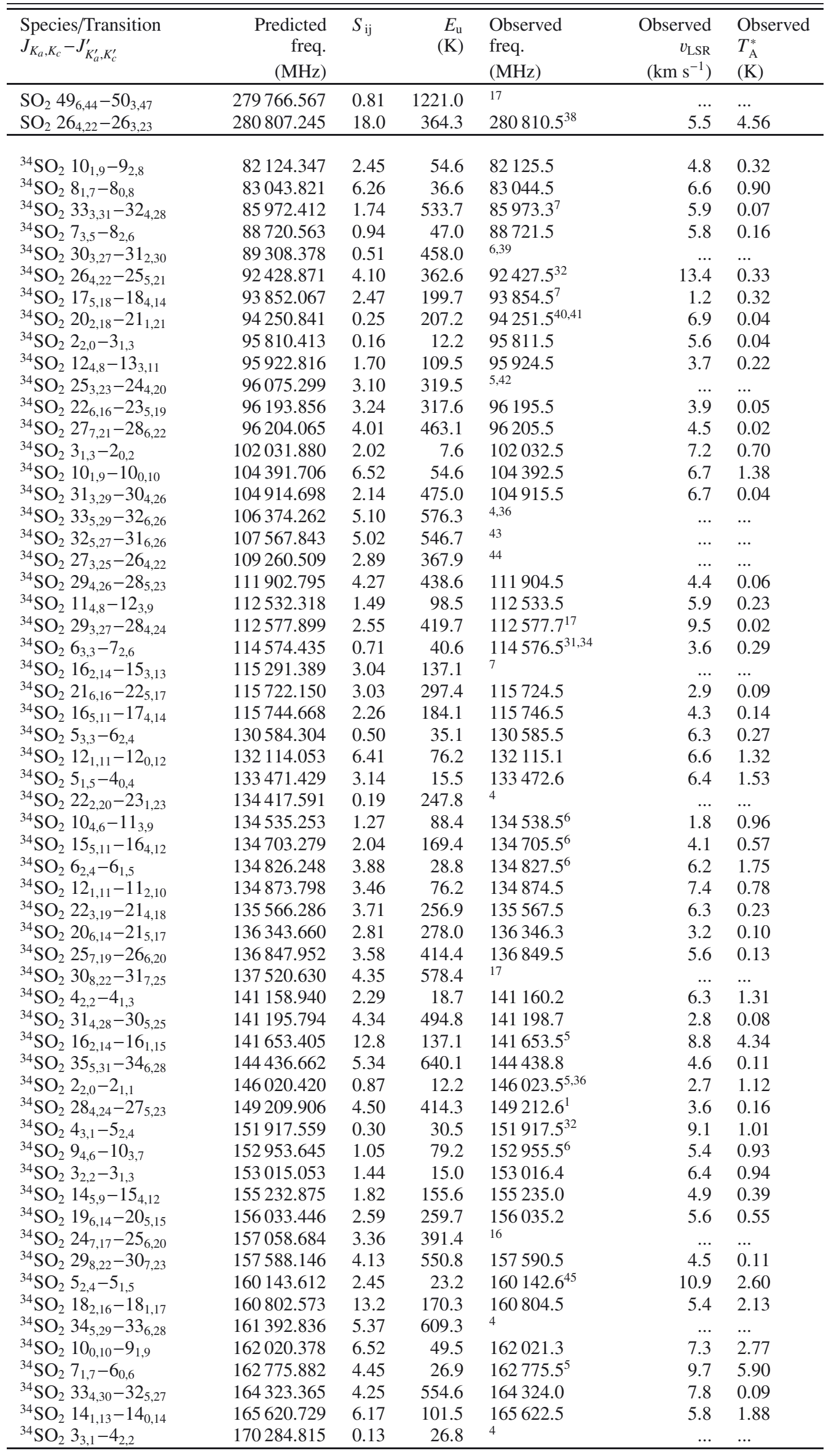


Table A.9. continued.

\begin{tabular}{|c|c|c|c|c|c|c|}
\hline $\begin{array}{l}\text { Species/Transition } \\
J_{K_{a}, K_{c}}-J_{K_{a}^{\prime}, K_{c}^{\prime}}^{\prime}\end{array}$ & $\begin{array}{r}\text { Predicted } \\
\text { freq. } \\
(\mathrm{MHz})\end{array}$ & $S_{\mathrm{ij}}$ & $\begin{array}{r}E_{\mathrm{u}} \\
(\mathrm{K})\end{array}$ & $\begin{array}{l}\text { Observed } \\
\text { freq. } \\
(\mathrm{MHz})\end{array}$ & $\begin{array}{r}\text { Observed } \\
v_{\mathrm{LSR}} \\
\left(\mathrm{km} \mathrm{s}^{-1}\right)\end{array}$ & $\begin{array}{l}\text { Observed } \\
T_{\mathrm{A}}^{*} \\
(\mathrm{~K})\end{array}$ \\
\hline${ }^{34} \mathrm{SO}_{2} 7_{2,6}-7_{1,7}$ & 170546.952 & 3.29 & 35.1 & $170548.9^{6}$ & 5.6 & 2.29 \\
\hline${ }^{34} \mathrm{SO}_{2} 8_{4,4}-9_{3,7}$ & 173207.298 & 0.84 & 70.9 & 173210.2 & 4.0 & 0.63 \\
\hline${ }^{34} \mathrm{SO}_{2} 13_{5,9}-14_{4,10}$ & 174576.459 & 1.60 & 142.7 & & $\ldots$ & $\ldots$ \\
\hline${ }^{34} \mathrm{SO}_{2} 18_{2,16}-17_{3,15}$ & 174850.251 & 3.81 & 170.3 & $174851.5^{5,46}$ & 6.9 & 1.45 \\
\hline${ }^{34} \mathrm{SO}_{2} 18_{6,12}-19_{5,15}$ & 176093.351 & 2.37 & 242.2 & 176096.4 & 3.8 & 0.74 \\
\hline${ }^{34} \mathrm{SO}_{2} 23_{7,17}-24_{6,18}$ & 176940.267 & 3.15 & 369.3 & 176944.5 & 1.8 & 0.54 \\
\hline${ }^{34} \mathrm{SO}_{2} 28_{8,20}-29_{7,23}$ & 177647.037 & 3.92 & 524.1 & 177648.5 & 6.5 & 0.45 \\
\hline${ }^{34} \mathrm{SO}_{2} 22_{7,15}-23_{6,18}$ & 196854.461 & 2.93 & 348.2 & 196856.1 & 6.5 & 0.22 \\
\hline${ }^{34} \mathrm{SO}_{2} 24_{3,21}-24_{2,22}$ & 197044.107 & 19.3 & 301.5 & $197046.1^{4,6}$ & 6.0 & 1.20 \\
\hline${ }^{34} \mathrm{SO}_{2} 27_{8,20}-28_{7,21}$ & 197555.307 & 3.70 & 498.4 & 4 & $\ldots$ & $\ldots$ \\
\hline${ }^{34} \mathrm{SO}_{2} 32_{9,23}-33_{8,26}$ & 198018.213 & 4.47 & 676.2 & 5 & $\ldots$ & $\ldots$ \\
\hline${ }^{34} \mathrm{SO}_{2} 24_{3,21}-23_{4,20}$ & 198348.517 & 4.28 & 301.5 & 198351.1 & 5.1 & 0.29 \\
\hline${ }^{34} \mathrm{SO}_{2} 11_{2,11}-11_{1,11}$ & 201376.485 & 4.50 & 69.7 & 201379.9 & 3.9 & 2.14 \\
\hline${ }^{34} \mathrm{SO}_{2} 3_{2,3}-3_{1,1}$ & 203225.060 & 1.67 & 15.0 & 203226.9 & 6.3 & 1.01 \\
\hline${ }^{34} \mathrm{SO}_{2} 16_{1,15}-16_{0,16}$ & 203504.216 & 5.93 & 130.3 & 203506.9 & 5.0 & 1.22 \\
\hline${ }^{34} \mathrm{SO}_{2} 12_{0,12}-11_{1,11}$ & 204136.230 & 8.54 & 69.9 & 204138.2 & 6.1 & 4.03 \\
\hline${ }^{34} \mathrm{SO}_{2} 16_{3,13}-16_{2,14}$ & 204525.183 & 10.9 & 146.9 & $204525.6^{7}$ & 8.4 & 2.71 \\
\hline${ }^{34} \mathrm{SO}_{2} 39_{5,35}-38_{6,32}$ & 210817.577 & 5.53 & 778.8 & 5 & $\ldots$ & $\ldots$ \\
\hline${ }^{34} \mathrm{SO}_{2} 30_{4,26}-29_{5,25}$ & 211418.824 & 4.92 & 469.9 & $211419.9^{1}$ & 7.5 & 0.13 \\
\hline${ }^{34} \mathrm{SO}_{2} 6_{4,2}-7_{3,5}$ & 211762.760 & 0.43 & 57.2 & 211764.8 & 6.1 & 0.20 \\
\hline${ }^{34} \mathrm{SO}_{2} 26_{3,23}-26_{2,24}$ & 212981.206 & 20.0 & 349.9 & 212983.7 & 5.5 & 1.19 \\
\hline${ }^{34} \mathrm{SO}_{2} 11_{5,7}-12_{4,8}$ & 213807.332 & 1.17 & 119.8 & 213811.1 & 3.7 & 0.45 \\
\hline${ }^{34} \mathrm{SO}_{2} 16_{6,10}-17_{5,13}$ & 215468.142 & 1.94 & 210.0 & 215471.2 & 4.7 & 0.35 \\
\hline${ }^{34} \mathrm{SO}_{2} 14_{3,11}-14_{2,12}$ & 215999.732 & 8.75 & 118.1 & $216002.4^{34}$ & 5.3 & 3.59 \\
\hline${ }^{34} \mathrm{SO}_{2} 21_{7,15}-22_{6,16}$ & 216593.474 & 2.71 & 328.0 & 216596.1 & 5.4 & 0.30 \\
\hline${ }^{34} \mathrm{SO}_{2} 26_{8,18}-27_{7,21}$ & 217412.916 & 3.48 & 473.6 & 38 & $\ldots$ & $\ldots$ \\
\hline${ }^{34} \mathrm{SO}_{2} 31_{9,23}-32_{8,24}$ & 217902.356 & 4.25 & 646.8 & 217903.6 & 7.3 & 0.11 \\
\hline \multirow[t]{3}{*}{${ }^{34} \mathrm{SO}_{2} 11_{1,11}-10_{0,10}$} & 219355.012 & 7.79 & 60.1 & two peaks: & $\ldots$ & \\
\hline & & & & 219347.5 & 19.3 & 1.83 \\
\hline & & & & 219357.3 & 5.9 & 4.49 \\
\hline${ }^{34} \mathrm{SO}_{2} 36_{5,31}-35_{6,30}$ & 220451.861 & 5.72 & 676.0 & 220453.7 & 6.5 & 0.12 \\
\hline${ }^{34} \mathrm{SO}_{2} 22_{2,20}-22_{1,21}$ & 221114.901 & 12.7 & 247.8 & 221117.4 & 5.6 & 1.40 \\
\hline${ }^{34} \mathrm{SO}_{2} 13_{2,12}-13_{1,13}$ & 221735.717 & 4.89 & 92.5 & $221738.7^{34}$ & 5.0 & 2.36 \\
\hline${ }^{34} \mathrm{SO}_{2} 26_{2,24}-27_{1,27}$ & 225583.126 & 0.14 & 339.6 & $225587.4^{6}$ & 3.3 & 1.03 \\
\hline${ }^{34} \mathrm{SO}_{2} 12_{3,9}-12_{2,10}$ & 227031.884 & 6.98 & 93.1 & 227034.9 & 5.0 & 3.61 \\
\hline${ }^{34} \mathrm{SO}_{2} 4_{2,2}-3_{1,3}$ & 229857.629 & 1.70 & 18.7 & $229859.9^{4,20}$ & 6.0 & 2.63 \\
\hline${ }^{34} \mathrm{SO}_{2} 15_{3,13}-16_{0,16}$ & 229866.232 & 0.10 & 131.6 & 16 & & $\ldots$ \\
\hline${ }^{34} \mathrm{SO}_{2} 177_{3,15}-18_{0,18}$ & 229888.286 & 0.12 & 161.9 & 229889.9 & 6.9 & 0.12 \\
\hline${ }^{34} \mathrm{SO}_{2} 5_{4,2}-6_{3,3}$ & 230933.358 & 0.25 & 51.7 & 230934.9 & 7.0 & 0.22 \\
\hline${ }^{34} \mathrm{SO}_{2} 10_{5,5}-11_{4,8}$ & 233296.401 & 0.96 & 109.7 & $233301.3^{48}$ & 2.7 & 0.19 \\
\hline${ }^{34} \mathrm{SO}_{2} 15_{6,10}-16_{5,11}$ & 235004.013 & 1.72 & 195.4 & 235006.5 & 5.8 & 0.40 \\
\hline${ }^{34} \mathrm{SO}_{2} 5_{2,4}-4_{1,3}$ & 235927.500 & 2.13 & 23.2 & $235933.5^{5}$ & 1.4 & 1.91 \\
\hline${ }^{34} \mathrm{SO}_{2} 10_{3,7}-10_{2,8}$ & 235951.921 & 5.48 & 71.9 & 235954.6 & 5.6 & 2.54 \\
\hline${ }^{34} \mathrm{SO}_{2} 20_{2,18}-19_{3,17}$ & 236225.098 & 4.77 & 207.2 & 49 & & . \\
\hline${ }^{34} \mathrm{SO}_{2} 20_{7,13}-21_{6,16}$ & 236295.678 & 2.49 & 308.7 & $236300.1^{36,50}$ & 3.4 & 0.29 \\
\hline${ }^{34} \mathrm{SO}_{2} 1_{3,17}-20_{0,20}$ & 236428.774 & 0.13 & 195.9 & 236432.6 & 4.2 & 0.24 \\
\hline${ }^{34} \mathrm{SO}_{2} 13_{3,11}-14_{0,14}$ & 236871.403 & 0.08 & 104.9 & 236874.5 & 5.1 & 0.19 \\
\hline${ }^{34} \mathrm{SO}_{2} 25_{8,18}-26_{7,19}$ & 237169.109 & 3.26 & 449.7 & 4 & & $\ldots$ \\
\hline${ }^{34} \mathrm{SO}_{2} 28_{3,25}-28_{2,26}$ & 237521.028 & 20.0 & 402.1 & 237523.9 & 5.4 & 1.06 \\
\hline${ }^{34} \mathrm{SO}_{2} 30_{9,21}-31_{8,24}$ & 237721.815 & 4.03 & 618.3 & 32 & . & $\ldots$ \\
\hline${ }^{34} \mathrm{SO}_{2} 16_{1,15}-15_{2,14}$ & 241509.049 & 6.25 & 130.3 & 241512.6 & 4.6 & 2.71 \\
\hline${ }^{34} \mathrm{SO}_{2} 8_{3,5}-8_{2,6}$ & 241985.451 & 4.15 & 54.4 & & $\ldots$ & $\ldots$ \\
\hline${ }^{34} \mathrm{SO}_{2} 18_{1,17}-18_{0,18}$ & 243935.963 & 5.77 & 162.6 & 243938.5 & 5.9 & 1.38 \\
\hline${ }^{34} \mathrm{SO}_{2} 14_{0,14}-13_{0,13}$ & 244481.520 & 10.6 & 93.5 & 244484.5 & 5.3 & 4.51 \\
\hline${ }^{34} \mathrm{SO}_{2} 15_{2,14}-15_{1,15}$ & 245178.728 & 5.17 & 118.7 & 245181.4 & 5.7 & 1.96 \\
\hline${ }^{34} \mathrm{SO}_{2} 6_{3,3}-6_{2,4}$ & 245302.240 & 2.90 & 40.6 & 245305.1 & 5.5 & 2.06 \\
\hline${ }^{34} \mathrm{SO}_{2} 4_{3,1}-4_{2,2}$ & 246686.119 & 1.62 & 30.5 & 246687.5 & 7.3 & 1.63 \\
\hline \multirow[t]{3}{*}{${ }^{34} \mathrm{SO}_{2} 3_{3,1}-3_{2,2}$} & 247127.390 & 0.89 & 26.8 & two peaks: & $\ldots$ & \\
\hline & & & & $247128.9^{18}$ & 7.2 & 0.67 \\
\hline & & & & 247133.9 & 1.1 & 0.49 \\
\hline${ }^{34} \mathrm{SO}_{2} 5_{3,3}-5_{2,4}$ & 247440.298 & 2.26 & 35.1 & 247442.7 & 6.1 & 1.33 \\
\hline${ }^{34} \mathrm{SO}_{2} 7_{3,5}-7_{2,6}$ & 248364.769 & 3.48 & 47.0 & 248367.7 & 5.5 & 3.07 \\
\hline
\end{tabular}


Table A.9. continued.

\begin{tabular}{|c|c|c|c|c|c|c|}
\hline $\begin{array}{l}\text { Species/Transition } \\
J_{K_{a}, K_{c}}-J_{K_{a}^{\prime}, K_{c}^{\prime}}^{\prime}\end{array}$ & $\begin{array}{r}\text { Predicted } \\
\text { freq. } \\
(\mathrm{MHz})\end{array}$ & $S_{\mathrm{ij}}$ & $\begin{array}{r}E_{\mathrm{u}} \\
(\mathrm{K})\end{array}$ & $\begin{array}{l}\text { Observed } \\
\text { freq. } \\
(\mathrm{MHz})\end{array}$ & $\begin{array}{r}\text { Observed } \\
v_{\mathrm{LSR}} \\
\left(\mathrm{km} \mathrm{s}^{-1}\right)\end{array}$ & $\begin{array}{l}\text { Observed } \\
T_{\mathrm{A}}^{*} \\
(\mathrm{~K})\end{array}$ \\
\hline${ }^{34} \mathrm{SO}_{2} 13_{1,13}-12_{0,12}$ & 248698.698 & 9.73 & 81.8 & 248702.5 & 4.4 & 5.83 \\
\hline${ }^{34} \mathrm{SO}_{2} 21_{3,19}-22_{0,22}$ & 248855.716 & 0.13 & 233.5 & $248856.5^{16}$ & 8.1 & 1.04 \\
\hline${ }^{34} \mathrm{SO}_{2} 30_{4,26}-30_{3,27}$ & 249099.208 & 23.7 & 469.9 & $249101.3^{32}$ & 6.5 & 0.80 \\
\hline${ }^{34} \mathrm{SO}_{2} 4_{4,0}-5_{3,3}$ & 250156.048 & 0.10 & 47.1 & 250163.9 & -0.4 & 0.75 \\
\hline \multirow[t]{3}{*}{${ }^{34} \mathrm{SO}_{2} 9_{3,7}-9_{2,8}$} & 250358.384 & 4.66 & 62.6 & two peaks: & & \\
\hline & & & & 250351.4 & 17.4 & 1.19 \\
\hline & & & & $250362.0^{4}$ & 4.7 & 2.57 \\
\hline${ }^{34} \mathrm{SO}_{2} 11_{3,9}-12_{0,12}$ & 251176.574 & 0.05 & 81.9 & 49 & $\ldots$ & $\ldots$ \\
\hline${ }^{34} \mathrm{SO}_{2} 25_{4,22}-26_{1,25}$ & 251438.065 & 0.28 & 337.2 & 6 & $\ldots$ & $\ldots$ \\
\hline${ }^{34} \mathrm{SO}_{2} 27_{4,24}-28_{1,27}$ & 251639.934 & 0.31 & 386.1 & 16 & $\ldots$ & $\ldots$ \\
\hline${ }^{34} \mathrm{SO}_{2} 32_{4,28}-32_{3,29}$ & 251758.330 & 25.6 & 529.6 & 251760.5 & 6.4 & 0.31 \\
\hline${ }^{34} \mathrm{SO}_{2} 9_{5,5}-10_{4,6}$ & 252615.371 & 0.76 & 100.5 & 252618.4 & 5.4 & 0.47 \\
\hline${ }^{34} \mathrm{SO}_{2} 11_{3,9}-11_{2,10}$ & 253936.319 & 5.79 & 81.9 & $253940.0^{49}$ & 4.7 & 3.63 \\
\hline${ }^{34} \mathrm{SO}_{2} 28_{4,24}-28_{3,25}$ & 254277.643 & 21.2 & 414.3 & & $\ldots$ & $\ldots$ \\
\hline${ }^{34} \mathrm{SO}_{2} 14_{6,8}-15_{5,11}$ & 254516.775 & 1.51 & 181.6 & $254519.5^{18}$ & 5.8 & 0.38 \\
\hline${ }^{34} \mathrm{SO}_{2} 19_{7,13}-20_{6,14}$ & 255892.295 & 2.27 & 290.3 & 255896.5 & 4.1 & 0.18 \\
\hline${ }^{34} \mathrm{SO}_{2} 24_{8,16}-25_{7,19}$ & 256864.330 & 3.04 & 426.7 & 51 & $\ldots$ & $\ldots$ \\
\hline${ }^{34} \mathrm{SO}_{2}{ }^{29_{9,21}}-30_{8,22}$ & 257466.731 & 3.81 & 590.8 & 13 & $\ldots$ & $\ldots$ \\
\hline${ }^{34} \mathrm{SO}_{2} 29_{4,26}-30_{1,29}$ & 258889.599 & 0.32 & 438.6 & 258893.6 & 4.4 & 0.08 \\
\hline${ }^{34} \mathrm{SO}_{2} 23_{4,20}-24_{1,23}$ & 259022.539 & 0.24 & 291.9 & & & $\ldots$ \\
\hline${ }^{34} \mathrm{SO}_{2} 13_{3,11}-13_{2,12}$ & 259617.206 & 6.87 & 104.9 & $259618.5^{5,7,34}$ & 7.5 & 2.28 \\
\hline${ }^{34} \mathrm{SO}_{2} 24_{2,22}-24_{1,23}$ & 260326.950 & 12.2 & 292.0 & $260331.4^{4,7}$ & 3.9 & 3.34 \\
\hline${ }^{34} \mathrm{SO}_{2} 23_{4,20}-24_{1,23}$ & 259022.539 & 0.24 & 291.9 & 52 & & \\
\hline${ }^{34} \mathrm{SO}_{2} 34_{4,30}-34_{3,31}$ & 263436.078 & 26.7 & 593.1 & $263441.4^{18}$ & 2.9 & 0.46 \\
\hline${ }^{34} \mathrm{SO}_{2} 26_{3,23}-25_{4,22}$ & 264682.899 & 4.98 & 349.9 & & & \\
\hline${ }^{34} \mathrm{SO}_{2}{ }^{26} 6_{4,22}-26_{3,23}$ & 265488.694 & 18.5 & 362.6 & $265485.1^{4,49}$ & 13.1 & 1.93 \\
\hline${ }^{34} \mathrm{SO}_{2} 7_{2,6}-6_{1,25}$ & 265554.053 & 2.68 & 35.1 & 265555.2 & 7.7 & 1.06 \\
\hline${ }^{34} \mathrm{SO}_{2} 23_{3,21}-24_{0,24}$ & 266469.801 & 0.13 & 274.7 & 266470.1 & 8.7 & 0.24 \\
\hline${ }^{34} \mathrm{SO}_{2} 33_{5,29}-34_{2,32}$ & 267094.152 & 0.45 & 576.3 & 267097.6 & 5.1 & 0.26 \\
\hline${ }^{34} \mathrm{SO}_{2} 15_{3,13}-15_{2,14}$ & 267871.064 & 7.85 & 131.6 & $267872.5^{39}$ & 7.4 & 1.74 \\
\hline${ }^{34} \mathrm{SO}_{2} 30_{3,27}-30_{2,28}$ & 270229.677 & 19.5 & 458.0 & $270231.4^{7}$ & 7.1 & 0.52 \\
\hline${ }^{34} \mathrm{SO}_{2} 17_{2,16}-17_{1,17}$ & 271410.227 & 5.36 & 148.5 & $271413.9^{18}$ & 4.9 & 1.19 \\
\hline${ }^{34} \mathrm{SO}_{2} 8_{5,3}-9_{4,6}$ & 271916.826 & 0.56 & 92.3 & $271928.5^{47}$ & -3.9 & 0.72 \\
\hline${ }^{34} \mathrm{SO}_{2} 31_{4,28}-32_{1,31}$ & 272363.869 & 0.32 & 494.8 & 16 & $\ldots$ & $\ldots$ \\
\hline${ }^{34} \mathrm{SO}_{2} 9_{3,7}-10_{0,10}$ & 272625.742 & 0.02 & 62.6 & 34 & $\ldots$ & $\ldots$ \\
\hline${ }^{34} \mathrm{SO}_{2} 28_{2,26}-29_{1,29}$ & 272789.518 & 0.12 & 390.7 & 272794.5 & 3.5 & 0.13 \\
\hline${ }^{34} \mathrm{SO}_{2} 13_{6,8}-14_{5,9}$ & 273929.985 & 1.29 & 168.7 & 273931.5 & 7.3 & 0.43 \\
\hline${ }^{34} \mathrm{SO}_{2} 21_{4,18}-22_{1,21}$ & 274940.961 & 0.18 & 250.4 & 274942.6 & 7.2 & 0.72 \\
\hline${ }^{34} \mathrm{SO}_{2} 18_{7,11}-19_{6,14}$ & 275434.219 & 2.06 & 272.9 & $275441.4^{32}$ & 1.2 & 0.89 \\
\hline${ }^{34} \mathrm{SO}_{2} 23_{8,16}-24_{7,17}$ & 276484.001 & 2.82 & 404.7 & 24 & & \\
\hline${ }^{34} \mathrm{SO}_{2} 6_{2,4}-5_{1,5}$ & 276999.606 & 1.85 & 28.8 & 277001.3 & 7.2 & 1.61 \\
\hline${ }^{34} \mathrm{SO}_{2} 28_{9,19}-29_{8,22}$ & 277150.593 & 3.60 & 564.1 & 277154.0 & 5.3 & 0.14 \\
\hline${ }^{34} \mathrm{SO}_{2} 33_{10,24}-34_{9,25}$ & 277470.086 & 4.37 & 751.2 & $277471.3^{53,54}$ & 7.7 & 0.57 \\
\hline${ }^{34} \mathrm{SO}_{2} 32_{4,28}-31_{5,27}$ & 278835.214 & 5.43 & 529.6 & $278834.5^{43}$ & 9.8 & 0.56 \\
\hline${ }^{34} \mathrm{SO}_{2} 17_{3,15}-17_{2,16}$ & 279075.261 & 8.72 & 161.9 & $279076.3^{5}$ & 7.9 & 3.39 \\
\hline${ }^{34} \mathrm{SO}_{2} 15_{1,15}-14_{0,14}$ & 279429.979 & 11.8 & 107.0 & $279433.8^{6,18}$ & 4.9 & 5.67 \\
\hline${ }^{34} \mathrm{SO}_{2} 24_{4,20}-24_{3,21}$ & 280407.893 & 15.9 & 314.9 & $280412.6^{6}$ & 4.0 & 2.09 \\
\hline${ }^{33} \mathrm{SO}_{2} 8_{3,5}-9_{2,8}$ & 82380.654 & 1.13 & 54.8 & 82380.5 & 9.6 & 0.03 \\
\hline${ }^{33} \mathrm{SO}_{2} 26_{4,22}-25_{5,21}$ & 82777.117 & 4.11 & 363.4 & 4 & & $\ldots$ \\
\hline${ }^{33} \mathrm{SO}_{2} 8_{1,7}-8_{0,8}$ & 83345.818 & 6.32 & 36.7 & 83347.5 & 3.0 & 0.06 \\
\hline${ }^{33} \mathrm{SO}_{2} 18_{5,13}-19_{4,16}$ & 83540.669 & 2.68 & 217.4 & 83541.5 & 6.0 & 0.01 \\
\hline${ }^{33} \mathrm{SO}_{2} 23_{6,18}-24_{5,19}$ & 84025.261 & 3.46 & 340.4 & 17 & $\cdots$ & $\ldots$ \\
\hline${ }^{33} \mathrm{SO}_{2} 28_{7,21}-29_{6,24}$ & 87241.461 & 4.22 & 491.2 & 5 & $\ldots$ & $\ldots$ \\
\hline${ }^{33} \mathrm{SO}_{2} 33_{8,26}-34_{7,27}$ & 89094.697 & 4.99 & 669.8 & 89096.4 & 3.3 & 0.01 \\
\hline${ }^{33} \mathrm{SO}_{2} 20_{2,18}-21_{1,21}$ & 90595.537 & 0.26 & 207.5 & 33 & $\ldots$ & $\ldots$ \\
\hline${ }^{33} \mathrm{SO}_{2} 33_{3,31}-32_{4,28}$ & 92105.596 & 1.87 & 534.7 & noise level & . & $\ldots$ \\
\hline${ }^{33} \mathrm{SO}_{2} 7_{3,5}-8_{2,6}$ & 93072.174 & 0.94 & 47.4 & 93073.5 & 4.7 & 0.04 \\
\hline${ }^{33} \mathrm{SO}_{2} 25_{3,23}-24_{4,20}$ & 93533.322 & 3.18 & 320.2 & 93535.5 & 2.0 & 0.03 \\
\hline${ }^{33} \mathrm{SO}_{2} 32_{5,27}-31_{6,26}$ & 96205.274 & 5.03 & 548.0 & $96208.5^{34}$ & $\ldots$ & 0.05 \\
\hline${ }^{33} \mathrm{SO}_{2} 33_{5,29}-32_{6,26}$ & 97491.820 & 5.13 & 577.7 & 97493.7 & 3.2 & 0.02 \\
\hline${ }^{33} \mathrm{SO}_{2} 2_{2,0}-3_{1,3}$ & 98261.870 & 0.16 & 12.4 & 34,43 & $\cdots$ & \\
\hline${ }^{33} \mathrm{SO}_{2} 17_{5,13}-18_{4,14}$ & 101560.254 & 2.48 & 200.9 & 7 & $\ldots$ & $\ldots$ \\
\hline
\end{tabular}


Table A.9. continued.

\begin{tabular}{|c|c|c|c|c|c|c|}
\hline $\begin{array}{l}\text { Species/Transition } \\
J_{K_{a}, K_{c}}-J_{K_{a}^{\prime}, K_{c}^{\prime}}^{\prime}\end{array}$ & $\begin{array}{r}\text { Predicted } \\
\text { freq. } \\
(\mathrm{MHz})\end{array}$ & $S_{\mathrm{ij}}$ & $\begin{array}{c}E_{\mathrm{u}} \\
(\mathrm{K})\end{array}$ & $\begin{array}{l}\text { Observed } \\
\text { freq. } \\
(\mathrm{MHz})\end{array}$ & $\begin{array}{r}\text { Observed } \\
v_{\mathrm{LSR}} \\
\left(\mathrm{km} \mathrm{s}^{-1}\right)\end{array}$ & $\begin{array}{l}\text { Observed } \\
T_{\mathrm{A}}^{*} \\
(\mathrm{~K})\end{array}$ \\
\hline${ }^{33} \mathrm{SO}_{2} 12_{4,8}-13_{3,11}$ & 101688.876 & 1.70 & 110.2 & 4 & & \\
\hline${ }^{33} \mathrm{SO}_{2} 3_{1,3}-2_{0,2}$ & 103000.258 & 2.02 & 7.7 & 103003.4 & -0.1 & 0.11 \\
\hline${ }^{33} \mathrm{SO}_{2} 10_{1,9}-10_{0,10}$ & 104301.966 & 6.61 & 54.6 & & & \\
\hline${ }^{33} \mathrm{SO}_{2} 22_{6,16}-23_{5,19}$ & 105452.527 & 3.24 & 319.3 & $105456.4^{6}$ & -2.0 & 0.13 \\
\hline${ }^{33} \mathrm{SO}_{2} 29_{4,26}-28_{5,23}$ & 105943.555 & 4.32 & 439.6 & 105944.5 & 6.3 & 0.02 \\
\hline${ }^{33} \mathrm{SO}_{2} 27_{7,21}-28_{6,22}$ & 107245.759 & 4.01 & 465.5 & 107246.5 & 6.9 & 0.02 \\
\hline${ }^{33} \mathrm{SO}_{2} 27_{3,25}-26_{4,22}$ & 108383.700 & 2.99 & 368.6 & & $\ldots$ & $\ldots$ \\
\hline${ }^{33} \mathrm{SO}_{2} 31_{3,29}-30_{4,26}$ & 108514.453 & 2.28 & 475.9 & 19 & $\ldots$ & $\ldots$ \\
\hline${ }^{33} \mathrm{SO}_{2} 32_{8,24}-33_{7,27}$ & 109681.906 & 4.78 & 639.4 & 6 & $\ldots$ & $\ldots$ \\
\hline${ }^{33} \mathrm{SO}_{2} 16_{2,14}-15_{3,13}$ & 109828.514 & 3.02 & 137.3 & 109829.5 & 6.3 & 0.11 \\
\hline${ }^{33} \mathrm{SO}_{2} 29_{3,27}-28_{4,24}$ & 113783.648 & 2.67 & 420.5 & 17 & $\ldots$ & $\ldots$ \\
\hline${ }^{33} \mathrm{SO}_{2} 14_{2,12}-14_{1,13}$ & 131191.102 & 11.7 & 107.9 & 131192.7 & 5.4 & 0.36 \\
\hline${ }^{33} \mathrm{SO}_{2} 8_{2,6}-8_{1,7}$ & 131247.049 & 5.73 & 43.0 & 131249.5 & 3.4 & 0.32 \\
\hline${ }^{33} \mathrm{SO}_{2} 12_{1,11}-12_{0,12}$ & 131561.786 & 6.53 & 76.3 & $131562.6^{47}$ & 7.1 & 0.29 \\
\hline${ }^{33} \mathrm{SO}_{2} 12_{1,11}-11_{2,10}$ & 132084.974 & 3.42 & 76.3 & $132086.4^{5,55}$ & 5.8 & 0.22 \\
\hline${ }^{33} \mathrm{SO}_{2} 5_{1,5}-4_{0,4}$ & 134550.979 & 3.14 & 15.6 & $134550.1^{4}$ & 11.0 & 2.72 \\
\hline${ }^{33} \mathrm{SO}_{2} 5_{3,3}-6,4$ & 134830.627 & 0.50 & 35.5 & 6,23 & & \\
\hline${ }^{33} \mathrm{SO}_{2} 35_{5,31}-34_{6,28}$ & 136073.824 & 5.39 & 641.6 & 136075.1 & 6.2 & 0.02 \\
\hline${ }^{33} \mathrm{SO}_{2} 31_{2,28}-30_{5,25}$ & 136345.497 & 4.41 & 495.9 & & & \\
\hline${ }^{33} \mathrm{SO}_{2} 6_{2,4}-6_{1,5}$ & 137478.134 & 3.85 & 29.0 & 137481.4 & 1.9 & 0.43 \\
\hline${ }^{33} \mathrm{SO}_{2} 10_{4,6}-11_{3,9}$ & 140348.741 & 1.27 & 89.1 & 140350.1 & 6.1 & 0.11 \\
\hline${ }^{33} \mathrm{SO}_{2} 16_{2,14}-16_{1,15}$ & 142281.376 & 12.9 & 137.3 & 142281.4 & 8.9 & 0.40 \\
\hline${ }^{33} \mathrm{SO}_{2} 15_{5,11}-16_{4,12}$ & 142295.587 & 2.04 & 170.5 & 17 & $\ldots$ & 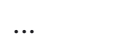 \\
\hline \multirow[t]{3}{*}{${ }^{33} \mathrm{SO}_{2} 4_{2,2}-4_{1,3}$} & 143795.870 & 2.28 & 18.8 & two peaks: & & \\
\hline & & & & 143795.5 & 9.8 & 0.27 \\
\hline & & & & 143799.5 & 1.4 & 0.48 \\
\hline${ }^{33} \mathrm{SO}_{2} 20_{6,14}-21_{5,17}$ & 145564.070 & 2.81 & 279.7 & & & \\
\hline${ }^{33} \mathrm{SO}_{2} 25_{7,19}-26_{6,20}$ & 147793.083 & 3.58 & 416.7 & 147795.5 & 4.1 & 0.11 \\
\hline${ }^{33} \mathrm{SO}_{2} 2_{2,0}-2_{1,1}$ & 148614.406 & 0.87 & 12.4 & 5 & $\ldots$ & $\ldots$ \\
\hline${ }^{33} \mathrm{SO}_{2} 34_{5,29}-33_{6,28}$ & 148926.741 & 5.39 & 610.6 & 17 & $\ldots$ & $\ldots$ \\
\hline${ }^{33} \mathrm{SO}_{2} 30_{8,22}-31_{7,25}$ & 150134.771 & 4.35 & 581.4 & 16 & $\ldots$ & $\ldots$ \\
\hline \multirow[t]{3}{*}{${ }^{33} \mathrm{SO}_{2} 3_{2,2}-3_{1,3}$} & 155523.945 & 1.44 & 15.2 & two peaks: & & \\
\hline & & & & 155523.5 & 9.9 & 0.27 \\
\hline & & & & 155526.4 & 4.3 & 0.24 \\
\hline${ }^{33} \mathrm{SO}_{2} 4_{3,1}-5_{2,4}$ & 156091.249 & 0.30 & 30.9 & 9 & $\ldots$ & $\ldots$ \\
\hline${ }^{33} \mathrm{SO}_{2} 9_{4,6}-10_{3,7}$ & 158845.420 & 1.05 & 79.9 & $158846.5^{49}$ & 7.0 & 0.17 \\
\hline${ }^{33} \mathrm{SO}_{2} 18_{2,16}-18_{1,17}$ & 160513.715 & 13.4 & 170.5 & 31 & $\ldots$ & $\ldots$ \\
\hline${ }^{33} \mathrm{SO}_{2} 33_{4,30}-32_{5,27}$ & 161071.892 & 4.36 & 555.7 & 4 & ... & \\
\hline${ }^{33} \mathrm{SO}_{2} 10_{0,10}-9_{1,9}$ & 161452.956 & 6.48 & 49.6 & $161452.6^{4,32}$ & 9.7 & 2.53 \\
\hline${ }^{33} \mathrm{SO}_{2} 5_{2,4}-5_{1,5}$ & 162562.342 & 2.45 & 23.4 & 162564.5 & 5.0 & 0.51 \\
\hline${ }^{33} \mathrm{SO}_{2} 14_{5,9}-15_{4,12}$ & 162745.229 & 1.82 & 156.7 & $162748.5^{5}$ & 3.0 & 0.48 \\
\hline${ }^{33} \mathrm{SO}_{2} 7_{1,7}-6_{0,6}$ & 163964.985 & 4.44 & 27.0 & 5 & & \\
\hline${ }^{33} \mathrm{SO}_{2} 14_{1,13}-14_{0,14}$ & 164626.053 & 6.29 & 101.6 & 164626.5 & 8.2 & 0.37 \\
\hline${ }^{33} \mathrm{SO}_{2} 19_{6,14}-20_{5,15}$ & 165265.989 & 2.59 & 261.3 & & & \\
\hline${ }^{33} \mathrm{SO}_{2} 24_{7,17}-25_{6,20}$ & 167953.648 & 3.36 & 393.7 & $167954.6^{34}$ & 7.3 & 0.14 \\
\hline${ }^{33} \mathrm{SO}_{2} 18_{2,16}-17_{3,15}$ & 169164.044 & 3.76 & 170.5 & 169167.6 & 2.7 & 0.23 \\
\hline${ }^{33} \mathrm{SO}_{2} 29_{8,22}-30_{7,23}$ & 170176.428 & 4.13 & 553.8 & 17 & & \\
\hline${ }^{33} \mathrm{SO}_{2} 7_{2,6}-7_{1,7}$ & 172832.024 & 3.29 & 35.3 & 172831.5 & 9.9 & 0.57 \\
\hline${ }^{33} \mathrm{SO}_{2} 24_{2,22}-25_{1,25}$ & 173951.097 & 0.17 & 292.4 & & & \\
\hline${ }^{33} \mathrm{SO}_{2} 3_{3,1}-4_{2,2}$ & 174505.972 & 0.13 & 27.2 & 174506.5 & 8.1 & 0.37 \\
\hline${ }^{33} \mathrm{SO}_{2} 74,4-8,5$ & 198125.389 & 0.63 & 64.3 & $198127.4^{55}$ & 6.0 & 0.22 \\
\hline${ }^{33} \mathrm{SO}_{2} 24_{3,21}-24_{2,22}$ & 198479.747 & 19.3 & 301.9 & 198482.4 & 5.0 & 0.52 \\
\hline${ }^{33} \mathrm{SO}_{2} 18_{3,15}-18_{2,16}$ & 199340.675 & 13.1 & 180.1 & 199343.6 & 4.6 & 0.54 \\
\hline${ }^{33} \mathrm{SO}_{2} 30_{4,26}-29,5,25$ & 199653.586 & 4.92 & 470.7 & 4 & $\cdots$ & $\ldots$ \\
\hline${ }^{33} \mathrm{SO}_{2} 12_{5,7}-13_{4,10}$ & 201927.690 & 1.39 & 131.9 & 201929.4 & 6.5 & 0.19 \\
\hline${ }^{33} \mathrm{SO}_{2} 16_{1,15}-16_{0,16}$ & 202188.357 & 6.04 & 130.5 & $202194.4^{5,57}$ & 0.0 & 0.89 \\
\hline${ }^{33} \mathrm{SO}_{2} 11_{2,10}-11_{1,11}$ & 203266.908 & 4.53 & 70.0 & 203268.2 & 7.1 & 0.47 \\
\hline${ }^{33} \mathrm{SO}_{2} 12_{0,12}-11_{1,11}$ & 203790.096 & 8.49 & 70.0 & 203793.3 & 4.3 & 0.83 \\
\hline${ }^{33} \mathrm{SO}_{2} 17_{6,12}-18_{5,13}$ & 204932.906 & 2.16 & 227.3 & 7 & & - \\
\hline${ }^{33} \mathrm{SO}_{2} 3_{2,2}-2_{1,1}$ & 205876.481 & 1.67 & 15.2 & $205876.1^{4,58}$ & 9.6 & 1.06 \\
\hline${ }^{33} \mathrm{SO}_{2} 36_{5,31}-35_{6,30}$ & 206591.663 & 5.74 & 677.2 & 6 & 1.0 & 1.00 \\
\hline${ }^{33} \mathrm{SO}_{2} 22_{7,15}-23_{6,18}$ & 207708.782 & 2.93 & 350.4 & 7 & $\ldots$ & $\ldots$ \\
\hline
\end{tabular}


Table A.9. continued.

\begin{tabular}{|c|c|c|c|c|c|c|}
\hline $\begin{array}{l}\text { Species/Transition } \\
J_{K_{a}, K_{c}}-J_{K_{a}^{\prime}, K_{c}^{\prime}}^{\prime}\end{array}$ & $\begin{array}{r}\text { Predicted } \\
\text { freq. } \\
(\mathrm{MHz})\end{array}$ & $S_{\mathrm{ij}}$ & $\begin{array}{c}E_{\mathrm{u}} \\
(\mathrm{K})\end{array}$ & $\begin{array}{l}\text { Observed } \\
\text { freq. } \\
(\mathrm{MHz})\end{array}$ & $\begin{array}{r}\text { Observed } \\
v_{\mathrm{LSR}} \\
\left(\mathrm{km} \mathrm{s}^{-1}\right)\end{array}$ & $\begin{array}{l}\text { Observed } \\
T_{\mathrm{A}}^{*} \\
(\mathrm{~K})\end{array}$ \\
\hline${ }^{33} \mathrm{SO}_{2} 16_{3,13}-16_{2,14}$ & 209431.260 & 10.8 & 147.4 & $209434.9^{59}$ & 3.8 & 1.15 \\
\hline${ }^{33} \mathrm{SO}_{2} 27_{8,20}-28_{7,21}$ & 210085.250 & 3.70 & 501.3 & 210088.7 & 4.1 & 0.16 \\
\hline${ }^{33} \mathrm{SO}_{2} 32_{9,23}-33_{8,26}$ & 212214.107 & 4.47 & 680.0 & noisy spectrum & $\ldots$ & $\ldots$ \\
\hline${ }^{33} \mathrm{SO}_{2} 26_{3,23}-26_{2,24}$ & 212860.266 & 20.2 & 350.3 & $212862.3^{7}$ & 6.1 & 0.18 \\
\hline${ }^{33} \mathrm{SO}_{2} 6_{4,2}-7,5$ & 217628.603 & 0.43 & 57.9 & 217629.8 & 7.4 & 0.18 \\
\hline${ }^{33} \mathrm{SO}_{2} 22_{2,20}-22_{1,21}$ & 218878.861 & 12.9 & 248.1 & $218879.9^{60}$ & 7.6 & 0.43 \\
\hline${ }^{33} \mathrm{SO}_{2} 11_{1,11}-10_{0,10}$ & 220619.071 & 7.75 & 60.2 & 57 & $\ldots$ & $\ldots$ \\
\hline${ }^{33} \mathrm{SO}_{2} 14_{3,11}-14_{2,12}$ & 220987.225 & 8.68 & 118.5 & $220986.2^{5,24,60}$ & 10.4 & 0.92 \\
\hline${ }^{33} \mathrm{SO}_{2} 11_{5,7}-12_{4,8}$ & 221328.839 & 1.17 & 120.9 & 221332.4 & 4.2 & 0.14 \\
\hline${ }^{33} \mathrm{SO}_{2} 13_{2,12}-13_{1,13}$ & 223378.596 & 4.93 & 92.7 & 4 & $\ldots$ & $\ldots$ \\
\hline${ }^{33} \mathrm{SO}_{2} 16_{6,10}-17_{5,13}$ & 224641.972 & 1.94 & 211.6 & 4 & $\ldots$ & $\ldots$ \\
\hline${ }^{33} \mathrm{SO}_{2} 21_{7,15}-22_{6,16}$ & 227436.553 & 2.71 & 330.2 & 56 & & \\
\hline${ }^{33} \mathrm{SO}_{2} 26_{8,18}-27_{7,21}$ & 229919.132 & 3.48 & 476.5 & $229919.9^{17}$ & 8.0 & 0.11 \\
\hline${ }^{33} \mathrm{SO}_{2} 20_{2,18}-19_{3,17}$ & 230438.867 & 4.69 & 207.5 & $230442.4^{5}$ & 4.4 & 0.24 \\
\hline${ }^{33} \mathrm{SO}_{2} 12_{3,9}-12_{2,10}$ & 231898.417 & 6.94 & 93.5 & $231904.9^{7,10,61}$ & 0.6 & 0.41 \\
\hline${ }^{33} \mathrm{SO}_{2} 31_{9,23}-32_{8,24}$ & 232073.029 & 4.25 & 650.5 & 36,39 & $\cdots$ & $\ldots$ \\
\hline${ }^{33} \mathrm{SO}_{2} 4_{2,2}-3_{1,3}$ & 232419.835 & 1.71 & 18.8 & 16 & $\ldots$ & $\ldots$ \\
\hline${ }^{33} \mathrm{SO}_{2} 17_{3,15}-18_{0,18}$ & 233838.726 & 0.12 & 162.4 & 233840.5 & 6.7 & 0.12 \\
\hline${ }^{33} \mathrm{SO}_{2} 15_{3,13}-16_{0,16}$ & 234641.219 & 0.10 & 132.0 & 234647.7 & 0.7 & 0.09 \\
\hline${ }^{33} \mathrm{SO}_{2} 28_{3,25}-28_{2,26}$ & 235726.867 & 20.3 & 402.5 & 17 & $\ldots$ & $\ldots$ \\
\hline${ }^{33} \mathrm{SO}_{2} 5_{4,2}-6_{3,3}$ & 236815.676 & 0.25 & 52.4 & 5,6 & $\ldots$ & $\ldots$ \\
\hline${ }^{33} \mathrm{SO}_{2} 5_{2,4}-4_{1,3}$ & 238683.410 & 2.12 & 23.4 & 13 & $\ldots$ & $\ldots$ \\
\hline${ }^{33} \mathrm{SO}_{2} 16_{1,15}-15_{2,14}$ & 238967.956 & 6.15 & 130.5 & 13 & $\ldots$ & $\ldots$ \\
\hline${ }^{33} \mathrm{SO}_{2} 19_{3,17}-20_{0,20}$ & 239546.722 & 0.13 & 196.4 & 17 & $\cdots$ & $\begin{array}{l}\cdots \\
\cdots\end{array}$ \\
\hline${ }^{33} \mathrm{SO}_{2} 10_{3,7}-10_{2,8}$ & 240612.356 & 5.46 & 72.3 & 240614.9 & 5.8 & 0.77 \\
\hline${ }^{33} \mathrm{SO}_{2} 10_{5,5}-11_{4,8}$ & 240814.508 & 0.96 & 110.8 & $240819.9^{17}$ & 2.3 & 0.43 \\
\hline${ }^{33} \mathrm{SO}_{2} 13_{3,11}-14_{0,14}$ & 242429.337 & 0.76 & 105.4 & 9 & 2.5 & 0.10 \\
\hline${ }^{33} \mathrm{SO}_{2} 18_{1,17}-18_{0,18}$ & 242489.055 & 5.88 & 162.8 & 4,16 & $\cdots$ & $\cdots$ \\
\hline${ }^{33} \mathrm{SO}_{2} 15_{6,10}-16_{5,11}$ & 244177.299 & 1.72 & 196.9 & 244178.9 & 7.0 & $\dddot{0.10}$ \\
\hline${ }^{33} \mathrm{SO}_{2} 14_{0,14}-13_{1,13}$ & 244388.890 & 1.06 & 93.7 & $244392.0^{59}$ & 5.2 & 1.53 \\
\hline${ }^{33} \mathrm{SO}_{2} 8_{3,5}-8_{2,6}$ & 246455.769 & 4.15 & 54.8 & $246457.6^{5}$ & 6.8 & 1.00 \\
\hline${ }^{33} \mathrm{SO}_{2} 15_{2,14}-15_{1,15}$ & 246558.644 & 5.22 & 119.0 & 62 & & 1000 \\
\hline${ }^{33} \mathrm{SO}_{2} 20_{7,13}-21_{6,16}$ & 247124.476 & 2.49 & 310.9 & $247128.9^{17}$ & 3.6 & 0.67 \\
\hline${ }^{33} \mathrm{SO}_{2} 6_{3,3}-6_{2,4}$ & 249650.188 & 2.90 & 41.0 & 249652.5 & 6.2 & 0.99 \\
\hline${ }^{33} \mathrm{SO}_{2} 25_{8,18}-26_{7,19}$ & 249659.233 & 3.26 & 452.6 & $249660.5^{10}$ & 7.5 & 0.89 \\
\hline${ }^{33} \mathrm{SO}_{2} 25_{8,17}-26_{7,20}$ & 249664.196 & 3.26 & 452.6 & 249668.5 & 3.8 & 0.41 \\
\hline${ }^{33} \mathrm{SO}_{2} 13_{1,13}-12_{0,12}$ & 249907.904 & 9.68 & 82.0 & 249909.4 & 7.2 & 1.33 \\
\hline${ }^{33} \mathrm{SO}_{2} 4_{3,1}-4_{2,2}$ & 250978.790 & 1.61 & 30.9 & $250981.5^{6}$ & 5.8 & 0.80 \\
\hline${ }^{33} \mathrm{SO}_{2} 21_{3,19}-22_{0,22}$ & 251161.805 & 0.13 & 234.1 & 16 & & $\ldots$ \\
\hline${ }^{33} \mathrm{SO}_{2} 3_{3,1}-3_{2,2}$ & 251401.862 & 0.89 & 27.2 & $251408.9^{43}$ & 0.6 & 0.48 \\
\hline${ }^{33} \mathrm{SO}_{2} 5_{3,3}-5_{2,4}$ & 251702.803 & 2.26 & 35.5 & $251706.5^{5}$ & 4.6 & 0.72 \\
\hline${ }^{33} \mathrm{SO}_{2} 30_{9,21}-31_{8,24}$ & 251869.264 & 4.03 & 622.0 & & & $\ldots$ \\
\hline${ }^{33} \mathrm{SO}_{2} 7_{3,5}-7_{2,6}$ & 252591.694 & 3.48 & 47.4 & 252594.5 & 5.7 & 0.64 \\
\hline${ }^{33} \mathrm{SO}_{2} 30_{4,26}-30_{3,27}$ & 253982.798 & 23.5 & 470.7 & & $\ldots$ & $\ldots$ \\
\hline${ }^{33} \mathrm{SO}_{2} 9_{3,7}-9_{2,8}$ & 254510.018 & 4.65 & 63.0 & $254518.8^{23}$ & -1.3 & 0.38 \\
\hline${ }^{33} \mathrm{SO}_{2} 32_{4,28}-32_{3,29}$ & 254706.303 & 25.6 & 530.3 & & $\ldots$ & $\ldots$ \\
\hline${ }^{33} \mathrm{SO}_{2} 26_{3,23}-25_{4,22}$ & 255285.450 & 4.92 & 350.3 & 255288.8 & 5.1 & 0.04 \\
\hline${ }^{33} \mathrm{SO}_{2} 4_{4,0}-5_{3,3}$ & 256049.817 & 0.10 & 47.8 & & $\ldots$ & $\ldots$ \\
\hline${ }^{33} \mathrm{SO}_{2} 24_{2,22}-24_{1,23}$ & 257349.346 & 12.5 & 292.4 & 13 & $\ldots$ & $\ldots$ \\
\hline${ }^{33} \mathrm{SO}_{2} 11_{3,9}-11_{2,10}$ & 257957.223 & 5.79 & 82.4 & 257959.0 & 6.9 & 0.32 \\
\hline${ }^{33} \mathrm{SO}_{2} 9_{5,5}-10_{4,6}$ & 260142.516 & 0.76 & 101.6 & $260141.4^{5,9}$ & 10.3 & 0.71 \\
\hline${ }^{33} \mathrm{SO}_{2} 28_{4,24}-28_{3,25}$ & 260651.733 & 20.9 & 415.1 & & & \\
\hline${ }^{33} \mathrm{SO}_{2} 13_{3,11}-13_{2,12}$ & 263439.631 & 6.87 & 105.4 & $263441.4^{23}$ & 7.0 & 0.46 \\
\hline${ }^{33} \mathrm{SO}_{2} 14_{6,8}-15_{5,11}$ & 263686.350 & 1.51 & 183.1 & $263688.5^{63}$ & 6.6 & 0.36 \\
\hline${ }^{33} \mathrm{SO}_{2} 34_{4,30}-31_{3,31}$ & 264112.472 & 26.9 & 593.9 & 264115.1 & 6.0 & 0.33 \\
\hline${ }^{33} \mathrm{SO}_{2} 32_{4,28}-31_{5,27}$ & 265999.703 & 5.40 & 530.3 & 32 & $\ldots$ & $\ldots$ \\
\hline${ }^{33} \mathrm{SO}_{2} 23_{4,20}-24_{1,23}$ & 266389.236 & 0.23 & 292.8 & 32 & $\ldots$ & $\ldots$ \\
\hline${ }^{33} \mathrm{SO}_{2} 19_{7,13}-20_{6,14}$ & 266714.606 & 2.27 & 292.5 & $266720.5^{47}$ & 2.4 & 0.77 \\
\hline${ }^{33} \mathrm{SO}_{2} 30_{3,27}-30_{2,28}$ & 266817.889 & 19.9 & 458.5 & 5 & $\ldots$ & $\ldots$ \\
\hline${ }^{33} \mathrm{SO}_{2} 23_{3,21}-24_{0,24}$ & 268010.417 & 0.13 & 275.4 & 4 & $\ldots$ & $\ldots$ \\
\hline${ }^{33} \mathrm{SO}_{2} 7_{2,6}-6_{1,5}$ & 268450.516 & 2.68 & 35.3 & 268455.1 & 3.9 & 0.35 \\
\hline${ }^{33} \mathrm{SO}_{2} 24_{8,17}-25_{7,18}$ & 269336.898 & 3.04 & 429.6 & 269338.8 & 6.9 & 0.32 \\
\hline
\end{tabular}


Table A.9. continued.

\begin{tabular}{|c|c|c|c|c|c|c|}
\hline $\begin{array}{l}\text { Species/Transition } \\
J_{K_{a}, K_{c}}-J_{K_{a}^{\prime}, K_{c}^{\prime}}^{\prime}\end{array}$ & $\begin{array}{r}\text { Predicted } \\
\text { freq. } \\
(\mathrm{MHz})\end{array}$ & $S_{\mathrm{ij}}$ & $\begin{array}{r}E_{\mathrm{u}} \\
(\mathrm{K})\end{array}$ & $\begin{array}{l}\text { Observed } \\
\text { freq. } \\
(\mathrm{MHz})\end{array}$ & $\begin{array}{r}\text { Observed } \\
v_{\mathrm{LSR}} \\
\left(\mathrm{km} \mathrm{s}^{-1}\right)\end{array}$ & $\begin{array}{l}\text { Observed } \\
T_{\mathrm{A}}^{*} \\
(\mathrm{~K})\end{array}$ \\
\hline${ }^{33} \mathrm{SO}_{2} 24_{8,16}-25_{7,19}$ & 269339.793 & 3.04 & 429.6 & 8 & & \\
\hline${ }^{3} \mathrm{SO}_{2} 38_{5,33}-37_{6,32}$ & 269919.292 & 6.10 & 747.8 & $269922.5^{41}$ & 5.4 & 0.09 \\
\hline${ }^{33} \mathrm{SO}_{2} 15_{3,13}-15_{2,14}$ & 271420.818 & 7.87 & 132.0 & $271413.9^{23}$ & 16.6 & 1.19 \\
\hline${ }^{33} \mathrm{SO}_{2} 29_{9,21}-30_{8,22}$ & 271595.561 & 3.82 & 594.4 & 271599.4 & 4.8 & 0.16 \\
\hline${ }^{33} \mathrm{SO}_{2} 17_{2,16}-17_{1,17}$ & 272529.988 & 5.42 & 148.9 & 272532.5 & 6.2 & 0.35 \\
\hline${ }^{33} \mathrm{SO}_{2} 26_{4,22}-26_{3,23}$ & 272834.379 & 18.3 & 363.4 & 272836.5 & 6.7 & 0.36 \\
\hline${ }^{33} \mathrm{SO}_{2} 34_{10,24}-35_{9,27}$ & 273528.762 & 4.59 & 787.0 & 273531.5 & 6.0 & 0.14 \\
\hline${ }^{33} \mathrm{SO}_{2} 6_{2,4}-5_{1,5}$ & 279434.518 & 1.86 & 29.0 & & & \\
\hline${ }^{33} \mathrm{SO}_{2} 8_{5,3}-94,6$ & 279451.477 & 0.56 & 93.3 & 279456.5 & 3.6 & 0.47 \\
\hline${ }^{33} \mathrm{SO}_{2} 15_{1,15}-14_{0,14}$ & 280557.119 & 11.7 & 107.2 & & $\ldots$ & $\ldots$ \\
\hline $\mathrm{SO}^{18} \mathrm{O} 19_{5,15}-20_{4,16}$ & 80417.639 & 2.91 & 225.1 & noise level & $\ldots$ & $\ldots$ \\
\hline $\mathrm{SO}^{18} \mathrm{O} 8_{3,6}-9_{2,7}$ & 80709.124 & 1.17 & 52.9 & & $\ldots$ & $\ldots$ \\
\hline $\mathrm{SO}^{18} \mathrm{O} 19_{5,14}-20_{4,17}$ & 83312.870 & 2.91 & 225.1 & 31 & & \\
\hline $\mathrm{SO}^{18} \mathrm{O} 2_{1,2}-1_{0,1}$ & 84094.060 & 1.50 & 4.9 & 84094.5 & 7.4 & 0.02 \\
\hline $\mathrm{SO}^{18} \mathrm{O} 16_{2,14}-15_{3,13}$ & 86720.509 & 2.95 & 130.1 & 86722.3 & 2.8 & 0.03 \\
\hline $\mathrm{SO}^{18} \mathrm{O} 7_{0,7}-6_{1,6}$ & 87752.674 & 3.73 & 24.1 & & $\cdots$ & \\
\hline $\mathrm{SO}^{18} \mathrm{O} 9_{1,8}-9_{0,9}$ & 88201.737 & 6.75 & 42.8 & $88202.5^{4}$ & . & 0.06 \\
\hline $\mathrm{SO}^{18} \mathrm{O} 26_{3,24}-25_{4,21}$ & 88869.508 & 3.38 & 326.4 & 88870.4 & 6.0 & 0.02 \\
\hline $\mathrm{SO}^{18} \mathrm{O} 26_{6,19}-25_{5,20}$ & 88950.657 & 3.68 & 347.0 & noise level & & \\
\hline $\mathrm{SO}^{18} \mathrm{O} 8_{3,5}-9_{2,8}$ & 90082.440 & 1.13 & 52.9 & 90082.6 & 8.5 & 0.02 \\
\hline $\mathrm{SO}^{18} \mathrm{O} 24_{6,18}-25_{5,21}$ & 90093.680 & 3.68 & 347.0 & noise level & $\ldots$ & \\
\hline $\mathrm{SO}^{18} \mathrm{O} 11_{1,10}-10_{2,9}$ & 90833.653 & 2.81 & 61.5 & 90835.5 & 2.9 & 0.02 \\
\hline $\mathrm{SO}^{18} \mathrm{O} 13_{4,10}-14_{3,11}$ & 91008.626 & 1.93 & 117.4 & 36 & $\cdots$ & $\cdots$ \\
\hline $\mathrm{SO}^{18} \mathrm{O} 22_{3,19}-21_{4,18}$ & 94940.503 & 3.67 & 243.9 & 32 & $\ldots$ & $\ldots$ \\
\hline $\mathrm{SO}^{18} \mathrm{O} 13_{4,9}-14_{3,12}$ & 95583.519 & 1.92 & 117.4 & noise level & $\ldots$ & $\ldots$ \\
\hline $\mathrm{SO}^{18} \mathrm{O} 27_{3,25}-26_{4,22}$ & 97271.829 & 3.31 & 349.7 & $97273.5^{65}$ & $\ldots$ & 0.02 \\
\hline $\mathrm{SO}^{18} \mathrm{O} 10_{1,9}-10_{0,10}$ & 98201.071 & 6.89 & 51.7 & 98201.5 & 7.7 & 0.07 \\
\hline $\mathrm{SO}^{18} \mathrm{O} 28_{4,24}-27_{5,23}$ & 98879.028 & 4.52 & 393.7 & 98881.4 & 1.8 & 0.02 \\
\hline $\mathrm{SO}^{18} \mathrm{O} 3_{1,3}-2_{0,2}$ & 100072.226 & 2.01 & 7.4 & & & \\
\hline $\mathrm{SO}^{18} \mathrm{O} 18_{5,14}-19_{4,15}$ & 100152.038 & 2.70 & 208.5 & $100152.6^{1,34}$ & 7.3 & 0.07 \\
\hline $\mathrm{SO}^{18} \mathrm{O} 2_{2,0}-3_{1,3}$ & 100241.696 & 0.16 & 12.2 & 66 & $\cdots$ & \\
\hline $\mathrm{SO}^{18} \mathrm{O}_{3,5}-8_{2,6}$ & 101189.989 & 0.94 & 45.9 & 16 & $\cdots$ & $\cdots$ \\
\hline $\mathrm{SO}^{18} \mathrm{O} 18_{5,13}-19_{4,16}$ & 102098.856 & 2.69 & 208.5 & 102099.5 & 7.1 & 0.01 \\
\hline $\mathrm{SO}^{18} \mathrm{O} 28_{3,26}-27_{4,23}$ & 103761.584 & 3.21 & 373.9 & $103761.5^{17}$ & 9.2 & 0.04 \\
\hline $\mathrm{SO}^{18} \mathrm{O}_{3,4}-8_{2,7}$ & 107207.806 & 0.92 & 45.9 & $107210.5^{67}$ & 1.5 & 0.06 \\
\hline $\mathrm{SO}^{18} \mathrm{O} 29_{3,27}-28_{4,24}$ & 108156.775 & 3.07 & 398.9 & 108158.5 & 4.2 & 0.03 \\
\hline $\mathrm{SO}^{18} \mathrm{O} 23_{6,18}-24_{5,19}$ & 108397.195 & 3.47 & 326.1 & 108398.5 & 5.4 & 0.02 \\
\hline $\mathrm{SO}^{18} \mathrm{O} 8_{0,8}-7_{1,7}$ & 108695.341 & 4.54 & 30.9 & $108697.5^{16}$ & 3.0 & 0.05 \\
\hline $\mathrm{SO}^{18} \mathrm{O} 23_{6,17}-24_{5,20}$ & 109165.615 & 3.46 & 326.1 & 31 & & \\
\hline $\mathrm{SO}^{18} \mathrm{O} 11_{1,1}-11_{0,11}$ & 109636.196 & 6.93 & 61.5 & 109637.5 & 5.4 & 0.07 \\
\hline $\mathrm{SO}^{18} \mathrm{O} 12_{4,9}-13_{3,10}$ & 110819.438 & 1.71 & 106.1 & $110820.5^{53}$ & 6.1 & 0.06 \\
\hline $\mathrm{SO}^{18} \mathrm{O} 12_{4,8}-13_{3,11}$ & 113802.293 & 1.70 & 106.1 & 7 & $\cdots$ & $\cdots$ \\
\hline $\mathrm{SO}^{18} \mathrm{O} 17_{2,15}-16_{3,14}$ & 113985.361 & 3.28 & 145.3 & 4 & & $\ldots$ \\
\hline $\mathrm{SO}^{18} \mathrm{O} 4_{1,4}-3_{0,3}$ & 115401.986 & 2.55 & 10.7 & 115404.5 & 2.5 & 0.08 \\
\hline $\mathrm{SO}^{18} \mathrm{O} 5_{1,5}-4_{0,4}$ & 130142.719 & 3.12 & 14.9 & 130146.4 & 0.5 & 0.13 \\
\hline $\mathrm{SO}^{18} \mathrm{O} 11_{4,8}-12_{3,9}$ & 130201.251 & 1.49 & 95.7 & 6 & & . \\
\hline $\mathrm{SO}^{18} \mathrm{O} 8_{2,6}-8_{1,7}$ & 131766.987 & 5.61 & 41.1 & 131767.6 & 7.6 & 0.13 \\
\hline $\mathrm{SO}^{18} \mathrm{O} 15_{2,13}-15_{1,14}$ & 131783.379 & 12.5 & 115.7 & $131785.5^{68}$ & 4.2 & 0.14 \\
\hline $\mathrm{SO}^{18} \mathrm{O} 11_{4,7}-12_{3,10}$ & 132076.129 & 1.49 & 95.7 & $132076.4^{17}$ & 8.4 & 0.09 \\
\hline $\mathrm{SO}^{18} \mathrm{O} 7_{2,5}-7_{1,6}$ & 134717.922 & 4.66 & 34.0 & 134719.6 & 5.3 & 0.14 \\
\hline $\mathrm{SO}^{18} \mathrm{O} 16_{2,14}-16_{1,15}$ & 136657.242 & 13.1 & 130.1 & 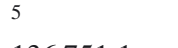 & $\tilde{\tau}$ & $\ldots$ \\
\hline $\mathrm{SO}^{18} \mathrm{O} 13_{1,12}-13_{0,13}$ & 136749.392 & 6.80 & 83.8 & 136751.1 & 5.3 & 0.21 \\
\hline $\mathrm{SO}^{18} \mathrm{O} 6_{2,4}-6_{1,5}$ & 137821.359 & 3.79 & 27.9 & 137824.5 & 2.2 & 0.20 \\
\hline $\mathrm{SO}^{18} \mathrm{O} 16_{5,12}-17_{4,13}$ & 138730.445 & 2.26 & 178.1 & $138730.5^{17}$ & 8.9 & 0.12 \\
\hline $\mathrm{SO}^{18} \mathrm{O} 16_{5,11}-17_{4,14}$ & 139548.900 & 2.26 & 178.1 & 139551.4 & 3.6 & 0.11 \\
\hline $\mathrm{SO}^{18} \mathrm{O} 5_{3,3}-6_{2,4}$ & 140259.456 & 0.50 & 34.6 & 53 & & $\cdots$ \\
\hline $\mathrm{SO}^{18} \mathrm{O} 5_{2,3}-5_{1,4}$ & 140879.971 & 2.99 & 22.7 & 140880.5 & 7.9 & 0.11 \\
\hline $\mathrm{SO}^{18} \mathrm{O} 13_{1,12}-12_{2,11}$ & 141009.800 & 3.85 & 83.8 & 141012.7 & 2.8 & 0.12 \\
\hline $\mathrm{SO}^{18} \mathrm{O} 18_{2,16}-17_{3,15}$ & 141890.087 & 3.64 & 161.4 & 141891.6 & 5.8 & 0.08 \\
\hline $\mathrm{SO}^{18} \mathrm{O} 17_{2,15}-17_{1,16}$ & 143096.211 & 13.6 & 145.3 & 16 & $\ldots$ & $\ldots$ \\
\hline $\mathrm{SO}^{18} \mathrm{O} 4_{2,2}-4_{1,3}$ & 143714.712 & 2.26 & 18.3 & 143715.5 & 7.4 & 0.10 \\
\hline $\mathrm{SO}^{18} \mathrm{O} 6_{1,6}-5_{0,5}$ & 144375.674 & 3.74 & 19.9 & 144377.6 & 5.0 & 0.14 \\
\hline
\end{tabular}


Table A.9. continued.

\begin{tabular}{|c|c|c|c|c|c|c|}
\hline $\begin{array}{l}\text { Species/Transition } \\
J_{K_{a}, K_{c}}-J_{K_{a}^{\prime}, K_{c}^{\prime}}^{\prime}\end{array}$ & $\begin{array}{r}\text { Predicted } \\
\text { freq. } \\
(\mathrm{MHz}) \\
\end{array}$ & $S_{\mathrm{ij}}$ & $\begin{array}{r}E_{\mathrm{u}} \\
(\mathrm{K})\end{array}$ & $\begin{array}{l}\text { Observed } \\
\text { freq. } \\
(\mathrm{MHz})\end{array}$ & $\begin{array}{r}\text { Observed } \\
v_{\mathrm{LSR}} \\
\left(\mathrm{km} \mathrm{s}^{-1}\right) \\
\end{array}$ & $\begin{array}{l}\text { Observed } \\
T_{\mathrm{A}}^{*} \\
(\mathrm{~K}) \\
\end{array}$ \\
\hline $\mathrm{SO}^{18} \mathrm{O} 3_{2,1}-3_{1,2}$ & 146171.277 & 1.57 & 14.8 & 1 & & \\
\hline $\mathrm{SO}^{18} \mathrm{O} 21_{6,16}-22_{5,17}$ & 146720.814 & 3.03 & 287.0 & $146725.4^{17}$ & -0.4 & 0.03 \\
\hline $\mathrm{SO}^{18} \mathrm{O} 21_{6,15}-22_{5,18}$ & 147048.896 & 3.03 & 287.0 & & . & $\ldots$ \\
\hline $\mathrm{SO}^{18} \mathrm{O} 2_{2,0}-2_{1,1}$ & 148124.155 & 0.87 & 12.2 & $148125.1^{17}$ & 7.1 & 0.24 \\
\hline $\mathrm{SO}^{18} \mathrm{O} 10_{4,7}-11_{3,8}$ & 149240.910 & 1.27 & 86.1 & 149241.3 & 8.2 & 0.08 \\
\hline $\mathrm{SO}^{18} \mathrm{O} 10_{0,10}-9_{1,9}$ & 150298.672 & 6.34 & 47.0 & 150301.4 & 3.6 & 0.18 \\
\hline $\mathrm{SO}^{18} \mathrm{O} 10_{4,6}-11_{3,9}$ & 150370.440 & 1.27 & 86.1 & & $\ldots$ & $\ldots$ \\
\hline $\mathrm{SO}^{18} \mathrm{O} 18_{2,16}-18_{1,17}$ & 151170.878 & 13.9 & 161.4 & $151172.6^{41}$ & 5.6 & 0.13 \\
\hline $\mathrm{SO}^{18} \mathrm{O} 24_{3,21}-23_{4,20}$ & 151524.215 & 4.17 & 285.9 & 151525.1 & 7.3 & 0.05 \\
\hline $\mathrm{SO}^{18} \mathrm{O} 2_{2,1}-2_{1,2}$ & 152273.960 & 0.83 & 12.2 & & & \\
\hline $\mathrm{SO}^{18} \mathrm{O} 14_{1,13}-14_{0,14}$ & 152276.995 & 6.68 & 96.2 & 152278.9 & 5.3 & 0.22 \\
\hline $\mathrm{SO}^{18} \mathrm{O} 3_{2,2}-3_{1,3}$ & 154383.207 & 1.44 & 14.8 & 154385.1 & 5.3 & 0.11 \\
\hline $\mathrm{SO}^{18} \mathrm{O} 4_{2,3}-4_{1,4}$ & 157205.792 & 1.98 & 18.3 & 157206.4 & 7.8 & 0.17 \\
\hline $\mathrm{SO}^{18} \mathrm{O} 15_{5,11}-16_{4,12}$ & 157677.252 & 2.04 & 164.2 & $157679.5^{40}$ & 4.7 & 0.11 \\
\hline $\mathrm{SO}^{18} \mathrm{O} 15_{5,10}-16_{4,13}$ & 158186.297 & 2.04 & 164.2 & 49 & $\ldots$ & $\ldots$ \\
\hline $\mathrm{SO}^{18} \mathrm{O} 7_{1,7}-6_{0,6}$ & 158202.045 & 4.40 & 25.7 & 49 & $\ldots$ & $\ldots$ \\
\hline $\mathrm{SO}^{18} \mathrm{O} 4_{3,2}-5_{2,3}$ & 159085.121 & 0.30 & 30.3 & 17 & $\ldots$ & $\ldots$ \\
\hline $\mathrm{SO}^{18} \mathrm{O} 4_{3,1}-5_{2,4}$ & 160099.923 & 0.30 & 30.3 & $160102.7^{17}$ & 3.8 & 0.19 \\
\hline $\mathrm{SO}^{18} \mathrm{O} 5_{2,4}-5_{1,5}$ & 160749.394 & 2.46 & 22.6 & 160750.5 & 6.9 & 0.19 \\
\hline $\mathrm{SO}^{18} \mathrm{O} 19_{2,17}-19_{1,18}$ & 160926.624 & 14.0 & 178.4 & 160927.5 & 7.4 & 0.15 \\
\hline $\mathrm{SO}^{18} \mathrm{O} 6_{2,5}-6_{1,6}$ & 165022.264 & 2.91 & 27.8 & 165023.9 & 6.0 & 0.14 \\
\hline $\mathrm{SO}^{18} \mathrm{O} 9_{2,7}-8_{2,6}$ & 165236.094 & 8.55 & 49.0 & 49 & $\ldots$ & $\ldots$ \\
\hline $\mathrm{SO}^{18} \mathrm{O} 20_{6,15}-21_{5,16}$ & 165650.855 & 2.82 & 268.7 & 5 & $\ldots$ & $\ldots$ \\
\hline $\mathrm{SO}^{18} \mathrm{O} 20_{6,14}-21_{5,17}$ & 165858.555 & 2.82 & 268.7 & 1,24 & $\ldots$ & $\ldots$ \\
\hline $\mathrm{SO}^{18} \mathrm{O} 14_{1,13}-13_{2,12}$ & 166375.483 & 4.45 & 96.2 & $166377.6^{70,71}$ & 5.2 & 0.15 \\
\hline $\mathrm{SO}^{18} \mathrm{O} 9_{4,6}-10_{3,7}$ & 168012.811 & 1.05 & 77.5 & $168014.5^{17}$ & 6.0 & 0.15 \\
\hline $\mathrm{SO}^{18} \mathrm{O} 9_{4,5}-10_{3,8}$ & 168660.086 & 1.05 & 77.5 & & & $\ldots$ \\
\hline $\mathrm{SO}^{18} \mathrm{O} 15_{1,14}-15_{0,15}$ & 168946.152 & 6.55 & 109.4 & $168947.5^{53}$ & 6.6 & 0.21 \\
\hline $\mathrm{SO}^{18} \mathrm{O} 7_{2,6}-7_{1,7}$ & 170032.391 & 3.32 & 33.9 & 5 & $\ldots$ & $\ldots$ \\
\hline $\mathrm{SO}^{18} \mathrm{O} 19_{2,17}-18_{3,16}$ & 170334.178 & 4.04 & 178.4 & 4 & $\ldots$ & $\ldots$ \\
\hline $\mathrm{SO}^{18} \mathrm{O} 11_{0,11}-10_{1,10}$ & 170740.229 & 7.31 & 56.3 & 49 & $\ldots$ & $\ldots$ \\
\hline $\mathrm{SO}^{18} \mathrm{O} 8_{1,8}-7_{0,7}$ & 171738.990 & 5.13 & 32.3 & 4 & $\ldots$ & $\ldots$ \\
\hline $\mathrm{SO}^{18} \mathrm{O} 20_{2,18}-20_{1,19}$ & 172376.560 & 14.1 & 196.3 & 5 & $\ldots$ & $\ldots$ \\
\hline $\mathrm{SO}^{18} \mathrm{O} 25_{7,19}-26_{6,20}$ & 173292.221 & 3.59 & 399.7 & 7 & $\ldots$ & $\ldots$ \\
\hline $\mathrm{SO}^{18} \mathrm{O} 25_{7,18}-26_{6,21}$ & 173372.106 & 3.59 & 399.7 & 9 & $\ldots$ & $\ldots$ \\
\hline $\mathrm{SO}^{18} \mathrm{O} 8_{2,7}-8_{1,8}$ & 175786.587 & 3.70 & 40.8 & 3 & $\ldots$ & $\ldots$ \\
\hline $\mathrm{SO}^{18} \mathrm{O} 14_{5,10}-15_{4,11}$ & 176449.762 & 1.82 & 151.1 & 17 & $\ldots$ & $\ldots$ \\
\hline $\mathrm{SO}^{18} \mathrm{O} 14_{5,9}-15_{4,12}$ & 176756.335 & 1.82 & 151.1 & 34 & $\ldots$ & $\ldots$ \\
\hline $\mathrm{SO}^{18} \mathrm{O} 3_{3,1}-4_{2,2}$ & 177592.074 & 0.13 & 26.8 & $177593.6^{72}$ & 6.4 & 0.33 \\
\hline $\mathrm{SO}^{18} \mathrm{O} 3_{3,0}-4_{2,3}$ & 178027.433 & 0.13 & 26.8 & 17 & $\ldots$ & $\ldots$ \\
\hline $\mathrm{SO}^{18} \mathrm{O} 25_{3,22}-25_{2,23}$ & 196757.077 & 20.2 & 308.3 & 6 & $\ldots$ & $\ldots$ \\
\hline $\mathrm{SO}^{18} \mathrm{O} 11_{2,10}-11_{1,11}$ & 197543.946 & 4.61 & 66.7 & 4 & $\cdots$ & $\cdots$ \\
\hline $\mathrm{SO}^{18} \mathrm{O} 19_{3,16}-19_{2,17}$ & 198011.793 & 13.9 & 187.9 & 5 & $\ldots$ & $\cdots$ \\
\hline $\mathrm{SO}^{18} \mathrm{O} 10_{1,10}-9_{0,9}$ & 198451.881 & 6.74 & 48.1 & 198454.9 & 4.4 & 0.23 \\
\hline $\mathrm{SO}^{18} \mathrm{O} 20_{2,18}-19_{3,17}$ & 199209.147 & 4.48 & 196.3 & 17 & $\ldots$ & $\ldots$ \\
\hline $\mathrm{SO}^{18} \mathrm{O} 22_{2,20}-22_{1,21}$ & 200212.306 & 13.8 & 234.8 & 200213.6 & 7.1 & 0.09 \\
\hline $\mathrm{SO}^{18} \mathrm{O} 26_{3,23}-26_{2,24}$ & 202204.122 & 20.7 & 331.6 & 13 & $\ldots$ & $\ldots$ \\
\hline $\mathrm{SO}^{18} \mathrm{O} 3_{2,2}-2_{1,1}$ & 202265.667 & 1.67 & 14.8 & 13 & 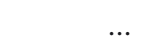 & $\ldots$ \\
\hline $\mathrm{SO}^{18} \mathrm{O} 18_{3,15}-18_{2,16}$ & 202393.329 & 12.7 & 171.1 & 202393.2 & 9.2 & 0.11 \\
\hline $\mathrm{SO}^{18} \mathrm{O} 18_{6,13}-19_{5,14}$ & 203148.227 & 2.38 & 234.8 & 203150.9 & 5.1 & 0.13 \\
\hline $\mathrm{SO}^{18} \mathrm{O} 18_{6,12}-19_{5,15}$ & 203225.585 & 2.38 & 234.8 & 23 & & 0.18 \\
\hline $\mathrm{SO}^{18} \mathrm{O}_{4,4}-8_{3,5}$ & 204989.937 & 0.63 & 62.7 & 204993.6 & 3.6 & 0.10 \\
\hline $\mathrm{SO}^{18} \mathrm{O} 17_{1,16}-17_{0,17}$ & 205002.547 & 6.31 & 138.4 & 5,7 & & $\ldots$ \\
\hline $\mathrm{SO}^{18} \mathrm{O}_{4,3}-8_{3,6}$ & 205164.732 & 0.63 & 62.7 & $205167.4^{26}$ & 5.1 & 0.42 \\
\hline $\mathrm{SO}^{18} \mathrm{O} 12_{2,11}-12_{1,12}$ & 206285.933 & 4.85 & 77.0 & 206286.2 & 8.6 & 0.28 \\
\hline $\mathrm{SO}^{18} \mathrm{O} 3_{2,1}-2_{1,2}$ & 206589.735 & 1.60 & 14.8 & 7 & $\ldots$ & $\ldots$ \\
\hline $\mathrm{SO}^{18} \mathrm{O} 17_{3,14}-17_{2,15}$ & 207401.220 & 11.5 & 155.2 & $4,7,73$ & $\ldots$ & $\ldots$ \\
\hline $\mathrm{SO}^{18} \mathrm{O} 27_{3,24}-27_{2,25}$ & 209536.690 & 21.1 & 355.8 & 16 & $\cdots$ & $\cdots$ \\
\hline $\mathrm{SO}^{18} \mathrm{O} 13_{0,13}-12_{1,12}$ & 210546.341 & 9.34 & 77.2 & $210548.7^{34}$ & 5.6 & 1.23 \\
\hline $\mathrm{SO}^{18} \mathrm{O} 11_{1,11}-10_{0,10}$ & 211873.232 & 7.63 & 57.2 & $211873.6^{60}$ & 8.5 & 0.82 \\
\hline $\mathrm{SO}^{18} \mathrm{O} 26_{3,23}-25_{4,22}$ & 211913.681 & 4.76 & 331.6 & noisy spectrum & $\ldots$ & $\ldots$ \\
\hline $\mathrm{SO}^{18} \mathrm{O} 16_{3,13}-16_{2,14}$ & 212789.912 & 10.4 & 140.3 & 32 & $\begin{array}{l}\cdots \\
\ldots\end{array}$ & $\ldots$ \\
\hline
\end{tabular}


Table A.9. continued.

\begin{tabular}{|c|c|c|c|c|c|c|}
\hline $\begin{array}{l}\text { Species/Transition } \\
J_{K_{a}, K_{c}}-J_{K_{a}^{\prime}, K_{c}^{\prime}}^{\prime}\end{array}$ & $\begin{array}{r}\text { Predicted } \\
\text { freq. } \\
(\mathrm{MHz})\end{array}$ & $S_{\mathrm{ij}}$ & $\begin{array}{r}E_{\mathrm{u}} \\
(\mathrm{K})\end{array}$ & $\begin{array}{l}\text { Observed } \\
\text { freq. } \\
(\mathrm{MHz})\end{array}$ & $\begin{array}{r}\text { Observed } \\
v_{\mathrm{LSR}} \\
\left(\mathrm{km} \mathrm{s}^{-1}\right)\end{array}$ & $\begin{array}{l}\text { Observed } \\
T_{\mathrm{A}}^{*} \\
(\mathrm{~K})\end{array}$ \\
\hline $\mathrm{SO}^{18} \mathrm{O} 12_{5,8}-13_{4,9}$ & 213591.909 & 1.39 & 127.7 & 213593.6 & 6.6 & 0.11 \\
\hline $\mathrm{SO}^{18} \mathrm{O} 12_{5,7}-13_{4,10}$ & 213691.030 & 1.39 & 127.7 & 213694.9 & 3.6 & 0.09 \\
\hline $\mathrm{SO}^{18} \mathrm{O} 13_{2,12}-13_{1,13}$ & 215756.356 & 5.05 & 88.2 & $215757.4^{4}$ & 7.6 & 0.51 \\
\hline $\mathrm{SO}^{18} \mathrm{O} 23_{2,21}-23_{1,22}$ & 216415.486 & 13.6 & 255.3 & $216416.1^{9}$ & 8.1 & 0.16 \\
\hline $\mathrm{SO}^{18} \mathrm{O} 16_{1,15}-15_{2,14}$ & 217102.694 & 5.86 & 123.5 & & $\ldots$ & $\ldots$ \\
\hline $\mathrm{SO}^{18} \mathrm{O} 4_{2,3}-3_{1,2}$ & 218230.244 & 1.88 & 18.3 & 15 & $\ldots$ & $\ldots$ \\
\hline $\mathrm{SO}^{18} \mathrm{O} 15_{3,12}-15_{2,13}$ & 218316.801 & 9.40 & 126.2 & 56 & $\ldots$ & $\ldots$ \\
\hline $\mathrm{SO}^{18} \mathrm{O} 28_{3,25}-28_{2,26}$ & 218793.885 & 21.3 & 380.9 & 218796.1 & 6.0 & 0.09 \\
\hline $\mathrm{SO}^{18} \mathrm{O} 17_{6,12}-18_{5,13}$ & 221746.496 & 2.16 & 219.2 & & 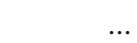 & $\ldots$ \\
\hline $\mathrm{SO}^{18} \mathrm{O} 17_{6,11}-18_{5,14}$ & 221791.775 & 2.16 & 219.2 & $221794.9^{17}$ & 4.8 & 0.57 \\
\hline $\mathrm{SO}^{18} \mathrm{O} 6_{4,3}-7_{3,4}$ & 223286.066 & 0.43 & 56.6 & 223287.4 & 7.2 & 0.09 \\
\hline $\mathrm{SO}^{18} \mathrm{O} 6_{4,2}-7_{3,5}$ & 223365.572 & 0.43 & 56.6 & $223367.4^{4}$ & 6.5 & 0.15 \\
\hline $\mathrm{SO}^{18} \mathrm{O} 14_{3,11}-14_{2,12}$ & 223753.919 & 8.47 & 113.1 & 223757.4 & 4.3 & 0.33 \\
\hline $\mathrm{SO}^{18} \mathrm{O} 18_{1,17}-18_{0,18}$ & 223997.568 & 6.22 & 154.2 & 4 & $\ldots$ & $\ldots$ \\
\hline $\mathrm{SO}^{18} \mathrm{O} 12_{1,12}-11_{0,11}$ & 225476.608 & 8.56 & 67.1 & 225479.8 & 4.8 & 0.33 \\
\hline $\mathrm{SO}^{18} \mathrm{O} 14_{2,13}-14_{1,14}$ & 225937.235 & 5.23 & 100.2 & 225939.9 & 5.5 & 0.16 \\
\hline $\mathrm{SO}^{18} \mathrm{O} 4_{2,2}-3_{1,3}$ & 227022.358 & 1.72 & 18.3 & 5 & . & 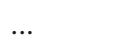 \\
\hline $\mathrm{SO}^{18} \mathrm{O} 21_{2,19}-20_{3,18}$ & 228399.026 & 4.97 & 215.1 & 228403.5 & 3.1 & 0.06 \\
\hline $\mathrm{SO}^{18} \mathrm{O} 13_{3,10}-13_{2,11}$ & 228899.481 & 7.61 & 100.8 & $228901.1^{25}$ & 6.9 & 1.25 \\
\hline $\mathrm{SO}^{18} \mathrm{O} 22_{7,16}-23_{6,17}$ & 229536.105 & 2.93 & 337.1 & $229541.1^{5}$ & 2.5 & 0.27 \\
\hline $\mathrm{SO}^{18} \mathrm{O} 22_{7,15}-23_{6,18}$ & 229554.746 & 2.93 & 337.1 & 229557.4 & 5.5 & 0.12 \\
\hline $\mathrm{SO}^{18} \mathrm{O} 14_{0,14}-13_{1,13}$ & 229854.843 & 10.4 & 88.9 & 23 & & \\
\hline $\mathrm{SO}^{18} \mathrm{O} 29_{3,26}-29_{2,27}$ & 229980.850 & 21.3 & 406.9 & 229984.9 & 3.7 & 0.15 \\
\hline $\mathrm{SO}^{18} \mathrm{O} 11_{5,7}-12_{4,8}$ & 232008.234 & 1.17 & 117.3 & 4 & & $\ldots$ \\
\hline $\mathrm{SO}^{18} \mathrm{O} 11_{5,6}-12_{4,9}$ & 232060.800 & 1.17 & 117.3 & 232064.9 & 3.7 & 0.16 \\
\hline $\mathrm{SO}^{18} \mathrm{O} 17_{3,15}-18_{0,18}$ & 233278.358 & 0.12 & 154.6 & 4 & $\cdots$ & $\ldots$ \\
\hline $\mathrm{SO}^{18} \mathrm{O} 5_{2,4}-4_{1,3}$ & 233497.590 & 2.12 & 22.6 & 4 & $\ldots$ & $\ldots$ \\
\hline $\mathrm{SO}^{18} \mathrm{O} 12_{3,9}-12_{2,10}$ & 233588.336 & 6.82 & 89.5 & 6 & $\ldots$ & $\ldots$ \\
\hline $\mathrm{SO}^{18} \mathrm{O} 24_{2,22}-24_{1,23}$ & 233949.989 & 13.3 & 276.6 & $233950.5^{6,36}$ & 8.3 & 0.27 \\
\hline $\mathrm{SO}^{18} \mathrm{O} 18_{3,16}-19_{0,19}$ & 233967.257 & 0.13 & 170.3 & 6 & $\cdots$ & $\ldots$ \\
\hline $\mathrm{SO}^{18} \mathrm{O} 16_{3,14}-17_{0,17}$ & 234113.397 & 0.11 & 139.8 & 5 & $\begin{array}{l}\cdots \\
\cdots\end{array}$ & $\cdots$ \\
\hline $\mathrm{SO}^{18} \mathrm{O} 19_{3,17}-20_{0,20}$ & 236122.215 & 0.14 & 186.8 & 17 & $\cdots$ & $\ldots$ \\
\hline $\mathrm{SO}^{18} \mathrm{O} 15_{3,13}-16_{0,16}$ & 236522.092 & 0.10 & 125.9 & 56 & $\begin{array}{l}\cdots \\
\cdots\end{array}$ & $\cdots$ \\
\hline $\mathrm{SO}^{18} \mathrm{O} 15_{2,14}-15_{1,15}$ & 236804.935 & 5.38 & 113.1 & 5,6 & $\begin{array}{l}\cdots \\
\cdots\end{array}$ & $\begin{array}{l}\cdots \\
\cdots\end{array}$ \\
\hline $\mathrm{SO}^{18} \mathrm{O} 27_{8,20}-28_{7,21}$ & 237018.562 & 3.70 & 481.6 & 237021.5 & 5.3 & 0.14 \\
\hline $\mathrm{SO}^{18} \mathrm{O} 27_{8,19}-28_{7,22}$ & 237025.774 & 3.70 & 481.6 & 237026.5 & 8.1 & 0.17 \\
\hline $\mathrm{SO}^{18} \mathrm{O} 11_{3,8}-11_{2,9}$ & 237700.285 & 6.09 & 79.0 & 237706.3 & 1.4 & 0.18 \\
\hline $\mathrm{SO}^{18} \mathrm{O} 13_{1,13}-12_{0,12}$ & 239336.024 & 9.53 & 77.8 & 239340.2 & 3.8 & 0.45 \\
\hline $\mathrm{SO}^{18} \mathrm{O} 16_{6,11}-17_{5,12}$ & 240261.313 & 1.94 & 204.4 & 35 & $\ldots$ & $\ldots$ \\
\hline $\mathrm{SO}^{18} \mathrm{O} 16_{6,10}-17_{5,13}$ & 240286.978 & 1.94 & 204.4 & 5 & $\ldots$ & $\ldots$ \\
\hline $\mathrm{SO}^{18} \mathrm{O} 10_{3,7}-10_{2,8}$ & 241165.049 & 5.40 & 69.4 & 16 & $\ldots$ & $\ldots$ \\
\hline $\mathrm{SO}^{18} \mathrm{O} 5_{4,2}-6_{3,3}$ & 241499.067 & 0.25 & 51.4 & 7,23 & $\cdots$ & $\cdots$ \\
\hline $\mathrm{SO}^{18} \mathrm{O} 5_{4,1}-6_{3,4}$ & 241530.882 & 0.25 & 51.4 & 7 & $\begin{array}{l}\cdots \\
\cdots\end{array}$ & $\begin{array}{l}\cdots \\
\cdots\end{array}$ \\
\hline $\mathrm{SO}^{18} \mathrm{O} 17_{1,16}-16_{2,15}$ & 242215.554 & 6.66 & 138.4 & 4 & $\cdots$ & $\begin{array}{l}\cdots \\
\ldots\end{array}$ \\
\hline $\mathrm{SO}^{18} \mathrm{O} 30_{3,27}-30_{2,28}$ & 243063.849 & 21.2 & 433.8 & 243066.3 & 6.0 & 0.43 \\
\hline $\mathrm{SO}^{18} \mathrm{O} 27_{3,24}-26_{4,23}$ & 243287.035 & 5.11 & 355.8 & 34 & & - \\
\hline $\mathrm{SO}^{18} \mathrm{O} 19_{1,18}-19_{0,19}$ & 243374.811 & 6.15 & 170.7 & 243377.6 & 5.6 & 0.17 \\
\hline $\mathrm{SO}^{18} \mathrm{O} 33_{4,29}-32_{5,28}$ & 243806.001 & 5.57 & 531.7 & $243810.5^{17}$ & 3.5 & 0.33 \\
\hline $\mathrm{SO}^{18} \mathrm{O} 9_{3,6}-9_{2,7}$ & 243962.753 & 4.75 & 60.7 & 243965.5 & 5.6 & 0.41 \\
\hline $\mathrm{SO}^{18} \mathrm{O} 21_{3,19}-22_{0,22}$ & 244570.319 & 0.14 & 222.4 & 33 & 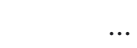 & 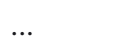 \\
\hline $\mathrm{SO}^{18} \mathrm{O} 8_{3,5}-8_{2,6}$ & 246119.337 & 4.12 & 52.9 & 246122.6 & 5.0 & 0.32 \\
\hline $\mathrm{SO}^{18} \mathrm{O} 13_{3,11}-14_{0,14}$ & 246199.086 & 0.07 & 100.7 & 56 & $\cdots$ & $\cdots$ \\
\hline $\mathrm{SO}^{18} \mathrm{O}_{3,4}-7_{2,5}$ & 247697.435 & 3.50 & 45.9 & 5 & ... & ... \\
\hline $\mathrm{SO}^{18} \mathrm{O} 6_{2,5}-5_{1,4}$ & 248074.508 & 2.38 & 27.8 & 49 & $\ldots$ & $\ldots$ \\
\hline $\mathrm{SO}^{18} \mathrm{O} 21_{7,15}-22_{6,16}$ & 248124.713 & 2.71 & 318.0 & $248128.9^{17}$ & 3.9 & 0.35 \\
\hline $\mathrm{SO}^{18} \mathrm{O} 21_{7,14}-22_{6,17}$ & 248135.684 & 2.71 & 318.0 & no spectrum & & $\ldots$ \\
\hline $\mathrm{SO}^{18} \mathrm{O} 16_{2,15}-16_{1,16}$ & 248330.358 & 5.50 & 126.8 & 248332.6 & 6.3 & 0.30 \\
\hline $\mathrm{SO}^{18} \mathrm{O} 5_{2,3}-4_{1,4}$ & 248435.799 & 1.83 & 22.7 & 4 & $\ldots$ & $\ldots$ \\
\hline $\mathrm{SO}^{18} \mathrm{O} 15_{0,15}-14_{1,14}$ & 248771.504 & 11.4 & 101.3 & 248772.5 & 7.8 & 0.75 \\
\hline $\mathrm{SO}^{18} \mathrm{O} 6_{3,3}-6_{2,4}$ & 248784.360 & 2.89 & 39.8 & & & $\ldots$ \\
\hline $\mathrm{SO}^{18} \mathrm{O} 5_{3,2}-5_{2,3}$ & 249479.459 & 2.26 & 34.6 & $249483.9^{7,71}$ & 3.7 & 0.36 \\
\hline $\mathrm{SO}^{18} \mathrm{O} 4_{3,1}-4_{2,2}$ & 249882.801 & 1.61 & 30.3 & 16 & $\ldots$ & $\ldots$ \\
\hline
\end{tabular}


Table A.9. continued.

\begin{tabular}{|c|c|c|c|c|c|c|}
\hline $\begin{array}{l}\text { Species/Transition } \\
J_{K_{a}, K_{c}}-J_{K_{a}^{\prime}, K_{c}^{\prime}}^{\prime}\end{array}$ & $\begin{array}{r}\text { Predicted } \\
\text { freq. } \\
(\mathrm{MHz})\end{array}$ & $S_{\mathrm{ij}}$ & $\begin{array}{c}E_{\mathrm{u}} \\
(\mathrm{K})\end{array}$ & $\begin{array}{l}\text { Observed } \\
\text { freq. } \\
(\mathrm{MHz})\end{array}$ & $\begin{array}{r}\text { Observed } \\
v_{\mathrm{LSR}} \\
\left(\mathrm{km} \mathrm{s}^{-1}\right)\end{array}$ & $\begin{array}{l}\text { Observed } \\
T_{\mathrm{A}}^{*} \\
(\mathrm{~K})\end{array}$ \\
\hline $\mathrm{SO}^{18} \mathrm{O} 3_{3,0}-3_{2,1}$ & 250086.400 & 0.89 & 26.8 & 39 & & \\
\hline $\mathrm{SO}^{18} \mathrm{O} 3_{3,1}-3_{2,2}$ & 250231.226 & 0.89 & 26.8 & 250236.3 & 2.9 & 0.15 \\
\hline $\mathrm{SO}^{18} \mathrm{O} 4_{3,2}-4_{2,3}$ & 250315.128 & 1.61 & 30.3 & & $\ldots$ & $\ldots$ \\
\hline $\mathrm{SO}^{18} \mathrm{O} 10_{5,6}-11_{4,7}$ & 250345.658 & 0.96 & 107.7 & 23 & $\ldots$ & $\ldots$ \\
\hline $\mathrm{SO}^{18} \mathrm{O} 10_{5,5}-11_{4,8}$ & 250371.975 & 0.96 & 107.7 & 23 & $\ldots$ & $\ldots$ \\
\hline $\mathrm{SO}^{18} \mathrm{O} 5_{3,3}-5_{2,4}$ & 250481.005 & 2.26 & 34.6 & $250482.6^{19,26,27}$ & 7.1 & 0.58 \\
\hline $\mathrm{SO}^{18} \mathrm{O} 22_{3,20}-23_{0,23}$ & 250723.320 & 0.14 & 241.5 & $250726.5^{72}$ & 5.2 & 0.08 \\
\hline $\mathrm{SO}^{18} \mathrm{O} 6_{3,4}-6_{2,5}$ & 250767.445 & 2.87 & 39.8 & no spectrum & $\ldots$ & $\ldots$ \\
\hline $\mathrm{SO}^{18} \mathrm{O}_{3,5}-7_{2,6}$ & 251218.717 & 3.47 & 45.9 & & $\ldots$ & $\ldots$ \\
\hline $\mathrm{SO}^{18} \mathrm{O} 8_{3,6}-8_{2,7}$ & 251883.714 & 4.06 & 52.9 & 16 & $\ldots$ & $\ldots$ \\
\hline $\mathrm{SO}^{18} \mathrm{O} 32_{4,28}-32_{3,29}$ & 252312.209 & 25.2 & 502.2 & 252316.4 & 4.0 & 0.11 \\
\hline $\mathrm{SO}^{18} \mathrm{O} 33_{4,29}-33_{3,30}$ & 252599.016 & 26.3 & 531.7 & $252601.5^{41}$ & 6.1 & 0.38 \\
\hline $\mathrm{SO}^{18} \mathrm{O} 25_{2,23}-25_{1,24}$ & 252627.480 & 13.1 & 298.8 & $252633.5^{4}$ & 1.9 & 0.55 \\
\hline $\mathrm{SO}^{18} \mathrm{O} 9_{3,7}-9_{2,8}$ & 252814.791 & 4.64 & 60.7 & 16 & $\ldots$ & $\ldots$ \\
\hline $\mathrm{SO}^{18} \mathrm{O} 12_{3,10}-13_{0,13}$ & 253493.155 & 0.06 & 89.4 & 69 & & \\
\hline $\mathrm{SO}^{18} \mathrm{O} 14_{1,14}-13_{0,13}$ & 253497.373 & 10.5 & 89.4 & 253501.3 & 4.4 & 0.28 \\
\hline $\mathrm{SO}^{18} \mathrm{O} 31_{4,27}-31_{3,28}$ & 253792.638 & 24.1 & 473.7 & $253793.5^{17}$ & 8.0 & 0.21 \\
\hline $\mathrm{SO}^{18} \mathrm{O} 10_{3,8}-10_{2,9}$ & 254066.518 & 5.21 & 69.4 & $254068.9^{4}$ & 6.2 & 0.93 \\
\hline $\mathrm{SO}^{18} \mathrm{O} 34_{4,30}-34_{3,31}$ & 254792.758 & 27.2 & 562.1 & 12 & $\cdots$ & $\cdots$ \\
\hline $\mathrm{SO}^{18} \mathrm{O} 26_{8,19}-27_{7,20}$ & 255656.625 & 3.48 & 458.1 & 22,75 & $\cdots$ & $\ldots$ \\
\hline $\mathrm{SO}^{18} \mathrm{O} 26_{8,18}-27_{7,21}$ & 255660.974 & 3.48 & 458.1 & 22,75 & $\ldots$ & $\ldots$ \\
\hline $\mathrm{SO}^{18} \mathrm{O} 11_{3,9}-11_{2,10}$ & 255694.394 & 5.78 & 78.9 & 62 & $\ldots$ & $\ldots$ \\
\hline $\mathrm{SO}^{18} \mathrm{O} 28_{4,25}-29_{1,28}$ & 256635.956 & 0.32 & 392.1 & 256640.4 & 3.8 & 0.07 \\
\hline $\mathrm{SO}^{18} \mathrm{O} 27_{4,24}-28_{1,27}$ & 256860.014 & 0.31 & 367.7 & 51 & $\ldots$ & . \\
\hline $\mathrm{SO}^{18} \mathrm{O} 30_{4,26}-30_{3,27}$ & 256869.345 & 22.8 & 446.1 & 51 & $\ldots$ & ... \\
\hline $\mathrm{SO}^{18} \mathrm{O} 12_{3,10}-12_{2,11}$ & 257753.563 & 6.33 & 89.4 & $257754.5^{5,23}$ & 7.9 & 0.28 \\
\hline $\mathrm{SO}^{18} \mathrm{O} 22_{2,20}-21_{3,19}$ & 257780.402 & 5.51 & 234.8 & $257783.5^{27}$ & 5.4 & 0.12 \\
\hline $\mathrm{SO}^{18} \mathrm{O} 31_{3,28}-31_{2,29}$ & 257966.427 & 21.0 & 461.5 & 257968.5 & 6.6 & 0.19 \\
\hline $\mathrm{SO}^{18} \mathrm{O} 29_{4,26}-30_{1,29}$ & 258050.529 & 0.34 & 417.4 & 5 & $\ldots$ & $\ldots$ \\
\hline $\mathrm{SO}^{18} \mathrm{O} 23_{3,21}-24_{0,24}$ & 258063.984 & 0.14 & 261.4 & 5 & $\ldots$ & $\ldots$ \\
\hline $\mathrm{SO}^{18} \mathrm{O} 15_{6,10}-16_{5,11}$ & 258703.135 & 1.72 & 190.5 & 5 & $\cdots$ & $\cdots$ \\
\hline $\mathrm{SO}^{18} \mathrm{O} 15_{6,9}-16_{5,12}$ & 258717.168 & 1.72 & 190.5 & 258720.5 & 5.1 & 0.12 \\
\hline $\mathrm{SO}^{18} \mathrm{O} 26_{4,23}-27_{1,26}$ & 258800.211 & 0.29 & 344.1 & $258802.5^{17}$ & 6.4 & 0.16 \\
\hline $\mathrm{SO}^{18} \mathrm{O} 35_{4,31}-35_{3,32}$ & 259001.896 & 27.9 & 593.5 & 52 & & $\ldots$ \\
\hline $\mathrm{SO}^{18} \mathrm{O} 29_{2,27}-30_{1,30}$ & 259066.034 & 0.14 & 395.8 & $259070.1^{17}$ & 4.3 & 0.19 \\
\hline $\mathrm{SO}^{18} \mathrm{O} 4_{4,1}-5_{3,2}$ & 259653.472 & 0.10 & 47.1 & 5 & $\ldots$ & $\ldots$ \\
\hline $\mathrm{SO}^{18} \mathrm{O} 4_{4,0}-5_{3,3}$ & 259664.080 & 0.10 & 47.1 & 5 & $\begin{array}{l}\cdots \\
\cdots\end{array}$ & $\cdots$ \\
\hline $\mathrm{SO}^{18} \mathrm{O} 13_{3,11}-13_{2,12}$ & 260297.574 & 6.87 & 100.7 & 6 & $\begin{array}{l}\cdots \\
\cdots\end{array}$ & $\begin{array}{l}\cdots \\
\cdots\end{array}$ \\
\hline $\mathrm{SO}^{18} \mathrm{O} 17_{2,16}-17_{1,17}$ & 260479.408 & 5.60 & 141.3 & 74 & $\cdots$ & $\cdots$ \\
\hline $\mathrm{SO}^{18} \mathrm{O} 30_{4,27}-31_{1,30}$ & 261020.897 & 0.34 & 443.6 & 17 & $\ldots$ & $\ldots$ \\
\hline $\mathrm{SO}^{18} \mathrm{O} 29_{4,25}-29_{3,26}$ & 261340.830 & 21.4 & 419.4 & 261341.4 & 8.3 & 0.48 \\
\hline $\mathrm{SO}^{18} \mathrm{O}_{2,6}-6_{1,5}$ & 261972.250 & 2.67 & 33.9 & $261971.5^{17,41}$ & 9.9 & 0.39 \\
\hline $\mathrm{SO}^{18} \mathrm{O} 11_{3,9}-12_{0,12}$ & 262401.534 & 0.04 & 78.9 & & $\ldots$ & $\ldots$ \\
\hline $\mathrm{SO}^{18} \mathrm{O} 25_{4,22}-26_{1,25}$ & 262526.174 & 0.27 & 321.4 & 30,49 & $\ldots$ & $\ldots$ \\
\hline $\mathrm{SO}^{18} \mathrm{O} 31_{9,23}-32_{8,24}$ & 262894.205 & 4.26 & 624.7 & 7 & $\ldots$ & $\ldots$ \\
\hline $\mathrm{SO}^{18} \mathrm{O} 31_{9,22}-32_{8,25}$ & 262895.846 & 4.26 & 624.7 & 7 & $\ldots$ & $\ldots$ \\
\hline $\mathrm{SO}^{18} \mathrm{O} 20_{1,19}-20_{0,20}$ & 262954.802 & 6.10 & 188.1 & 26 & $\ldots$ & $\ldots$ \\
\hline $\mathrm{SO}^{18} \mathrm{O} 14_{3,12}-14_{2,13}$ & 263377.210 & 7.39 & 112.8 & $263377.6^{5}$ & 8.6 & 0.19 \\
\hline $\mathrm{SO}^{18} \mathrm{O} 36_{4,32}-36_{3,33}$ & 265303.263 & 28.3 & 625.7 & $265302.7^{68}$ & 9.6 & 0.17 \\
\hline $\mathrm{SO}^{18} \mathrm{O} 31_{4,28}-32_{1,31}$ & 265460.709 & 0.35 & 470.6 & 25 & 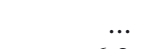 & $\ldots$ \\
\hline $\mathrm{SO}^{18} \mathrm{O} 20_{7,14}-21_{6,15}$ & 266646.030 & 2.49 & 299.8 & 266648.5 & 6.2 & 0.19 \\
\hline $\mathrm{SO}^{18} \mathrm{O} 20_{7,13}-21_{6,16}$ & 266652.322 & 2.49 & 299.8 & $266653.5^{77}$ & 7.7 & 0.24 \\
\hline $\mathrm{SO}^{18} \mathrm{O} 28_{4,24}-28_{3,25}$ & 266977.664 & 20.1 & 393.7 & 266980.5 & 5.8 & 0.32 \\
\hline $\mathrm{SO}^{18} \mathrm{O} 18_{1,17}-17_{2,16}$ & 266993.928 & 7.52 & 154.2 & 6 & & \\
\hline $\mathrm{SO}^{18} \mathrm{O} 15_{3,13}-15_{2,14}$ & 267039.427 & 7.90 & 125.9 & 267043.9 & 4.0 & 0.17 \\
\hline $\mathrm{SO}^{18} \mathrm{O} 16_{0,16}-15_{1,15}$ & 267322.270 & 12.5 & 114.5 & no spectrum & & $\ldots$ \\
\hline $\mathrm{SO}^{18} \mathrm{O} 15_{1,15}-14_{0,14}$ & 267979.833 & 11.5 & 101.7 & 267985.5 & 2.7 & 0.41 \\
\hline $\mathrm{SO}^{18} \mathrm{O} 24_{4,21}-25_{1,24}$ & 268096.198 & 0.24 & 299.6 & $268096.4^{17}$ & 8.8 & 0.31 \\
\hline $\mathrm{SO}^{18} \mathrm{O} 9_{5,5}-10_{4,6}$ & 268618.479 & 0.76 & 99.0 & 268620.5 & 6.7 & 0.19 \\
\hline $\mathrm{SO}^{18} \mathrm{O}_{5,4}-10_{4,7}$ & 268630.772 & 0.76 & 99.0 & & & \\
\hline $\mathrm{SO}^{18} \mathrm{O} 6_{2,4}-5_{1,5}$ & 270970.943 & 1.90 & 27.9 & $270974.5^{34}$ & 5.1 & 0.39 \\
\hline $\mathrm{SO}^{18} \mathrm{O} 32_{4,29}-33_{1,32}$ & 271281.411 & 0.35 & 498.5 & & $\ldots$ & $\ldots$ \\
\hline
\end{tabular}


Table A.9. continued.

\begin{tabular}{|c|c|c|c|c|c|c|}
\hline $\begin{array}{l}\text { Species/Transition } \\
J_{K_{a}, K_{c}}-J_{K_{a}^{\prime}, K_{c}^{\prime}}^{\prime}\end{array}$ & $\begin{array}{r}\text { Predicted } \\
\text { freq. } \\
(\mathrm{MHz})\end{array}$ & $S_{\mathrm{ij}}$ & $\begin{array}{c}E_{\mathrm{u}} \\
(\mathrm{K})\end{array}$ & $\begin{array}{l}\text { Observed } \\
\text { freq. } \\
(\mathrm{MHz})\end{array}$ & $\begin{array}{r}\text { Observed } \\
v_{\mathrm{LSR}} \\
\left(\mathrm{km} \mathrm{s}^{-1}\right)\end{array}$ & $\begin{array}{l}\text { Observed } \\
T_{\mathrm{A}}^{*} \\
(\mathrm{~K})\end{array}$ \\
\hline $\mathrm{SO}^{18} \mathrm{O} 16_{3,14}-16_{2,15}$ & 271326.403 & 8.37 & 139.8 & $271328.9^{36}$ & 6.2 & 0.18 \\
\hline $\mathrm{SO}^{18} \mathrm{O} 26_{2,24}-26_{1,25}$ & 272235.733 & 12.9 & 321.9 & & $\ldots$ & $\ldots$ \\
\hline $\mathrm{SO}^{18} \mathrm{O} 10_{3,8}-11_{0,11}$ & 272869.061 & 0.03 & 69.4 & 56 & $\ldots$ & $\ldots$ \\
\hline $\mathrm{SO}^{18} \mathrm{O} 18_{2,17}-18_{1,18}$ & 273213.674 & 5.69 & 156.7 & 273216.5 & 5.9 & 0.14 \\
\hline $\mathrm{SO}^{18} \mathrm{O} 27_{4,23}-27_{3,24}$ & 273527.753 & 18.7 & 368.9 & 273528.6 & 8.1 & 0.24 \\
\hline $\mathrm{SO}^{18} \mathrm{O} 37_{4,33}-37_{3,34}$ & 273740.474 & 28.6 & 658.9 & 48 & $\ldots$ & $\ldots$ \\
\hline $\mathrm{SO}^{18} \mathrm{O} 25_{8,18}-26_{7,19}$ & 274232.871 & 3.26 & 435.5 & 69 & $\ldots$ & $\ldots$ \\
\hline $\mathrm{SO}^{18} \mathrm{O} 25_{8,17}-26_{7,20}$ & 274235.442 & 3.26 & 435.5 & 274236.3 & 8.1 & 0.08 \\
\hline $\mathrm{SO}^{18} \mathrm{O} 32_{3,29}-32_{2,30}$ & 274568.048 & 20.7 & 490.1 & $274568.5^{5}$ & 8.5 & 0.33 \\
\hline $\mathrm{SO}^{18} \mathrm{O} 8_{2,7}-7_{1,6}$ & 275207.551 & 2.97 & 40.8 & & & $\ldots$ \\
\hline $\mathrm{SO}^{18} \mathrm{O} 28_{3,25}-27_{4,24}$ & 275282.312 & 5.49 & 380.9 & 275283.9 & 7.3 & 0.17 \\
\hline $\mathrm{SO}^{18} \mathrm{O} 23_{4,20}-24_{1,23}$ & 275552.789 & 0.22 & 278.6 & no spectrum & $\ldots$ & $\ldots$ \\
\hline $\mathrm{SO}^{18} \mathrm{O} 25_{3,23}-26_{0,26}$ & 276001.955 & 0.14 & 303.9 & & & \\
\hline $\mathrm{SO}^{18} \mathrm{O} 17_{3,15}-17_{2,16}$ & 276274.719 & 8.82 & 154.6 & 276277.6 & 5.9 & 0.21 \\
\hline $\mathrm{SO}^{18} \mathrm{O} 34_{4,30}-33_{5,29}$ & 276277.576 & 5.84 & 562.1 & & & $\ldots$ \\
\hline $\mathrm{SO}^{18} \mathrm{O} 14_{6,9}-15_{5,10}$ & 277081.114 & 1.51 & 177.5 & $277086.3^{9,37}$ & 3.4 & 0.36 \\
\hline $\mathrm{SO}^{18} \mathrm{O} 14_{6,8}-15_{5,11}$ & 277088.479 & 1.51 & 177.5 & 277092.6 & 4.5 & 0.22 \\
\hline $\mathrm{SO}^{18} \mathrm{O} 26_{4,22}-26_{3,23}$ & 280724.381 & 17.5 & 345.0 & $280727.5^{68}$ & 5.7 & 0.25 \\
\hline $\mathrm{SO}_{2} v_{2}=125_{3,23}-24_{4,20}$ & 82488.410 & 3.28 & 1066.4 & 82489.5 & 5.0 & 0.02 \\
\hline $\mathrm{SO}_{2} v_{2}=18_{1,7}-8_{0,8}$ & 85208.089 & 6.40 & 781.9 & 85208.5 & 7.6 & 0.08 \\
\hline $\mathrm{SO}_{2} v_{2}=124_{6,18}-25_{5,21}$ & 88029.007 & 3.67 & 1111.3 & $88031.4^{17}$ & 0.7 & 0.04 \\
\hline $\mathrm{SO}_{2} v_{2}=129_{4,26}-28_{5,23}$ & 88888.803 & 4.39 & 1186.5 & 17 & $\ldots$ & $\ldots$ \\
\hline $\mathrm{SO}_{2} v_{2}=113_{4,10}-14_{3,11}$ & 91400.957 & 1.93 & 869.0 & noise level & & $\ldots$ \\
\hline $\mathrm{SO}_{2} v_{2}=18_{3,5}-9_{2,8}$ & 92660.362 & 1.13 & 800.8 & 92661.5 & 5.4 & 0.03 \\
\hline $\mathrm{SO}_{2} v_{2}=129_{7,23}-30_{6,24}$ & 93456.549 & 4.44 & 1268.1 & 93457.5 & 6.1 & 0.02 \\
\hline $\mathrm{SO}_{2} v_{2}=139_{6,34}-38_{7,31}$ & 93474.213 & 6.15 & 1555.0 & 88 & $\ldots$ & $\ldots$ \\
\hline $\mathrm{SO}_{2} v_{2}=116_{2,14}-15_{3,13}$ & 98264.696 & 2.99 & 882.8 & $98265.5^{6}$ & 6.4 & 0.17 \\
\hline $\mathrm{SO}_{2} v_{2}=127_{3,25}-26_{4,22}$ & 99177.397 & 3.14 & 1114.8 & & & $\ldots$ \\
\hline $\mathrm{SO}_{2} v_{2}=118_{5,13}-19_{4,16}$ & 102335.197 & 2.69 & 965.1 & 102337.0 & 3.7 & 0.06 \\
\hline $\mathrm{SO}_{2} v_{2}=17_{3,5}-8_{2,6}$ & 103699.749 & 0.94 & 793.5 & $103699.5^{17}$ & 9.6 & 0.09 \\
\hline $\mathrm{SO}_{2} v_{2}=131_{3,29}-30_{4,26}$ & 104210.533 & 2.47 & 1222.2 & 32 & & $\ldots$ \\
\hline $\mathrm{SO}_{2} v_{2}=12_{2,0}-3_{1,3}$ & 104518.097 & 0.16 & 757.9 & $104518.6^{41}$ & 7.5 & 0.02 \\
\hline $\mathrm{SO}_{2} v_{2}=13_{1,3}-2_{0,2}$ & 105117.218 & 2.01 & 752.9 & 105118.5 & 5.4 & 0.08 \\
\hline $\mathrm{SO}_{2} v_{2}=1 \quad 10_{1,9}-10_{0,10}$ & 105956.755 & 6.73 & 799.9 & 105957.5 & 6.9 & 0.16 \\
\hline $\mathrm{SO}_{2} v_{2}=129_{3,27}-28_{4,24}$ & 106870.586 & 2.85 & 1166.8 & $106870.5^{17}$ & 9.3 & 0.10 \\
\hline $\mathrm{SO}_{2} v_{2}=123_{6,18}-24_{5,19}$ & 107251.291 & 3.46 & 1089.2 & $107253.5^{6}$ & 2.8 & 0.25 \\
\hline $\mathrm{SO}_{2} v_{2}=122_{3,19}-21_{4,18}$ & 110003.703 & 3.68 & 1003.3 & 110004.5 & 6.9 & 0.04 \\
\hline $\mathrm{SO}_{2} v_{2}=135_{5,31}-34_{6,28}$ & 114050.625 & 5.45 & 1389.3 & 6 & & $\ldots$ \\
\hline $\mathrm{SO}_{2} v_{2}=128_{7,21}-29_{6,24}$ & 114467.268 & 4.23 & 1241.3 & $114470.5^{34}$ & 0.7 & 0.10 \\
\hline $\mathrm{SO}_{2} v_{2}=112_{2,10}-12_{1,11}$ & 131530.479 & 9.89 & 827.9 & 131531.4 & 6.9 & 0.21 \\
\hline $\mathrm{SO}_{2} v_{2}=110_{2,8}-10_{1,9}$ & 132594.603 & 7.77 & 806.3 & 132595.5 & 6.9 & 0.34 \\
\hline $\mathrm{SO}_{2} v_{2}=112_{1,11}-12_{0,12}$ & 133003.613 & 6.69 & 821.6 & $133005.1^{90}$ & 5.5 & 0.19 \\
\hline $\mathrm{SO}_{2} v_{2}=111_{4,8}-12_{3,9}$ & 133271.748 & 1.49 & 846.0 & 7 & $\ldots$ & $\ldots$ \\
\hline $\mathrm{SO}_{2} v_{2}=127_{7,21}-28_{6,22}$ & 134483.137 & 4.01 & 1215.6 & 4 & & $\ldots$ \\
\hline $\mathrm{SO}_{2} v_{2}=114_{2,12}-14_{1,13}$ & 135531.563 & 11.7 & 853.4 & 135532.6 & 6.7 & 0.31 \\
\hline $\mathrm{SO}_{2} v_{2}=15_{1,5}-4_{0,4}$ & 136675.406 & 3.13 & 760.8 & 136676.5 & 6.6 & 0.22 \\
\hline $\mathrm{SO}_{2} v_{2}=18_{2,6}-8_{1,7}$ & 137234.335 & 5.68 & 788.5 & 16 & $\cdots$ & $\ldots$ \\
\hline $\mathrm{SO}_{2} v_{2}=132_{8,24}-33_{7,27}$ & 140968.037 & 4.78 & 1391.0 & 34 & $\ldots$ & $\cdots$ \\
\hline $\mathrm{SO}_{2} v_{2}=116_{5,11}-17_{4,14}$ & 142044.339 & 2.26 & 932.9 & 36 & $\ldots$ & $\ldots$ \\
\hline $\mathrm{SO}_{2} v_{2}=16_{2,4}-6_{1,5}$ & 143663.844 & 3.83 & 774.5 & $143664.5^{1}$ & 7.7 & 0.42 \\
\hline $\mathrm{SO}_{2} v_{2}=15_{3,3}-6_{2,4}$ & 145331.342 & 0.51 & 781.5 & 145332.7 & 6.3 & 0.05 \\
\hline $\mathrm{SO}_{2} v_{2}=116_{2,14}-16_{1,15}$ & 145739.989 & 13.0 & 882.8 & 145741.5 & 5.9 & 0.39 \\
\hline $\mathrm{SO}_{2} v_{2}=133_{4,30}-32_{5,27}$ & 147129.710 & 4.51 & 1302.6 & 13 & $\cdots$ & $\ldots$ \\
\hline $\mathrm{SO}_{2} v_{2}=121_{6,16}-22_{5,17}$ & 148089.279 & 3.03 & 1047.8 & 16 & 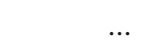 & $\ldots$ \\
\hline $\mathrm{SO}_{2} v_{2}=14_{2,2}-4_{1,3}$ & 150060.477 & 2.27 & 764.4 & 150062.6 & 4.7 & 0.16 \\
\hline $\mathrm{SO}_{2} v_{2}=137_{5,33}-36_{6,30}$ & 151196.604 & 5.66 & 1456.9 & 17 & & $\ldots$ \\
\hline $\mathrm{SO}_{2} v_{2}=122_{2,0}-2_{1,1}$ & 154896.423 & 0.87 & 757.9 & $154899.5^{17}$ & 3.0 & 0.25 \\
\hline $\mathrm{SO}_{2} v_{2}=1 \quad 10_{4,6}-11_{3,9}$ & 154925.408 & 1.27 & 835.8 & 154926.5 & 6.9 & 0.13 \\
\hline $\mathrm{SO}_{2} v_{2}=126_{7,19}-27_{6,22}$ & 154937.399 & 3.80 & 1190.7 & 154939.6 & 4.8 & 0.08 \\
\hline $\mathrm{SO}_{2} v_{2}=118_{2,16}-17_{3,15}$ & 157562.692 & 3.70 & 916.0 & 157563.9 & 6.7 & 0.16 \\
\hline $\mathrm{SO}_{2} v_{2}=110_{0,10}-9_{1,9}$ & 159887.299 & 6.41 & 794.8 & 4 & $\cdots$ & $\ldots$ \\
\hline $\mathrm{SO}_{2} v_{2}=131_{8,24}-32_{7,25}$ & 161118.533 & 4.57 & 1361.5 & 6 & $\ldots$ & $\ldots$ \\
\hline
\end{tabular}


Table A.9. continued.

\begin{tabular}{|c|c|c|c|c|c|c|}
\hline $\begin{array}{l}\text { Species/Transition } \\
J_{K_{a}, K_{c}}-J_{K_{a}^{\prime}, K_{c}^{\prime}}^{\prime}\end{array}$ & $\begin{array}{r}\text { Predicted } \\
\text { freq. } \\
(\mathrm{MHz}) \\
\end{array}$ & $S_{\mathrm{ij}}$ & $\begin{array}{c}E_{\mathrm{u}} \\
(\mathrm{K})\end{array}$ & $\begin{array}{l}\text { Observed } \\
\text { freq. } \\
(\mathrm{MHz}) \\
\end{array}$ & $\begin{array}{r}\text { Observed } \\
v_{\mathrm{LSR}} \\
\left(\mathrm{km} \mathrm{s}^{-1}\right) \\
\end{array}$ & $\begin{array}{l}\text { Observed } \\
T_{\mathrm{A}}^{*} \\
(\mathrm{~K}) \\
\end{array}$ \\
\hline $\mathrm{SO}_{2} v_{2}=115_{5,11}-16_{4,12}$ & 161153.766 & 2.04 & 918.2 & 5 & & \\
\hline $\mathrm{SO}_{2} v_{2}=13_{2,2}-3_{1,3}$ & 161799.286 & 1.44 & 760.7 & 161802.5 & 3.1 & 0.37 \\
\hline $\mathrm{SO}_{2} v_{2}=118_{2,16}-18_{1,17}$ & 162976.601 & 13.6 & 916.0 & 162977.5 & 7.3 & 0.34 \\
\hline $\mathrm{SO}_{2} v_{2}=114_{1,13}-14_{0,14}$ & 165963.827 & 6.46 & 846.9 & 165964.6 & 7.7 & 0.42 \\
\hline $\mathrm{SO}_{2} v_{2}=17_{1,7}-6_{0,6}$ & 166061.130 & 4.43 & 772.2 & & $\cdots$ & $\ldots$ \\
\hline $\mathrm{SO}_{2} v_{2}=14_{3,1}-5_{2,4}$ & 166507.963 & 0.30 & 776.9 & 73 & & \\
\hline $\mathrm{SO}_{2} v_{2}=135_{4,32}-34_{5,29}$ & 166834.689 & 4.35 & 1366.1 & 166836.5 & 5.7 & 0.05 \\
\hline $\mathrm{SO}_{2} v_{2}=120_{6,14}-21_{5,17}$ & 168508.840 & 2.81 & 1028.5 & & $\cdots$ & $\ldots$ \\
\hline $\mathrm{SO}_{2} v_{2}=15_{2,4}-5_{1,5}$ & 168826.259 & 2.46 & 768.9 & 51 & & \\
\hline $\mathrm{SO}_{2} v_{2}=124_{3,21}-23_{4,20}$ & 171566.838 & 4.21 & 1047.8 & 171567.5 & 7.9 & 0.13 \\
\hline $\mathrm{SO}_{2} v_{2}=19_{4,6}-10_{3,7}$ & 173495.943 & 1.05 & 826.6 & & & $\ldots$ \\
\hline $\mathrm{SO}_{2} v_{2}=125_{7,19}-26_{6,20}$ & 174901.050 & 3.58 & 1166.8 & $174903.5^{70}$ & 4.8 & 0.56 \\
\hline $\mathrm{SO}_{2} v_{2}=130_{4,26}-29_{5,25}$ & 176012.893 & 4.91 & 1217.2 & $176015.1^{41}$ & 5.3 & 0.37 \\
\hline $\mathrm{SO}_{2} v_{2}=137_{4,34}-36_{5,31}$ & 177865.345 & 4.04 & 1433.2 & noisy spectrum & & $\ldots$ \\
\hline $\mathrm{SO}_{2} v_{2}=122_{3,19}-22_{2,20}$ & 199756.971 & 17.6 & 1003.3 & $199758.7^{5}$ & 6.5 & 0.62 \\
\hline $\mathrm{SO}_{2} v_{2}=113_{5,9}-14_{4,10}$ & 200888.344 & 1.60 & 891.5 & 16 & $\cdots$ & $\ldots$ \\
\hline $\mathrm{SO}_{2} v_{2}=129_{8,22}-30_{7,23}$ & 201308.491 & 4.14 & 1305.4 & 5 & $\ldots$ & $\ldots$ \\
\hline $\mathrm{SO}_{2} v_{2}=120_{3,17}-20_{2,18}$ & 201972.010 & 15.4 & 962.7 & 201974.4 & 5.4 & 0.40 \\
\hline $\mathrm{SO}_{2} v_{2}=112_{0,12}-11_{1,11}$ & 202562.326 & 8.41 & 815.2 & 202564.4 & 5.9 & 0.47 \\
\hline $\mathrm{SO}_{2} v_{2}=1 \quad 16_{1,15}-16_{0,16}$ & 203652.511 & 6.21 & 875.8 & 203654.4 & 6.2 & 0.44 \\
\hline $\mathrm{SO}_{2} v_{2}=124_{3,21}-24_{2,22}$ & 204331.692 & 19.4 & 1047.8 & 204333.2 & 6.8 & 0.28 \\
\hline $\mathrm{SO}_{2} v_{2}=134_{9,25}-35_{8,28}$ & 207420.884 & 4.91 & 1494.9 & 6 & $\cdots$ & $\ldots$ \\
\hline $\mathrm{SO}_{2} v_{2}=118_{6,12}-19_{5,15}$ & 208172.440 & 2.38 & 992.6 & $2,4,6$ & $\ldots$ & $\ldots$ \\
\hline $\mathrm{SO}_{2} v_{2}=11_{3,15}-18_{2,16}$ & 209433.722 & 12.9 & 926.1 & $209434.9^{18}$ & 7.4 & 1.15 \\
\hline $\mathrm{SO}_{2} v_{2}=111_{2,10}-11_{1,11}$ & 209454.261 & 4.56 & 815.5 & 209456.1 & 6.3 & 0.48 \\
\hline $\mathrm{SO}_{2} v_{2}=13_{2,2}-2_{1,1}$ & 212177.612 & 1.67 & 760.7 & 212179.9 & 5.7 & 0.14 \\
\hline $\mathrm{SO}_{2} v_{2}=17_{4,4}-8_{3,5}$ & 212726.193 & 0.63 & 811.0 & $212728.6^{34}$ & 5.5 & 0.11 \\
\hline $\mathrm{SO}_{2} v_{2}=123_{7,17}-24_{6,18}$ & 214835.983 & 3.15 & 1121.7 & $214837.5^{5}$ & 7.0 & 0.25 \\
\hline $\mathrm{SO}_{2} v_{2}=126_{3,23}-26_{2,24}$ & 216758.559 & 20.5 & 1096.2 & $216759.9^{5}$ & 7.1 & 0.60 \\
\hline $\mathrm{SO}_{2} v_{2}=120_{2,18}-19_{3,17}$ & 218995.835 & 4.59 & 953.0 & 218997.4 & 6.9 & 0.31 \\
\hline $\mathrm{SO}_{2} v_{2}=122_{2,20}-22_{1,21}$ & 219465.546 & 13.3 & 993.7 & $219467.4^{4,7}$ & 6.5 & 1.00 \\
\hline $\mathrm{SO}_{2} v_{2}=116_{3,13}-16_{2,14}$ & 220165.252 & 10.6 & 893.4 & 5 & $\cdots$ & $\ldots$ \\
\hline $\mathrm{SO}_{2} v_{2}=112_{5,7}-13_{4,10}$ & 220657.897 & 1.39 & 879.5 & 4 & ... & $\ldots$ \\
\hline $\mathrm{SO}_{2} v_{2}=128_{8,20}-29_{7,23}$ & 221277.998 & 3.92 & 1278.7 & 5 & 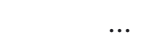 & $\ldots$ \\
\hline $\mathrm{SO}_{2} v_{2}=111_{1,11}-10_{0,10}$ & 222424.457 & 7.70 & 805.5 & $222423.7^{5,7}$ & 10.1 & 1.21 \\
\hline $\mathrm{SO}_{2} v_{2}=117_{6,12}-18_{5,13}$ & 227808.377 & 2.16 & 976.0 & 16 & & $\ldots$ \\
\hline $\mathrm{SO}_{2} v_{2}=113_{2,12}-13_{1,13}$ & 229545.293 & 4.98 & 838.3 & $229548.6^{54}$ & 4.7 & 0.22 \\
\hline $\mathrm{SO}_{2} v_{2}=114_{3,11}-14_{2,12}$ & 231980.527 & 8.58 & 864.6 & 7 & $\ldots$ & $\ldots$ \\
\hline $\mathrm{SO}_{2} v_{2}=16_{4,2}-7_{3,5}$ & 232210.300 & 0.43 & 804.6 & 39 & $\ldots$ & $\ldots$ \\
\hline $\mathrm{SO}_{2} v_{2}=116_{1,15}-15_{2,14}$ & 233724.927 & 6.02 & 875.8 & 233728.8 & 4.0 & 0.25 \\
\hline $\mathrm{SO}_{2} v_{2}=122_{7,15}-23_{6,18}$ & 234679.037 & 2.93 & 1100.5 & 16 & $\ldots$ & $\ldots$ \\
\hline $\mathrm{SO}_{2} v_{2}=126_{3,23}-25_{4,22}$ & 237062.226 & 4.84 & 1096.2 & 18 & & \\
\hline $\mathrm{SO}_{2} v_{2}=128_{3,25}-28_{2,26}$ & 237602.207 & 20.8 & 1148.5 & $237603.6^{32}$ & 7.2 & 0.51 \\
\hline $\mathrm{SO}_{2} v_{2}=14_{2,2}-3_{1,3}$ & 238697.756 & 1.72 & 764.4 & 238698.9 & 7.6 & 0.37 \\
\hline $\mathrm{SO}_{2} v_{2}=138_{5,33}-37_{6,32}$ & 239753.000 & 6.11 & 1495.2 & & & \\
\hline $\mathrm{SO}_{2} v_{2}=111_{5,7}-12_{4,8}$ & 240057.470 & 1.17 & 868.5 & 240060.5 & 5.3 & 0.07 \\
\hline $\mathrm{SO}_{2} v_{2}=127_{8,20}-28_{7,21}$ & 241126.743 & 3.70 & 1252.9 & 241128.6 & 6.7 & 0.13 \\
\hline $\mathrm{SO}_{2} v_{2}=132_{4,28}-31_{5,27}$ & 241193.824 & 5.36 & 1276.8 & 16 & $\cdots$ & $\cdots$ \\
\hline $\mathrm{SO}_{2} v_{2}=112_{3,9}-12_{2,10}$ & 242872.869 & 6.88 & 839.6 & 5 & $\ldots$ & $\ldots$ \\
\hline $\mathrm{SO}_{2} v_{2}=114_{0,14}-13_{1,13}$ & 243522.666 & 10.5 & 839.0 & $243523.9^{12}$ & 7.5 & 1.18 \\
\hline $\mathrm{SO}_{2} v_{2}=118_{1,17}-18_{0,18}$ & 244386.673 & 6.03 & 908.2 & & & \\
\hline $\mathrm{SO}_{2} v_{2}=15_{2,4}-4_{1,3}$ & 245002.780 & 2.12 & 768.9 & 245004.5 & 6.9 & 0.46 \\
\hline $\mathrm{SO}_{2} v_{2}=132_{9,23}-33_{8,26}$ & 247275.019 & 4.47 & 1433.3 & 32 & ... $>$ & $\cdots$ \\
\hline $\mathrm{SO}_{2} v_{2}=116_{6,10}-17_{5,13}$ & 247485.487 & 1.94 & 960.4 & $247490.1^{32,91}$ & 3.4 & 0.29 \\
\hline $\mathrm{SO}_{2} v_{2}=15_{4,2}-6_{3,3}$ & 251401.371 & 0.25 & 799.1 & 43 & 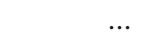 & $\cdots$ \\
\hline $\mathrm{SO}_{2} v_{2}=1 \quad 10_{3,7}-10_{2,8}$ & 251428.540 & 5.43 & 818.3 & $251428.8^{6}$ & 8.7 & 1.04 \\
\hline $\mathrm{SO}_{2} v_{2}=113_{1,13}-12_{0,12}$ & 251450.180 & 9.61 & 827.3 & $251452.6^{6,34}$ & 6.2 & 0.83 \\
\hline $\mathrm{SO}_{2} v_{2}=115_{2,14}-15_{1,15}$ & 252731.060 & 5.29 & 864.6 & 252733.5 & 6.1 & 0.47 \\
\hline $\mathrm{SO}_{2} v_{2}=121_{7,15}-22_{6,16}$ & 254381.132 & 2.71 & 1080.3 & $254385.1^{36}$ & 4.3 & 0.20 \\
\hline $\mathrm{SO}_{2} v_{2}=18_{3,5}-8_{2,6}$ & 257099.338 & 4.13 & 800.8 & 49 & & 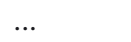 \\
\hline $\mathrm{SO}_{2} v_{2}=124_{2,22}-24_{1,23}$ & 257420.276 & 12.8 & 1038.0 & $257422.7^{31}$ & 6.2 & 0.38 \\
\hline $\mathrm{SO}_{2} v_{2}=110_{5,5}-11_{4,8}$ & 259525.559 & 0.96 & 858.4 & 5 & & $\cdots$ \\
\hline $\mathrm{SO}_{2} v_{2}=16_{3,3}-6_{2,4}$ & 260176.150 & 2.89 & 787.0 & 260178.9 & 5.8 & 0.46 \\
\hline
\end{tabular}


Table A.9. continued.

\begin{tabular}{|c|c|c|c|c|c|c|}
\hline $\begin{array}{l}\text { Species/Transition } \\
J_{K_{a}, K_{c}}-J_{K_{a}^{\prime}, K_{c}^{\prime}}^{\prime}\end{array}$ & $\begin{array}{r}\text { Predicted } \\
\text { freq. } \\
(\mathrm{MHz})\end{array}$ & $S_{\mathrm{ij}}$ & $\begin{array}{r}E_{\mathrm{u}} \\
(\mathrm{K})\end{array}$ & $\begin{array}{l}\text { Observed } \\
\text { freq. } \\
(\mathrm{MHz})\end{array}$ & $\begin{array}{r}\text { Observed } \\
v_{\mathrm{LSR}} \\
\left(\mathrm{km} \mathrm{s}^{-1}\right) \\
\end{array}$ & $\begin{array}{l}\text { Observed } \\
T_{\mathrm{A}}^{*} \\
(\mathrm{~K}) \\
\end{array}$ \\
\hline $\mathrm{SO}_{2} v_{2}=126_{8,18}-27_{7,21}$ & 260920.931 & 3.48 & 1228.1 & 260922.6 & 7.1 & 0.52 \\
\hline $\mathrm{SO}_{2} v_{2}=14_{3,1}-4_{2,2}$ & 261450.266 & 1.61 & 776.9 & 261453.8 & 4.9 & 0.53 \\
\hline $\mathrm{SO}_{2} v_{2}=13_{3,1}-3_{2,2}$ & 261855.237 & 0.89 & 773.3 & & & $\ldots$ \\
\hline $\mathrm{SO}_{2} v_{2}=15_{3,3}-5_{2,4}$ & 262144.899 & 2.26 & 781.5 & 262145.2 & 8.7 & 0.36 \\
\hline $\mathrm{SO}_{2} v_{2}=17_{3,5}-7_{2,6}$ & 262999.768 & 3.48 & 793.5 & $263004.5^{26}$ & 3.7 & 0.66 \\
\hline $\mathrm{SO}_{2} v_{2}=132_{4,28}-32_{3,29}$ & 264129.781 & 25.5 & 1276.8 & $264128.9^{17}$ & 10.1 & 0.19 \\
\hline $\mathrm{SO}_{2} v_{2}=19_{3,7}-9_{2,8}$ & 264846.220 & 4.65 & 809.1 & 264849.5 & 5.3 & 0.22 \\
\hline $\mathrm{SO}_{2} v_{2}=130_{4,26}-30_{3,27}$ & 266030.564 & 23.2 & 1217.2 & 266032.6 & 6.7 & 0.42 \\
\hline $\mathrm{SO}_{2} v_{2}=130_{3,27}-30_{2,28}$ & 266815.527 & 20.5 & 1204.5 & & & $\ldots$ \\
\hline $\mathrm{SO}_{2} v_{2}=115_{6,10}-16_{5,11}$ & 267006.778 & 1.72 & 945.7 & 267008.5 & 7.1 & 0.15 \\
\hline $\mathrm{SO}_{2} v_{2}=131_{9,23}-32_{8,24}$ & 267091.922 & 4.25 & 1403.8 & 47 & $\ldots$ & $\ldots$ \\
\hline $\mathrm{SO}_{2} v_{2}=111_{3,9}-11_{2,10}$ & 268169.791 & 5.78 & 828.4 & 49 & ... & $\ldots$ \\
\hline $\mathrm{SO}_{2} v_{2}=134_{4,30}-34_{3,31}$ & 270528.378 & 27.1 & 1340.3 & 5 & $\ldots$ & $\ldots$ \\
\hline $\mathrm{SO}_{2} v_{2}=14_{4,0}-5_{3,3}$ & 270633.756 & 0.10 & 794.5 & 17 & $\ldots$ & $\ldots$ \\
\hline $\mathrm{SO}_{2} v_{2}=113_{3,11}-13_{2,12}$ & 273467.380 & 6.87 & 851.4 & 49 & . & $\ldots$ \\
\hline $\mathrm{SO}_{2} v_{2}=120_{7,13}-21_{6,16}$ & 274039.760 & 2.49 & 1060.9 & 274041.3 & 7.3 & 0.05 \\
\hline $\mathrm{SO}_{2} v_{2}=128_{4,24}-28_{3,25}$ & 274778.408 & 20.5 & 1161.7 & 274780.5 & 6.7 & 0.36 \\
\hline $\mathrm{SO}_{2} v_{2}=17_{2,6}-6_{1,5}$ & 274789.404 & 2.67 & 780.8 & 274791.5 & 6.8 & 0.27 \\
\hline $\mathrm{SO}_{2} v_{2}=117_{2,16}-17_{1,17}$ & 278755.123 & 5.50 & 894.5 & 278757.4 & 6.5 & 0.59 \\
\hline $\mathrm{SO}_{2} v_{2}=199_{5,5}-10_{4,6}$ & 278849.605 & 0.76 & 849.2 & $278851.5^{36}$ & 7.0 & 0.49 \\
\hline $\mathrm{SO}_{2} v_{2}=125_{8,18}-26_{7,19}$ & 280629.381 & 3.26 & 1204.2 & $280631.5^{73}$ & 6.7 & 0.40 \\
\hline
\end{tabular}

